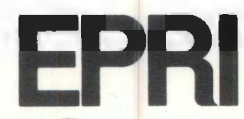

Elnctric Power arch Institute
Topics:

Spent-fuel storage

Thermal hydraulics models

Heat transfer

Shielding

$$
\text { PNL-6631 }
$$

$$
1 \text { - }
$$

EPRI NP-6191

Project 2813-16

PNL-6631

UC-85

Interim Report

February 1989

\title{
Testing and Analyses of the TN-24P PWR Spent-Fuel Dry Storage Cask Loaded With Consolidated Fuel
}

Prepared by

Pacific Northwest Laboratory

Richland, Washington

and

EG\&G Idaho, Idaho National Engineering Laboratory

Idaho Falls, Idaho 


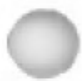

0

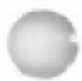




R E P O O R T $T$ S U M M A R Y

SUBJECTS Light water reactor fuel / High-level radioactive waste management

TOPICS Spent-fuel storage Heat transfer

Thermal hydraulics models Shielding

AUDIENCE Fuels engineers / R\&D scientists

\section{Testing and Analyses of the TN-24P PWR Spent-Fuel Dry Storage Cask Loaded With Consolidated Fuel}

Full-scale testing has confirmed that the TN-24P storage cask offers a technically sound and practical method for storing consolidated spent fuel. COBRA-SFS code predictions of cask performance at conditions near its design limits agreed very well with actual test data.

BACKGROUND

As at-reactor storage basins attain maximum capacity, many utilities are expected to implement dry spent-fuel storage systems. To demonstrate the storage of dry spent fuel in large metal casks, EPRI and DOE have sponsored tests of metal casks loaded with unconsolidated fuel at the Idaho National Engineering Laboratory (INEL). This most recent study was initiated to investigate a TN-24P cask containing consolidated fuel.

OBJECTIVES To demonstrate the thermal, shielding, and operational performance of the TN-24P cask loaded with consolidated spent nuclear fuel; to assess the ability of the COBRA-SFS heat transfer code (developed by Pacific Northwest Laboratory) to model the cask system and predict thermal performance.

APPROACH Prior to the testing, the TN-24P cask contained 24 unconsolidated PWR assemblies from Virginia Power's Surry nuclear power station. The project team replaced the assemblies with 24 canisters of spent fuel, consolidated at a ratio of two assemblies per canister. INEL's rod consolidation project provided the filled test canisters. Researchers used the COBRA-SFS computer code to predict cask thermal performance. The team then instrumented and tested the cask in horizontal and vertical positions with three internal storage environments (nitrogen, helium, and vacuum). They compared the COBRA-SFS predictions with actual test data, refined the code to reflect test results, and performed posttest predictions. Transnuclear, Inc., the cask manufacturer, sponsored an additional test to simulate the insulating influence of impact limiters.

RESULTS The TN-24P cask is well suited to store consolidated spent fuel. Its heat transfer performance was exceptionally good, as peak cladding temperatures for a cask heat load of $23.3 \mathrm{~kW}$ were well under $300^{\circ} \mathrm{C}$ with helium, 
nitrogen, and vacuum backfills. In general, performance of the cask shielding met design expectations, with minor exceptions occurring at the cask bottom and the sidewalls near the ends of the cask. The test, sponsored by Transnuclear, Inc., measured only a minor increase in the fuel-cladding peak temperature when insulation was added to the ends of the cask.

The COBRA-SFS code performed very well in predicting the shapes of the temperature profiles and the actual temperatures. Pretest predictions agreed within $35^{\circ} \mathrm{C}$ of actual test data. In the posttest analysis, these differences were reduced to about $13^{\circ} \mathrm{C}$. Prediction improvements resulted largely from the use of a more detailed fuel model in the calculation code.

EPRI The results of this test program represent a major milestone toward PERSPECTIVE qualifying large metal casks for on-site storage of consolidated spent nuclear fuel. The tests not only quantified the thermal and shielding performance of the TN-24P cask but further demonstrated that the handling and loading of these large, 100-t containers are relatively straightforward processes that introduce no unusual demands on personnel or facilities.

This project was a follow-up to a cooperative program sponsored by EPRI, DOE, and Virginia Power that demonstrated performance of casks, loaded with unconsolidated fuel, from three vendors. These tests are described in EPRI reports NP-4487 (CASTORV/21), NP-5128 (TN-24P), and NP-5268 (MC-10). As part of the cooperative program, Virginia Power applied for and received a license to store unconsolidated fuel in metal casks at the Surry station. The testing with consolidated fuel described in this report concludes the cask testing program at INEL.

PROJECT RP2813-16

EPRI Project Manager: Ray W. Lambert

Nuclear Power Division

Contractors: Pacific Northwest Laboratory; EG\&G Idaho, Idaho National Engineering Laboratory

For further information on EPRI research programs, call EPRI Technical Information Specialists (415) 855-2411. 


\title{
Testing and Analyses of the TN-24P PWR Spent-Fuel Dry Storage Cask Loaded With Consolidated Fuel
}

\author{
NP-6191 \\ Research Project 2813-16 \\ PNL-6631 \\ UC-85 \\ Interim Report, February 1989 \\ Prepared by \\ PACIFIC NORTHWEST LABORATORY \\ Richland, Washington 99352 \\ Principal Investigators \\ M. A. McKinnon \\ T. E. Michener \\ EG\&G IDAHO, IDAHO NATIONAL ENGINEERING LABORATORY \\ Idaho Falls, Idaho 83415 \\ Principal Investigators \\ M. F. Jensen \\ G. R. Rodman
}

Prepared for

U.S. Department of Energy

and

Electric Power Research Institute

3412 Hillview Avenue

Palo Alto, California 94304

EPRI Project Manager

R. W. Lambert

High Level Waste Program

Nuclear Power Division 


\section{ORDERING INFORMATION}

Requests for copies of this report should be directed to Research Reports Center (RRC), Box 50490, Palo Alto, CA 94303, (415) 965-4081. There is no charge for reports requested by EPRI member utilities and affiliates, U.S. utility associations, U.S. government agencies (federal, state, and local), media, and foreign organizations with which EPRI has an information exchange agreement. On request, RRC will send a catalog of EPRI reports.

\section{DISCLAIMER}

This report was prepared as an account of work sponsored by the United States Government. Neither the United States nor the United States Department of Energy, nor any of their employees, makes any warranty, express or implied, or assumes any legal liability or responsibility for the accuracy, completeness, or usefulness of any information, apparatus, product, or process disclosed, or represents that its use would not infringe privately owned rights. Reference herein to any specific commercial product, process, or service by trade name, mark, manufacturer, or otherwise, does not necessarily constitute or imply its endorsement, recommendation, or favoring by the United States Government or any agency thereof. The views and opinions of authors expressed herein do not necessarily state or reflect those of the Uniled States Government or any agency thereof.

\section{NOTICE}

This report was prepared by the organization(s) named below as an account of work sponsored by the Electric Power Research Institute, Inc. (EPRI). Neither EPRI, members of EPRI, the organization(s) named below, nor any person acting on behalf of any of them: (a) makes any warranty, express or implied, with respect to the use of any information, apparatus, method, or process disclosed in this report or that such use may not infringe privately owned rights; or (b) assumes any liabilities with respect to the use of, or for damages resulting from the use of, any information, apparatus, method, or process disclosed in this report.

Prepared by

Pacific Northwest Laboratory

Richland, Washington

and

EG\&G Idaho, Idaho National Engineering Laboralory

Idaho Falls, Idaho 
ABSTRACT

A performance test of a Transnuclear, Inc. TN-24P storage cask configured for pres surized water reactor (PWR) spent fuel was performed. The work was performed by the Pacific Northwest Laboratory (PNL) and Idaho National Engineering Laboratory (INEL) for the U.S. Department of Energy Office of Civilian Radioactive Waste Management (OCRWM) and the Electric Power Research Institute. The performance test consisted of loading the TN-24P cask with 24 canisters of consolidated PWR spent fuel from Virginia Power's Surry and Florida Power \& Light's Turkey Point reactors. Cask surface and fuel canister guide tube temperatures were measured, as were cask surface gamma and neutron dose rates. Testing was performed with vacuum, nitrogen, and helium backfill environments in both vertical and horizontal cask orientations. Transnuclear, Inc., arranged to have a partially insulated run added to the end of the test to simulate impact limiters. Limited spent fuel integrity data were also obtained.

Results of the performance test indicate that the TN-24P cask exhibited exceptionally good heat transfer performance when dissipating $23 \mathrm{~kW}$. Maximum measured canister guide tube temperatures in vacuum, nitrogen, and helium backfills in a vertical/horizontal cask orientation were $291 / 280^{\circ} \mathrm{C}, 267 / 251^{\circ} \mathrm{C}$, and $211 / 205^{\circ} \mathrm{C}$, respectively. These temperatures are significantly lower than the $340^{\circ} \mathrm{C}$ allowable for the fuel used and a total heat load of $24 \mathrm{~kW}$. Some convection heat transfer was evident in the vertical nitrogen test run, but it was much less than detected previously for unconsolidated fuel. Pretest temperature predictions computed with the COBRA-SFS heat transfer computer code were in good agreement (within $35^{\circ} \mathrm{C}$ ) with test data, and post-test predictions agreed exceptionally well (within $13^{\circ} \mathrm{C}$ ) with data. Insulating the ends of the cask had little effect on peak fuel temperatures.

Measured cask surface gamma and neutron dose rates were generally less than the design goal of $60 \mathrm{mrem} / \mathrm{h}$. The absence of non-fuel-bearing components was apparent from the reduced magnitude of the gamma dose rate profiles for the consolidated fue1. Neutron rate dose magnitudes remained about the same as for unconsolidated fuel. Localized peaks as high as $55 \mathrm{mrem} / \mathrm{h}$ were measured on the side of the cask. The maximum dose rate on the bottom of the cask was $70 \mathrm{mrem} / \mathrm{h}$ ( $3 \mathrm{mrem} / \mathrm{h}$ gamma plus 
$67 \mathrm{mrem} / \mathrm{h}$ neutron). The removal of the non-fuel-bearing components during fuel consolidation greatly reduced the gamma dose rate. This was most apparent on the bottom of the cask where the gamma dose rate fell from $135 \mathrm{mrem} / \mathrm{h}$ for unconsolidated fuel to $3 \mathrm{mrem} / \mathrm{h}$ for consolidated fuel. With minor refinements to the shielding design, dose rates can be 1 imited to less than $60 \mathrm{mrem} / \mathrm{h}$.

From both heat transfer and shielding perspectives, the TN-24P cask with minor refinements can be effectively implemented at reactor sites and central storage facilities for safe storage of unconsolidated and consolidated spent fuel.

Fuel integrity was established prior to testing as part of other cask performance tests. Gas sampling during this test indicated that approximately 7 of the 9800 fuel rods in the cask developed leaks during testing. The rod leakage was not detrimental to the test or its operations. 


\section{ACKNOWLEDGMENTS}

The authors acknowledge the support of the U.S. Department of Energy, the Electric Power Research Institute, EG\&G Idaho, Inc., and the Pacific Northwest Laboratory. Additionally, acknowledgment is given that the EPRI participation in the project was sponsored as part of the joint program of EPRI and Japan's Central Research Institute of Electric Power Industry (CRIEPI).

DOE-Headquarters

D. E. Shelor

DOE-Richland Operations Office

J. P. Collins

D. E. Kenyon

M. S. Karol

DOE-Idaho Operations Office

S. T. Hinchberger

M. Fisher

EG\&G Idaho, Inc.

R. C. Hill

Transnuclear

M. E. Mason

Transnucleaire

R. Cagnon
Electric Power Research Institute

R. W. Lambert

R. F. Williams

Pacific Northwest Laboratory

J. M. Creer

C. M. Heeb

C. M. Stewart

A. J. Currie

E. R. Gilbert

J. E. Tanner

Virginia Power

M. L. Smith

D. P. Batalo

B. H. Wakeman

\section{CRIEPI}

S. Fukuda

T. Onchi 


\section{CONTENTS}

\section{Section}

1 INTRODUCTION

2 CONCLUSIONS AND RECOMMENDATIONS $2-1$

Conclusions $2-1$

Cask Performance Test 2-1

Heat Transfer Performance 2-2

COBRA Heat Transfer Analysis 2-3

Shielding Performance 2-3

Fuel Characterization and Integrity 2-4

Recommendations 2-4

Cask-Handling and Loading 2-4

Heat Transfer Performance 2-4

COBRA-SFS Heat Transfer Analysis 2-5

Shielding Performance 2-5

Fuel Characteristics and Integrity 2-5

3 CASK PERFORMANCE TESTING $3-1$

TN-24P Cask and Associated Instrumentation 3-1

Cask Body 3-3

Spent Fuel Basket 3-3

Cask Lid $3-5$

Cask Cavity Pressure Measurements $\quad 3-8$

Internal Temperature Instrumentation 3-9

Exterior Surface Temperature Instrumentation 3-10

Exterior Surface Dose Rate Instrumentation 3-11

PWR Spent Fuel and Associated Instrumentation 3-14

Fuel Assembly/Canister Design 3-16

Predicted Decay Heat Rates 3-20

Predicted Axial Decay Heat Profile 3-23

Spent Fuel Integrity 3-24

Data Acquisition System $3-28$ 
Data Uncertainty Estimates $3-29$

INEL Cask Testing Facility $3-30$

TAN-607 Facility $3-30$

TAN Railroad System $3-39$

Long-Term Surveillance Facilities $\quad 3-40$

Test Plan 3-42

INEL Cask-Handling and Operating Experience 3-44

Storage and Shipping Cask-Handling Studies 3-45

Facilities and Equipment 3-45

Operational Preparations 3-46

Fuel Transfers and Loading 3-49

Cask Performance Testing 3-51

4 CASK HEAT TRANSFER AND SHIELDING, AND FUEL PERFORMANCE

Heat Transfer 4-1

Heat Transfer Performance Overview 4-2

Vacuum Runs $4-3$

Nitrogen Runs $4-11$

Helium Runs $\quad$ 4-17

Effects of Backfill Environment 4-22

Surface Temperature Characteristics 4-28

Temperature Transients 4-31

Shielding Performance 4-33

Cask Lid and Bottom Dose Rate Measurements 4-33

Cask Side Dose Rate Measurements 4-36

Cask Dose Rate Attenuation 4-37

Fuel Integrity 4-40

Dry Rod Consolidation 4-41

Cask Cover Gas Sampling 4-41

5 COBRA-SFS ANALYSIS 5-1

COBRA-SFS Computer Program 5-1

Modeling Capabilities $\quad 5-2$

Conservation Equations $\quad 5-2$

COBRA-SFS Models and Input 5-8

One-Half Section Cask Model 5-8

Heat Transfer Models 5-10

Boundary Specifications $5-13$

Material Properties 5-14 
Modeling Uncertainties

5- 15

COBRA-SFS Simulations Compared to Test Data

$5-16$

Pretest Predictions Compared to Test Data

$5-16$

Post-Test Predictions Compared to Test Data

$5-30$

6 REFERENCES

$6-1$

APPENDIX A FUEL ASSEMBLY DATA

A-1

APPENDIX B TEMPERATURE AND PRESSURE MEASUREMENT UNCERTAINTIES

B-1

ARPENDIX C HEAT TRANSFER DATA

C-1

APPENDIX D DOSE RATE DATA

D-1 


\section{ILLUSTRATIONS}

\section{Figure}

Page

3-1 TN-24P PWR Spent Fuel Storage Cask

3-2 TN-24P Cask Cross Section

3-3 TN-24P Cask Lid

3-4 TN-24P Cask Nonstandard Test Lid

3-5 Pressure Transducer Valve Tree

3-6 Basket Thermocouple Locations

3-7 Thermocouple Lance

3-8 Thermocouple Lance Locations

3-9 Cask Surface Thermocouple Locations

3-10 Cask Top and Bottom Thermocouple Locations

3-11 Cask Surface Dose Rate Measurement Locations

3-12 Cask Top and Bottom Dose Rate Measurements Locations

3-13 Surry and Turkey Point $15 \times 15$ PWR Fuel Assembly

3-14 Surry and Turkey Point $15 \times 15$ PWR Fuel Assembly Cross Section

3-15 Consolidated Fuel Canister

3-16 Cross Section of a Loaded Consolidated Fuel Canister

3-17 Selected Assembly Power Histories

3-18 Load Map for TN-24P with Consolidated Fuel

3-19 Predicted Axial Decay Heat Profile

3-20 Data Acquisition System

3-21 INEL Facility

3-22 TAN-607 Facility

3-23 North End of TAN-607 
3-24 TAN-607 Hot Shop

3-25 Elevation View of Hot Shop and Handling Equipment

3-26 Dual Work Stand for Spent Fuel Transfers

3-27 Cask with Lift Yoke Attached

3-28 Elevation View of TAN Warm Shop

3-29 Warm Shop Test Area

3-30 Hot Shop Complex and Four-Track Rail System

3-31 Moving TN-24P Cask Between Hot Shop and Warm Shop on

3-32 TN-24P Cask on Long-Term Surveillance Pad with Adjacent Data Acquisition System Building

3-33 TN-24P Cask in Hot Shop

3-34 Installing Thermocouple Lances into the Fuel Assembly Guide Tubes Through the TN-24P Test Lid

3-35 TN-24P Cask Being Moved to the Warm Shop Test Bay

3-36 TN-24P Cask with Ends Insulated

4-1 Relationship of Topmost TC Location to Cask Lid, Basket, and Fuel Canister

$4-4$

4-2 Axial Temperature Profiles for the Vertical Vacuum Run

4-3 Axial Temperature Profiles for the Horizontal Vacuum Run

4-4 Axial Temperature Profiles for the Horizontal Vacuum Run with Cask Ends Insulated

4-5 Comparison of Axial Temperature Profiles for the Vertical and Horizontal Vacuum Runs

4-6 Radial Temperature Profiles for the Vertical and Horizontal Vacuum Runs

4-7 Axial Temperature Profiles for the Vertical Nitrogen Run

4-8 Axial Temperature Profiles for the Horizontal Nitrogen Run

4-9 Comparison of Axial Temperature Profiles for the Vertical and Horizontal Nitrogen Runs

4-10 Radial Temperature Profiles for the Vertical and Horizontal Nitrogen Runs 
4-12 Axial Temperature Profiles for the Horizontal Helium Run 4-19

4-13 Comparison of Axial Temperature Profiles for the Vertical 4-20

4-14 Radial Temperature Profiles for the Vertical and Horizontal 4-21 Helium Runs

4-15 Effect of Backfill Gas Environment and Cask Orientation on Axial 4-23 Temperature Profiles in the TN-24P Cask Loaded with Consolidated Fue1

4-16 Effect of Backfill Gas Environment and Cask Orientation on Axial Temperature Profiles in the TN-24P Cask Loaded with Unconsolidated Fuel

4-17 Radial Temperature Profiles Measured Near Peak Axial Temperature for the TN-24P Cask Loaded with Consolidated Fuel

4-18 Radial Temperature Profiles Measured Near Peak Axial Temperatures for TN-24P Cask Loaded with Unconsolidated Fuel

4-19 Axial Surface Temperature Profiles 4-28

4-20 Circumferential Surface Temperature Profiles 4-30

4-21 Cask, Basket, and Ambient Temperature History During Cask Testing 4-31

4-22 Gamma and Neutron Dose Rate Profiles Measured on Cask Bottom 4-34 and Test Lid with Consolidated Fuel in the Cask

4-23 Comparison of Gamma and Neutron Dose Rate Profiles Measured on Cask 4-35 Bottom and Test Lid for Consolidated or Unconsolidated Fuel in the TN-24P Cask

4-24 Axial Gamma and Neutron Dose Rate Profiles Measured on Cask 4-36 Surface with Consolidated Fuel in the TN-24P Cask

4-25 Comparison of Axiat Gamma and Neutron Dose Rate Profiles Measured 4-38 on Cask Surface with Consolidated or Unconsolidated Fuel in the TN-24P Cask

4-26 Dose Rates (mrem/h) Measured on and Near Cask Surface 4-39

4-27 ${ }^{85} \mathrm{Kr}$ Release from the Fuel During Test Runs 4-45

4-28 Cumulative ${ }^{85} \mathrm{Kr}$ Release from Fuel from Time Cask Was Fully 4-45 Loaded with Consolidated Fuel to the End of Testing

5-1 Subchannel Definition 5-4

5-2 Transverse Momentum Control Volume 5-6

5-3 Axial Computational Cask Model 5-9

5-4 One-Half Transverse Section Computational Cask Model 5-10 
5-5 Pretest Consolidated Fuel Model 5-11

5-6 Pretest Peak Temperature Predictions Compared to Test Data 5-17

5-7 Pretest Vertical, Helium Axial Temperature Profile Predictions 5-18 - Compared to Test Data

5-8 Pretest Vertical, Nitrogen Axial Temperature Profile Predictions 5-19 Compared to Test Data

5-9 Pretest Vertical, Vacuum Axial Temperature Profile Predictions 5-20 Compared to Test Data

5-10 Effect of Fill Gas on Pretest Vertical Axial Temperature Profile 5-22 Predictions Compared to Data

5-11 Pretest Vertical, Helium, Nitrogen, and Vacuum Radial Temperature 5-23 Profile Predictions Compared to Test Data at Peak Axial Locations

5-12 Pretest Horizontal, Helium Axial Temperature Profile Predictions 5-25 Compared to Test Data

5-13 Pretest Horizontal, Nitrogen Axial Temperature Profile Predictions Compared to Test Data

5-14 Pretest Horizontal, Vacuum Axial Temperature Profile Predictions Compared to Test Data

5-15 Effect of Fill Gas on Pretest Horizontal Axial Temperature Profile Predictions Compared to Data

5-16 Pretest Horizontal, Helium, Nitrogen, and Vacuum Radial Temperature Profile Predictions Compared to Test Data at Peak Axial Locations

5-17 Full Transverse Unconsolidated Fuel Assembly Lumped Rod and Lumped 5-32 Channel Computational Model

5-18 Post-Test Consolidated Fuel Model 5-33

5-19 Post-Test Peak Temperature Predictions Compared to Pretest Predictions 5-34 and Test Data

5-20 Post-Test Vertical, Helium Axial Temperature Profile Predictions 5-35 Compared to Test Data

5-21 Post-Test Vertical, Nitrogen Axial Temperature Profile Predictions 5-36 Compared to Test Data

5-22 Post-Test Vertical, Vacuum Axial Temperature Profile Predictions 5-37 Compared to Test Data

5-23 Post-Test Vertical, Helium, Nitrogen, and Vacuum Axial Temperature Profile Predictions Compared to Test Data at a Center Canister Location 
5-24 Post-Test Vertical, HeTium, Nitrogen, and Vacuum Radial Temperature Profile Predictions Compared to Test Data at Peak Temperature Axial Locations

5-25 Post-Test Horizontal, Helium Axial Temperature Profile Predictions Compared to Test Data

5-26 Post-Test Horizontal, Nitrogen Axial Temperature Profile Predictions Compared to Test Data

5-27 Post-Test Horizontal, Vacuum Axial Temperature Profile Predictions Compared to Test Data

5-28 Post-Test Horizontal, Helium, Nitrogen, and Vacuum Axial Temperature Profile Predictions Compared to Test Data at a Center Canister Location

5-29 Post-Test Horizontal, Vertical, Helium, Nitrogen, and Vacuum Radial Temperature Profile Predictions Compared to Test Data at Peak Temperature Axial Locations 
TABLES

Table

Page

3-1 Differences Between TN-24 Prototype and TN-24 Standard Casks

3-2 Surry 2 Assembly Average Burnup Histories

3-3 Turkey Point Assembly Average Burnup Histories

3-4 TN-24P Cask Fuel Canister Composition and Loading Arrangement

3-5 Cask Performance Test Matrix

3-6 Detailed Operating Procedures for TN-24P PWR Consolidated

4-1 Test Matrix and Peak Temperatures for the TN-24P Cask

4-2 Comparison of Peak Fuel Temperatures in the TN-24P Cask Loaded with Unconsolidated Fuel Assemblies and Consolidated Fuel Canisters

4-3 Cask Surface Temperature Measurements

4-4 Comparison of Peak Surface Dose Rates on the TN-24P Cask Loaded with Unconsolidated Fuel Assemblies or Consolidated Fuel Canisters

4-5 Cover Gas Samples Taken During Performance Testing

4-6 Cask Gas Sample Composition

4-7 ${ }^{85} \mathrm{Kr}$ Concentration of Gas Samples

5-1 COBRA-SFS Capabilities and Limitations

5-2 Boundary Convection Heat Transfer Correlations

5-3 Material Properties

5-4 Peak Temperature Comparisons 


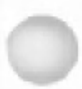

0

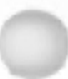


NOMENCLATURE

ABBREVIATIONS AND ACRONYMS

$\begin{array}{ll}\text { CFA } & \text { INEL Central Facilities Area } \\ \text { CPP } & \text { INEL Chemical Processing Plant } \\ \text { DAS } & \text { data acquisition system } \\ \text { DOE } & \text { U.S. Department of Energy } \\ \text { DOE-RL } & \text { DOE Richland Operations Office } \\ \text { DOP } & \text { Detailed Operating Procedure } \\ \text { DRCT } & \text { Dry Rod Consolidation Technology } \\ \text { EFPD } & \text { effective full-power days } \\ \text { EOC } & \text { end of cycle } \\ \text { EPRI } & \text { Electric Power Research Institute } \\ \text { FRDS } & \text { failed fuel rod detection system } \\ \text { H/U } & \text { hydrogen-to-uranium (ratio) } \\ \text { INEL } & \text { Idaho National Engineering Laboratory } \\ \text { LLNL } & \text { Lawrence Livermore National Laboratory } \\ \text { M/S } & \text { multisphere spectrometer } \\ \text { MTU } & \text { metric ton uranium } \\ \text { NBS } & \text { National Bureau of Standards } \\ \text { NOD } & \text { VP Nuclear Operations Department } \\ \text { NRC } & \text { U.S. Nuclear Regulatory Commission } \\ \text { NWPA } & \text { Nuclear Waste Policy Act } \\ \text { OSRD } & \text { Operation Safety Requirements Document } \\ \text { PNL } & \text { Pacific Northwest Laboratory } \\ \text { PWR } & \text { pressurized water reactor } \\ \text { R\&D } & \text { research and development } \\ \text { RPD } & \text { relative power density } \\ \text { SAR } & \text { Safety Analysis Report } \\ \text { SCAP } & \text { Solicitation for Cooperative Agreement Proposal } \\ \text { SWR } & \text { Site Work Release } \\ \text { TAN } & \text { Test Area North } \\ \text { TC } & \text { thermocouple } \\ \text { TED } & \text { track etch dosimeter } \\ \text { TEPC } & \text { tissue equivalent proportional counter } \\ \text { TLD } & \text { thermoluminescent dosimeter } \\ \text { TN } & \text { Transnuclear Inc. } \\ \text { UBC } & \text { Uniform Building Code } \\ \text { UT } & \text { ultrasonic techniques } \\ \text { VP } & \text { Virginia Power } \\ & \end{array}$

SYMBOLS AND NOTATIONS

$\alpha_{\mathbf{i}}$

set of wall numbers with a thermal conduction connnection to wall node $i$

$\beta_{j} \quad$ set of wall numbers with a thermal radiation connection to rod $i$

$\tau_{j} \quad$ set of subchannel numbers with a thermal connection to rod $i$

$\Delta \mathrm{t} \quad$ time step 


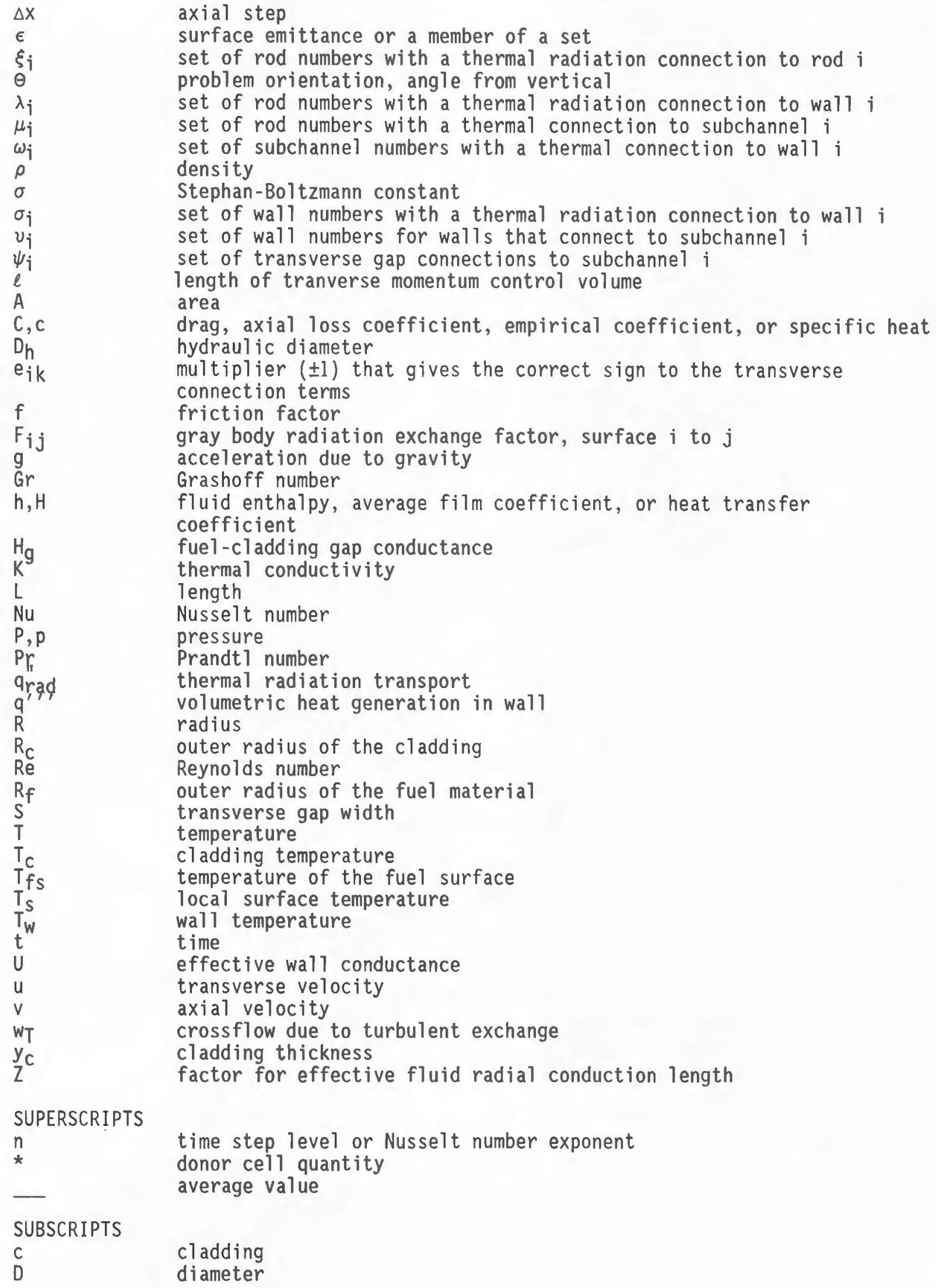


friction or fuel

subchannel number or generalized subscript for matrix notation heat transfer from a rod heat transfer from a wall axial level or generalized subscript for matrix notation refer to channel numbers on either side of a transverse gap

transverse gap number

mixed convection or wall number

rod number

radiation

rod

fuel surface

transverse

wall 
o

0

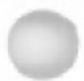




\section{EXECUTIVE SUMMARY}

This report documents a heat transfer and shielding performance test conducted on a Transnuclear, Inc., TN-24P pressurized water reactor (PWR) spent fuel storage cask loaded with consolidated spent fuel. The performance testing was conducted for the U.S. Department of Energy (DOE) and the Electric Power Research Institute (EPRI) by the Pacific Northwest Laboratory (PNL), operated for DOE by Battelle Memorial Institute, and the Idaho National Engineering Laboratory (INEL), operated for DOE by EG\&G Idaho, Inc. Testing was conducted at INEL's Test Area North (TAN) cask-testing facility and consisted of pretest preparations, performance testing, and post-test activities. Pretest preparations included conducting cask-handling dry (cold) runs and dry rod consolidation. The performance test matrix included seven runs consisting of two cask orientations and three backfill environments. The final test run was sponsored by Transnuclear, Inc., and Transnucleaire (France) to simulate the insulating effect of impact limiters.

The TN-24P spent fuel storage cask consists of a forged steel body for structural integrity and gamma shielding, surrounded by a resin layer for neutron shielding. The resin layer is enclosed in a smooth steel outer shell. The cask cross section is shown in Figure $S-1$. The cask is $5.0 \mathrm{~m}(16 \mathrm{ft}) 1 \mathrm{ong}$ and $2.3 \mathrm{~m}(7.5 \mathrm{ft})$ in diameter and weighs approximately 100 tons when loaded with unconsolidated PWR spent fuel. The cask is closed with a lid having two concentric metallic 0-ring seals plus a protective cover sealed with one rubber 0 -ring gasket to seal the cask cavity from the environment. The fuel basket within the cask is configured to hold 24 PWR spent fuel assemblies or consolidated canisters and is composed of stacked, interlocking plates constructed of aluminum and boron. Twenty-four canisters of spent fuel rods from the INEL Dry Rod Consolidation Technology Project were used during testing. Each consolidated fuel canister contained fuel rods from two surry or two Turkey Point spent fuel assemblies of a standard Westinghouse $15 \times 15$ rod design.

Dry/cold runs (trial runs) of cask handling and fuel loading were performed during a previous test when unconsolidated surry spent fuel assemblies were loaded in the cask. The objectives of the dry runs were to gain operational experience and to finalize handling and test procedures. Each dry run was conducted successfully 


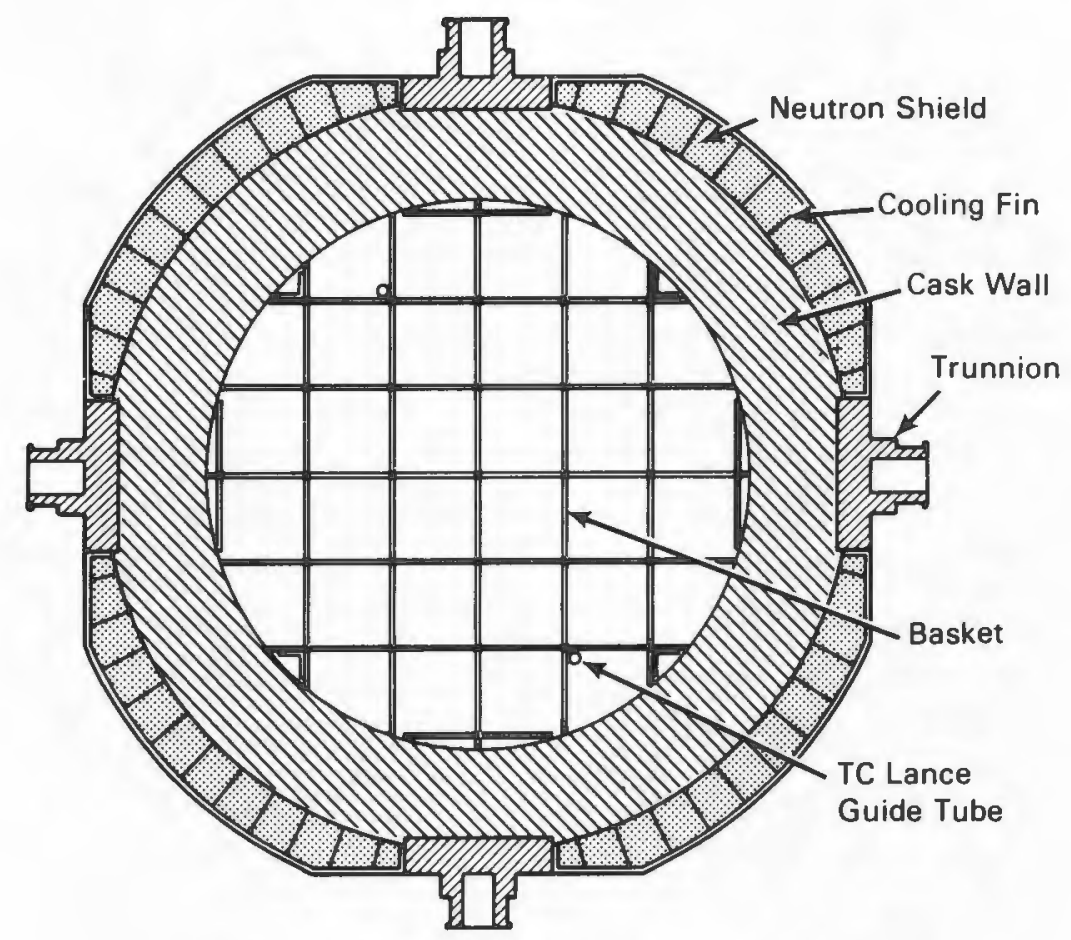

Figure S-1. TN-24P Cask Cross Section

without unusual problems or significant modifications to the cask or handling equipment. The PWR spent fuel assemblies had been well characterized prior to testing. The results of these examinations indicated the presence of two or three leaking fuel rods before the TN-24P cask performance test with consolidated fuel canisters. Gas samples taken after the consolidated canisters had been loaded in the cask and during the actual testing indicated that an additional seven rods developed leaks.

Based on pretest ORIGEN2 predictions, fuel rod decay heat generation rates totaled approximately $23 \mathrm{~kW}$ during testing (Table S-1). The decay heat output of the canisters of consolidated rods ranged from 700 to $1180 \mathrm{~W}$, with an average output per canister of $970 \mathrm{~W}$ at the start of testing. The fuel assemblies had cooling times of 6 to 12 years. The fuel loading pattern was expected to create a relatively flat radial temperature profile across the basket during testing with the cooler fuel canisters in the center of the basket and the hotter fuel canisters around the outside. Pretest heat transfer predictions using the COBRA-SFS computer code indicated that peak cladding temperatures in vacuum, nitrogen, and helium would be below or near 257,242 , and $203^{\circ} \mathrm{C}$, respectively. 
Table S-1

TN-24P CASK FUEL CANISTER COMPOSITION

\begin{tabular}{|c|c|c|c|c|c|c|}
\hline \multirow{2}{*}{$\begin{array}{l}\text { Assembly } \\
\text { ID\# } \\
\end{array}$} & \multirow[b]{2}{*}{$\begin{array}{c}\text { Assembly } \\
\text { Source }\end{array}$} & \multirow[b]{2}{*}{$\begin{array}{l}\text { Burnup, } \\
\text { GWd/MTU }\end{array}$} & \multirow{2}{*}{$\begin{array}{l}\text { Cooling } \\
\text { Time, } \\
\text { Years } \\
\end{array}$} & \multirow{2}{*}{$\begin{array}{c}\text { Initial } \\
\text { Enrichment, } \\
\% \\
\end{array}$} & \multicolumn{2}{|c|}{$1 / 15 / 88$ Decay Heat } \\
\hline & & & & & $\begin{array}{c}\text { Assembly, } \\
W\end{array}$ & $\begin{array}{c}\text { Canister, } \\
W\end{array}$ \\
\hline D01 & $T-P$ & 28.43 & 10.2 & 2.56 & 429.9 & 859.8 \\
\hline D04 & $T-P$ & 28.43 & 10.2 & 2.56 & 429.9 & \\
\hline N05 & S-MC10 & 26.82 & 11.7 & 2.56 & 375.7 & 754.9 \\
\hline N11 & S-MC10 & 27.04 & 11.7 & 2.56 & 379.2 & \\
\hline W10 & S-TN24P & 29.80 & 6.2 & 3.20 & 578.7 & 1157.4 \\
\hline W02 & S-TN24P & 29.80 & 6.2 & 3.20 & 578.7 & \\
\hline N16 & S-MC10 & 26.82 & 11.7 & 2.56 & 375.7 & 751.4 \\
\hline N35 & S-MC10 & 26.82 & 11.7 & 2.56 & 375.7 & \\
\hline R01 & S-MC10 & 35.44 & 9.0 & 3.10 & 581.5 & 1163.0 \\
\hline R15 & S-MC10 & 35.44 & 9.0 & 3.10 & 581.5 & \\
\hline W52 & $\mathrm{S}-\mathrm{TN} 24 \mathrm{P}$ & 29.99 & 6.2 & 3.20 & 583.1 & 1161.8 \\
\hline W49 & S-TN24P & 29.80 & 6.2 & 3.20 & 578.7 & \\
\hline D06 & $\mathrm{T}-\mathrm{P}$ & 28.43 & 10.2 & 2.56 & 429.9 & 859.8 \\
\hline D15 & $T-P$ & 27.86 & 10.2 & 2.56 & 429.9 & \\
\hline B03 & $T-P$ & 25.67 & 12.2 & 2.56 & 350.6 & 701.2 \\
\hline B02 & $\mathrm{T}-\mathrm{P}$ & 25.67 & 12.2 & 2.56 & 350.6 & \\
\hline W06 & S-TN24P & 30.52 & 6.2 & 3.20 & 592.4 & 1184.8 \\
\hline W13 & S-TN24P & 30.52 & 6.2 & 3.20 & 592.4 & \\
\hline N36 & S-MC10 & 26.82 & 11.7 & 2.56 & 375.7 & 751.4 \\
\hline NO4 & S-MC10 & 26.82 & 11.7 & 2.56 & 375.7 & \\
\hline R34 & S-MC10 & 35.33 & 9.0 & 3.10 & 579.9 & 1159.8 \\
\hline R35 & S-MC10 & 35.33 & 9.0 & 3.10 & 579.9 & \\
\hline W38 & S-TN24P & 29.99 & 6.2 & 3.20 & 583.1 & 1166.2 \\
\hline W01 & S-TN24P & 29.99 & 6.2 & 3.20 & 583.1 & \\
\hline D35 & $T-P$ & 28.43 & 10.2 & 2.56 & 429.9 & 859.8 \\
\hline D40 & $T-P$ & 28.43 & 10.2 & 2.56 & 429.9 & \\
\hline N37 & S-MC10 & 27.04 & 11.7 & 2.56 & 379.2 & 758.4 \\
\hline N17 & S-MC10 & 27.04 & 11.7 & 2.56 & 379.2 & \\
\hline W19 & $S-T N 24 P$ & 29.80 & 6.2 & 3.20 & 578.7 & 1157.4 \\
\hline W16 & S-TN24P & 29.80 & 6.2 & 3.20 & 578.7 & \\
\hline L25 & S- $-M C 10$ & 24.18 & 10.4 & 1.86 & 362.1 & 732.5 \\
\hline LO4 & S-MC10 & 24.53 & 10.4 & 1.86 & 370.4 & \\
\hline R18 & S-MC10 & 35.44 & 9.0 & 3.10 & 581.5 & 1161.4 \\
\hline R09 & S-MC10 & 35.33 & 9.0 & 3.10 & 579.9 & \\
\hline W44 & S-TN24P & 29.99 & 6.2 & 3.20 & 583.1 & 1166.2 \\
\hline W46 & S-TN24P & 29.99 & 6.2 & 3.20 & 583.1 & \\
\hline D47 & $T-P$ & 28.43 & 10.2 & 2.56 & 429.9 & 859.8 \\
\hline D46 & $T-P$ & 28.43 & 10.2 & 2.56 & 429.9 & \\
\hline B41 & $T-P$ & 25.67 & 12.2 & 2.56 & 350.6 & 700.1 \\
\hline B43 & $T-P$ & 25.60 & 12.2 & 2.56 & 349.5 & \\
\hline W34 & S-TN24P & 30.52 & 6.2 & 3.20 & 592.4 & 1184.8 \\
\hline W27 & S-TN24P & 30.52 & 6.2 & 3.20 & 592.4 & \\
\hline N15 & S-MC10 & 26.82 & 11.7 & 2.56 & 375.7 & 751.4 \\
\hline N09 & S-MC10 & 26.82 & 11.7 & 2.56 & 375.7 & \\
\hline W09 & S-MC10 & 28.29 & 6.2 & 3.20 & 534.7 & 1114.6 \\
\hline R41 & S-MC10 & 35.33 & 9.0 & 3.10 & 579.9 & \\
\hline W28 & S-TN24P & 29.99 & 6.2 & 3.20 & 583.1 & 1166.2 \\
\hline W17 & S-TN24P & 29.99 & 6.2 & 3.20 & 583.1 & \\
\hline
\end{tabular}


Figure S-2 shows the predicted axial decay heat profile assumed for the consolidated fuel canisters. Measured axial power profiles were not available for predicting axial decay heat profiles so axial gamma radiation scans previously obtained on Turkey Point reactor fuel assemblies were used to predict the fuel's axial burnup distribution. ORIGEN2 was used with the assembly axial burnup distribution and the reactor operating history to determine the predicted axial decay heat profile shown in Figure S-2. The axial decay heat profiles were smoothed for the heat transfer analysis. Axial decay heat profiles are important input to heat transfer computer codes because they strongly affect the shape of predicted axial fuel temperature profiles.

The outer surface of the cask was instrumented with 27 thermocouples (TCs). Fiftyfour TCs contained in nine lances (six per lance) were inserted through the cask lid into fuel canister or basket guide tubes, seven in fuel canister guide tubes, and two in simulated guide tubes attached to the basket, as shown in Figure S-3. An additional 14 TCS were attached to the basket, as shown in Figure S-4.

The cask test matrix included assessments of performance with a full load of consolidated fuel (24 canisters), vertical and horizontal cask orientations, and

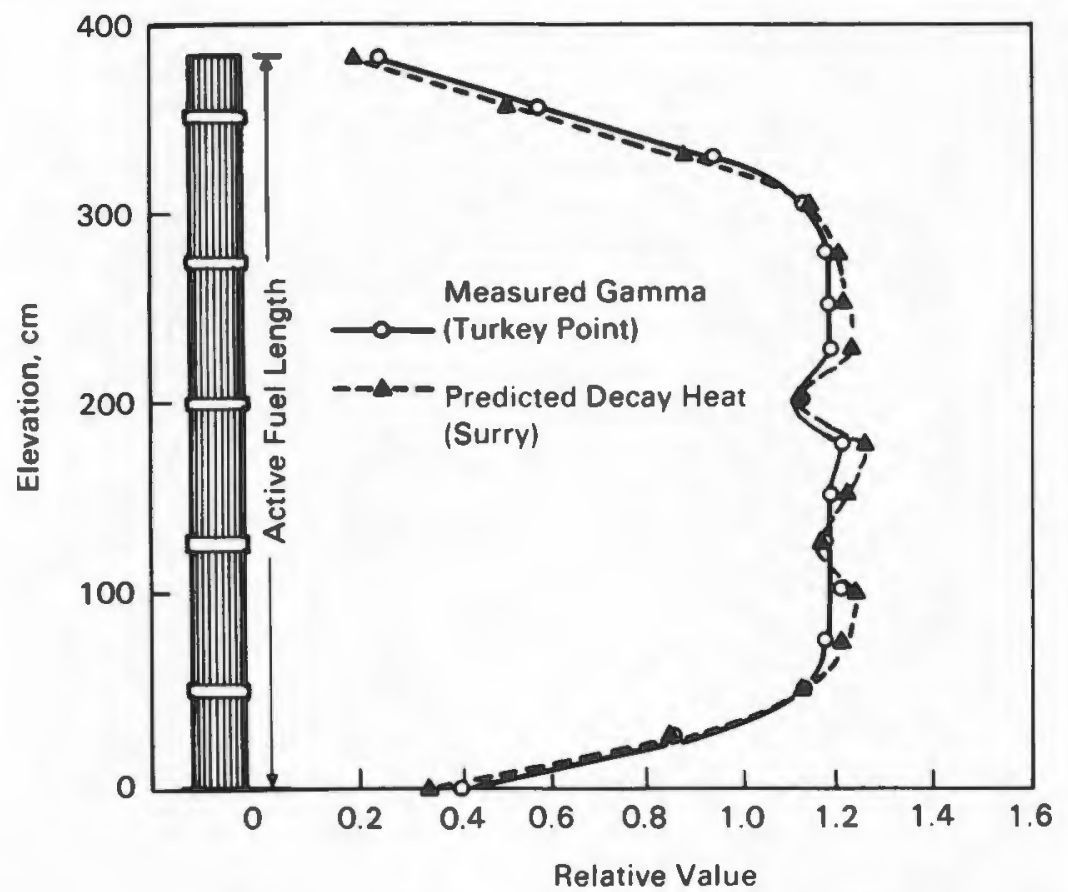

Figure S-2. Measured Gamma and Predicted Decay Heat Axial Profiles 


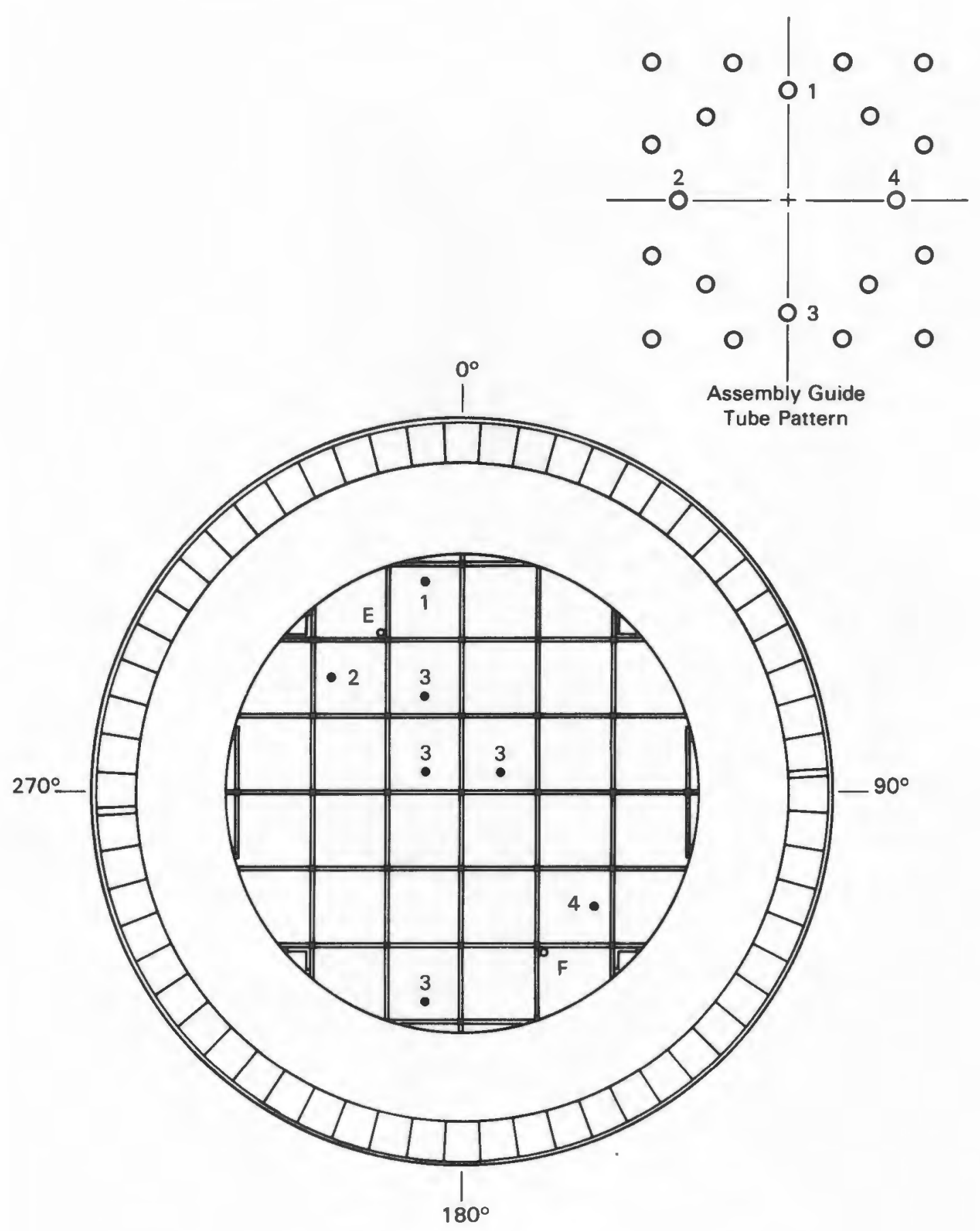

Figure S-3. Thermocouple Lance Locations

vacuum, nitrogen, and helium backfill environments. The test matrix and corresponding measured peak guide tube temperatures and estimated peak cladding temperatures 


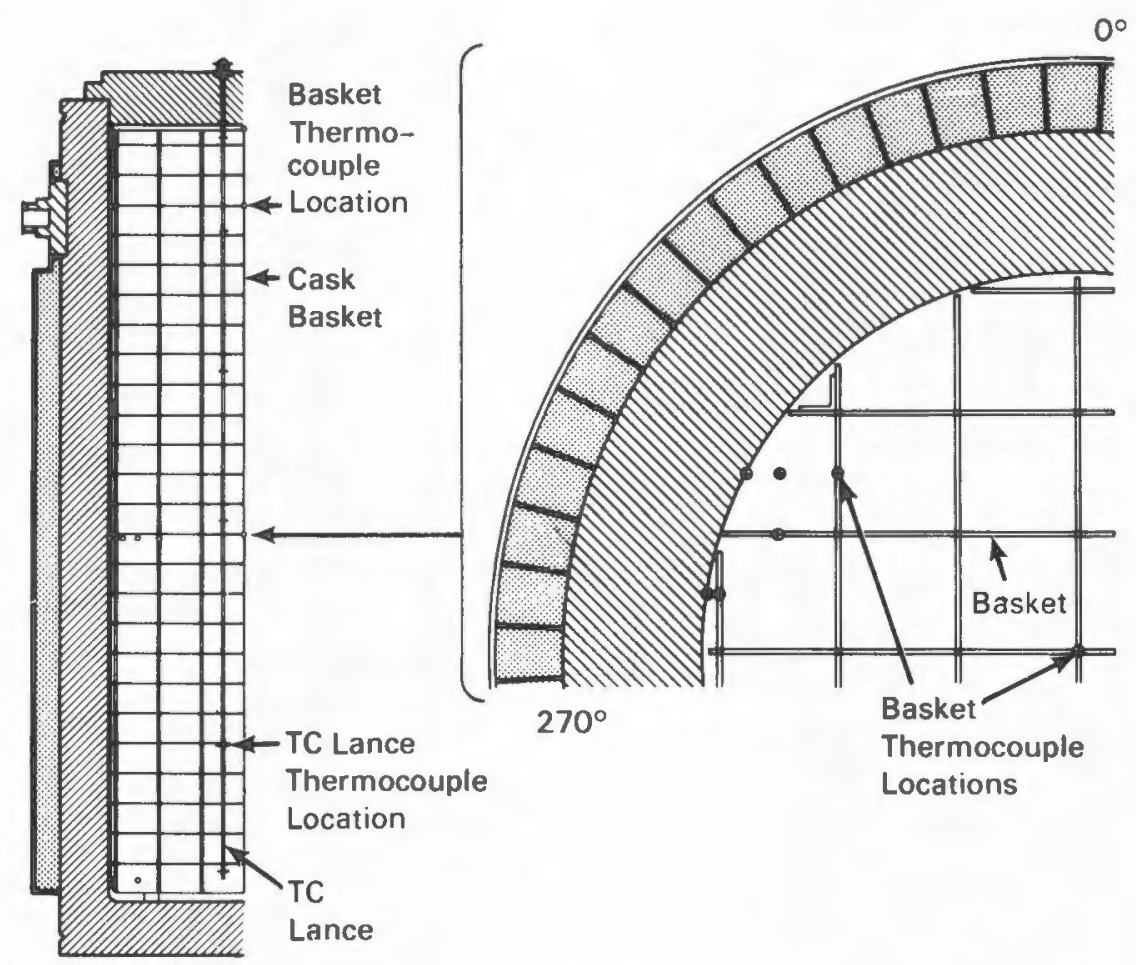

Figure S-4. Basket Thermocouple Locations

are presented in Table S-2. Peak cladding temperatures were estimated by using calculated guide tube-to-hot rod temperature differences from the COBRA-SFS computer code.

The data in Table S-2 indicate that peak cladding temperatures for all fill gases and cask orientations tested were less than $300^{\circ} \mathrm{C}$. In general, the cask heat transfer performance was concluded to be exceptionally good, because the difference between the ambient and the peak cladding temperature in helium and nitrogen, when the cask was dissipating approximately $23 \mathrm{~kW}$, was $100^{\circ} \mathrm{C}$ less than specified for the cask operating limit of $24 \mathrm{~kW}$ in the cask topical safety analysis report.

Axial and radial guide tube temperature profiles for the six test runs are shown in Figures S-5 and S-6. Attention should be given to data points only. The corresponding curves are provided for clarity and do not necessarily represent actual profiles. The axial profiles are for the hot center assembly, and the radial profiles are for the axial location of the peak temperature for each of the respective runs. The axial profiles show the small effect of convection in nitrogen in a vertical orientation where peak temperatures are skewed toward the top of the cask. 
Table S-2

TEST MATRIX AND PEAK TEMPERATURES FOR THE TN-24P CASK LOADED WITH CONSOLIDATED FUEL

\begin{tabular}{|c|c|c|c|c|c|c|c|c|}
\hline $\begin{array}{l}\text { Run } \\
\text { №. }\end{array}$ & Orientation & Backfill & $\begin{array}{l}\text { Cask } \\
\text { Heat } \\
\text { Load, } \\
\text { kW } \\
\end{array}$ & $\begin{array}{l}\text { Ambient } \\
\text { Temp, } \\
{ }^{\circ} \mathrm{C} \\
\end{array}$ & $\begin{array}{l}\text { Side } \\
\text { Surface } \\
\text { Temp, } \\
{ }^{\circ} \mathrm{C} \\
\end{array}$ & $\begin{array}{c}\text { Measured } \\
\text { Peak } \\
\text { Basket } \\
\text { Temp, }{ }^{\circ} \mathrm{C}\end{array}$ & $\begin{array}{l}\text { Measured } \\
\text { Guide } \\
\text { Tube } \\
\text { Temp, }{ }^{\circ} \mathrm{C} \\
\end{array}$ & $\begin{array}{l}\text { Estimated } \\
\text { Peak Clad. } \\
\text { Temp, }{ }^{\circ} \mathrm{C} \\
\end{array}$ \\
\hline 1 & Vertical & Hel i um & 23.3 & 22 & 71 & 203 & 211 & 211 \\
\hline 2 & Vertical & Nitrogen & 23.3 & 16 & 71 & 240 & 267 & 268 \\
\hline 3 & Vertical & Vacuum & 23.2 & 22 & 70 & 262 & 291 & 293 \\
\hline 4 & Horizontal & Hel i um & 23.2 & 17 & 71 & 198 & 205 & 205 \\
\hline 5 & Horizontal & Nitrogen & 23.2 & 22 & 69 & 229 & 251 & 252 \\
\hline 6 & Horizontal & Vacuum & 23.1 & 23 & 73 & 252 & 280 & 282 \\
\hline $7^{\mathrm{a}}$ & Horizontal & Vacuum & 23.1 & 24 & 85 & 255 & 280 & 282 \\
\hline
\end{tabular}

$\overline{\text { aThe top }}$ and bottom of the cask were insulated during this run. This run was sponsored by Transnucleaire.

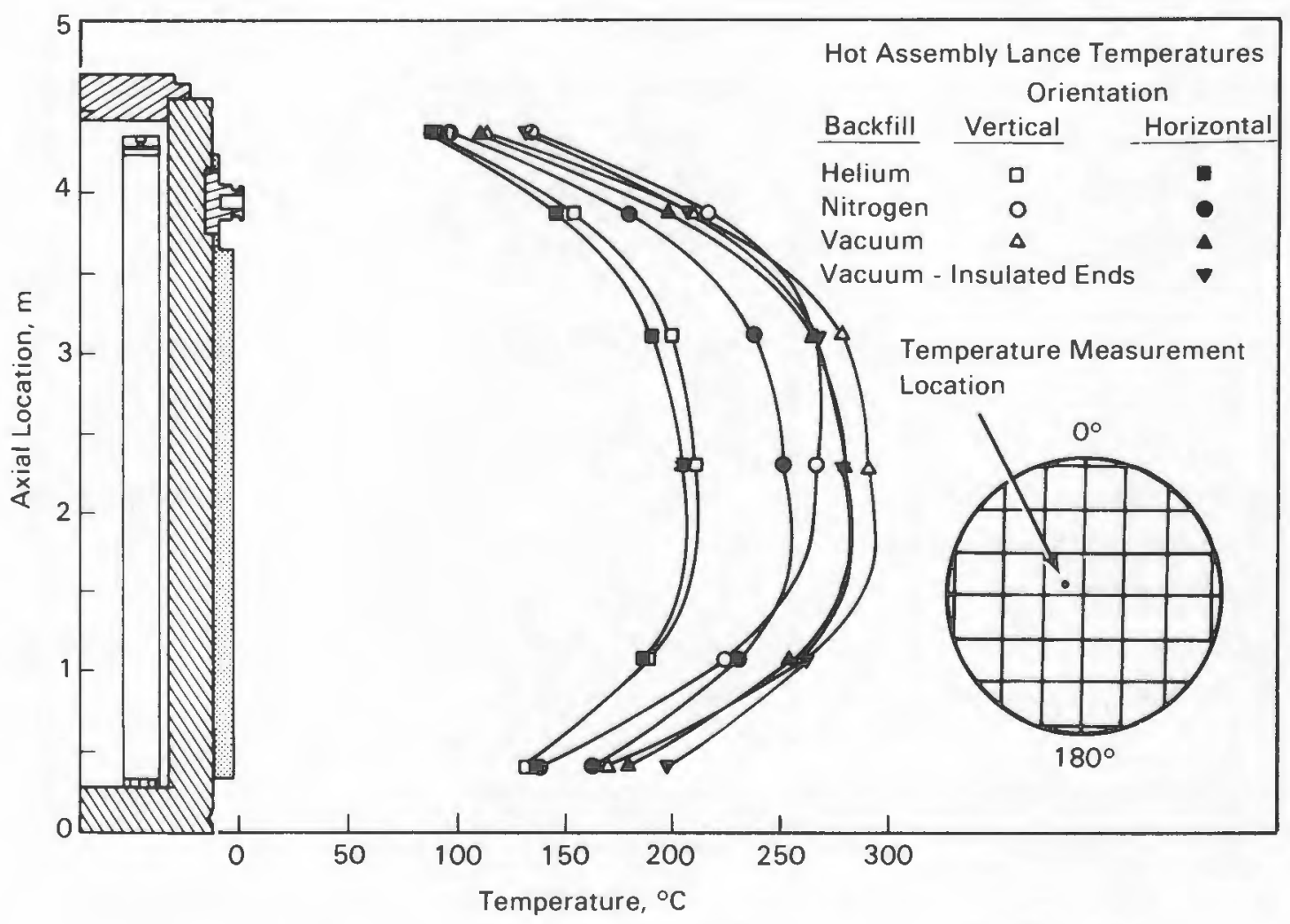

Figure S-5. Effect of gas environment and cask orientation on axial temperature profiles. 


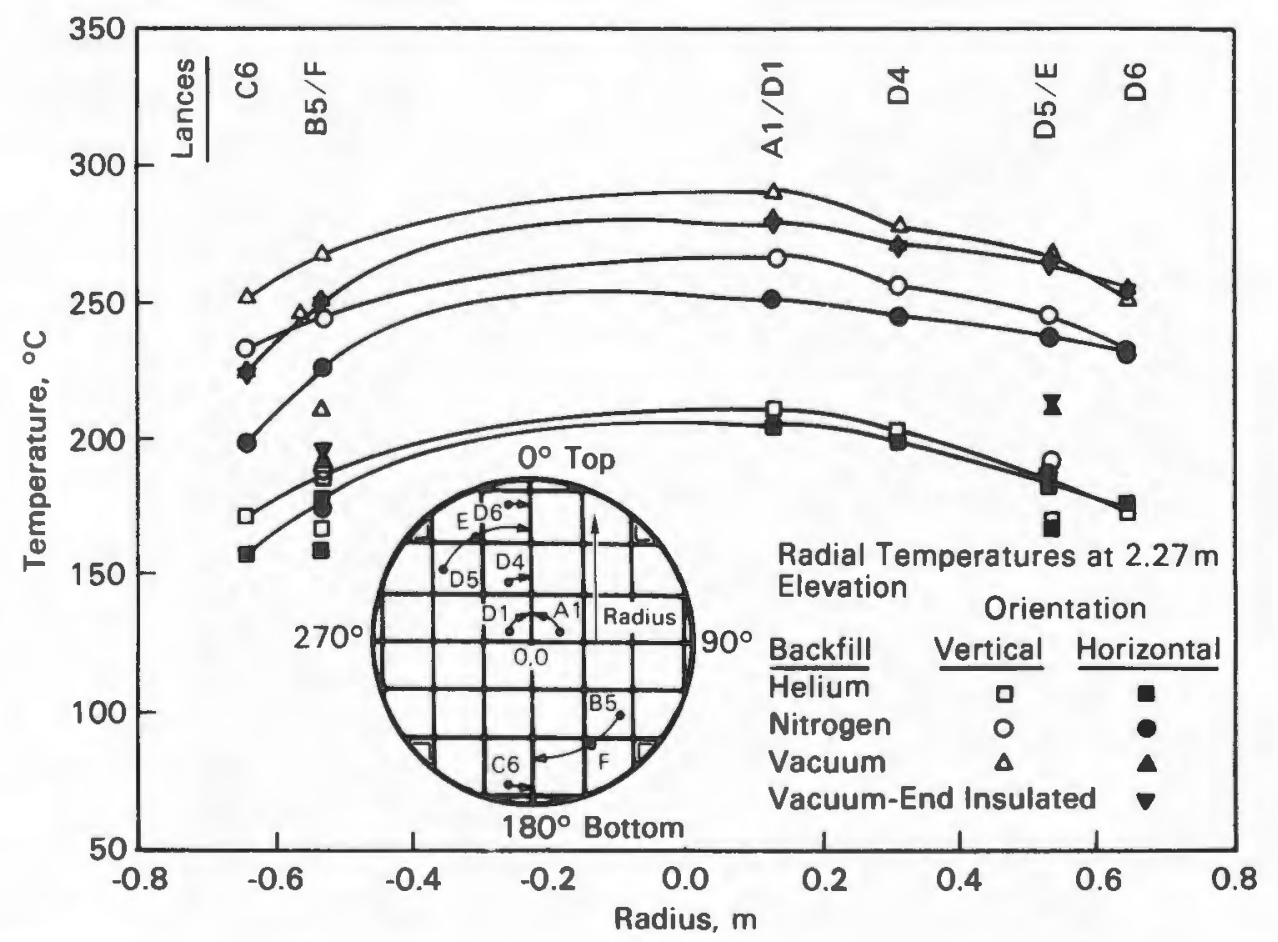

Figure S-6. Radial Temperature Profiles Measured Near Peak Axial Temperatures

In the nitrogen case, convection moves the location of the peak axial temperature from an elevation of $1.9 \mathrm{~m}(6.2 \mathrm{ft})$ to $2.7 \mathrm{~m}(8.9 \mathrm{ft})$; in the helium case, the change is too small to determine. Figure S-5 shows that insulating the ends of the cask has little, if any, effect on peak fuel temperatures.

The effect of convection on axial temperature profiles with consolidated fuel in the cask is much less than was seen for the cask loaded with unconsolidated fuel assemblies. The consolidated fuel canisters are densely packed and have limited flow areas for the axial flow of gas compared to the open design of unconsolidated fuel assemblies. With consolidated fuel and a nitrogen backfill gas in the cask, there was an $0.8-\mathrm{m}(2.6-\mathrm{ft})$ shift in the location of the peak temperature due to cask orientation. A previous test with unconsolidated fuel experienced a $1.7-\mathrm{m}(5.6-\mathrm{ft})$ shift in the location of the peak temperature because of convection.

Note that the peak temperatures in all vertical runs are greater than the peak temperatures in the horizontal runs. This indicates that increased conduction between the basket and cask wall in the horizontal runs exceeds the limited convection in the vertical runs. The relationship between the center basket temperatures and the 
adjacent fuel lance temperatures indicates that contact between the basket and fuel had negligible effect on fuel temperatures.

Except for the vertical nitrogen runs, symmetry with respect to the predicted axial decay heat profile over the active length of the fuel assemblies indicates that axial convection was negligible (Figure S-5). These profiles are similar to the axial gamma and decay heat profiles previously presented in Figure S-2. In essence, the consolidated fuel canister blocks most of the flow through the basket. The high conductivity of helium masks what little convection may be occurring for the helium run. Only the vertical nitrogen run shows skewing of the axial temperature profile caused by convection.

Radial temperature profiles at the hot elevation for the fuel assemblies of six test runs are shown in Figure S-6. Most of the temperature drop in the cask occurs between the basket and the inner wall of the cask. Steep gradients across the basket-to-inner wall gap indicate that the gap is important to the heat transfer design of the cask.

The COBRA-SFS heat transfer code was used to predict temperatures in the cask. The code used a half-section cask model and a five-node lumped-rod model of the consolidated fuel in the pretest runs. The annuli formed between the fuel canisters and basket were modeled to include conduction and radiation heat transfer only. In actuality, some convection was expected to exist; however, its contribution to the overall heat transfer was expected to be negligible due to the narrowness of the annulus.

In general, the COBRA-SFS pretest predictions of peak guide tube temperatures agree well with experimental data. The largest variation occurred for the horizontal vacuum run, where a $13 \%\left(34^{\circ} \mathrm{C}\right)$ lower peak temperature was predicted. The mean difference between calculated and measured peak temperatures for the six test runs was $8 \%\left(21^{\circ} \mathrm{C}\right)$, with a standard deviation of $\pm 4 \%\left( \pm 12^{\circ} \mathrm{C}\right)$. All six pretest simulations underpredicted the peak fuel temperature. The underprediction was primarily caused by use of an oversimplified fuel model. In the post-test analysis, the five-node lumped-rod model of the fuel was replaced with a 13-ring fuel lumping scheme. The 13-ring fuel model resulted in better temperature predictions. In the post-test runs, the greatest difference in peak temperatures occurred for the vertical nitrogen run, a $5 \%\left(13^{\circ} \mathrm{C}\right)$ underprediction. The mean temperature difference between the data and the post-test predictions for the six test runs was $3 \%\left(6^{\circ} \mathrm{C}\right)$, with a standard deviation of $\pm 2 \%\left( \pm 5^{\circ} \mathrm{C}\right)$. 
Selected COBRA-SFS pre- and post-test predictions are shown in Figures S-7 and S-8 for vertical test runs. These results show marked improvement in predictions due to the fuel model change. Figure S-7 indicates that the effect of convection was not negligible for the vertical nitrogen run. Convection caused a small shift in the location of the peak temperature, but probably has little effect on its magnitude.

The effort needed to correct the model to properly account for convection in the vertical nitrogen run was not felt to be justified by the small expected improvement in performance of the code.

Gamma and neutron dose rates on the top, bottom, and side of the cask are shown in Figures S-9 and S-10. These measurements were taken with portable survey instruments. The surface neutron dose rates for the TN-24P cask loaded with consolidated fuel were about the same as those measured previously when the cask was loaded with unconsolidated fuel; however, the gamma dose rates show significant reductions from those measured with unconsolidated fuel. Removal of the top and bottom nozzles plus the spacer grids during fuel consolidation removed most of the gamma source $\left({ }^{60} \mathrm{Co}\right)$. The total dose rate on the top of the primary lid occurred at the center of the lid and was $52 \mathrm{mrem} / \mathrm{h}--14 \mathrm{mrem} / \mathrm{h}$ gamma (reduced from $58 \mathrm{mrem} / \mathrm{h}$ for unconsolidated fuel) and $38 \mathrm{mrem} / \mathrm{h}$ neutron. When the neutron shield and protective cover are used on the cask during normal operation, the neutron dose rate should be reduced significantly.

The total dose rates along most of the cask side were less than $10 \mathrm{mrem} / \mathrm{h}$, about 5 $\mathrm{mrem} / \mathrm{h}$ gamma and $5 \mathrm{mrem} / \mathrm{h}$ neutron (Figure S-10). There were localized neutron dose rate peaks of $42 \mathrm{mrem} / \mathrm{h}$ and $17 \mathrm{mrem} / \mathrm{h}$ at the top and bottom end of the neutron shield, respectively. These peaks would disappear if the neutron shield were extended to the top and bottom of the cask. No gamma peak was apparent on the side of the cask near the bottom, and a small gamma peak (14 mrem/ $\mathrm{h}$ ) was observed on the side of the cask just above the neutron shield at the top. When unconsolidated fuel was in the cask, the respective top and bottom gamma peaks were $33 \mathrm{mrem} / \mathrm{h}$ and $55 \mathrm{mrem} / \mathrm{h}$.

The peak dose rate on the bottom of the cask $12.5 \mathrm{mrem} / \mathrm{h}$ gamma and $68 \mathrm{mrem} / \mathrm{h}$ neutron) occurred at the center. When unconsolidated fuel was in the cask, the peak gamma dose rate on the bottom of the cask was about $140 \mathrm{mrem} / \mathrm{h}$. The reduction of gamma dose rate for consolidated fuel reflects the removal of the non-fuel-bearing components containing ${ }^{60} \mathrm{Co}$. The smaller reduction in gamma dose rate on the top of the cask is associated with the ${ }^{60} \mathrm{Co}$ in the springs in the top of the fuel rods that provide a gamma source near the top of the cask. 


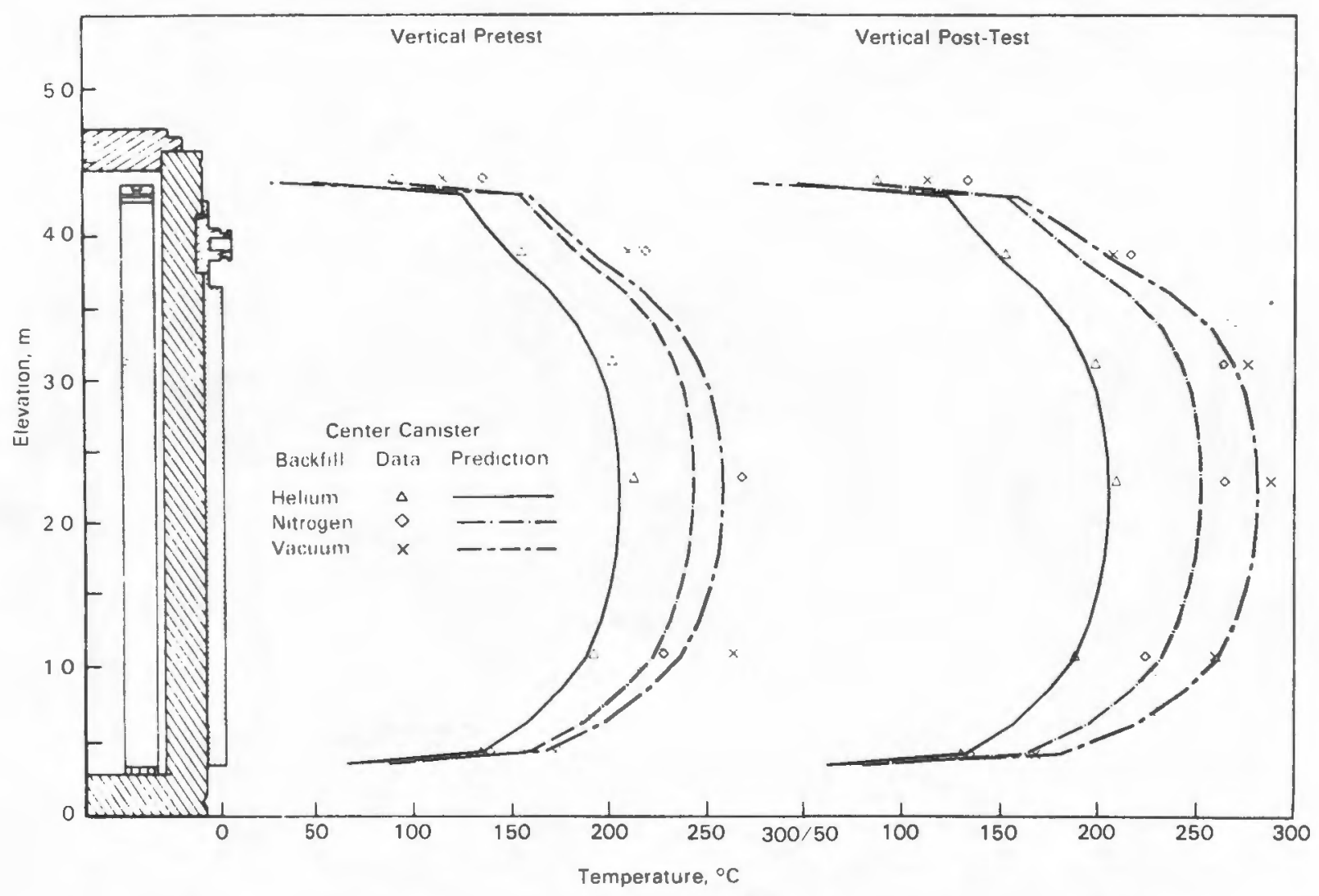

Figure S-7. Pretest and post-test axial temperature profile predictions compared to vertical, vacuum, nitrogen, and helium data. 


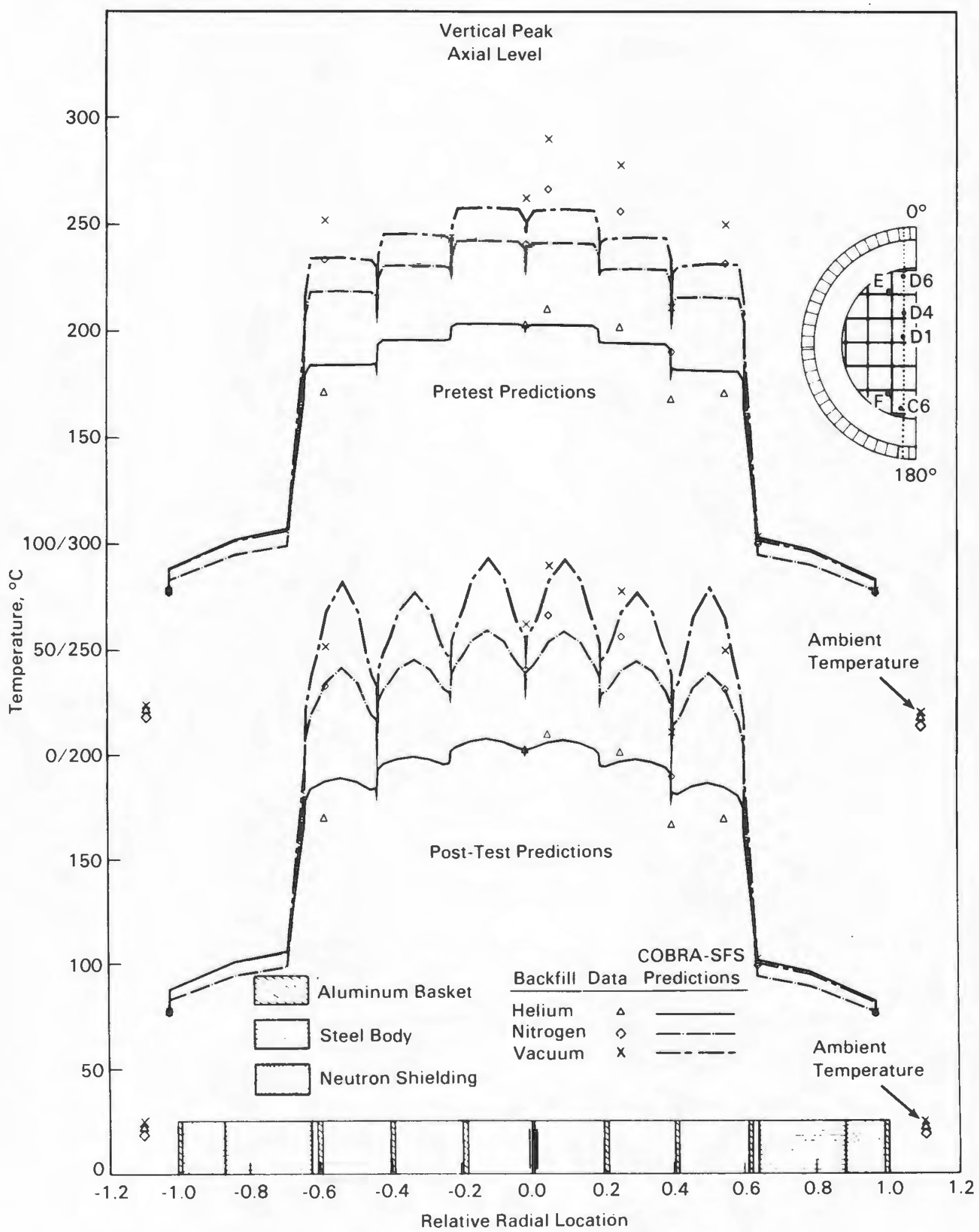

Figure S-8. Post-test and pretest radial temperature profile predictions compared to vertical vacuum, nitrogen, and helium data. 


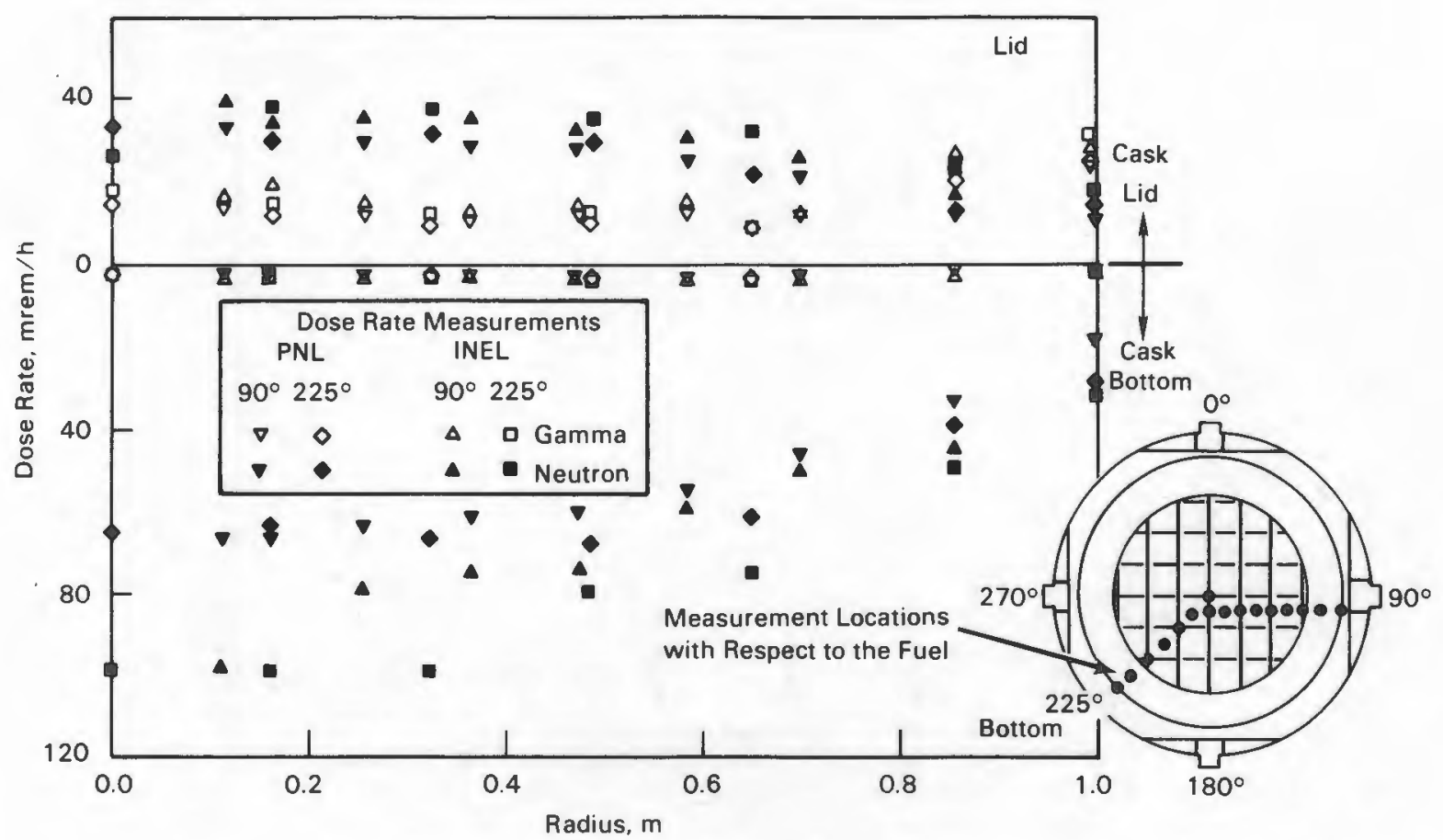

Figure S-9. Gamma and Neutron Dose Rate Profiles Measured on Cask Test Lid and Cask Bottom

The overall shielding performance of the TN-24P cask was good and met the intended design goal of $60 \mathrm{mrem} / \mathrm{h}$, except on the bottom. The magnitude of the dose rate on the bottom of the cask is not of concern during vertical storage on a pad and can be easily shielded if the cask requires transport in a horizontal orientation. With a very minor refinement in the gamma and neutron shielding design, total dose rates can easily be reduced to less than $60 \mathrm{mrem} / \mathrm{h}$ if desirable. It should also be noted that fuel consolidation results in a significant reduction in gamma dose rate.

The cask performance test demonstrated that the TN-24P cask could be satisfactorily handled and loaded dry. It was concluded that the heat transfer performance of the cask was exceptionally good. Peak cladding temperatures with helium and nitrogen backfills in a vertical cask orientation were significantly less than $300^{\circ} \mathrm{C}$ with a total cask heat load of $23 \mathrm{~kW}$. The shielding performance of the cask met design expectations $(60 \mathrm{mrem} / \mathrm{h})$, except on the cask bottom. Cask surface dose rates of $<60$ $\mathrm{mrem} / \mathrm{h}$ can easily be achieved with minor refinements in the gamma and neutron shielding design. From both heat transfer and shielding perspectives, the TN-24P 


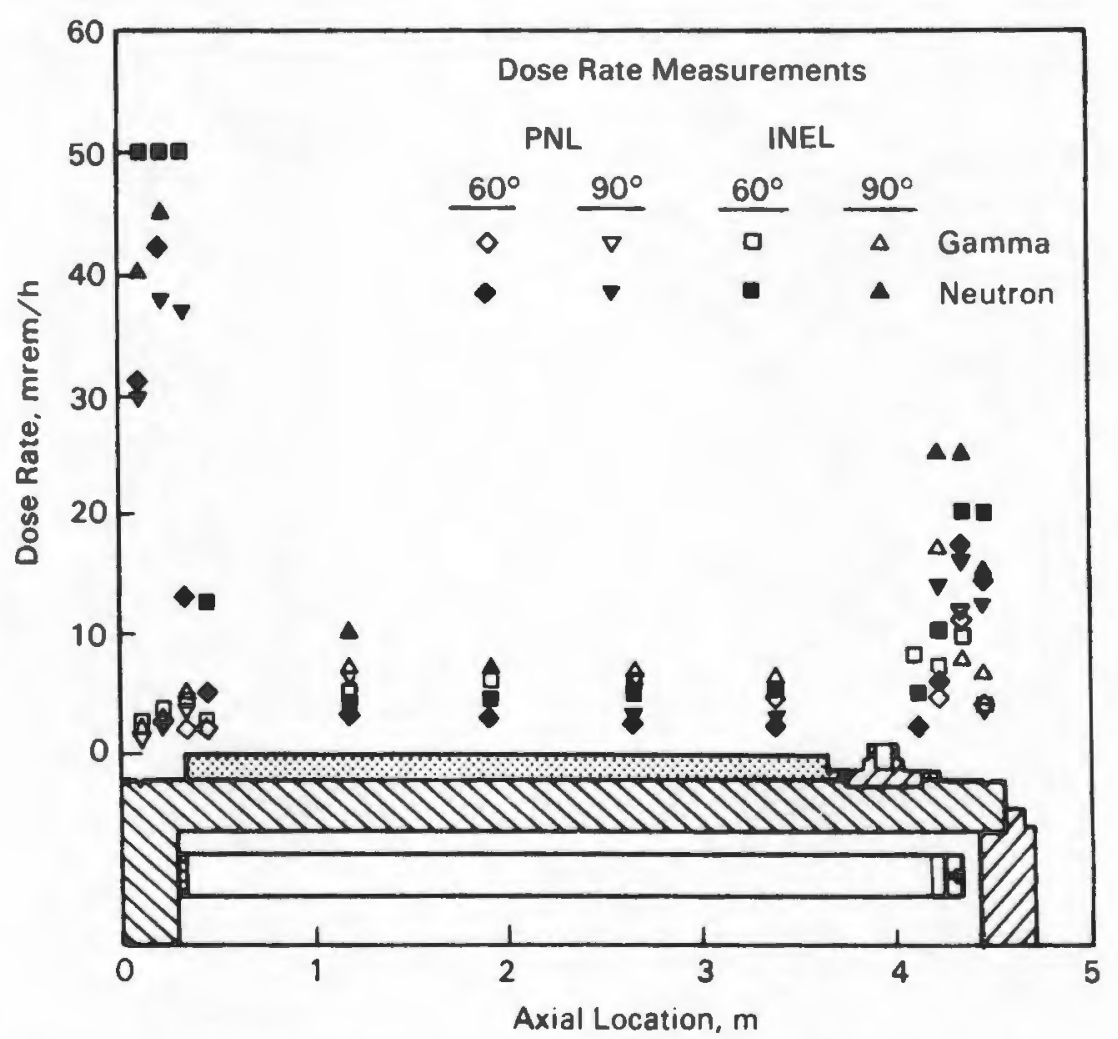

Figure S-10. Gamma and Neutron Dose Rate Profiles Measured on Cask Side

cask can, with minor refinements, be effectively implemented at reactor sites and central storage facilities for safe storage of consolidated spent fuel.

Consolidation of spent fuel has a major impact on gamma source strengths. The primary source of gamma radiation from spent fuel is associated with the ${ }^{60} C_{0}$ in the non-fuel-bearing components and the springs in the top of the fuel rods. The storage of consolidated fuel without the non-fuel-bearing components makes gamma shielding of secondary importance relative to neutron shielding. 
Section 1

INTRODUCTION

Implementation of spent fuel dry storage systems will be required in the late 1980 s when several at-reactor storage basins attain maximum capacity (1). The Nuclear Waste Policy Act of 1982 (NWPA) assigns the U.S. Department of Energy (DOE) the responsibility for assisting utilities with their spent fuel storage problems. An additional provision of the NWPA is that research and development (R\&D) on candidate dry storage systems be performed at federal sites to provide experimental data needed to support licensing efforts of utilities.

In May 1983, a Solicitation for Cooperative Agreement Proposal (SCAP) was issued to the private sector by the DOE-Richland Operations office (DOE-RL), and proposals were received in August 1983. Virginia Power (VP) proposed that pressurized water reactor (PWR) spent fuel storage cask performance testing be conducted at a federal site in support of its at-reactor license demonstration. VP and DOE signed a Cooperative Agreement in March 1984, and VP signed a separate agreement with the Electric Power Research Institute (EPRI), essentially establishing a three-party cooperative agreement.

A preliminary assessment of candidate federal sites capable for performing dry storage system tests was undertaken by the Pacific Northwest Laboratory (PNL) in parallel with the issuance and response to the SCAP. The three sites evaluated were Idaho, Nevada, and Hanford. In July 1984, DOE selected the Test Area North (TAN) facility located at the Idaho National Engineering Laboratory (INEL) operated by EG\&G Idaho, Inc., as the federal cask-testing facility, and the VP/DOE cask performance testing effort was initiated.

The original scope included demonstrations of storing both unconsolidated and consolidated fuel at INEL. The technical baseline of the cooperative agreement for cask performance testing at TAN was to test three different cask designs with unconsolidated spent fuel and two cask designs with consolidated fuel. To date, this project has resulted in the testing of three casks (CASTOR-V/21, TN-24P, and $M C-10)$ with unconsolidated fuel at INEL, as reported previously $(\underline{2}, \underline{3}, \underline{4})$. 
Dry rod consolidation and cask testing with consolidated fuel at INEL were removed from the VP/DOE cooperative agreement. However, a decision was made to continue the design, checkout, and operation of the dry rod consolidation system at INEL as a DOE-only funded activity. Later, after cask performance testing with unconsolidated fuel was completed in the VP/DOE cooperative program, a decision was made by DOE and EPRI to extend the performance testing to include consolidated fuel in the TN-24P cask. Transnuclear, Inc., arranged to have an additional partially insulated run added to the end of the test matrix to simulate impact limiters.

The work began with a revision to TAN's safety analysis documents to permit dry loading of consolidated PWR fuel in the TN-24P cask. Dry (cold) runs with a nonirradiated dummy fuel assembly were performed previously during the TN-24P cask performance test with unconsolidated fuel $(\underline{3})$ to gain operating experience and finalize handling and test procedures. The PWR consolidated fuel canisters were loaded with fuel from the Surry and Turkey Point nuclear reactors. The Surry assemblies had been used previously in the TN-24P and MC-10 cask performance tests. The integrity of the fuel assemblies and the acceptable peak cladding temperature were determined during previous test programs $(\underline{2}, \underline{3}, \underline{4}, \underline{5}, \underline{6})$. The exterior cask surface was instrumented with thermocouples (TCS). The interior of the cask and basket came with 14 TCs attached. Additional TCs were inserted into guide tube and basket locations located in the fuel. A test station was prepared, comprising a rail car and a data acquisition system. Seven runs involving a combination of cover gases and cask orientations were performed during the test. The backfill environments used were vacuum, nitrogen, and helium; nitrogen and helium were sampled and analyzed to detect leaking fuel. Both vertical and horizontal orientations were investigated, with the test run indoors under controlled conditions. The final test run was conducted with the ends of the cask insulated simulating impact limiters and was sponsored by Transnuclear and Transnucleaire (France).

This report documents the performance test using a TN-24P cask loaded with consolidated PWR spent fuel. The conclusions and recommendations are presented in Section 2. In Section 3, the TN-24P cask, the PWR fuel canisters, cask and fuel instrumentation, the TAN cask-testing facility, the test plan, and the cask-handling procedures and experience are presented. Heat transfer, shielding, and fuel integrity data are presented and discussed in Section 4. Pre- and post-test heat transfer predictions obtained with the COBRA-SFS computer program are compared to test data in Section 5 . 
Section 2

CONCLUSIONS AND RECOMMENDATIONS

Performance testing of a TN-24P PWR spent fuel storage cask loaded with consolidated spent nuclear fuel was successfully completed at TAN. The test demonstrated that the cask could be satisfactorily handled and loaded dry, and demonstrated the heat transfer and shielding performance of the cask when loaded with 24 canisters of consolidated (2:1 rod consolidation ratio) PWR spent fuel generating approximately $23 \mathrm{~kW}$. The heat transfer performance of the cask was exceptionally good, as indicated by acceptable peak cladding temperatures $\left(<340^{\circ} \mathrm{C}\right.$ allowable for the fuel cladding []ㅡ and the $<375^{\circ} \mathrm{C}$ cask design goal for $\left.24 \mathrm{~kW}\right)^{\mathrm{a}}$ with vacuum, nitrogen, and helium backfill gases and for vertical and horizontal cask orientations. The shielding performance met design expectations $(<60 \mathrm{mrem} / \mathrm{h})$, with the exception of the bottom of the cask. Dose rates of $<60 \mathrm{mrem} / \mathrm{h}$ could be easily established with minor neutron shielding design refinements on the bottom of the cask if desired; however, when the cask is stored vertical, the bottom is shielded by the storage pad. From both heat transfer and shielding perspectives, the TN-24P cask can, with minor refinements, be used effectively to safely store consolidated spent fuel at reactor sites and central storage facilities.

The following sections present specific conclusions and recommendations noted during the testing and analyses effort.

CONCLUSIONS

\section{Cask Performance Test}

The results of the cask performance test permit the following conclusions:

aThe accepted peak fuel cladding storage temperature limit at the time of cask design was $380^{\circ} \mathrm{C}$. Work done since that time (지 indicates allowable peak cladding temperatures depend on fuel design and burnup. For the fuel used in this test, the acceptable peak fuel cladding temperature was calculated to be $340^{\circ} \mathrm{C}$. 
- The TN-24P cask can be satisfactorily handled in many reactor facilities with only minor modifications to the supplied handling equipment and procedures.

- Previous dry (cold) runs with a nonirradiated dummy assembly of all steps required to handle and test the cask were valuable in familiarizing personnel with cask-handling characteristics and in finalizing test procedures.

- Approximately $1 \mathrm{~h}$ was required to pump down the cask to $1 \mathrm{mbar}$ and backfill with gas to 850 mbar. Steady-state vacuum runs demonstrate that vacuum-drying the cask will not result in excessive fuel cladding temperatures.

- Contamination was not a major problem during fuel air transfers between the fuel storage silo, consolidation location, and storage casks.

- When the cask is loaded dry, protectors are required to ensure that crud or particles do not lodge on sealing surfaces and result in blemishes or scratches that could compromise their finish.

- The total personnel radiation exposures during the 9 months in which the TN-24P cask was handled, loaded, and tested were relatively low (approximately 1.2 man-rem). The exposure at a reactor or storage facility will be even lower because casks will not be loaded incrementally or worked around continuously.

\section{Heat Transfer Performance}

- The heat transfer performance of the cask was exceptionally good. Peak temperatures were $80^{\circ} \mathrm{C}$ less than the allowable fuel cladding temperature $\left(<340^{\circ} \mathrm{C}\right)$ for a 11 backfill conditions and orientations tested when dissipating $23 \mathrm{~kW}$. The cask was designed to maintain fuel cladding temperatures below $375^{\circ} \mathrm{C}$ a for a 24-kW decay heat load.

- The design of the consolidated fuel canister reduced the effects of convection for the vertical nitrogen run, and almost eliminated any noticeable effect of convection for the vertical helium run.

- In a horizontal orientation, the added thermal contact between fuel rods, canister, basket, and cask wall reduced temperatures from those observed in the vertical orientation; i.e., peak temperatures in a horizontal orientation were lower than they were in a vertical orientation.

aThe accepted peak fuel cladding storage temperature limit at the time of cask design was $380^{\circ} \mathrm{C}$. Work done since that time ()ㅡ indicates allowable peak cladding temperatures depend on fuel design and burnup. For the fuel used in this test, the acceptable peak fuel cladding temperature was calculated to be $340^{\circ} \mathrm{C}$. 
- Relatively large temperature differences $\left(20\right.$ to $100^{\circ} \mathrm{C}$ ) between the basket and the cask wall indicate that the basket-to-inner cask wall interface is important to the heat transfer performance of the cask. Backfill gas thermal conductivity affects the temperature drop across this interface.

- Fuel temperature transients in the cask were not excessive. They were less than $4^{\circ} \mathrm{C} / \mathrm{h}$ on heatup (helium to nitrogen) and $8^{\circ} \mathrm{C} / \mathrm{h}$ on cooldown (vacuum to helium) for a $23-\mathrm{kW}$ heat load in the cask.

- The largest temperature transient in the cask occurred in the basket when the cask was backfilled with helium after a vacuum run. The temperature transient went from a momentary $25^{\circ} \mathrm{C} / \mathrm{h}$. heatup to a $-8^{\circ} \mathrm{C} / \mathrm{h}$ cooldown.

- For a given heat load, temperatures in a standard TN-24 cask will be higher than for the TN-24P test cask because of the use of aluminum in the TN-24P basket and stainless steel in the TN-24 basket and the additional contact resistance in the neutron shield of the TN-24 cask.

\section{COBRA Heat Transfer Analys is}

- Comparison of pretest COBRA-SFS predictions of peak temperatures with data showed excellent agreement. The maximum disagreement was less than $35^{\circ} \mathrm{C}$, and that occurred for the vertical vacuum run.

- Comparisons of pretest predictions with data showed the need to increase detail in the fuel canister model so it would be similar to that used for fuel assemblies.

- Post-test predictions of peak temperatures were in excellent agreement with data. The mean temperature difference between predicted peak temperature and measured value was $6^{\circ} \mathrm{C}$, with a standard deviation of $\pm 7^{\circ} \mathrm{C}$. The greatest difference $\left(13^{\circ} \mathrm{C}\right)$ was for the vertical nitrogen run. Better agreement could be achieved through modeling of convection between the fuel canisters and basket.

\section{Shielding Performance}

- Except for the bottom of the cask, the total dose rates on the cask surface were less than the design goal of $60 \mathrm{mrem} / \mathrm{h}$.

- Gamma dose rates from the consolidated fuel were greatly reduced from those from unconsolidated fuel assemblies, due to removal of most of the non-fuel-bearing components that contain ${ }^{60} \mathrm{Co}$.

- Dose rates from standard TN-24 casks will be higher than those measured on the TN-24P test cask due to a thinner cask wall, lid, and bottom in the TN-24 cask. 


\section{Fuel Characterization and Integrity}

- More ${ }^{85} \mathrm{Kr}$ was detected in the cask loaded with consolidated fuel than had previously been detected, indicating the development of seven or more leaking rods from the time the cask was fully loaded with consolidated fuel to the end of the test. The rod pulling forces and bending of the fuel rods during consolidation may have initiated growth of shallow microcracks that contributed to the additional ${ }^{85} \mathrm{Kr}$ leakage.

- Only two leaking fuel rods had been detected during previous cask performance tests, one in the TN-24P cask loaded with unconsolidated PWR fuel and one in the REA 2023 cask loaded with unconsolidated BWR fuel.

- Visual observations during consolidation did not reveal any defective fuel rods or cladding breaches.

\section{RECOMMENDATIONS}

The results and conclusions of this work led to the following recommendations:

\section{Cask-Handling and Loading}

- The information required before handling a cask should include cask design drawings and specifications, operating and maintenance manuals, procedures, and spare parts.

- Dry (cold) runs of the cask and associated equipment should be performed for all phases of cask handling and loading, including backfilling the cask with a cover gas and gas sampling. Cask vendor representatives should be present onsite for operational and functional checkouts of the cask.

- Cask-handling procedures are site-specific, and procedures should be developed for each site. The experience gained during this performance test will be helpful in developing such procedures.

- The cover gas system used to evacuate, backfill, monitor, and obtain gas samples should be carefully designed. The difficulty associated with backfilling the cask with a pure $(>99 \%)$ cover gas and obtaining gas samples without introducing air should not be underestimated. The cask should be pumped down and backfilled a minimum of two times to ensure purity (>99\%) of the final cover gas.

\section{Heat Transfer Performance}

- Critical basket gaps should be controlled. Basket designs should maximize thermal conductance between the basket and cask wall. 


\section{COBRA-SFS Heat Transfer Analysis}

- $\quad$ COBRA-SFS is an effective code that can be used to accurately predict temperatures in spent fuel dry storage systems.

- $\quad$ COBRA-SFS predictions of peak dry storage system temperatures within $35^{\circ} \mathrm{C}$ can be obtained. If better agreement is desired, the following, in order of importance, should be pursued:

- Use sufficient detail for a representative model of the fuel canister.

- -System geometries, especially gap widths and characteristics of contacting surfaces, must be better known.

--Emissivities of important basket/cask components should be measured.

--The accuracy of the correlation used to represent heat transfer to and from the cask exterior wall should be improved.

- The heat transfer data contained in this report can be used to evaluate other heat transfer codes.

\section{Shielding Performance}

- Shielding designs for consolidated fuel storage should consider the effect of the absence of non-fuel-bearing components on the gamma shielding requirements. Casks containing only consolidated fuel require less gamma shielding than casks that contain unconsolidated fuel or the non-fuel-bearing components.

\section{Fuel Characteristics and Integrity}

- Post-test gas sampling of casks at INEL containing unconsolidated fuel and casks containing consolidated fuel are recommended to determine the long-term impact of consolidation on fuel integrity. 


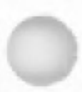

0 
Section 3

CASK PERFORMANCE TESTING

Details of the cask performance test using a TN-24P cask loaded with consolidated PWR fuel canisters are discussed in this section. The same TN-24P cask used for the unconsolidated fuel tests $(\underline{3})$ was for used this test. The TN-24P cask and instrumentation are described, as are the consolidated fuel canisters containing Surry and Turkey Point PWR spent fuel and associated instrumentation. The major differences between the TN-24P and a commercial TN-24 cask are discussed, as is the effect these differences have on the performance results. The data acquisition system used to receive and process instrumentation signals is described. A description of the INEL cask-testing facility is provided. The test plan is presented, and the procedures resulting from the plan are summarized. Experiences gained during cask-handling dry runs and testing are described.

\section{TN-24P CASK AND ASSOCIATED INSTRUMENTATION}

The TN-24P cask has a forged steel body for structural integrity and gamma shielding, surrounded by a resin layer for neutron shielding, which is enclosed in a smooth steel outer shel1. The loaded cask weighs approximately 100 tons on the fuel pool crane hook. The cask has a cylindrical cavity that holds a fuel basket designed to accommodate 24 consolidated or unconsolidated PWR fuel canisters/ assemblies. The basket is made of a neutron-absorbing material, borated aluminum, to control criticality. The cavity atmosphere is designed to be nitrogen or helium at a positive pressure.

The cask is sealed with a single lid. A protective cover, bolted to the body, provides weather protection for the lid penetrations. Two concentric metallic 0 -rings are provided for sealing the 1 id to the cask body, and an elastomer 0 -ring is used with the protective cover. The body is fitted with three pairs of removable trunnions for handling and transport. A polyethylene neutron shielding disk is attached to the lid when the cask is in storage. If the cask is stored in a horizontal orientation, a neutron shielding disk must also be attached to the cask bottom. 
The major differences between the TN-24P test cask and standard TN-24 casks are cask body thickness, basket material, and neutron shield structure. These differences are listed in Table 3-1.

Table 3-1

DIFFERENCES BETWEEN TN-24 PROTOTYPE (TN-24P) AND TN-24 STANDARD CASKS

Parameter

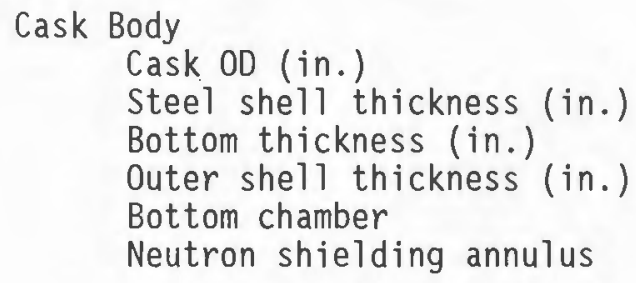

TN -24

88.5

9.5

10.5

0.75

yes

Resin in

al uminum

cans that

butt against

cask body

and outer

shell.

None

10.5

$48 \times 1.50$

2.75

2

Borated stainless steel with copper cladding

$16.2 \times 0.22$, 0.118 -in. copper Full interlocking plates

No internal thermocouples

0.75 -in. -thick bolted to cask body

184,000

\section{TN-24P}

89.8

10.6

11.0

0.39

no

Resin butts against cask body and is between copper fins that are welded to outer shell.

One

11.2

$40 \times 1.65$

4.2

1

Borated a) uminum

$6.3 \times 0.39$

Semi - interlocking

plates with connecting angles Internal thermocouples

0.315-in.-thick attached by clamps to cask body 192,000 
The TN-24P basket is composed of borated aluminum plates, while the standard TN-24 basket is assembled from copper-clad borated stainless steel plates. The TN-24P has an instrument penetration in the cask body for leads from thermocouples (TCS) that are attached to the basket. The standard TN-24 contains no instrument penetration.

These differences impact the cask performance in two ways: 1) the dose rate for standard TN-24 casks will be higher than for the TN-24P test cask due to differences in wall thickness, and 2) temperatures in standard TN-24 casks will be higher due to basket materials and neutron shield structure.

The remainder of this section will describe the TN-24P cask. A detailed description of the cask can be found in References $\underline{7}$ and $\underline{8}$.

\section{Cask Body}

The cask body is a one-piece cylindrical structure composed of forged steel ( $\mathbf{7})$. The overall external length of the cask body is $5063 \mathrm{~mm}$ (16.6 ft); the body is $2281 \mathrm{~mm}(7.5 \mathrm{ft}$ ) in diameter (Figure $3-1)$. All surfaces except sealing surfaces are coated with a deposit of zinc-aluminum alloy. Sealing surfaces are clad with stainless steel. Internal surfaces have an aluminum titanium oxide overcoat; exterior surfaces are covered with white silicone paint.

The cask body consists of a 270 -mm-thick (10.6-in.) cylindrical shell welded to a $280-\mathrm{mm}(11-$ in.) bottom plate. A neutron shield containing L-shaped copper plates is welded to the cylindrical shell. The copper plates are welded to the inner surface of the neutron shield and provide enhanced heat conduction through the resin compound of the neutron shield. The cask can accommodate six bolted trunnions for handling and tie-down, four near the top and two near the bottom. Finally, the cask body has an instrumentation orifice sealed by a metallic gasket.

The diameter of the inner cavity is $1455 \mathrm{~mm}$ ( $57.3 \mathrm{in.})$, and the overall inner cavity length is $4150 \mathrm{~mm}$ (163.4 in.). Precision-machined surfaces are provided at the open end of the cask cavity for positive gasket sealing, and bolt holes are included at these location to secure the cask lid and protective cover.

\section{Spent Fuel Basket}

The basket is an array of 24 fuel tubes/channels that provide structural support and positive positioning of the fuel canisters/assemblies. The basket (Figure 3-2) is composed of stacked interlocking plates constructed of aluminum and boron. The 


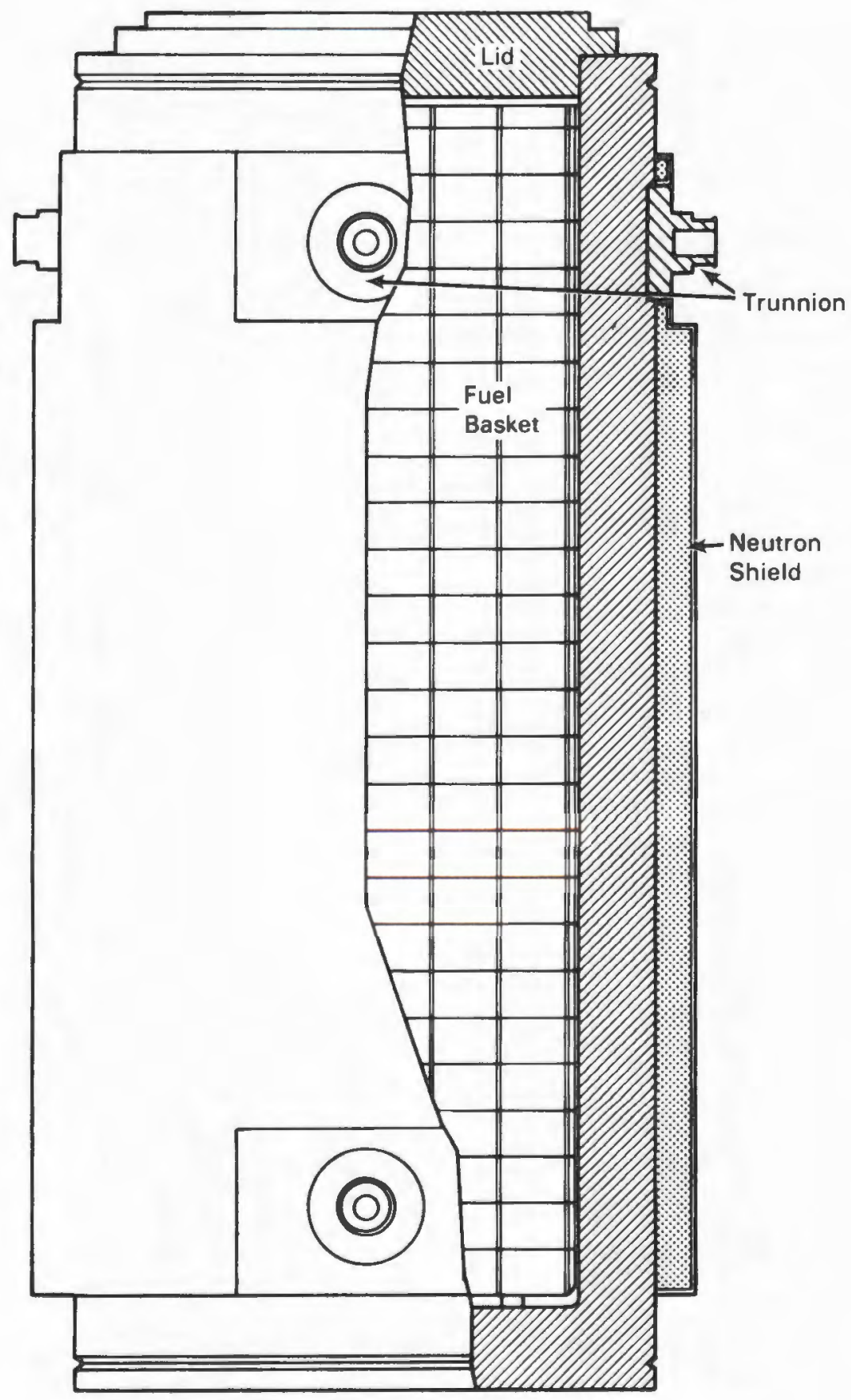

Figure 3-1. TN-24P PWR Spent Fuel Storage Cask

plates are $10 \mathrm{~mm}(0.4 \mathrm{in.})$ thick and $160 \mathrm{~mm}$ (6.3 in.) wide, and vary in length depending on their position in the basket. Each 1ayer of the basket is bolted to four uprights that are used to support and tie the basket together in the axial direction. The uprights provide a $45-\mathrm{mm}$ (1.8-in.) gap between the bottom of the 


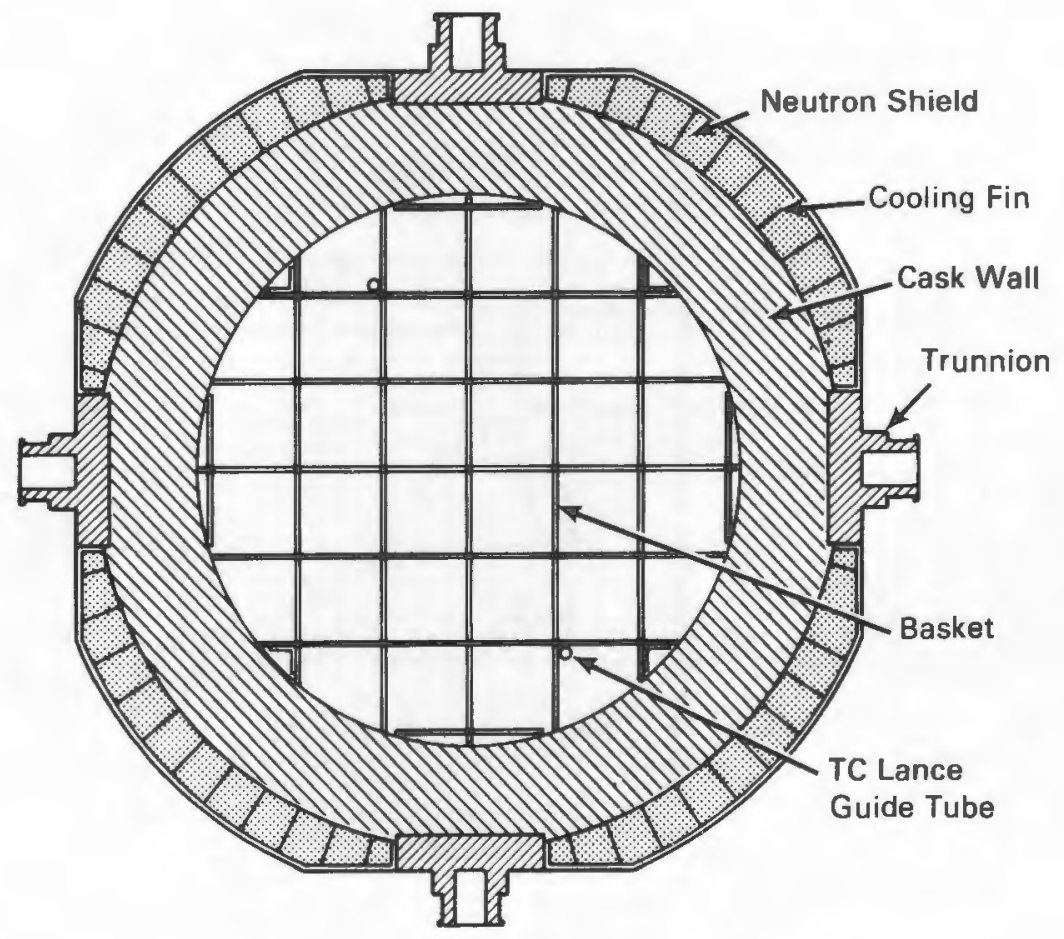

Figure 3-2. TN-24P Cask Cross Section

basket and the bottom of the cask. This gap plus the 29-mm (1.1-in.) gap between the top of the basket and the cask 1id provide convection paths for the gas in the cask. The basket overall height is $4121 \mathrm{~mm}$ (162.2 in.). The position of the basket within the cask is maintained by bars welded to the interior surface of the cask. The bars act as guides for the interlocking plates.

Two aluminum tubes are welded to the aluminum basket in two locations that did not interfere with the fuel. The tube locations match penetrations in the test lid used to insert TC lances and provide temperature readings typical of the basket.

\section{Cask Lid}

A carbon-stee $11 \mathrm{id}, 1720 \mathrm{~mm}(5.6 \mathrm{ft})$ in diameter and $285 \mathrm{~mm}(11.2 \mathrm{in.})$ thick, is provided (Figure $3-3$ ). The lid is fastened to the cask body with 40 bolts matching index marks on the lid and cask for proper alignment. Sealing is ensured by a double 0 -ring metallic gasket installed in a stainless steel-coated 1id groove. A 5-mm-diameter (0.2-in.) penetration through the lid provides access to the annulus between the two seals, for post-assembly leak testing. Additional sealing is 


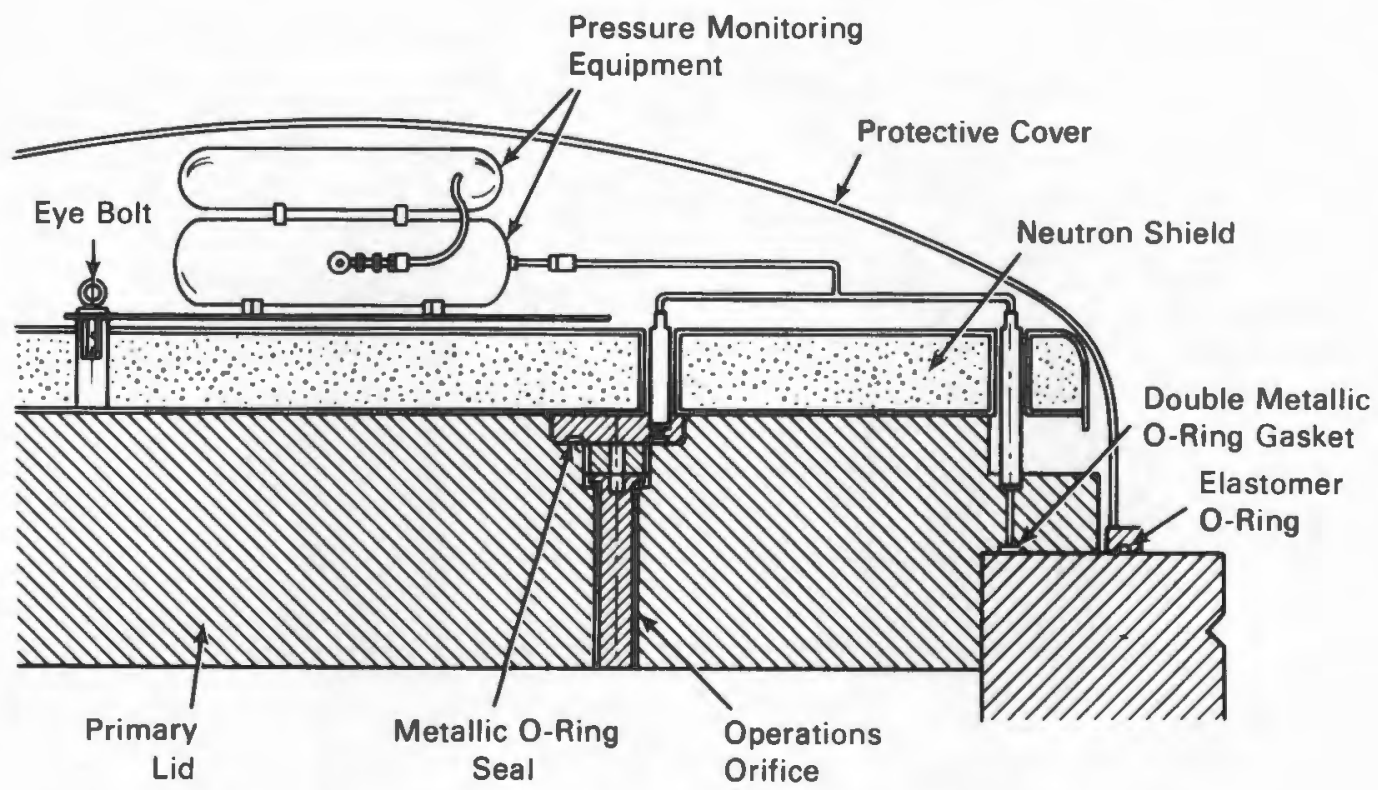

Figure 3-3. TN-24P Cask Lid

obtained by a Viton ${ }^{m}$-ring fitted between the protective cover and a groove in the top surface of the cask wall.

An operations orifice is located in the lid for access to the internal cavity. It consists of a plug extended by a base acting as a radiation trap, a tightening ring, and an orifice plate. Sealing of this penetration is ensured by an 0-ring metallic gasket fitted on the orifice plate. Sealing is monitored through a test orifice closed by a test plug.

A neutron shielding drum is bolted to the 1id. It consists of granular polypropylene wrapped in a carbon-steel drum. The drum is composed of a flat circular head closed with a circular welded plate. Its finished size is $105.5 \mathrm{~mm}$ (4.2 in.) thick by about $1700 \mathrm{~mm}$ (70 in.) in diameter. To facilitate operations, test plugs in the lid and operations orifice plate are easily accessible while the drum is in place.

A protective cover fits over the lid and neutron shielding drum. This cover consists of a carbon-steel ellipsoidal head and a flange equipped with one rubber 0-ring gasket. The cover is $1815 \mathrm{~mm}$ (71.5 in.) in diameter and $498 \mathrm{~mm}$ (19.6 in.) deep. It is fastened to the body of the cask using eight bolts and clamps. Two

"M fluoroelastomer manufactured by E. I. DuPont de Nemours \& CO., Elastomers Division, Wilmington, Delaware. 
penetrations are provided in the protective cover for instrumentation leads and for leak-checking the attached cover. The interspace between the $1 \mathrm{id}$ and the protective cover contains the pressure monitoring loop. This loop pressurizes and monitors the space between the double 0-ring metallic gaskets during long-term storage. It also pressurizes and monitors the operations orifice sea1. The loop consists of connections to the lid and operations spaces to be monitored, a pressure monitoring tank, a reference pressure tank, a pressure sensor, and two TCS. The TCs provide data concerning whether pressures changes are due to temperature changes or leakage.

A nonstandard lid (test 1 id) with nine penetrations for TC lances was used during the performance testing (Figure $3-4$ ). The TC 1 ances will be described in detail in the next section. Eight of the penetrations are machined with 18-mm (0.7-in.) holes through the lid and countersunk (20 mm, $0.8 \mathrm{in.})$ to accept the TC lances and 105-mm-diameter (4-in.) flanges. The ninth penetration has a hole through the lid for a TC lance and accepts a 140-mm-diameter (5.5-in.) flange. The pattern of the nine fuel canister/assembly instrumentation penetrations was selected to correspond with guide tube locations of unconsolidated fuel assemblies and matches the location of simulated guide tubes placed in selected consolidated fuel canisters. The TC

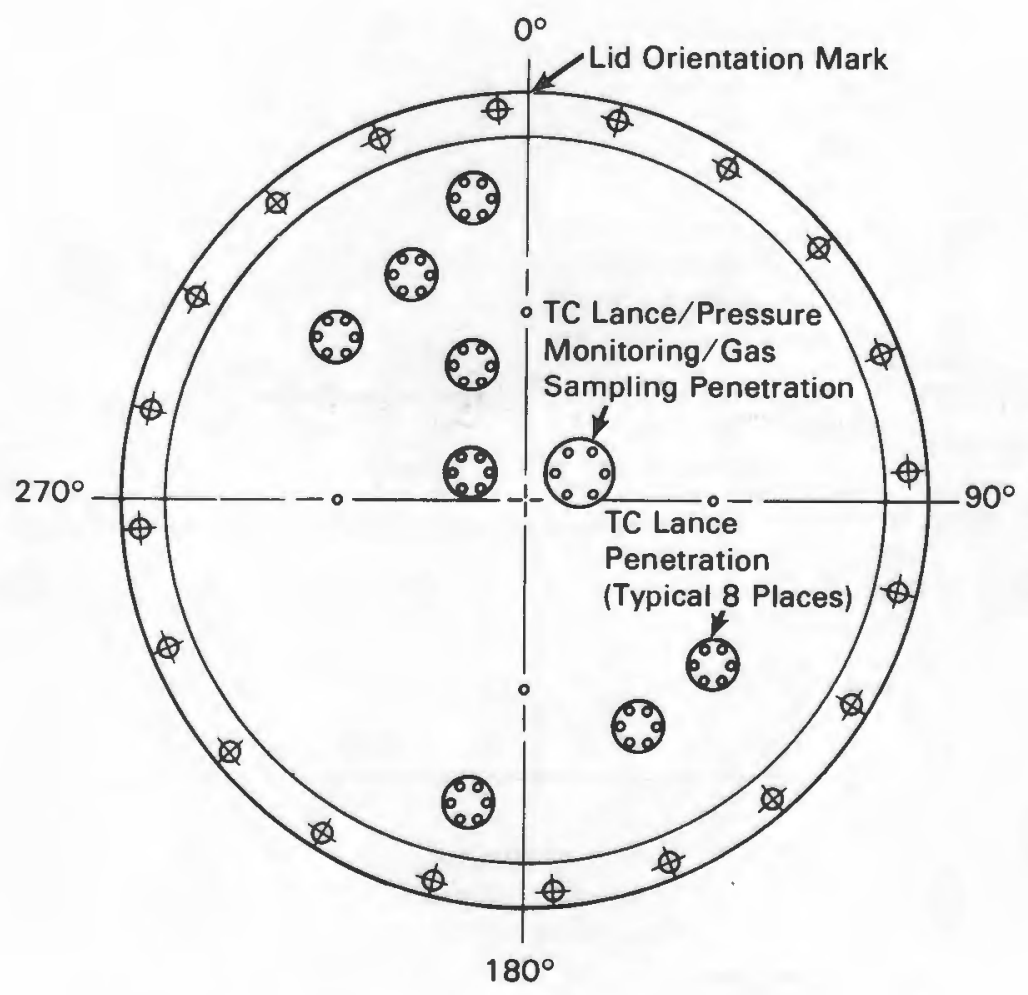

Figure 3-4. TN-24P Cask Nonstandard Test Lid 
lances provide a means to measure radial and axial temperature profiles in the cask. Cask evacuation, gas backfill, pressure monitoring, and gas sampling were done using the instrumentation port through the side of the cask.

The test lid used a single Viton 0 -ring and 20 bolts instead of the double 0 -ring metallic seal and 40 bolts used with the primary lid. Like the primary lid, the test lid was $1725 \mathrm{~mm}$ in diameter and $285 \mathrm{~mm}$ thick. However, the neutron shielding drum, protective cover, and pressure monitoring loop were not used during the performance test. Gas backfilling, gas sampling, and pressure monitoring were performed through the instrumentation port by means of a cross manifold when the test lid was on the cask.

\section{Cask Cavity Pressure Measurements}

A Leybold Heraeus model MAC 2000 pressure transducer was used to measure cask cavity pressures. The transducer had a range of 0 to 2000 mbar and a stated accuracy of $\pm 0.2 \%$ of ful1 scale. The transducer was connected to the quick-disconnect penetration provided in the instrument orifice at approximately $35^{\circ}$, near the top of the cask (Figure 3-4) via the valve tree shown in Figure 3-5. The signal from the transducer was conditioned and read out on the data acquisition system (DAS) described in a later section.

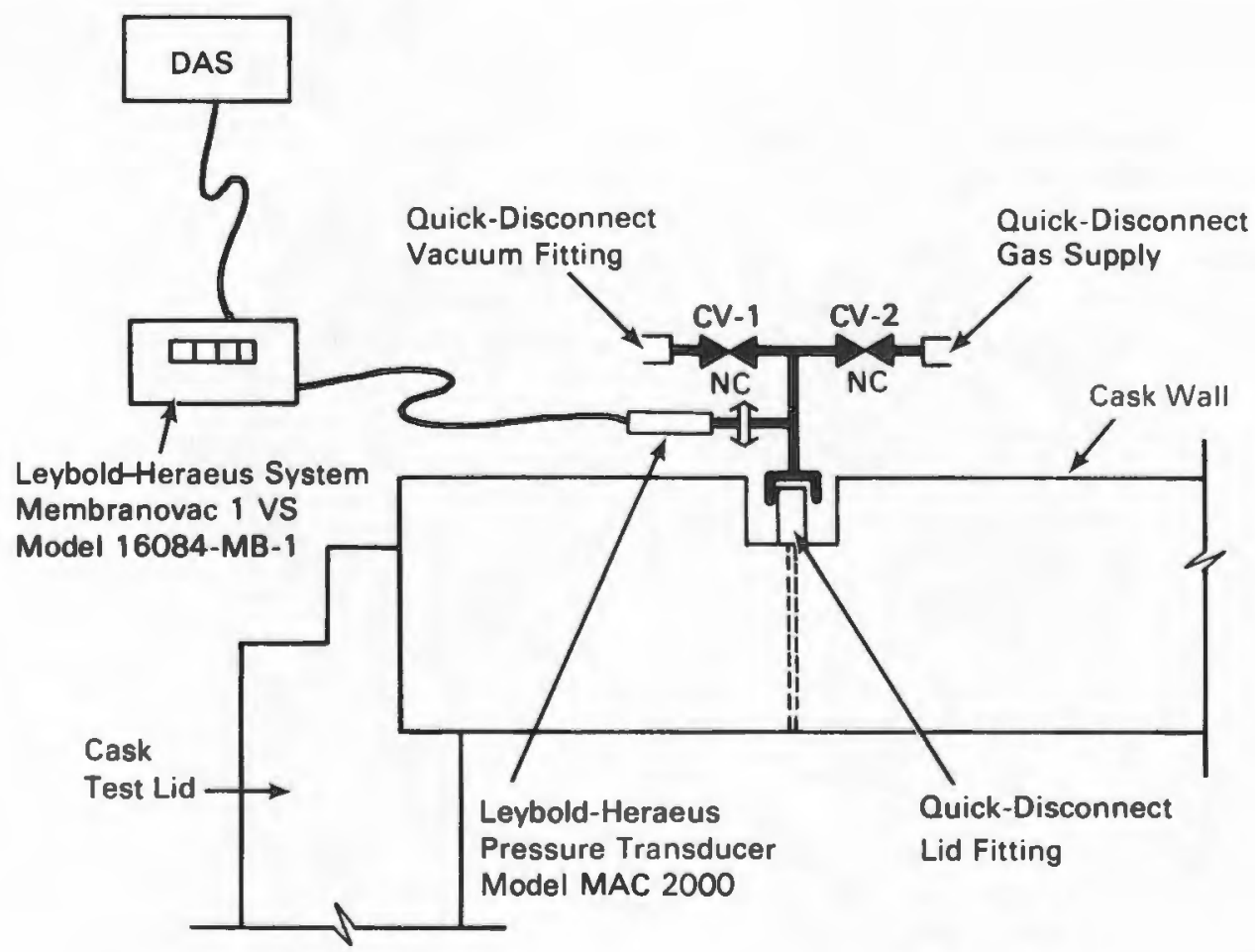

Figure 3-5. Pressure Transducer Valve Tree 


\section{Internal Temperature Instrumentation}

Fourteen Type K TCs were permanently attached to the inner wall and basket of the cask. Figure 3-6 identifies the locations of these TCs. An additional 54 TCs were

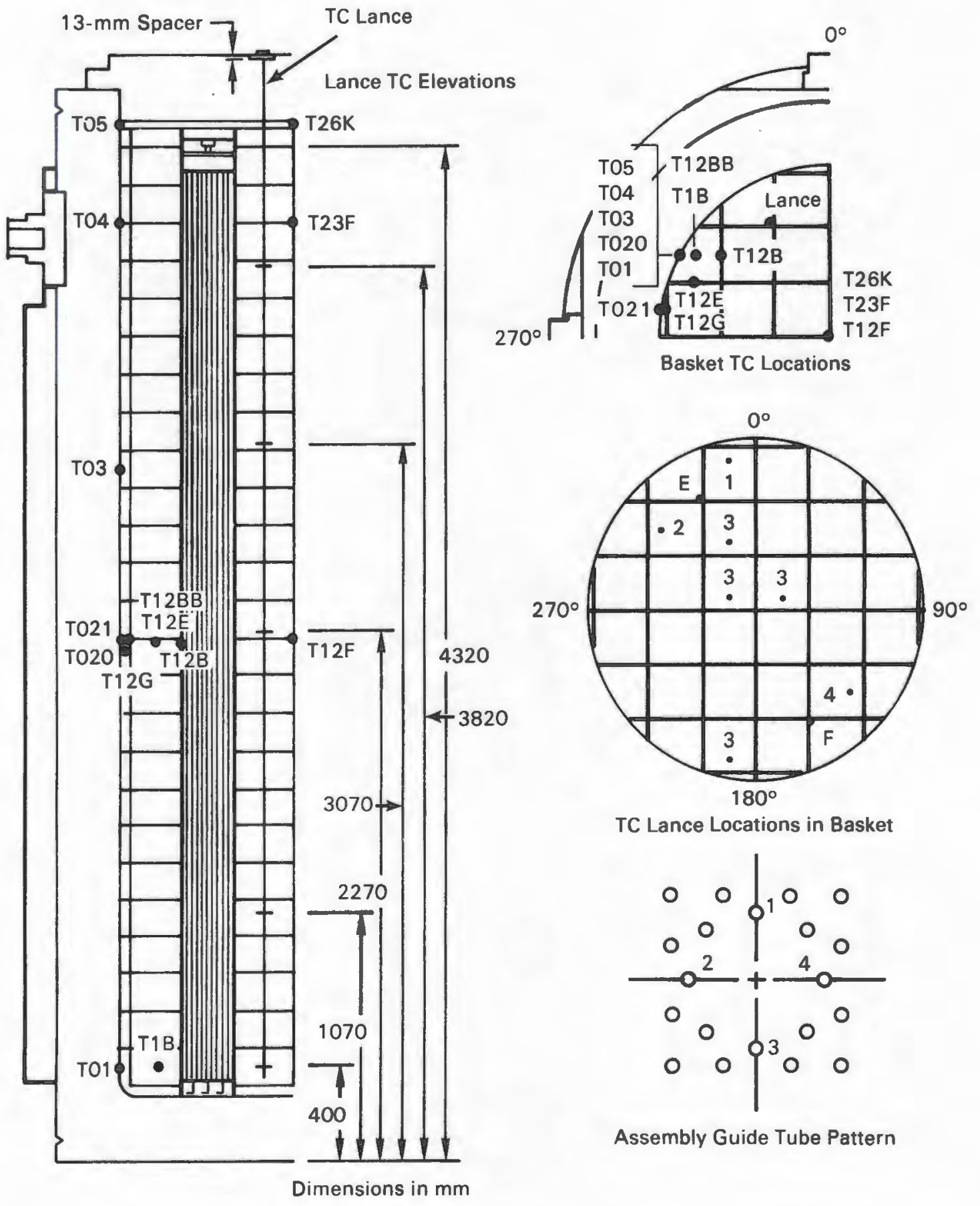

Figure 3-6. Basket Thermocouple Locations 
placed in the fuel canisters and basket using TC lances (Figures 3-7 and 3-8). Each TC lance had six TCs installed in an 8-mm-diameter (0.315-in.) tube as shown in Figure 3-7. Lances were inserted through instrumentation penetrations in the test lid (Figure 3-4) and into selected guide tubes placed in seven fuel canisters and into two simulated guide tubes attached to the basket (Figure 3-8). Standard elastomer 0 -rings in the TC lance flanges were used to establish seals between the cask inner cavity containing spent fuel and the outside environment. The selected axial and cross-sectional locations of the TC lance thermocouples facilitated redundancy, evaluations of temperature symmetry, and determinations of axial and radial temperature profiles in both vertical and horizontal orientations.

\section{Exterior Surface Temperature Instrumentation}

The exterior surface of the cask was instrumented with 27 iron/constant and Type $\mathrm{J}$ TCs. Figures 3-9 and 3-10 identify the locations of the TCS on the test 1id, barrel, and bottom of the cask. Only during horizontal testing were TCs placed on the bottom of the cask. The TC patterns on each surface were selected to provide appropriate axial, radial, and circumferential temperature profiles.

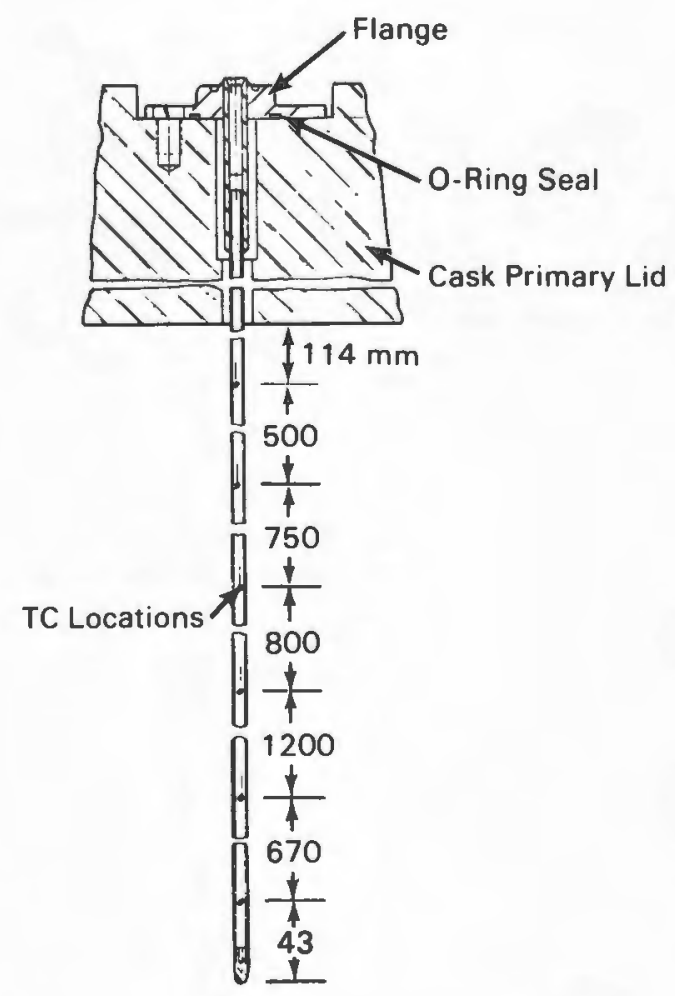

Figure 3-7. Thermocouple Lance 


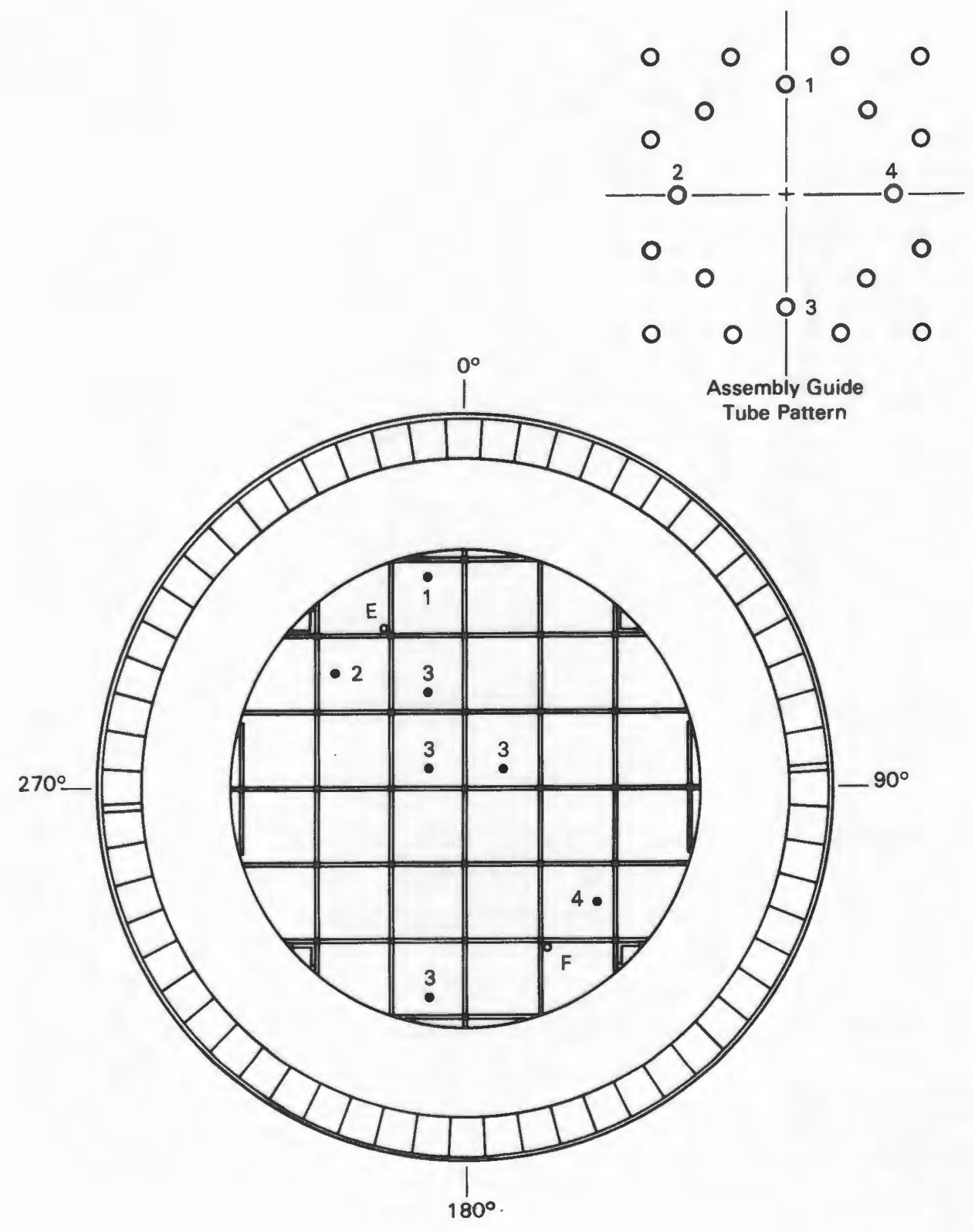

Figure 3-8. Thermocouple Lance Locations

\section{Exterior Surface Dose Rate Instrumentation}

Gamma and neutron dose rates were measured on the surface of the cask with portable hand-held survey instruments. Data obtained from these instruments are presented and discussed in Section 4. Because previous energy spectra measurements made on 


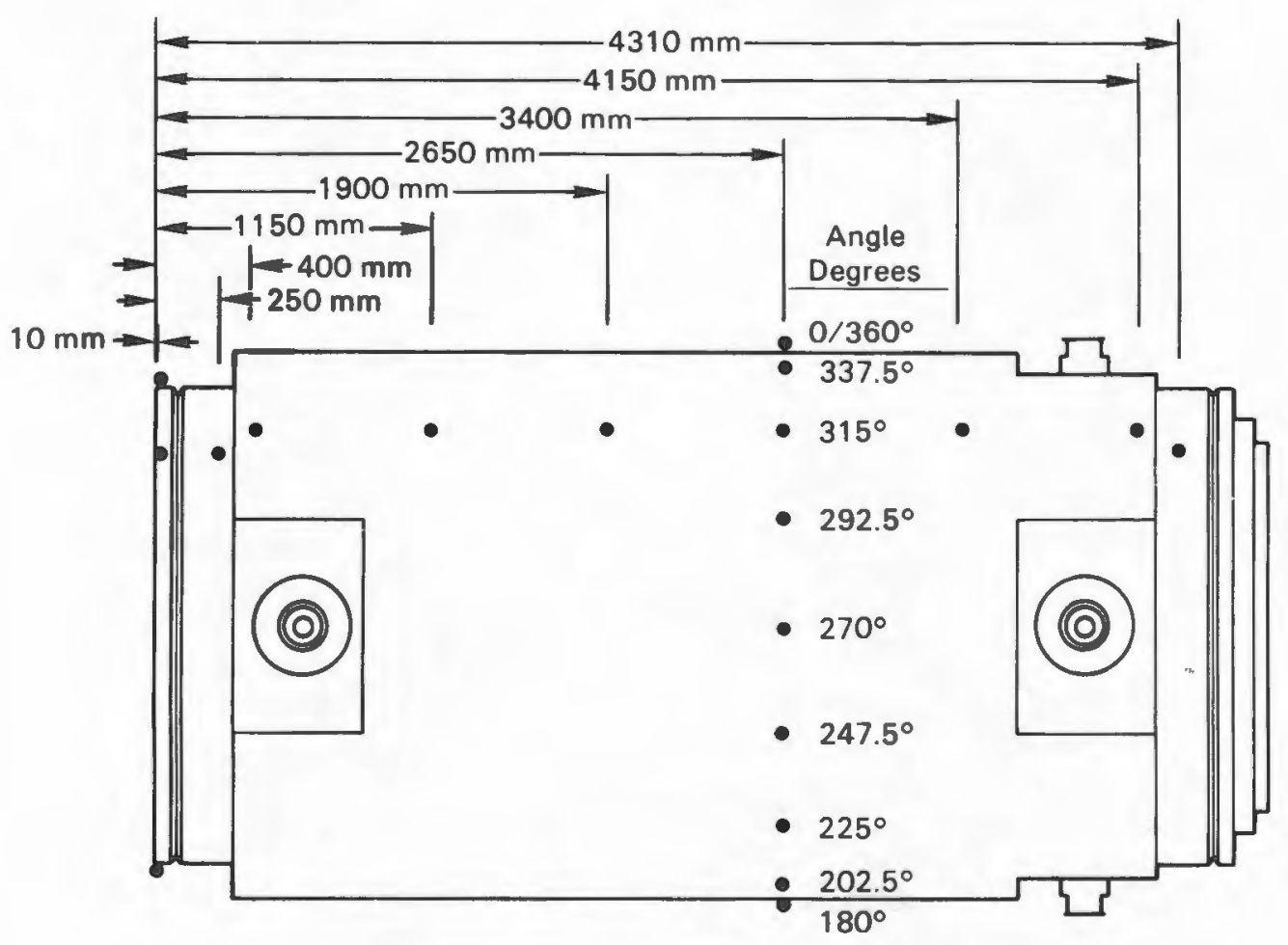

Figure 3-9. Cask Surface Thermocouple Locations

the TN-24P cask loaded with unconsolidated fuel did not show a reason to adjust dose rate measurements made with hand-held instruments, energy spectra measurements were not made. The hand-held instruments are briefly discussed in the remainder of this section.

Two standard portable survey instruments were used by INEL to measure gamma and neutron dose rates at the locations shown in Figures 3-11 and 3-12. Gamma dose rate measurements were made using an Eberline R0-3A air ion chamber with a $3.5-\mathrm{mg} / \mathrm{cm}^{2}$ Mylarm window. Neutron dose rates were measured with an Eberline PNR-4. The PRN-4 consisted of a $\mathrm{BF}_{3}$ tube moderated by a 9-in.-diameter polyethylene sphere.

Pacific Northwest Laboratory also performed radiation surveys of the cask to corroborate INEL's results. The PNL gamma survey readings were taken with an Eberline R0-3B, which is the same type of instrument as the R0-3A but with a different readout format. The neutron survey was performed using a SNOOPY, which consists of a $\mathrm{BF}_{3}$ detector moderated by an 8.5-in.-diameter polyethylene cylinder.

MA polyester film manufactured by E. I. Du Pont de Nemours \& Co., Wilmington, Delaware. 

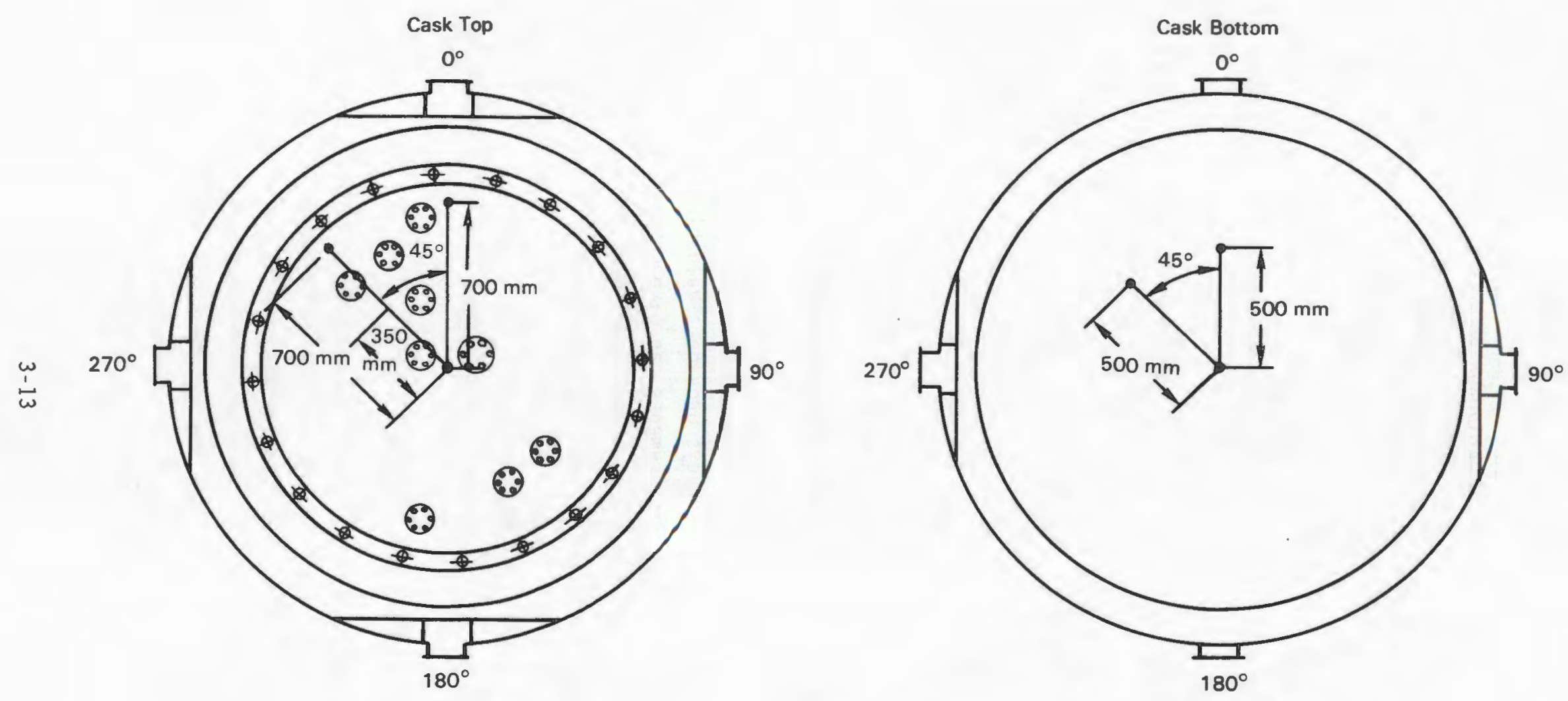

Figure 3-10. Cask Top and Bottom Thermocoupłe Locations 


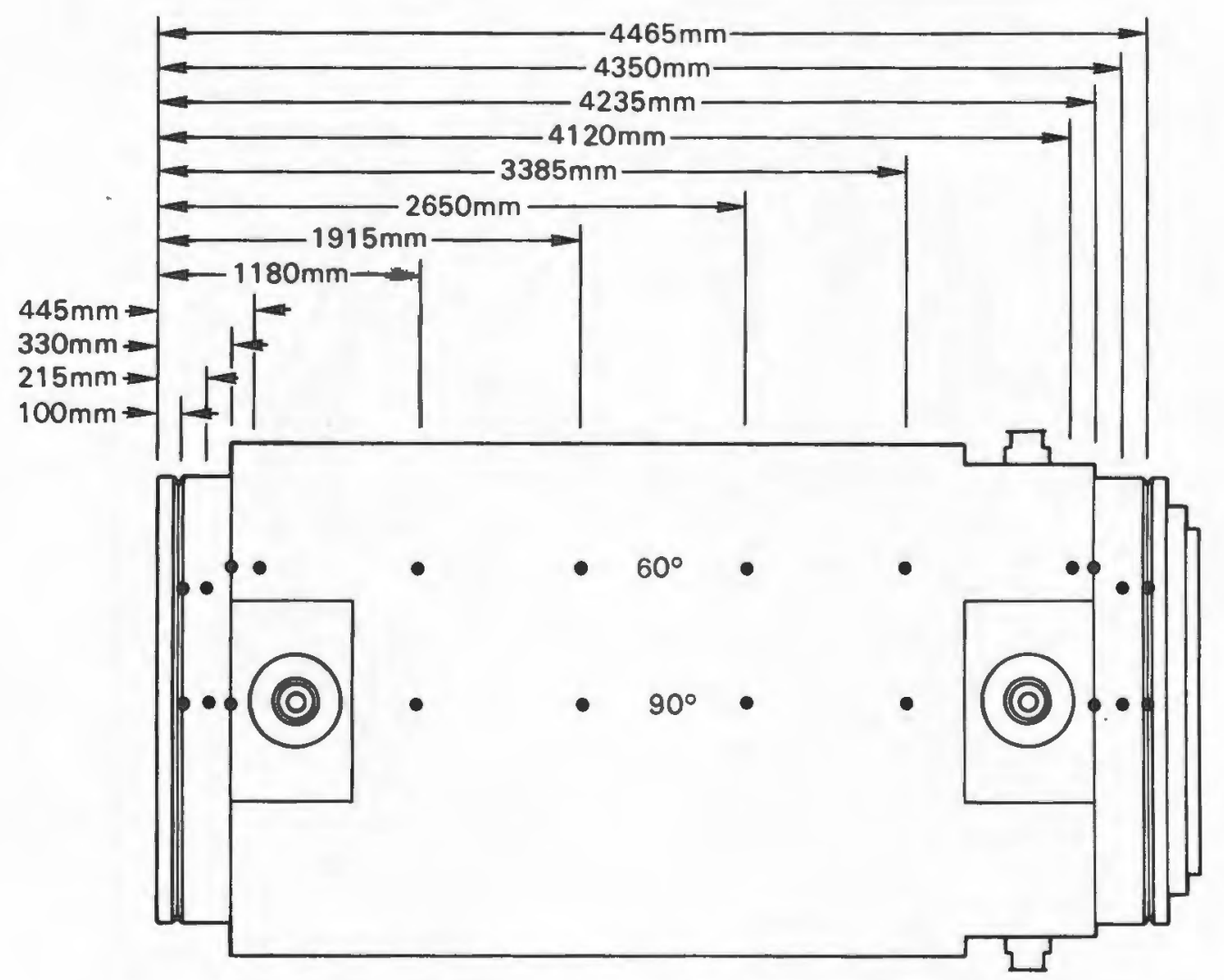

Figure 3-11. Cask Surface Dose Rate Measurement Locations

The results of the PNL and INEL surveys provide a valuable comparison and an example of how the same types of survey instruments can give consistently different readings, depending on the method and source used to calibrate the instrument and the source of radiation being measured. The INEL gamma survey instruments are calibrated using ${ }^{137} \mathrm{Cs}$, and the neutron survey instruments are calibrated with an unmoderated ${ }^{252} \mathrm{Cf}$ source. The PNL gamma survey instruments also are calibrated with a ${ }^{137} \mathrm{Cs}$ source, but the SNOOPY is calibrated against an unmoderated PuBe source.

\section{PWR SPENT FUEL AND ASSOCIATED INSTRUMENTATION}

In this section, a Westinghouse $15 \times 15$ PWR spent fuel assembly design and the consolidation canister used in the TN-24P cask performance test are described. The spent fuel used in the test comes from two PWR reactor sources, Surry and Turkey Point. Results of predictions of the decay heat rates and associated average axial decay heat profile for the consolidation canisters are presented. The instrumentation used to measure canister guide tube temperatures is described. The methods used to determine spent fuel integrity before, during, and after testing are discussed. 

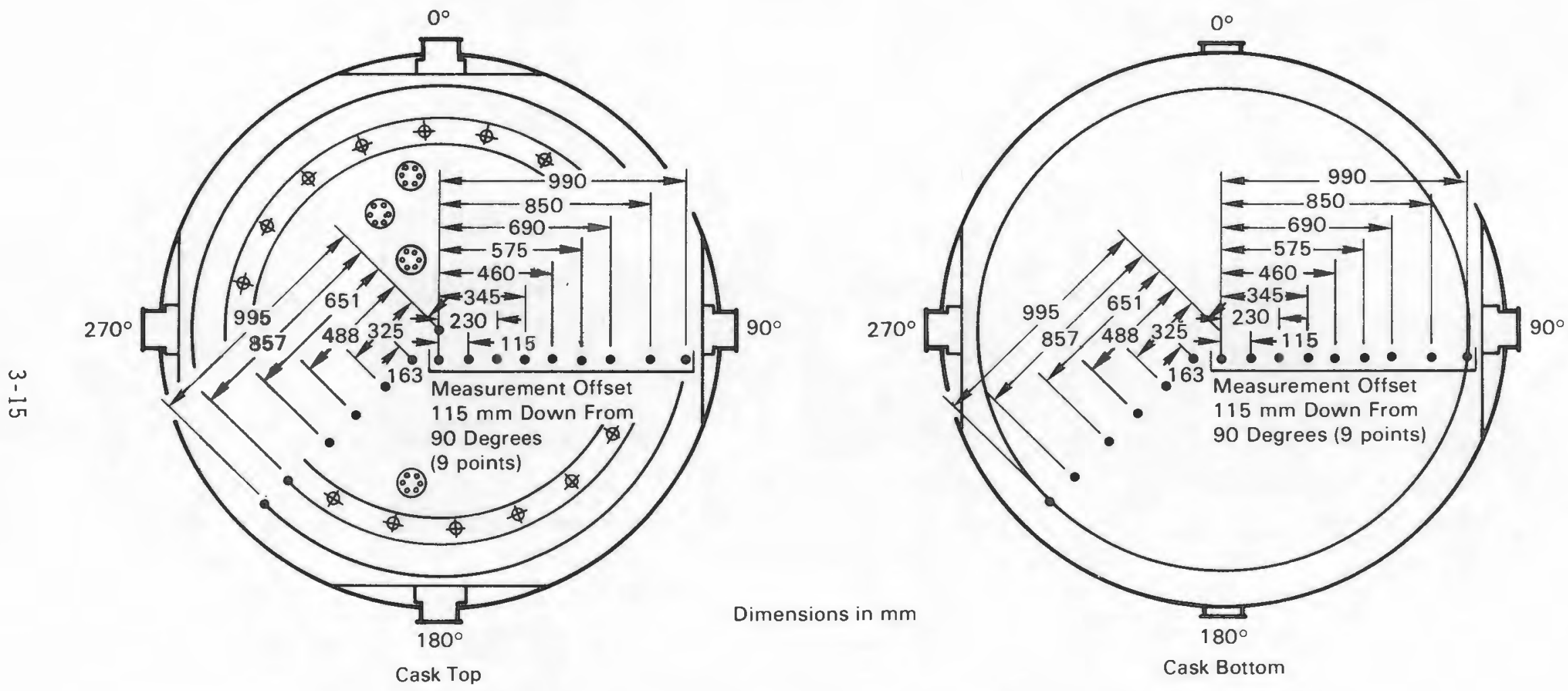

Figure 3-12. Cask Top and Bottom Dose Rate Measurement Locations 


\section{Fuel Assembly/Canister Design}

The fuel assemblies were square in cross section, nominally $214 \mathrm{~mm}$ (8.426 in.) on a side, and had a total length of $4058 \mathrm{~mm}$ (159.765 in.). The fuel column is $3658 \mathrm{~mm}$ (144 in.) long. The overall configuration is shown in Figure 3-13.

The fuel rods in a fuel assembly were arranged in a square array with 15 rod locations per side and a nominal rod-to-rod centerline pitch of $14.3 \mathrm{~mm}$ ( $0.563 \mathrm{in}$.), as shown in Figure 3-14. Of the total possible 225 rod locations per assembly, 20 were occupied by guide tubes for the control rods and burnable poison rods, and one central thimble was reserved for in-core instrumentation. The remaining 204 locations contained fuel rods. In addition, a fuel assembly also included a top nozzle, a bottom nozzle, and seven grid assemblies. The guide tubes, central thimble, grid assemblies, and the top and bottom nozzles provide the basic structure for the fuel assembly.

During the consolidation process $(\underline{9})$, the fuel rods were removed from the fuel assembly and placed into canisters. Two-to-one consolidation was consistently achieved, because each canister was able to hold 410 fuel rods and two fuel assemblies provide only 408 rods. This left two extra fuel rod storage locations per canister. Simulated guide tubes with funnel-shaped tops were placed in seven canisters to provide locations for inserting TC lances during performance testing.

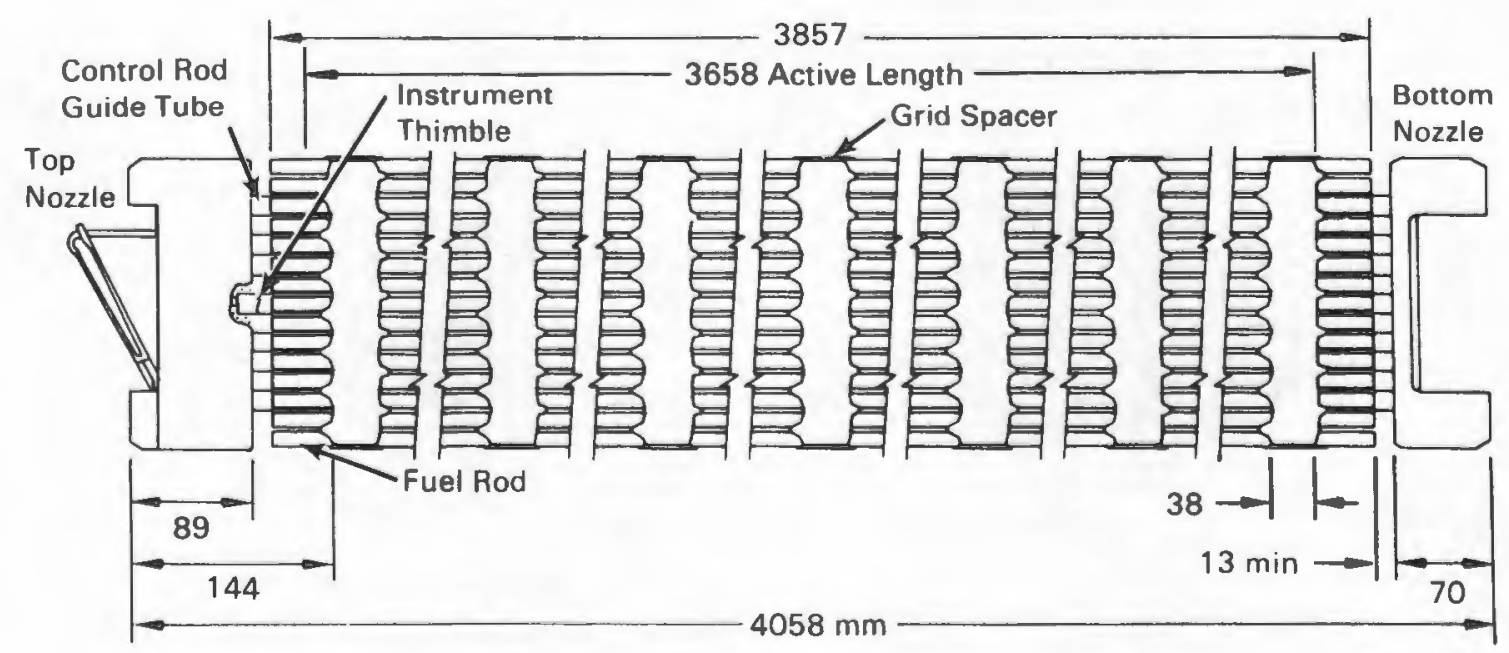

Figure 3-13. Surry and Turkey Point $15 \times 15$ PWR Fuel Assembly 


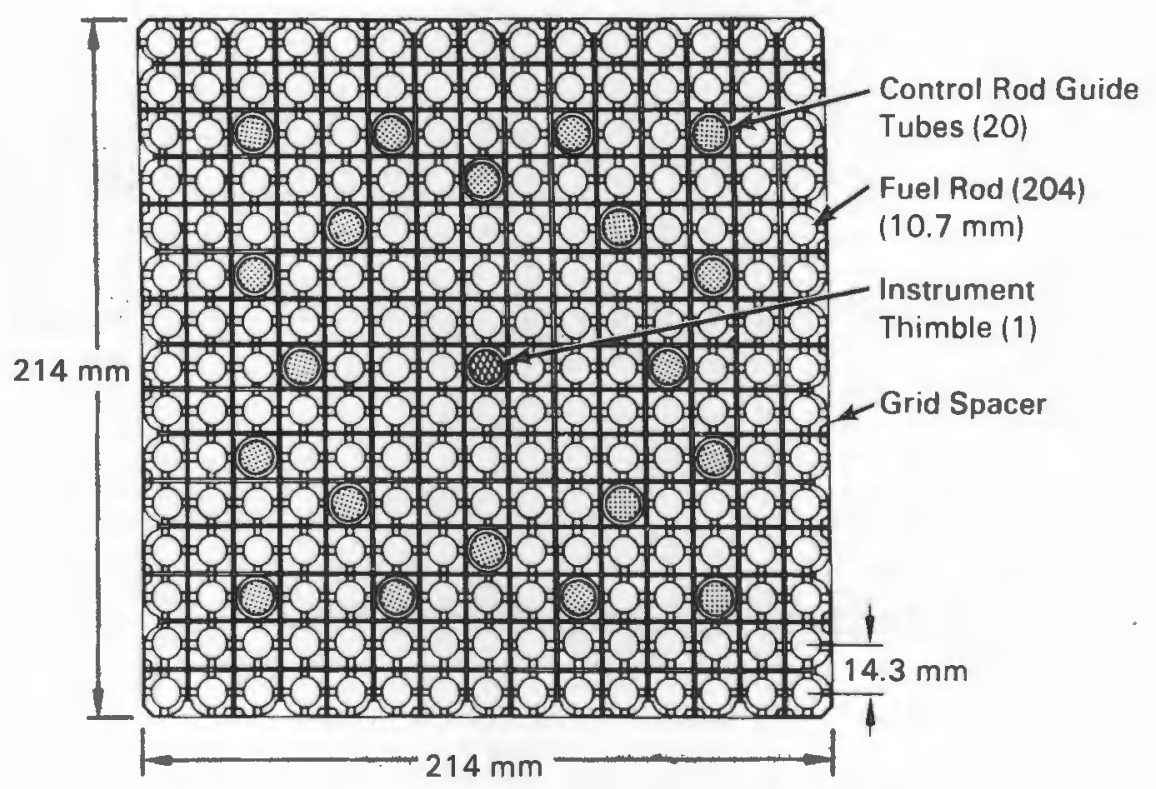

Figure 3-14. Surry and Turkey Point $15 \times 15$ PWR Fuel Assembly Cross Section

The simulated guide tubes were designed to occupy three fuel rod locations. The overflow fuel rod caused by inserting a guide tube in a canister was placed in the next canister of fuel.

A stainless steel fuel canister, Figure 3-15, consists of a base and a top-locking cover. A series of spacers, support bars, and tines is attached to the base of the canister to align and hold the fuel rods during consolidation. Once all the fuel rods have been placed on the base, the top cover is placed over the fuel and locked into place (Figure 3-16). The design of the top cover, the sliding fit between the top cover and base, and the canister locking mechanism do not seal the canister, but do limit gas flow into and out of the canister. The loaded canister is $216 \mathrm{~mm}(8.5$ in.) square by $4053 \mathrm{~mm}$ (159.57 in.) long. The lower end plate and support angles attached to the top cover raise the fuel $41.5 \mathrm{~mm}$ (1.635 in.) off the bottom of the cask.

The fuel rods consist of $\mathrm{UO}_{2}$ ceramic pellets contained in slightly cold-worked and partially annealed Zircaloy $4^{\text {m }}$ tubing, which is plugged and seal-welded at the ends

$\overline{M A}$ Zirconium alloy manufactured by Westinghouse Electric Corporation, Specialty Metals Division, Blairsville, Pennsylvania. 

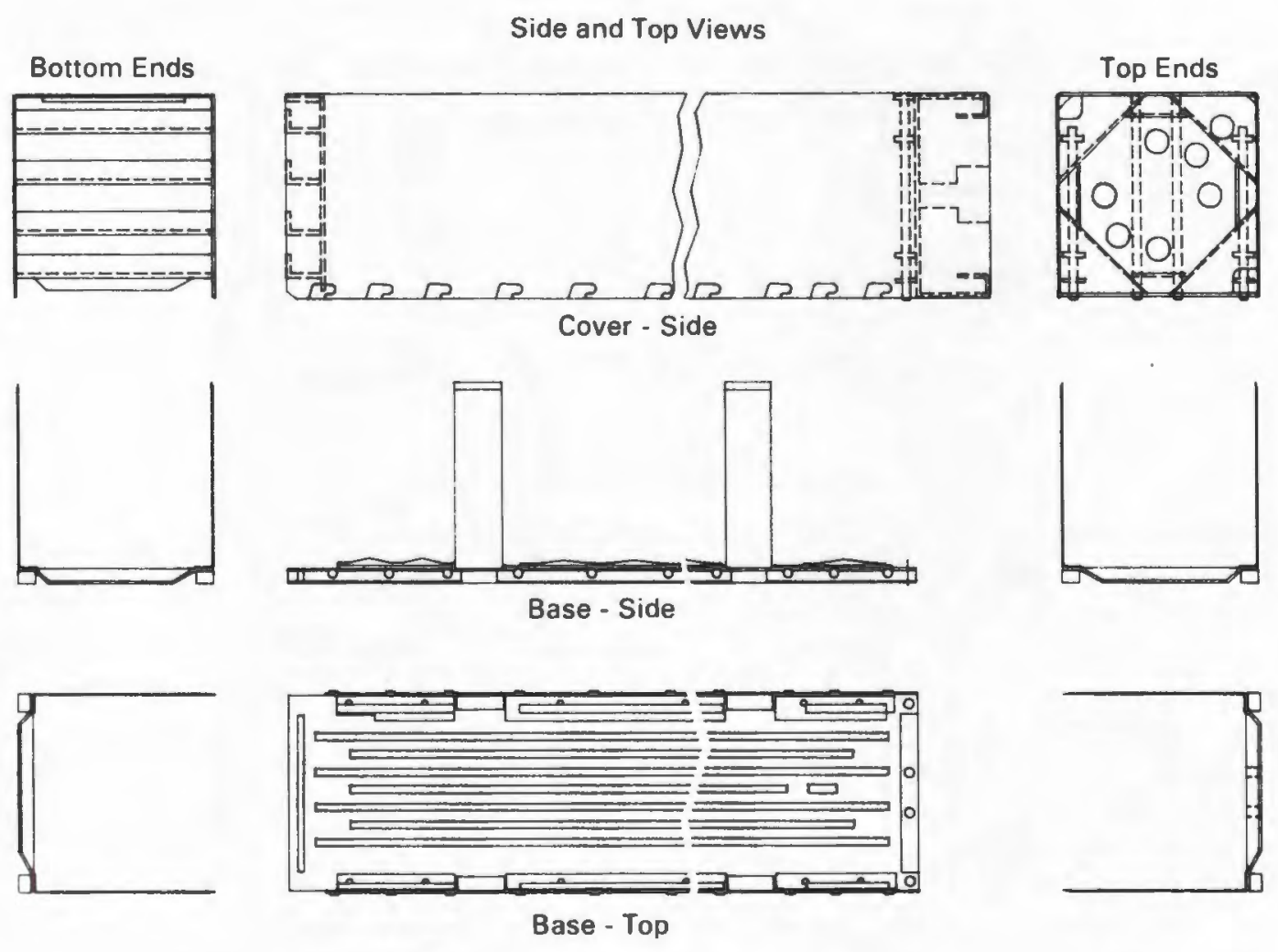

Figure 3-15. Consolidated Fuel Canister

to $\mathrm{clad}$ the fuel. Nominal dimensions include a $9.29-\mathrm{mm}(0.3659-\mathrm{in}$.) pellet diameter, $10.71-\mathrm{mm}(0.422-\mathrm{in.})$ tube outside diameter, $0.62-\mathrm{mm}(0.0243-\mathrm{in}$.$) tube$ thickness, and 3860-mm (152-in.) length.

Sufficient void volume and clearances are provided within the rod to accommodate fission gases released from the fuel, differential thermal expansion between the cladding and the fuel, and fuel swelling due to accumulated fission products without overstressing of the cladding or seal welds. Shifting of the fuel within the cladding is prevented during handling or shipping prior to core loading by a carbonsteel helical compression spring that bears on the top of the fuel pellet column. The holddown force to prevent fuel shifting is obtained by compression of the spring between the top end plug and the top fuel pellet of the stack.

During assembly, the pellets are stacked in the cladding to the required fuel height. The compression spring is then inserted into the top end of the fuer, and 


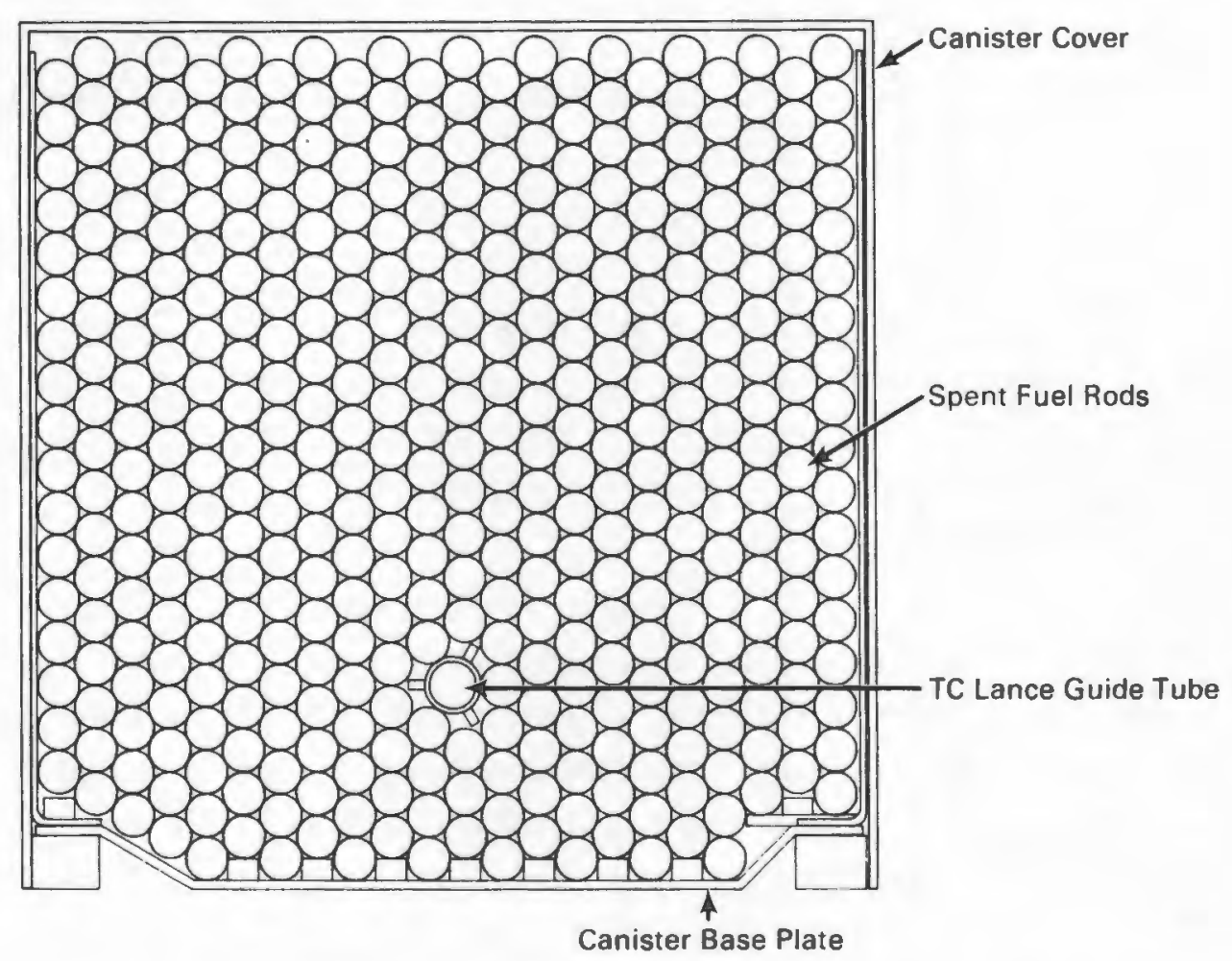

Figure 3-16. Cross Section of a Loaded Consolidated Fuel Canister

the end plugs are pressed into the ends of the tube and welded. During the welding process, the fuel rods are internally pressurized with helium to between 20.7 and $27.6 \operatorname{bar}(300$ and $400 \mathrm{psia})$.

The fuel rod void space is sized to ensure adherence to the pressure criterion. The end-of-1ife pressure is evaluated for the worst rod under expected conditions of fuel operation and at the peak steady-state power. The model used to predict the quantity of fission gas in the gap at end-of-life is based on an extensive comparison to published performance of fuel rods under a variety of conditions. The composition of the gas in the gap at end-of-life is a maximum of approximately $50 \%$ fission.

The fuel pellets are right circular cylinders consisting of slightly enriched $\mathrm{UO}_{2}$ powder, which is compacted by cold pressing and sintering to the required density. The ends of each pellet are dished slightly to allow the greater axial expansion at the center of the pellets to be taken up within the pellets themselves and not in the overall fuel length. The nominal design enrichment is 2.56 wt\% for the "B," 
"D," and "N" assemblies and 1.86 wt\%, $3.10 \mathrm{wt} \%$, and $3.20 \mathrm{wt} \%$ for the "L," "R," and

"W" assemblies, respectively. The nominal density is $95 \%$ of theoretical density for all of the fuel pellets.

\section{Predicted Decay Heat Rates}

The ORIGEN2 code $(\underline{10})$ was used to predict decay heat generation rates of the PWR spent fuel assemblies used for loading the canister in the TN-24P cask performance test. A brief description of ORIGEN2, a summary of the input, and the predicted decay heat rates and average axial decay heat profile are provided.

ORIGEN2 Computer Code. The ORIGEN2 computer code is widely used in the nuclear industry to predict decay heat rates of spent fuel assemblies. It is a generalpurpose burnup and decay code featuring extensive data libraries containing information on over 1200 nuclides. The code can be used to perform transmutation calculations in steps of constant power or constant neutron flux level. The resulting nuclide concentrations can be decayed with user-specified time intervals. Output options are available for decay heat rate as well as spent fuel compositions and radioactivity.

Input Specifications. The PWR spent fuel assembly design data were provided in a previous section for the assemblies used in the TN-24P cask performance test.

Additional input data used in the ORIGEN2 calculations for the assemblies included:

- reactor operating histories and decay times after final cycle of operation for each assembly

- monthly measured fuel assembly relative power density (RPD)

- measured end-of-cycle (EOC) fuel assembly burnups

- as-built fuel batch assembly average metric ton uranium (MTU) loadings and isotopics.

The spent fuel consolidated and used in the tests came from two reactors, Surry 2 and Turkey Point. The detail used in the calculation varied based on reactor source. A description of the information from each source will be treated separately beginning with the fuel from Surry 2.

The Surry 2 reactor operating history for each cycle was based on the monthly core exposure $\log$ sheets obtained from the VP Nuclear Operations Department (NOD). The reactor operating histories for cycles 1 through 5 are given in Appendix $A$. The monthly measured fuel assembly RPDs were extracted from the monthly INCORE (11) 
computer code maps produced by NOD. The measured EOC fuel assembly burnups were obtained from NEWTOTE (12) computer code results. A history of the assembly EOC average burnups is given in Table $3-2$. The batch average assembly MTU loadings were obtained from Westinghouse as-built data. These data are provided in Appendix $A$.

The assembly-specific power for each irradiation step was calculated using three equations:

$$
\begin{aligned}
\operatorname{POWER}(K) & =(\text { LOADF * RPDAVG * 2441)/157 } \\
\text { BURNUP } & =\{\text { SUM }[P O W E R(K) * \text { DAYS }]\} / \text { MTFUEL } \\
\operatorname{IRP}(K) & =\operatorname{POWER}(K) * \text { AVGEOC / BURNUP }
\end{aligned}
$$

where $\operatorname{POWER}(k)=$ specific power for irradiation step $K$ based on reactor operating history and measured RPDs

LOADF = reactor power level from reactor operation history for irradiation step K (fraction of 2441 MWth)

RPDAVG = average RPD for symmetric fuel assemblies for irradiation step $K$

$2441=$ full power core heat output (MWth)

$157=$ total number of assemblies in Surry core

BURNUP = average EOC assembly burnup based on reactor operating history

SUM = summation over all irradiation steps

DAYS = number of days operated for irradiation step $K$

MTFUEL = metric tons uranium (MTU) loading per assembly

$\operatorname{IRP}(K)=$ specific power input for irradiation step $K$

$A V G E O C$ = average measured EOC burnup for symmetric assemblies.

The data in Table 3-2 were compiled for each Surry 2 assembly, and calculations were performed for each similar set of fuel assemblies. Typical assembly power histories are shown in Figure 3-17.

The Turkey Point assemblies were from Unit 3. The "B" assemblies were irradiated in Cycles 1 and 2 to 827 effective full-power days (EFPD) during a residence time of 1382 days. The early part of Cycle 1 included an extended period at low power, so that the entire residence time was not modeled. Instead, the power history was assumed to consist of three full-power periods of 259 days, 284 days, and 284 days separated by two 111-day shutdown periods. The "D" assemblies were irradiated in Cycles 2 through 4 . This history was modeled by three full-power periods of 284 
Table 3-2

SURRY 2 ASSEMBLY AVERAGE BURNUP HISTORIES

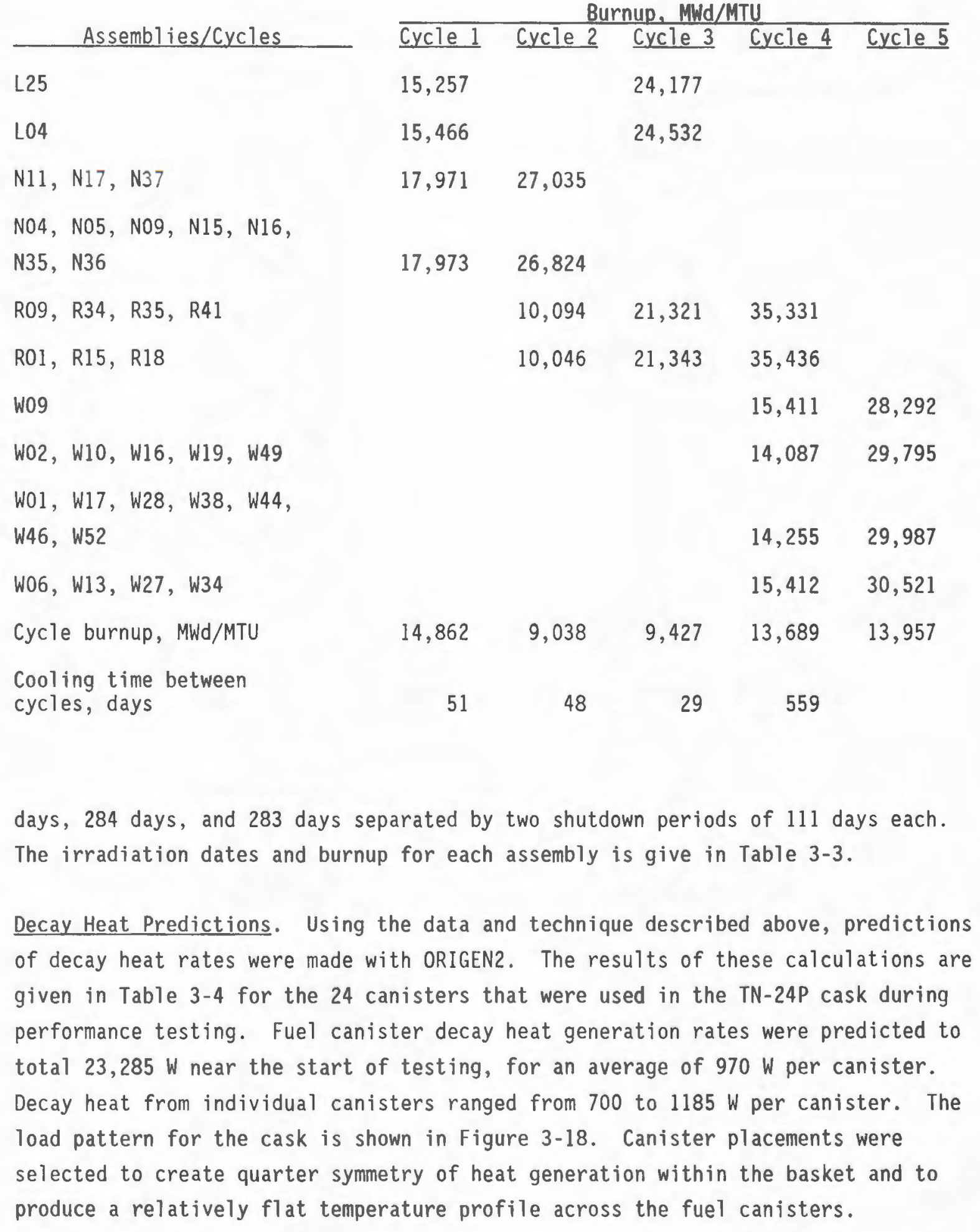




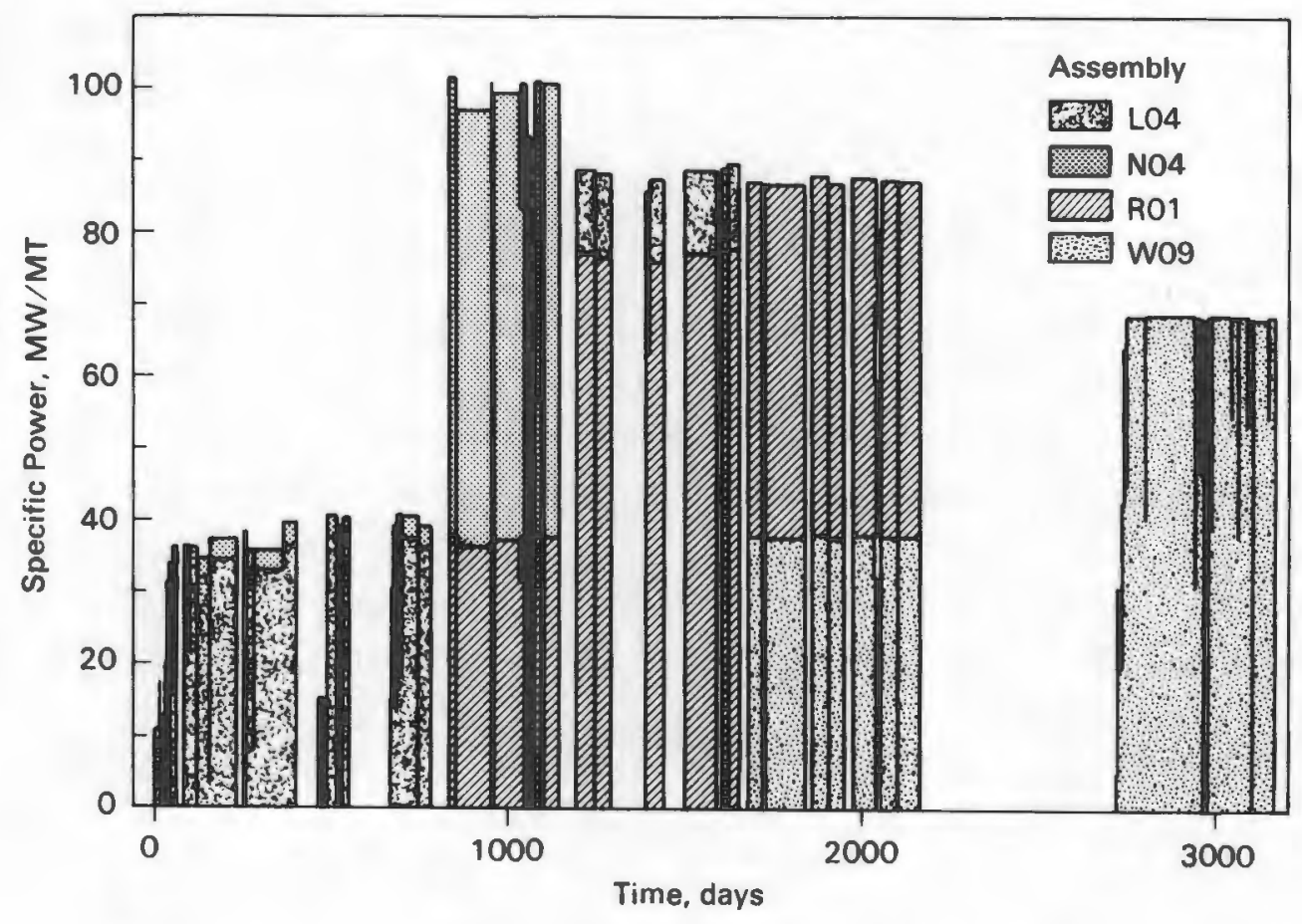

Figure 3-17. Selected Assembly Power Histories

\section{Predicted Axial Decay Heat Profile}

Measured axial decay heat profiles or gamma scans for the Surry spent fuel assemblies were not available as input data to the ORIGEN2 computer code to predict axial decay heat profiles. Axial gamma radiation scans previously obtained on Turkey Point reactor spent fuel assemblies were therefore used to develop a typical

Table 3-3

TURKEY POINT ASSEMBLY AVERAGE BURNUP HISTORIES

$\frac{\text { Assemblies }}{\mathrm{B} 02, \mathrm{~B} 03, \mathrm{~B} 41}$
$\mathrm{~B} 43$
$\mathrm{D} 1, \mathrm{D} 04, \mathrm{D} 06, \mathrm{D} 15, \mathrm{D} 35$,
$\mathrm{D} 40, \mathrm{D} 46, \mathrm{D} 47$

\begin{tabular}{|c|c|c|}
\hline \multicolumn{2}{|c|}{ Irradiation Dates } & \multirow{2}{*}{$\begin{array}{l}\text { Burnup, } \\
\text { MWd/MTU }\end{array}$} \\
\hline Start & End & \\
\hline $1 / 12 / 72$ & $10 / 25 / 75$ & 25,665 \\
\hline $1 / 12 / 72$ & $10 / 25 / 75$ & 25,596 \\
\hline $12 / 12 / 74$ & $11 / 19 / 77$ & 28,430 \\
\hline
\end{tabular}


assembly axial burnup distribution (13). The Turkey Point and Surry PWRs and spent fuel assemblies are of the same designs, so axial decay heat profiles should be very similar.

The axial burnup distribution required as input to ORIGEN2 consisted of an average from gamma scans of 25 rods from five Turkey Point assemblies. ORIGEN2, with the measured gamma distribution and the appropriate Surry operating history, was then used to predict the relationship between burnup values and decay heat rates in specific axial regions (nodes) along the length of a fuel assembly. The measured gamma activity from Turkey Point assemblies and predicted Surry assembly decay heat axial profiles are shown in Figure 3-19. Both profiles are typical of those for spent fuel assemblies from PWRs. The dips in the profiles are a result of grid spacers at those locations.

Axial decay heat profiles are important because they strongly influence the shape of axial temperature profiles in the fuel assemblies, especially in vacuum and in a horizontal orientation where convection heat transfer is minimized. A smoothed representation of the predicted axial decay heat profile (Figure 3-19) was used as input to the COBRA-SFS heat transfer computer program to facilitate pre- and post-test temperature predictions (Section 5).

\section{Spent Fuel Integrity}

Information on fuel integrity is of interest in evaluating the impact of dry storage on the behavior of spent fuel rods during long-term dry storage and fuel-handling operations associated with dry storage. The main areas of interest for the spent fuel include the integrity of the fuel cladding, the condition of the spent fuel assembly hardware, and the character and condition of the crud. Selected spent fuel assemblies used in the TN-24P cask performance test were examined before they were consolidated, to determine the condition of the spent fuel and non-fuel-bearing components prior to dry storage. Further examinations of the spent fuel upon completion of the long-term surveillance period will help determine whether long-term dry storage affects the spent fuel integrity or characteristics.

Pretest Fuel Integrity. Four examination methods were used to assess the integrity of the Surry fuel assembly rods before the performance test. These included ultrasonic examinations at VP; visual observations, including full-length black and white videos at both VP and INEL, and color photographs at INEL; analyses of the cover gas in the TN-24P cask; and crud sampling. Although crud behavior does not directly relate to fuel rod integrity, crud sampling was performed because crud spallation 
Table 3-4

TN-24P CASK FUEL CANISTER COMPOSITION AND LOADING ARRANGEMENT

\begin{tabular}{|c|c|c|c|c|c|c|c|}
\hline \multirow{2}{*}{$\begin{array}{c}\text { Canister } \\
\text { Basket } \\
\text { Location } \\
\end{array}$} & \multirow[b]{2}{*}{$\begin{array}{c}\text { Assembly } \\
\text { ID\# }\end{array}$} & \multirow[b]{2}{*}{$\begin{array}{l}\text { Assembly } \\
\text { Source }\end{array}$} & \multirow[b]{2}{*}{$\begin{array}{l}\text { Burnup, } \\
\text { GWd/MTU }\end{array}$} & \multirow{2}{*}{$\begin{array}{l}\text { Cooling } \\
\text { Time, } \\
\text { Years } \\
\end{array}$} & \multirow{2}{*}{$\begin{array}{c}\text { Initial } \\
\text { Enrichment, } \\
\% \\
\end{array}$} & \multicolumn{2}{|c|}{ 1/15/88 Decay Heat } \\
\hline & & & & & & $\begin{array}{c}\text { Assembly, } \\
W\end{array}$ & $\begin{array}{c}\text { Canister, } \\
W\end{array}$ \\
\hline \multirow[t]{2}{*}{$A 1$} & D01 & $T-P$ & 28.43 & 10.2 & 2.56 & 429.9 & 859.8 \\
\hline & D04 & $T-P$ & 28.43 & 10.2 & 2.56 & 429.9 & \\
\hline \multirow[t]{2}{*}{$A 2$} & N05 & S-MC10 & 26.82 & 11.7 & 2.56 & 375.7 & 754.9 \\
\hline & N11 & $S-M C 10$ & 27.04 & 11.7 & 2.56 & 379.2 & \\
\hline \multirow[t]{2}{*}{$A 3$} & W10 & S-TN24P & 29.80 & 6.2 & 3.20 & 578.7 & 1157.4 \\
\hline & W02 & S-TN24P & 29.80 & 6.2 & 3.20 & 578.7 & \\
\hline \multirow[t]{2}{*}{ A4 } & N16 & S-MC10 & 26.82 & 11.7 & 2.56 & 375.7 & 751.4 \\
\hline & N35 & S-MC10 & 26.82 & 11.7 & 2.56 & 375.7 & \\
\hline \multirow[t]{2}{*}{ A5 } & R01 & S-MC10 & 35.44 & 9.0 & 3.10 & 581.5 & 1163.0 \\
\hline & R15 & S-MC10 & 35.44 & 9.0 & 3.10 & 581.5 & \\
\hline \multirow[t]{2}{*}{ A6 } & W52 & S-TN24P & 29.99 & 6.2 & 3.20 & 583.1 & 1161.8 \\
\hline & W49 & S-TN24P & 29.80 & 6.2 & 3.20 & 578.7 & \\
\hline \multirow[t]{2}{*}{ B1 } & D06 & $T-P$ & 28.43 & 10.2 & 2.56 & 429.9 & 859.8 \\
\hline & D15 & $\mathrm{T}-\mathrm{P}$ & 27.86 & 10.2 & 2.56 & 429.9 & \\
\hline \multirow[t]{2}{*}{ B2 } & $\mathrm{B} 03$ & $T-P$ & 25.67 & 12.2 & 2.56 & 350.6 & 701.2 \\
\hline & $\mathrm{B} 02$ & $T-P$ & 25.67 & 12.2 & 2.56 & 350.6 & \\
\hline \multirow[t]{2}{*}{ B3 } & W06 & S-TN24P & 30.52 & 6.2 & 3.20 & 592.4 & 1184.8 \\
\hline & W13 & S-TN24P & 30.52 & 6.2 & 3.20 & 592.4 & \\
\hline \multirow[t]{2}{*}{ B4 } & N36 & S-MC10 & 26.82 & 11.7 & 2.56 & 375.7 & 751.4 \\
\hline & N04 & S-MC10 & 26.82 & 11.7 & 2.56 & 375.7 & \\
\hline \multirow[t]{2}{*}{ B5 } & R34 & S-MC 10 & 35.33 & 9.0 & 3.10 & 579.9 & 1159.8 \\
\hline & R35 & S-MC 10 & 35.33 & 9.0 & 3.10 & 579.9 & \\
\hline \multirow[t]{2}{*}{ B6 } & W38 & S-TN24P & 29.99 & 6.2 & 3.20 & 583.1 & 1166.2 \\
\hline & W01 & S-TN24P & 29.99 & 6.2 & 3.20 & 583.1 & \\
\hline \multirow[t]{2}{*}{$\mathrm{Cl}$} & D35 & $T-P$ & 28.43 & 10.2 & 2.56 & 429.9 & 859.8 \\
\hline & D40 & $T-P$ & 28.43 & 10.2 & 2.56 & 429.9 & \\
\hline C2 & N37 & $S-M C 10$ & 27.04 & $11 . \overline{7}$ & 2.56 & 379.2 & 758.4 \\
\hline & N17 & $S-M C 10$ & 27.04 & 11.7 & 2.56 & 379.2 & \\
\hline C3 & W19 & S-TN24P & 29.80 & 6.2 & 3.20 & 578.7 & 1157.4 \\
\hline & W16 & S-TN24P & 29.80 & 6.2 & 3.20 & 578.7 & \\
\hline C4 & L25 & S-MC10 & 24.18 & 10.4 & 1.86 & 362.1 & 732.5 \\
\hline & L04 & $S-M C 10$ & 24.53 & 10.4 & 1.86 & 370.4 & \\
\hline C5 & R18 & S-MC10 & 35.44 & 9.0 & 3.10 & 581.5 & 1161.4 \\
\hline & R09 & S-MC10 & 35.33 & 9.0 & 3.10 & 579.9 & \\
\hline C6 & W44 & S-TN24P & 29.99 & 6.2 & 3.20 & 583.1 & 1166.2 \\
\hline & W46 & S-TN24P & 29.99 & 6.2 & 3.20 & 583.1 & \\
\hline D1 & D47 & $T-P$ & 28.43 & 10.2 & 2.56 & 429.9 & 859.8 \\
\hline & D46 & $T-P$ & 28.43 & 10.2 & 2.56 & 429.9 & \\
\hline D2 & B41 & $T-P$ & 25.67 & 12.2 & 2.56 & 350.6 & 700.1 \\
\hline & B43 & $T-P$ & 25.60 & 12.2 & 2.56 & 349.5 & \\
\hline D3 & W34 & S-TN24P & 30.52 & 6.2 & 3.20 & 592.4 & 1184.8 \\
\hline & W27 & S-TN24P & 30.52 & 6.2 & 3.20 & 592.4 & \\
\hline D4 & N15 & S-MC10 & 26.82 & 11.7 & 2.56 & 375.7 & 751.4 \\
\hline & N09 & S-MC10 & 26.82 & 11.7 & 2.56 & 375.7 & \\
\hline D5 & W09 & S-MC 10 & 28.29 & 6.2 & 3.20 & 534.7 & 1114.6 \\
\hline & R41 & S-MC10 & 35.33 & 9.0 & 3.10 & 579.9 & \\
\hline D6 & W28 & S-TN24P & 29.99 & 6.2 & 3.20 & 583.1 & 1166.2 \\
\hline & W17 & S-TN24P & 29.99 & 6.2 & 3.20 & 583.1 & \\
\hline
\end{tabular}




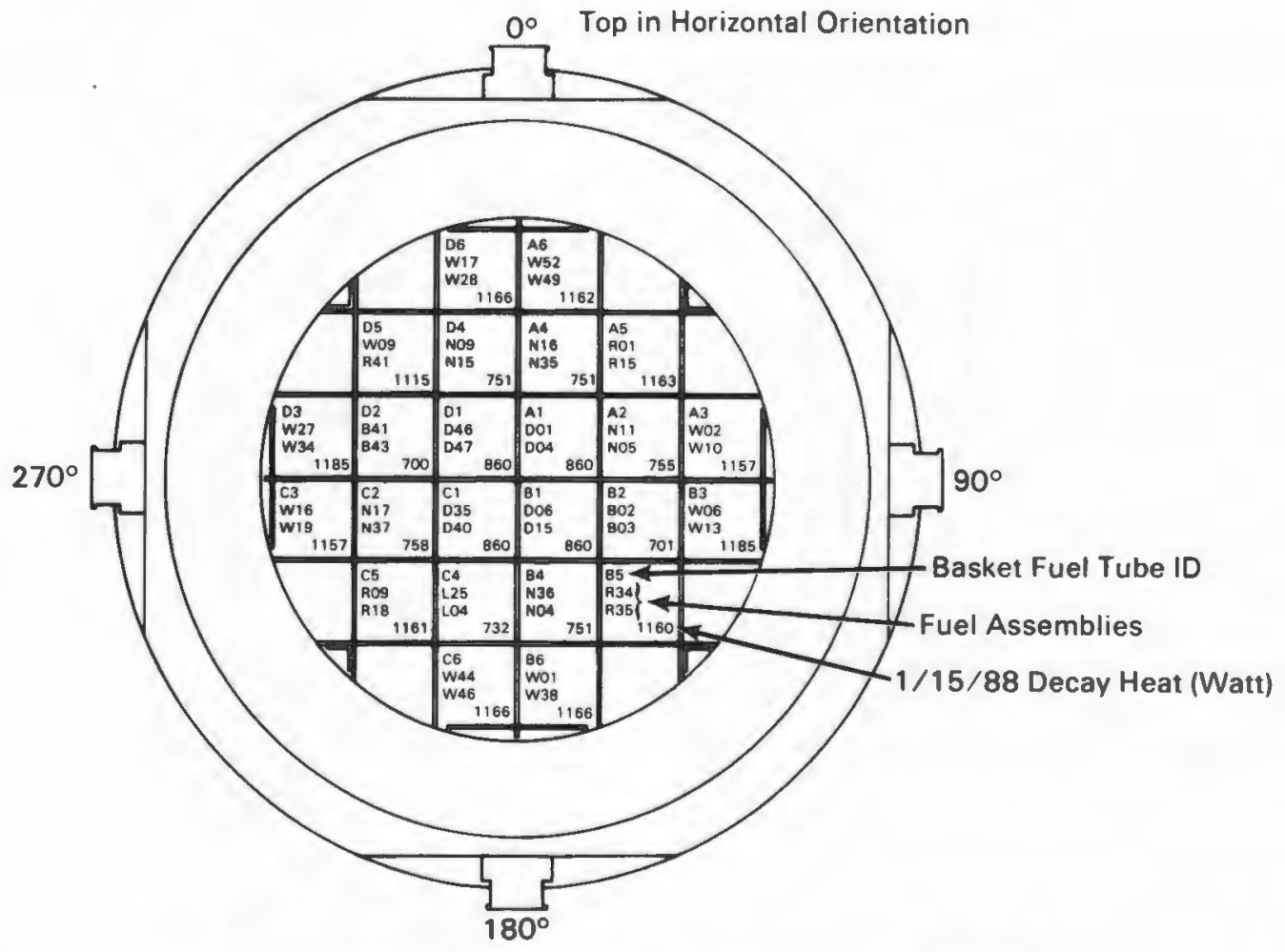

Figure 3-18. Load Map for TN-24P with Consolidated Fuel

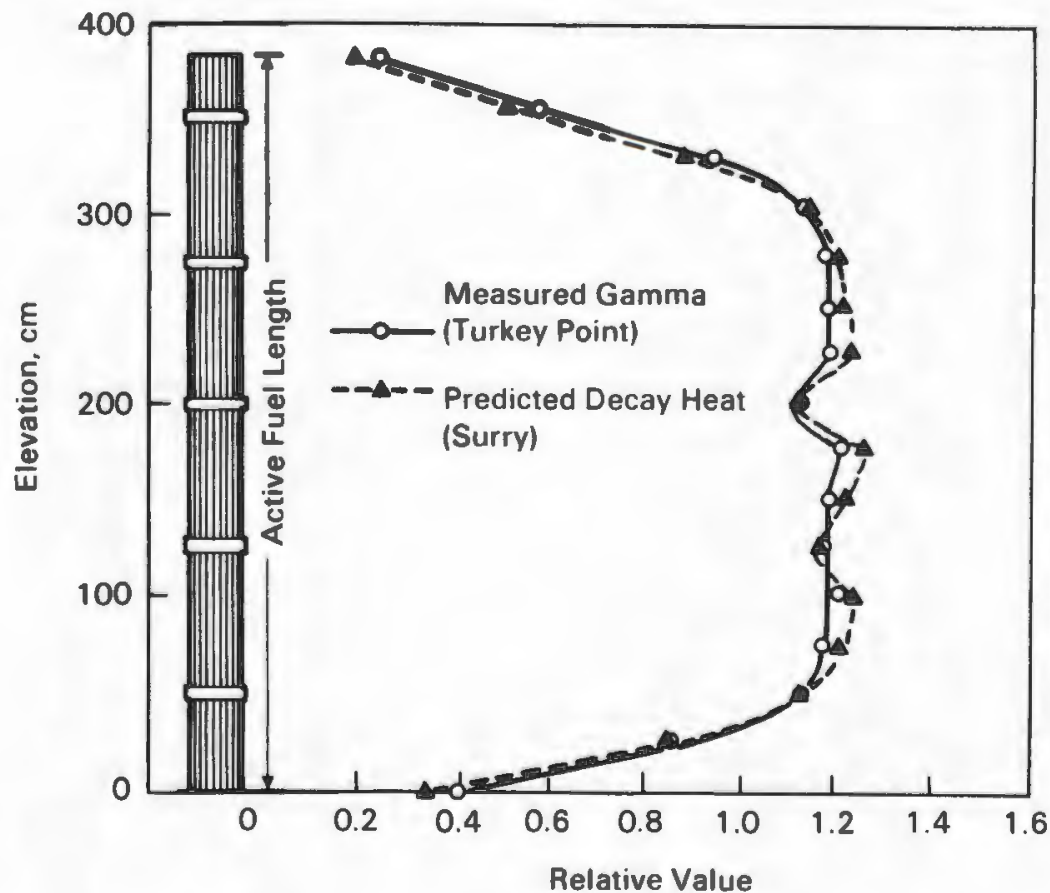

Figure 3-19. Predicted Axial Decay Heat Profile 
has been known to impact fuel-handling operations. Evidence that crud soaks loose during wet storage of some spent fuel rods has led to increased interest in crud behavior during rod consolidation and other dry operations.

Based on U1trasonic examination of the Surry fuel at VP using the Failed Fuel Rod Detection System (FRDS), ${ }^{a}$ all the Surry fuel was determined to be free of cladding defects prior to shipment to INEL. Gas sampling during the TN-24P cask performance test with unconsolidated fuel indicated that a leak developed in a fuel $\operatorname{rod}(s)$ during the performance test. Because the identity of the fuel $\operatorname{rod}(s)$ or assembly containing the fuel $\operatorname{rod}(s)$ was not determined and because most of the fuel used in the previous TN-24P performance test ( $\underline{3}$ ) was consolidated and loaded in the TN-24P for this testing, this leaking fuel rod is probably in one of the consolidated canisters in the TN-24P cask.

At least two other leaking fuel rods were included in the consolidated fuel in the TN-24P cask. Based on wet sipping tests performed at Turkey Point Power Station or Battelle-Columbus Laboratories, elevated Cs indication during shipping cask monitoring, and elevated ${ }^{85} \mathrm{Kr}$ levels during dry storage canister atmosphere monitoring at the Nevada Test Site (NTS), one or more leaking rods were present in Turkey Point assembly $B 41(\underline{5})$. The other leaking $\operatorname{rod}(s)$ were in Turkey Point fuel assembly B02. The results of gas analysis during the Fuel Temperature Tests at the NTS indicated a cladding failure in assembly $\mathrm{B} 02(\underline{5})$. Analysis of gas release rates suggests that

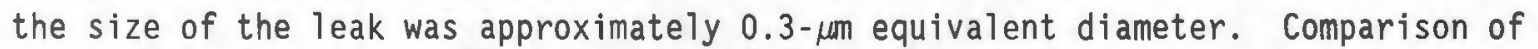
release rates of He and ${ }^{85} \mathrm{Kr}$ suggested the leak was in the form of microcracks ( $\left.\underline{5}\right)$.

At the end of the consolidation process, $\approx 980$ fuel rods had been placed in fuel canisters without rod failure. During the consolidation process, the gases exhausted through the ventilation system were continuously monitored for fission product emissions. No fission gas release was detected, indicating that no fuel cladding failed during the consolidation process. Nothing unusual was observed during the dry rod consolidation process that would suggest or identify any leaking fuel rods. However, extensive visual examination was not made of all fuel rods from suspect assemblies, nor were all assemblies visually examined.

aThe FRDS detects the present of moisture in fuel rods. Defective fuel rods containing moisture and even small amounts of water diffuse and attenuate the signals, providing distinctive tracts on an oscilloscope and X-Y plotter. Additional details on the FRDS can be found in $\underline{2}-\underline{4}$. 
Fuel Integrity During Testing. The cask cover gas was sampled prior to and at the end of each performance test run, to evaluate the integrity of the spent fuel rods. Each sample was collected in a separate 500 -cc stainless steel cylinder equipped with bellows-sealed valves as part of the closure. The cylinders were checked for purity and leaks prior to sampling.

The gas samples were sent to INEL's Chemical Processing Plant (CPP) for analysis. Mass spectra were analyzed for all common gases with masses less than 100 . The post-test run samples were processed for ${ }^{85} \mathrm{Kr}$. The radionuclide concentration of ${ }^{85} \mathrm{Kr}$ was determined by gamma counting to find ${ }^{85} \mathrm{Kr}$ activity greater than $60 \mathrm{pCi} / \mathrm{cc}$. The results of the gas analyses are presented in Section 4 of this report.

\section{DATA ACQUISITION SYSTEM}

The data acquisition system (DAS) used to receive and process signals from the cask and fuel TCs and the cask pressure transducer is shown schematically in Figure 3-20. The system consisted of extension leads from the respective sensors to a junction box (JB\#1). Additional extension leads were required from junction box 1 (JB\#1) to junction box 2 (JB\#2) located near the Keithley Series 500 DAS.

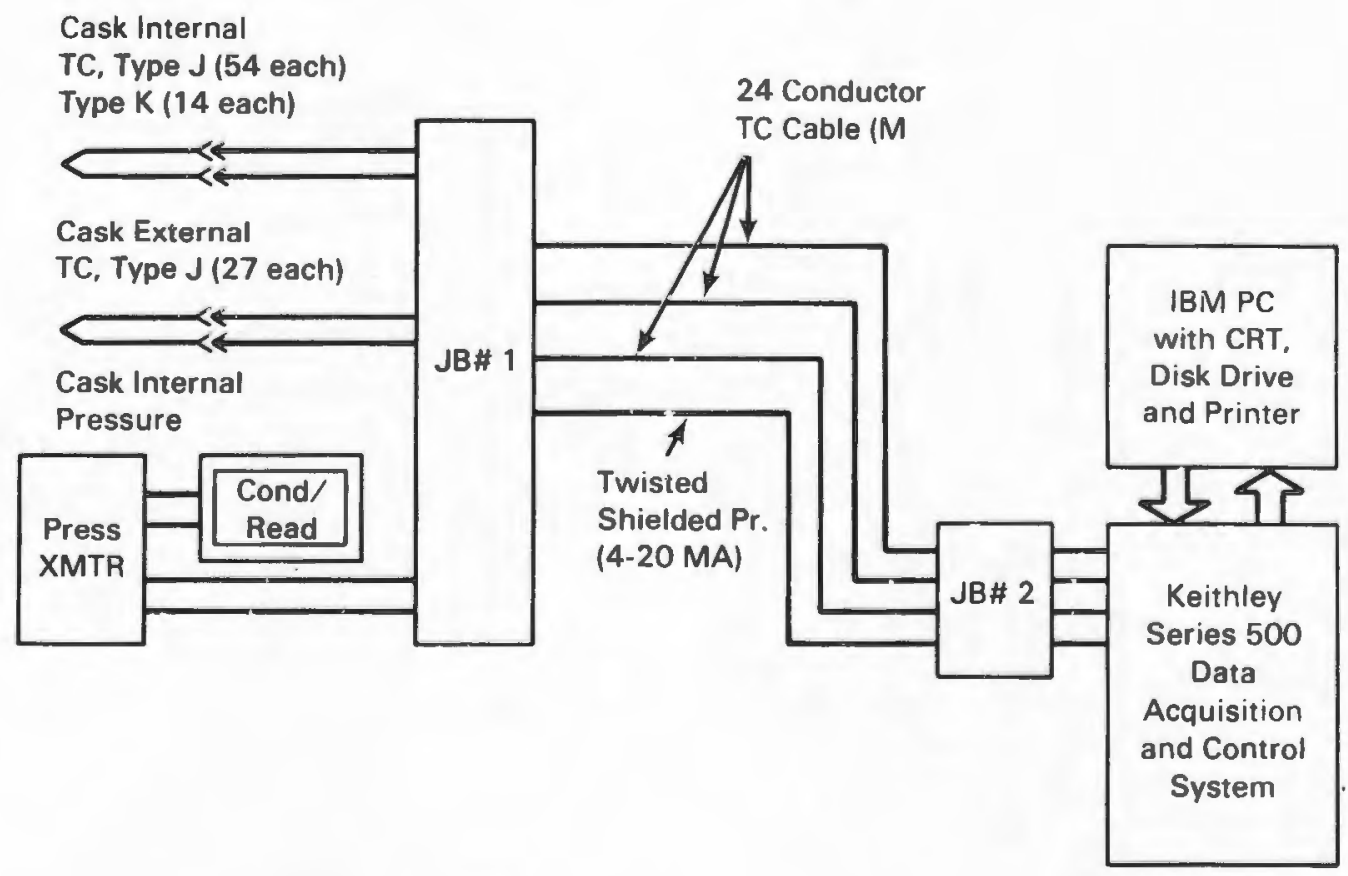

Figure 3-20. Data Acquisition System 
The Keithley Series 500 DAS is a general-purpose data acquisition and control device consisting of a Keithley Series 500 mainframe and a standard IBM PC with a CRT display, floppy disk drive, and printer (14). The Keithley Series 500 mainframe provides an interface between an IBM PC and the real world (instrumentation sensors). Therefore, any IBM PC can be used for direct data acquisition and intelligent process control.

The Keithley Series 500 mainframe is a modular system, centered around a low-noise chassis containing a precision power supply and baseboard with slots for $10 \mathrm{plug}$-in modules. The module family provides all of the conditioning, conversion, and control capabilities needed for laboratory and industrial automation. All four kinds of real-world signals--analog input, analog output, digital input, and digital output--are accepted by the Keithley Series 500.

Analog input from the cask instrumentation pressure and temperature sensors was processed in two stages. The initial conditioning and selection of all signals was provided by a series of the analog input module (AIM3). Different modules offer amplification, isolation, bridge detection, excitation, and cold junction reference. Programmable gain allowed the range of the signal to match that of the converter. Signals were then directed to a single analog-to-digital module (ADM) that accesses the level of the signal with an $A / D$ converter, returning a digital value understood by the IBM computer.

Signals from the Keithley Series 500 were received, converted to engineering units, stored on floppy disks, and printed out on hard copy by the IBM PC. Further processing of the pressure and temperature data consisted of applying appropriate calibrations to the raw temperature data and plotting selected data presented in Section 4.

\section{DATA UNCERTAINTY ESTIMATES}

Temperature uncertainties for the internal TC lance temperature measurements are within $\pm 4^{\circ} \mathrm{C}$, and external temperature measurements are within $\pm 4.5^{\circ} \mathrm{C}$ based on the combined uncertainties of the TCs, extension wires, and data acquisition system. The higher accuracy of the internal measurements results because the lance TCs were calibrated, whereas the TCs attached to the casks surface were not. Where independent calibration data were not obtained, vendor certifications were used to estimate the TC contribution to temperature measurement uncertainty. 
Pressure measurement uncertainties were within \pm 1.5 mbar for the low-pressure vacuum measurements and within \pm 6 mbar for the readings near 1500 mbar. The pressure measurement uncertainty is a combination of the uncertainty in the pressure transducer's 4- to 20-mA output and the voltage drop across a precision resistor (1\%) in the DAS. Detailed uncertainty calculations for both pressure and temperature measurements are presented in Appendix B.

Survey instruments are field instruments and can have large overresponses, depending on the energy spectrum of the calibration source and the energy spectrum being measured. The gamma survey instruments should be accurate to with in $10 \%$ for room temperature measurements. For measurements not in the range of 15 to $26^{\circ} \mathrm{C}$, an appropriate temperature correction should be applied. This was not necessary for the cask survey where the front of the instrument was 1 in. from the surface at about $25^{\circ} \mathrm{C}$. The neutron survey instruments can overrespond by a factor of 1.5 to 2 for neutrons with energies in the hundreds of kiloelectronvolts [based on CASTOR-V/21 and TN-24P cask results $(\underline{2}, \underline{3})$, the average energy on the surface of the cask should be between 150 to $200 \mathrm{keV}$ ]. They overrespond by a factor of 3 to 4 for 1 owerenergy neutrons; for $14-\mathrm{MeV}$ neutrons, they underrespond by a factor of about 3 .

\section{INEL CASK TESTING FACILITY}

The primary INEL facilities are shown in Figure 3-21. The spent fuel storage cask performance tests are being performed at the Test Area North (TAN) facilities. The TAN is a large, multipurpose testing and support area near the northern boundaries of INEL. Storage casks arrive at the INEL Central Facilities Area (CFA) by rail and are transported by heavy-haul transporter to the TAN facility where all fuelhandling and testing activities are performed.

\section{TAN-607 Facility}

The primary cask-testing facility is Building TAN-607 (Figure 3-22). This building includes several large shops: a high-bay hot shop area with unique capabilities for remote handling of highly radioactive materials involving either delicate and precise work or massive, industrial-sized operations; a water pit for interim storage of radioactive materials and components; a hot cell for observation and analysis of small radioactive objects, for disassembly and examination of fuel rods, and for fuel rod consolidation; and a high-bay warm shop for receipt, assembly, and testing. The two shops used for cask testing are the hot shop and warm shop at the north end of TAN-607 (Figure 3-23). In addition, a pad was constructed west of TAN-607 for long-term surveillance of the cask. 


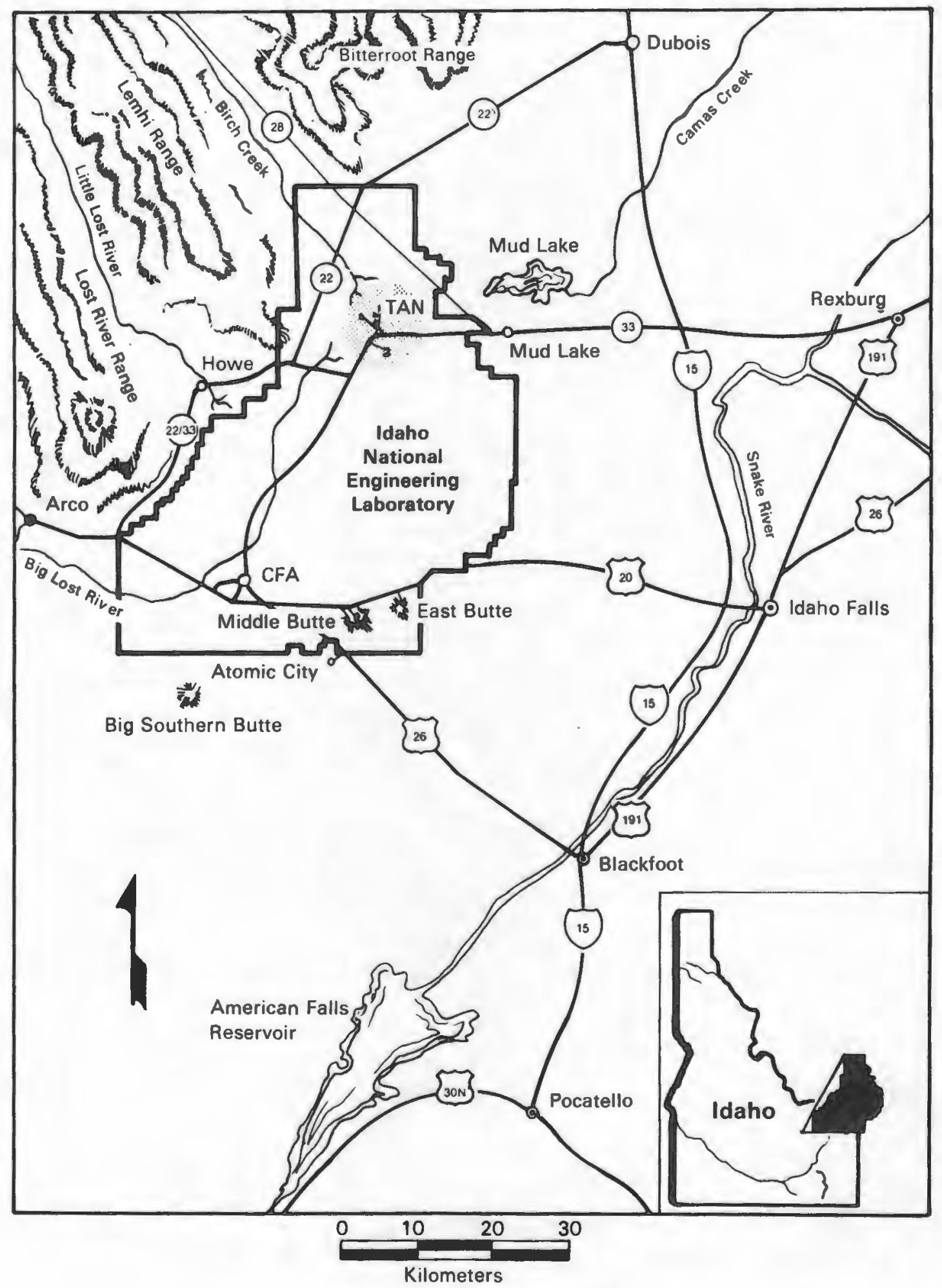

Figure 3-21. INEL Facility 
1. ن.scontamination

biti us Area

(iin!? al Room

4. . . ell Annex Gallery

$M_{12}$ ' lanical Equipment Room

1. Room

IV.1 er Pit Vestibule

i. . Jiated Fuel Storage Facility

$\$$. ith Turntable

iv th Silo

...oyrinth

- icility Vestubule

cot Shop Change Room

Hot Cell Contro

Hollery

Tot Cell Change

Decon Area
HP Storage

18
Counting Room-Spectral Lab $\quad 19$

Respirator Issue

Clothing Issue Room

Office

19
20
21

Record Storage Vault

\section{Storage Vault}

Radiography Facility

Radiography Film Lab

Instrument Repair and Storage

Lunch Room

Electric Shop

Equipment Room

Locker Room

Lavatory

Emergency Generator

Decontamination Change Room 34

Decontamination Room

23
24
25
26
27
28
29
30
31
32
33
34
35

Figure 3-22. TAN-607 Facility 


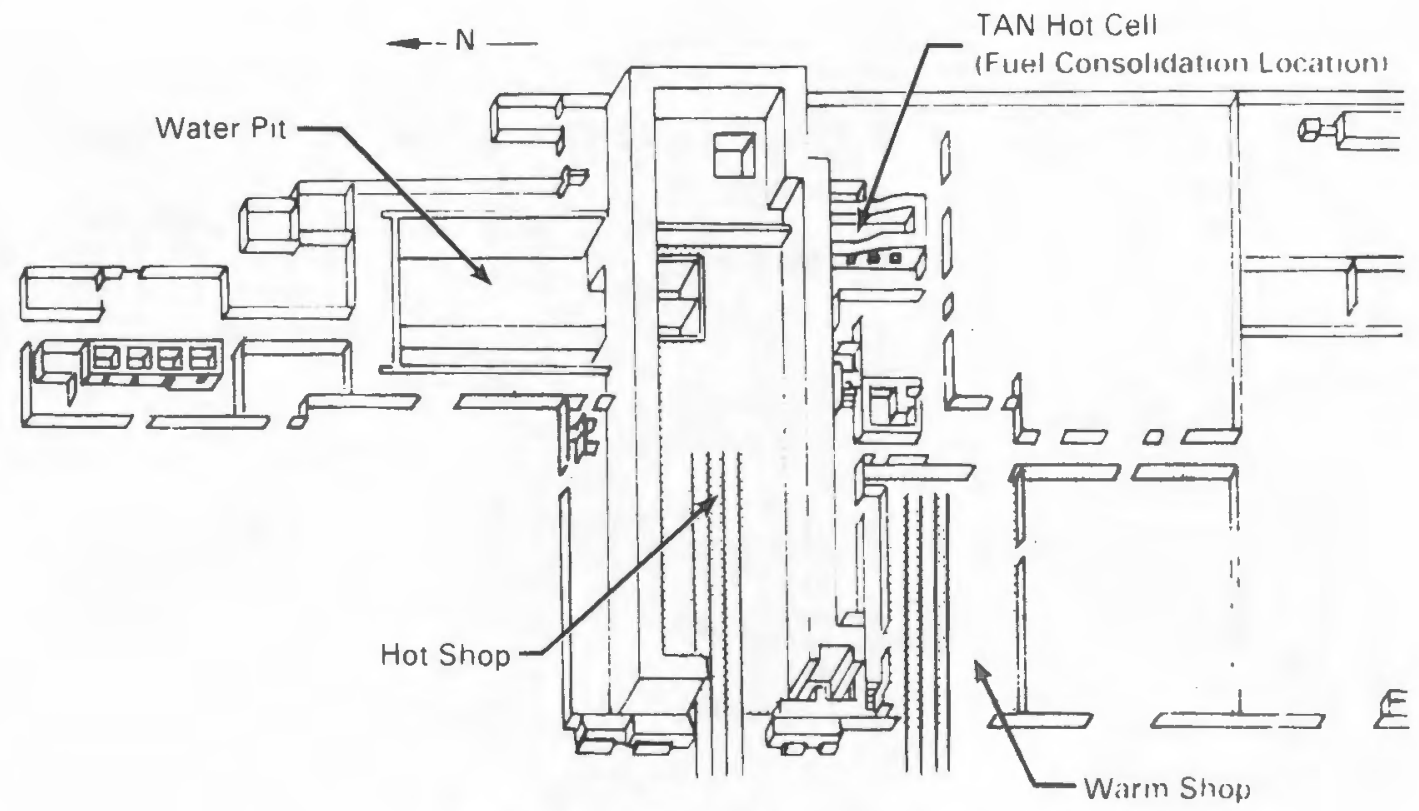

Figure 3-23. North End of TAN-607

TAN-607 Hot Shop. The TAN-607 hot shop shown in Figure 3-24 is a shielded cell designed for the remote handling of large radioactive components. The shop is $15.5 \mathrm{~m}$ (51 ft) wide by $48.8 \mathrm{~m}$ (160 ft) long by $16.8 \mathrm{~m}(55 \mathrm{ft}$ ) high and constructed with 2 -m-thick $(7-f t)$ concrete walls. Shielded viewing is provided by nine 1.8 -m-thick $(6-\mathrm{ft}) \mathrm{glass}$ windows. The main door to the hot shop is $8.5 \mathrm{~m}(28 \mathrm{ft})$ wide by $9.8 \mathrm{~m}(32 \mathrm{ft})$ high, allowing the entry of large vehicles including rail cars. The hot shop is serviced by a four-rail railroad system. The TAN hot shop is designed to a Uniform Building Code (UBC) Seismic Zone 2. The floor loading for the shop is $1222 \mathrm{~kg} / \mathrm{m} 2(250 \mathrm{lb} / \mathrm{ft} 2)$, but heavily concentrated loads can be located within the hot shop by positioning them over specific support areas. The ventilation system exhausts the hot shop air through prefilters, HEPA filters, and silver zeolite absorbers to a $45.7-\mathrm{m}(150-\mathrm{ft})$ stack. A negative pressure is maintained in the hot shop to ensure constant air flow into the shop. The hot shop is not a sealed alpha-containment facility. Appropriate hot and warm waste systems are provided in the facility.

The hot shop is served by a variety of remotely operated handling equipment as shown in Figure 3-25. The largest piece of equipment is the 100/10-ton bridge crane. The crane services the entire shop and has a maximum lift height of approximately $15.5 \mathrm{~m}$ (51 ft). A bridge-mounted overhead electromechanical manipulator can also cover the entire shop. The manipulator can 1ift a $272-\mathrm{kg}(600-1 \mathrm{~b})$ 1oad with its hand, and 


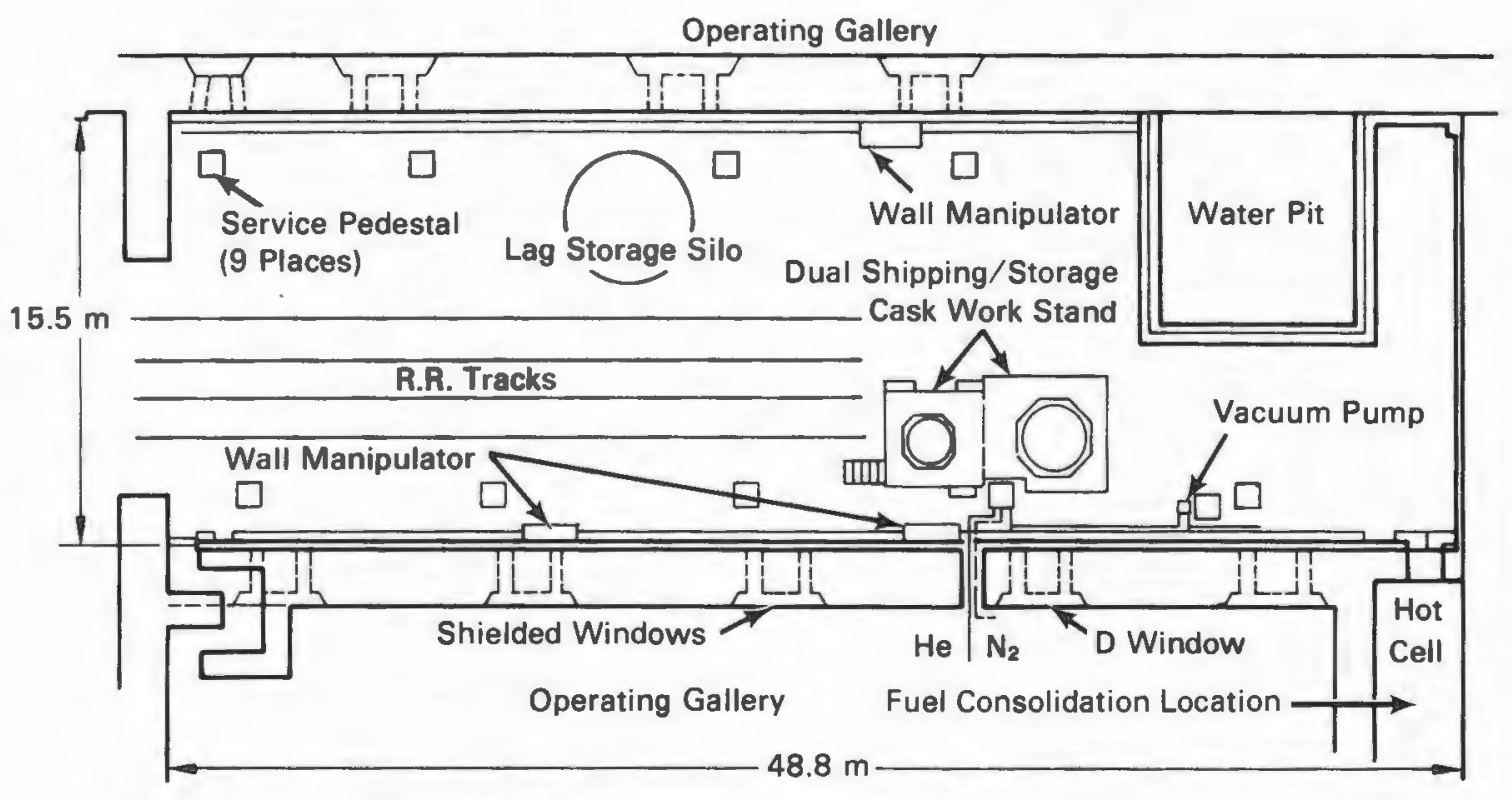

Figure 3-24. TAN-607 Hot Shop

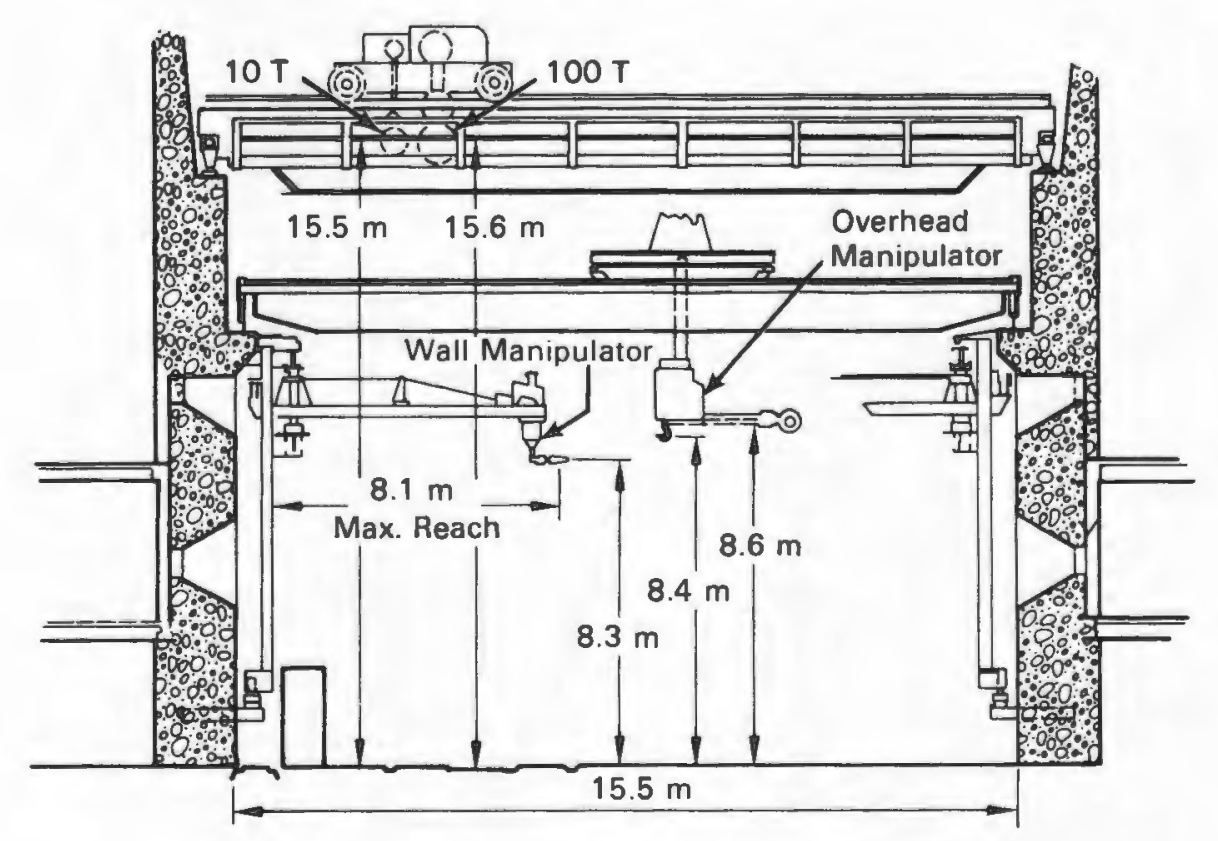

Figure 3-25. Elevation View of Hot Shop and Handling Equipment

has a shoulder hook capable of lifting $2270 \mathrm{~kg}(5000 \mathrm{lb})$ to a height of $9.1 \mathrm{~m}$ (30 ft). Three wall-mounted manipulators are installed for lighter-duty work. These manipulators can travel both horizontally and vertically [up to about $9.1 \mathrm{~m}$ (30 ft)] along the hot shop walls, and have jib booms that can be swung from the 
wall to the center of the shop. The shielded window in the northwest corner of the hot shop contains heavy-duty master-slave manipulators.

Service pedestals are located on the hot shop floor to provide all of the utilities normally used in the hot shop operations, including compressed air, oxygen, acetylene, demineralized water, raw water, electricity, telephone, and intercom. All are conveniently accessible via quick-disconnect couplings designed for remote manipulation. Remotely operated power tools are plugged into these service pedestals by the manipulators when needed. Pedestal "D" has been expanded to include helium and nitrogen gas supplies, a vacuum system to evacuate the casks, instrument hookups to a DAS, and electrical hookups for the video camera pan-tilt controls and light system.

Visual access to the hot shop is gained through a series of 1.8 -m-thick (6-ft) windows arranged and installed on either side of the shop and in two rows corresponding roughly to second- and third-story heights. Binoculars, mirrors, periscopes, remote microscopes, and closed circuit television are all used to enhance the visual observation and control of the remote functions within the hot shop. A control pedestal is located at each window for controlling the functioning of the crane and the pertinent manipulators. All of the stations on a given side and level are housed in a common "operating gallery."

A work platform was fabricated and installed below window "D" in the hot shop to contain a shipping and storage cask during fuel transfer (Figure 3-26). This platform was modified to also contain a mounting station for a strongback containing two fuel assemblies and a consolidated fuel canister. The strongback was used for transferring fuel assemblies to the hot cell for consolidation and for transferring the loaded canister from the hot cell to the workstand. The canister of consolidated fuel was removed from the strongback using the fuel assembly grapple and was loaded into the storage cask positioned in the workstand.

The working level of the platform is $4 \mathrm{~m}$ (13 ft) above the hot shop floor. The top of the cask is approximately $1 \mathrm{~m}(3 \mathrm{ft})$ above the platform's working level, thus allowing operators easy access to the cask lid bolts and gas connections.

The cask is placed into the work platform using a lifting yoke attached to the 100-ton hot shop crane (Figure 3-27). The work platform has a removable section of grating that permits side access, thus precluding lifting the cask above the 


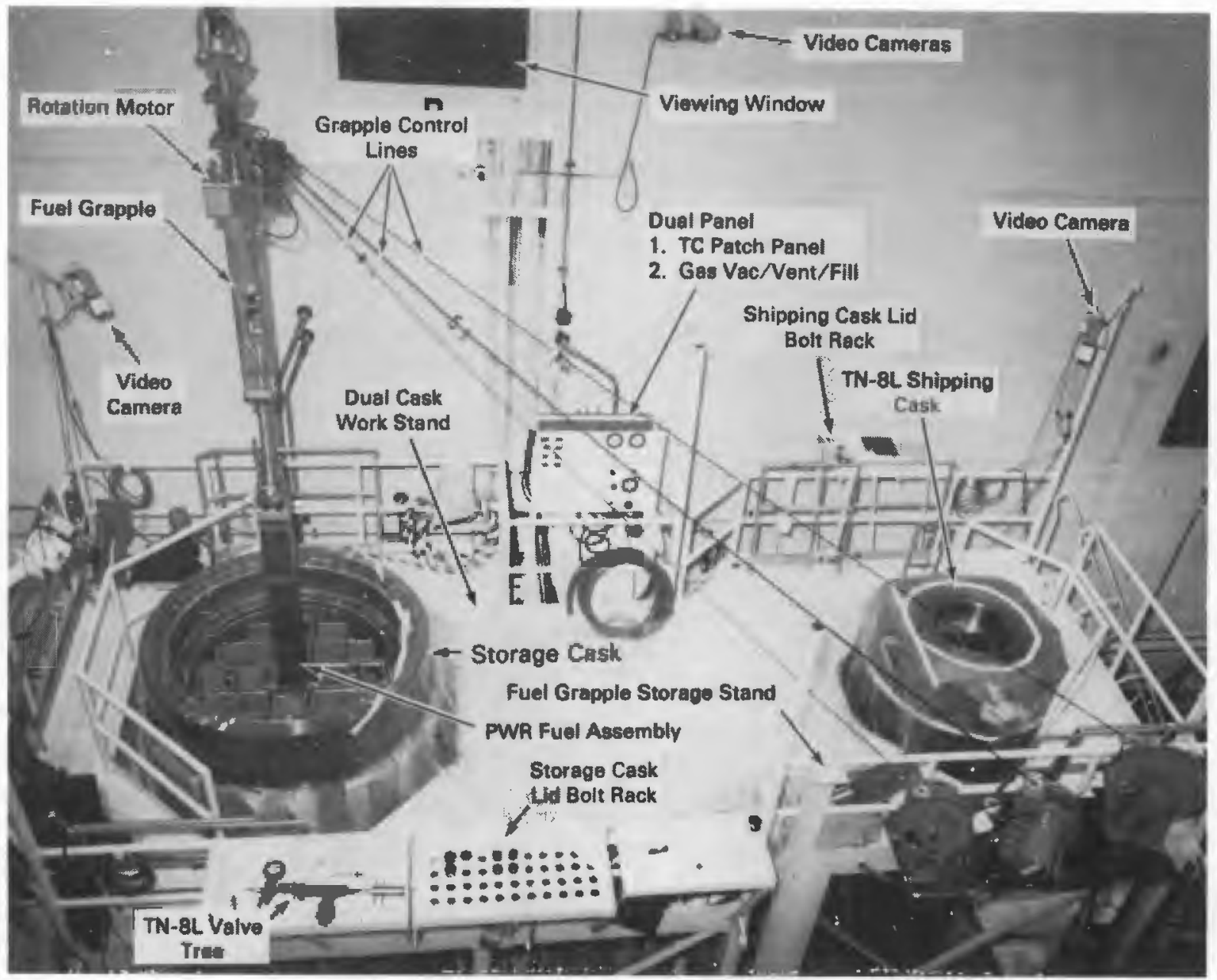

Figure 3-26. Dual Work Stand for Spent Fuel Transfers

platform's working level. The grating is removed and replaced using the 10 -ton hot shop crane and lifting slings attached to lifting lugs on the removable section.

Access to the working level is via a stairway located on the south side of the platform. A notch in the storage cask side of the platform allows easy access to utility pedestal "D" from the platform level.

The assembled work stand contains six posts that support TV cameras with a pan and tilt mechanism (Figure 3-26). Two cameras are mounted on the outer end of the shipping cask stand and two on the outer end of the storage cask stand. Mounts are also provided at the midsection of the assembly. The cameras are used for assisting operations with fuel transfer and for fuel assembly inspection. 


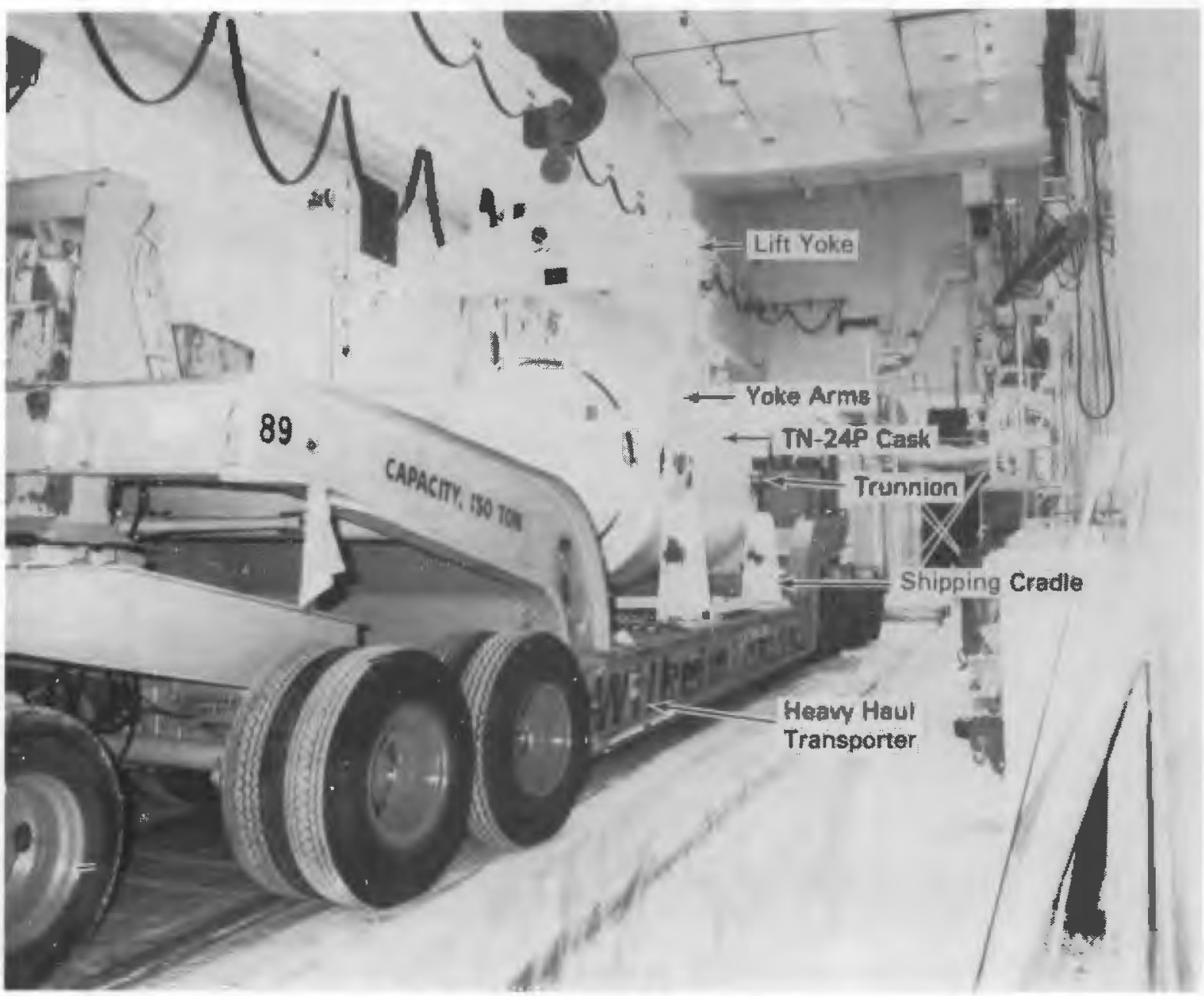

Figure 3-27. Cask with Lift Yoke Attached

The work platform also contains platforms for storing cask lid bolts and tool boxes, and for temporarily storing TC lances before and after installation into the casks (Figure 3-26).

IAN-607 Warm Shop. The TAN-607 warm shop is located south of the hot shop as shown in Figure 3-22. The warm shop is designed as a service area for handling test assemblies with low to medium radiation or contamination. It is currently used as an area for familiarization and training on casks upon receipt, instrumenting casks, and testing casks in a controlled environment. The warm shop is $15.5 \mathrm{~m}(51 \mathrm{ft})$ wide by $24 \mathrm{~m}(80 \mathrm{ft}$ ) long by $15 \mathrm{~m}(50 \mathrm{ft})$ high. It has a main door $8.5 \mathrm{~m}(28 \mathrm{ft})$ wide by $10 \mathrm{~m}$ (33 ft) high as shown in Figure 3-28. The warm shop is served by a 30/5-ton 


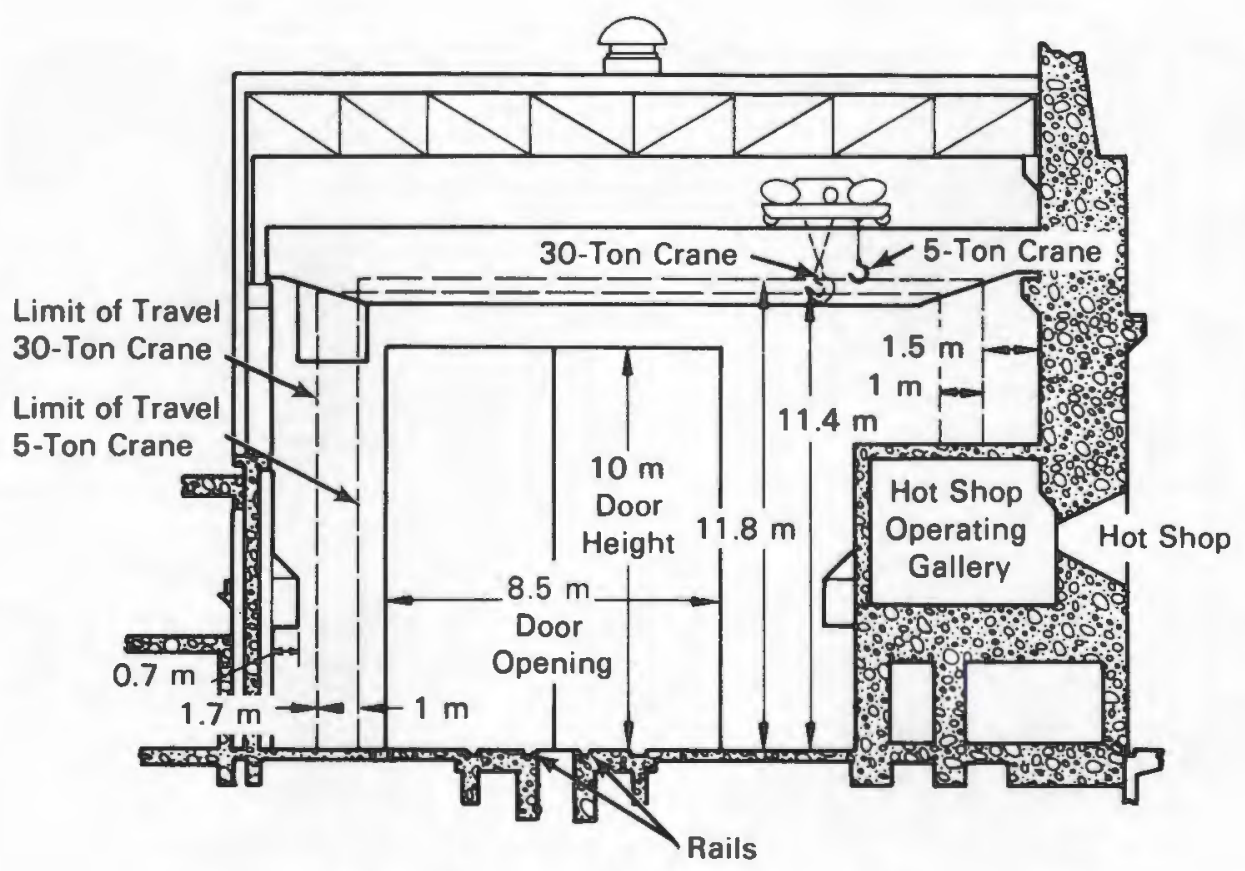

Figure 3-28. Elevation View of TAN Warm Shop

overhead bridge crane. The warm shop is designed to UBC Seismic Zone 2 requirements. The floor drains for the facility are connected to a hot waste holding tank.

The warm shop (Figure 3-29) was modified to include helium and nitrogen gas supply systems and a vacuum system for use in cask performance testing. These systems interface with corresponding hot shop systems. Two gas cylinder banks, one helium and one nitrogen, were installed against the north wall of the TAN warm shop. These banks supply gas to either the hot shop control panel at the work platform or the warm shop control panel that is also mounted on the north wall.

The warm shop control panel provides connection to a vacuum system. The vacuum suction line and a pressure relief line are routed from the control panel, out of the warm shop, and into the hot shop, where they join the hot shop systems. The control panel also provides a connection between an instrumented cask in the warm shop and the DAS located in the hot shop control room at "D" window.

A radiation shielding wall was added to the warm shop to protect personnel in adjoining hallways and change rooms from exposure when a loaded cask is being tested. 


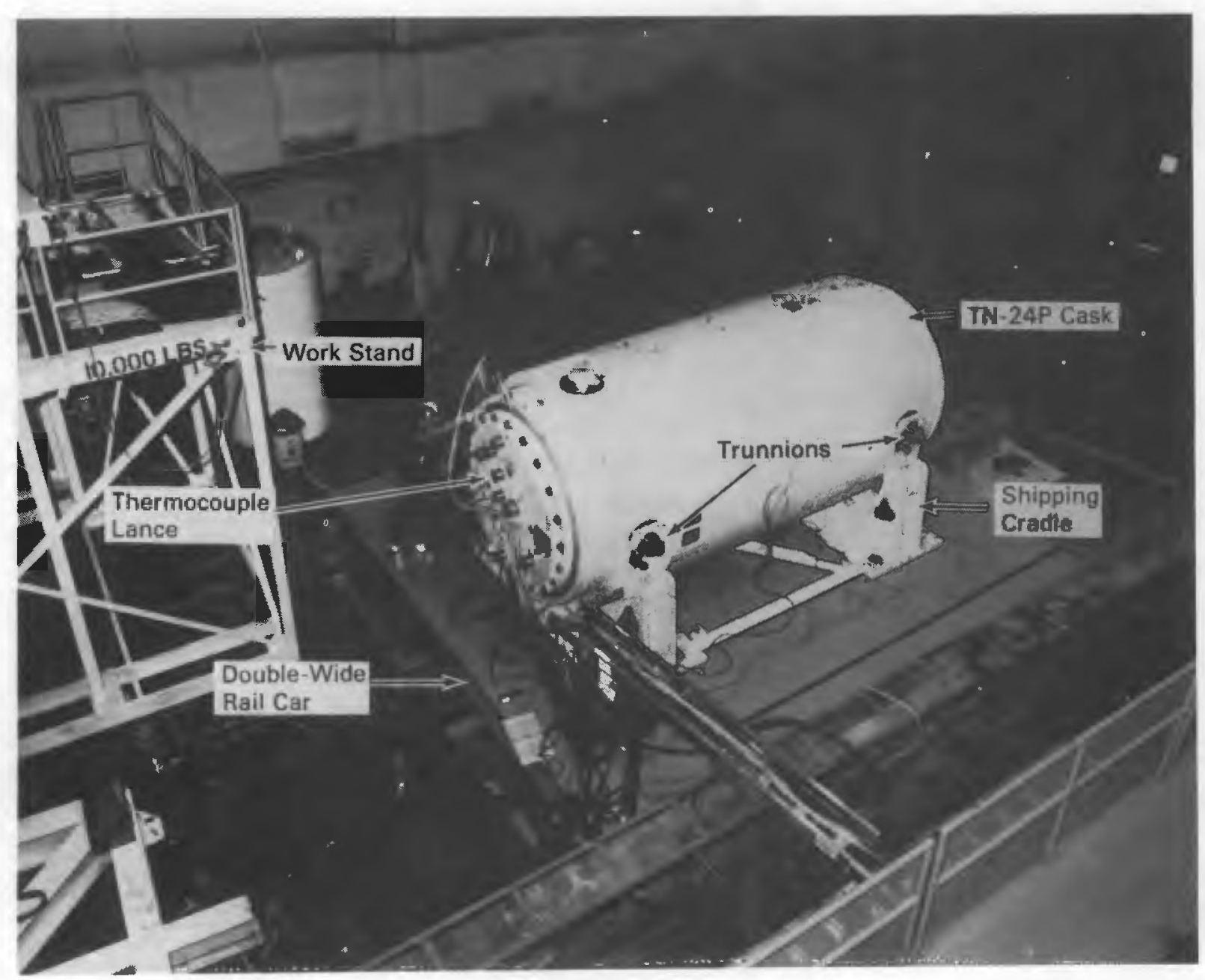

Figure 3-29. Warm Shop Test Area

\section{TAN Railroad System}

Casks are moved between the TAN hot shop and warm shop by a special shielded locomotive and rail-car dolly over a four-track standard gauge railroad system (Figure 3-30). A 27 -m-diameter (90-ft) turntable is located just west of the hot shop and pad in the four-track railroad system. Indicators for showing the position of the turntable, turntable alignment, controls for positioning the turntable, and turntable locking controls are located in the Turntable Control Building adjacent to the turntable.

The double-wide rail-car dolly used to move the casks was modified with a heavier underframe to support the weight of the storage casks (Figure 3-31). 


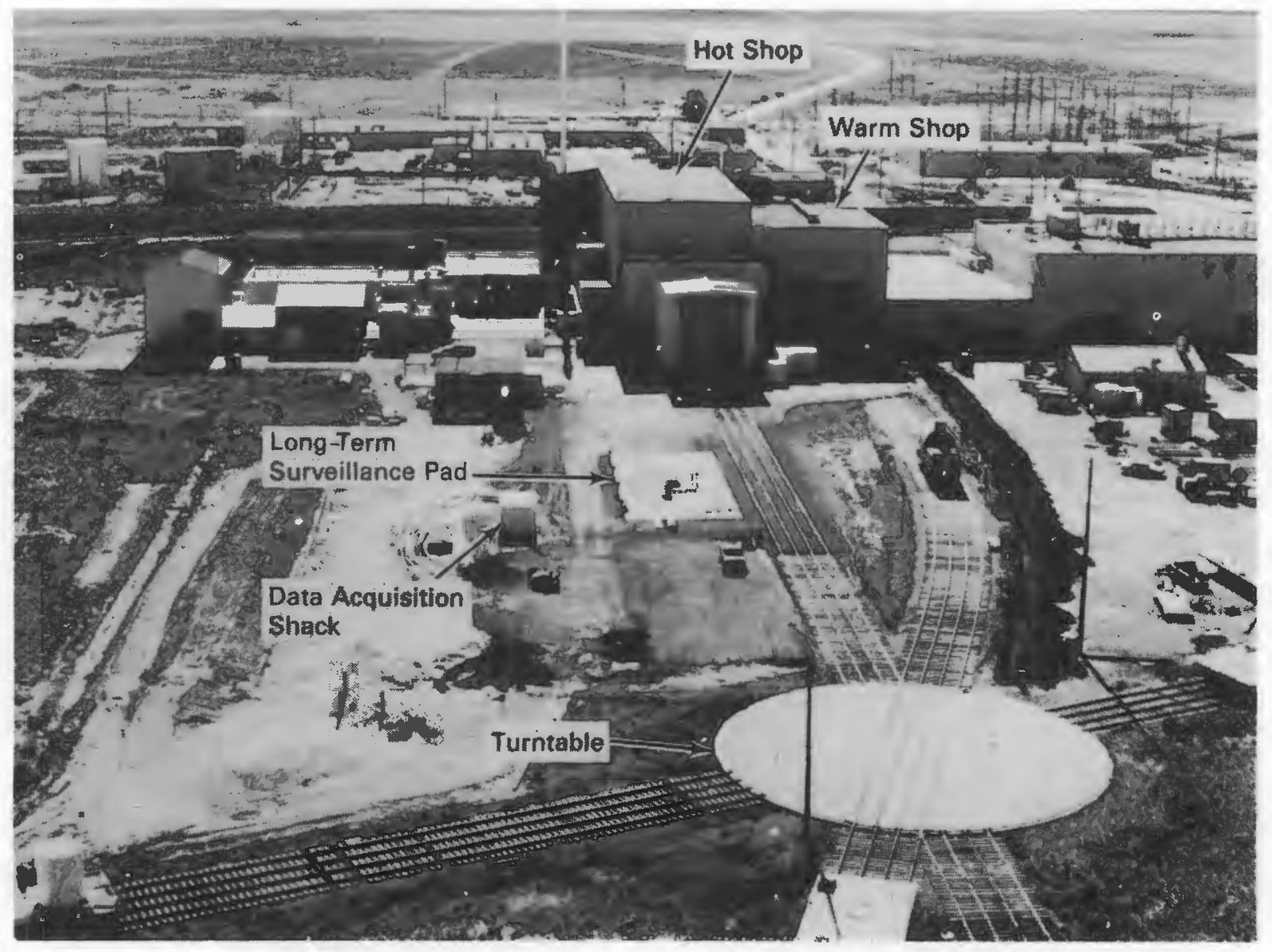

Figure 3-30. Hot Shop Complex and Four-Track Rail System

\section{Long-Term Surveillance Facilities}

Facilities for conducting long-term surveillance of the casks were constructed west of TAN-607. These consist of a concrete long-term surveillance pad, data acquisition building, and weather station. A special cask transporter is used to transport casks between the pad and TAN hot shop. The transporter and the TN-24P cask on the pad with the data acquisition building in the background are shown in Figure 3-32.

The long-term surveillance pad is located adjacent to the rail track that exits the TAN hot shop. It is sized to hold six spent fuel storage casks, four from the VP project and two from the Nuclear Fuel Services (NFS) project. The pad is 0.6-m-thick (2-ft) reinforced concrete, $28.7 \mathrm{~m}$ (94 ft) long by $12 \mathrm{~m}(40 \mathrm{ft}$ ) wide. An asphalt paved apron surrounds the pad to permit vehicle access. A fence will be constructed to limit access and provide radiation area exclusion after the casks are placed on the pad. 


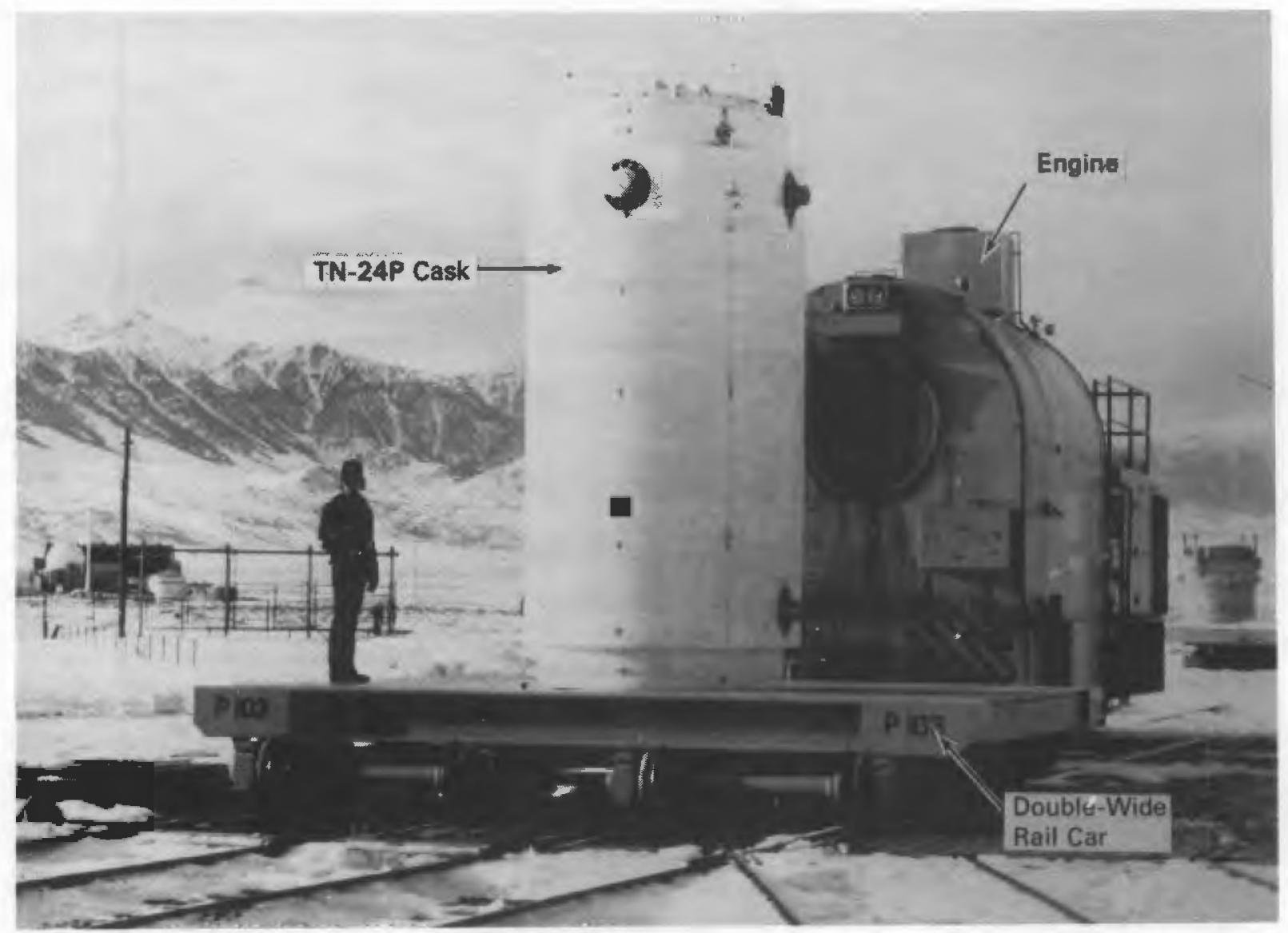

Figure 3-31. Moving TN-24P cask between hot shop and warm shop on modified rail-car dolly.

The data acquisition building rests on a small concrete pad near the test pad. The building, constructed of metal framework and siding, is $3.35 \mathrm{~m}$ (11 ft) square by $2.75 \mathrm{~m}(9 \mathrm{ft}) \mathrm{ta} 11$. Instrumentation leads pass through underground conduit from the pad to the building. Inside the building are a Keithley DAS with an IBM XT personal computer. The PC will be used for storing and reporting monitored data. The building is heated during winter to protect the electronic equipment.

The weather station is located adjacent to the data acquisition building. The smal1, self-contained unit measures wind speed and direction, air temperature, relative humidity, and solar insolation. Instrument cables connect the weather station to the DAS. 


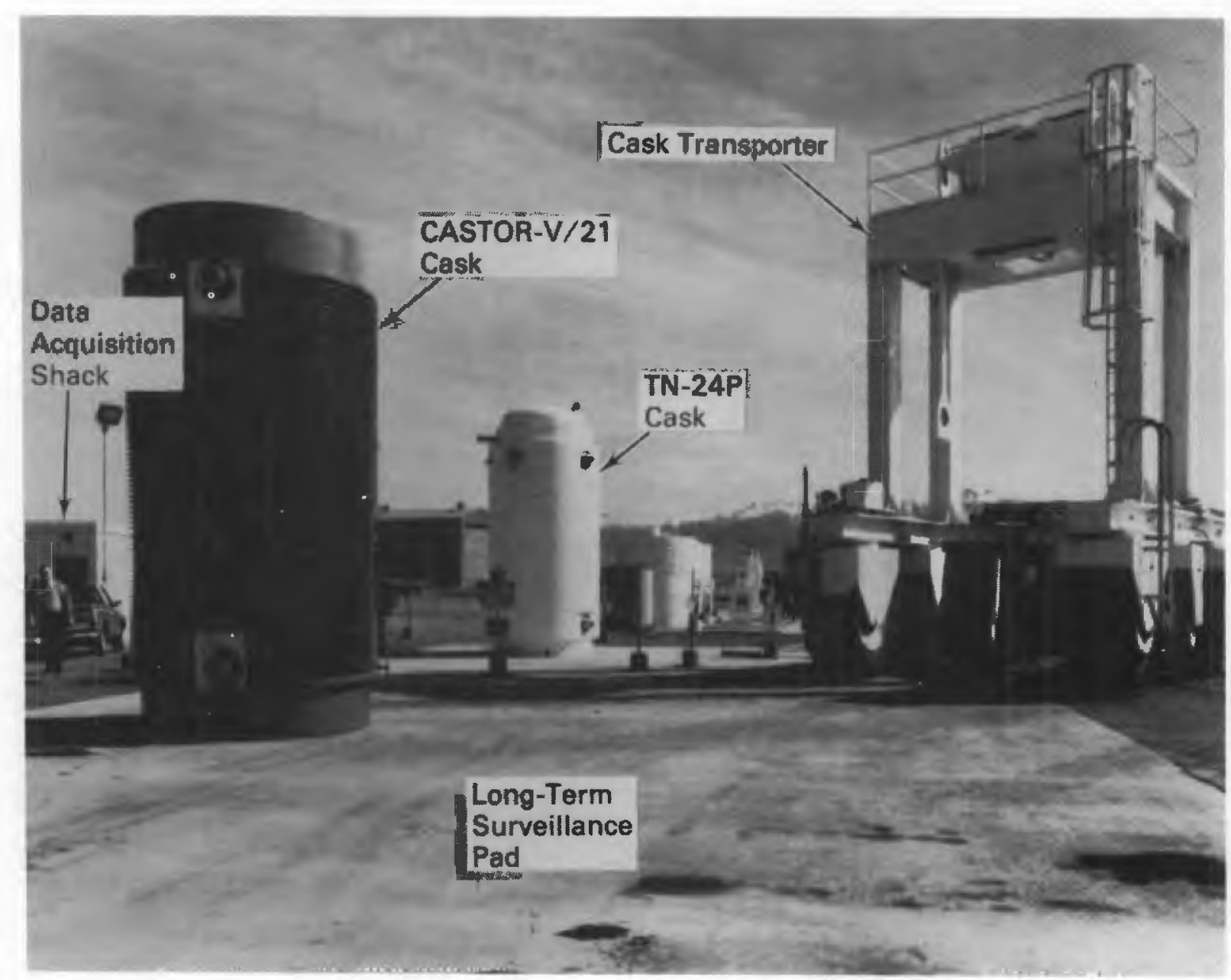

Figure 3-32. TN-24P cask on long-term surveillance pad with adjacent data acquisition system building.

\section{TEST PLAN}

The TN-24P cask performance test consisted of the seven runs indicated in Table 3-5. The test runs involved a fully loaded cask (24 spent fuel canisters), three backfill media (helium, nitrogen, and vacuum), and two cask orientations (vertical and horizonta1). A test plan specified the order of the runs, the fuel assembly load pattern (see Figure 3-18 in Fuel Assembly Section), instrumentation/measurement locations, calibration requirements, and gas and crud sampling intervals. The test plan also addressed cask-handling and fuel assembly characterization activities that were required before, during, and after performance testing.

Consolidated canisters of fuel from the dry rod consolidation program at INEL were loaded into the TN-24P cask, displacing the unconsolidated fuel that was in the cask 
Table 3-5

CASK PERFORMANCE TEST MATRIX

\begin{tabular}{cll}
$\begin{array}{c}\text { Run } \\
\text { Number }\end{array}$ & \multicolumn{1}{c}{$\begin{array}{c}\text { Cask } \\
\text { Orientation }\end{array}$} & \multicolumn{1}{c}{$\begin{array}{c}\text { Backfill } \\
\text { Medium }\end{array}$} \\
\cline { 1 - 1 } 1 & Vertical & Heliumb \\
2 & Vertical & Nitrogen ${ }^{b}$ \\
3 & Vertical & Vacuum \\
4 & Horizontal & Heliumb \\
5 & Horizontal & Nitrogen $b$ \\
6 & Horizontal & Vacuum \\
7 & Horizontal & Vacuum-Insulatedc
\end{tabular}

\begin{abstract}
aA11 runs were performed with a fully loaded cask (24 canisters). The total predicted cask heat load was $23.3 \mathrm{~kW}$ at the beginning of the month-long test and $23.1 \mathrm{~kW}$ at the end of the test.

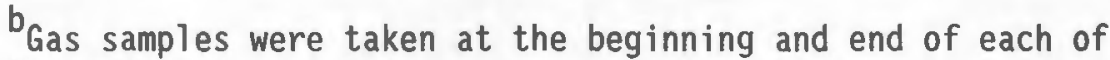
these test runs.

${ }^{\mathrm{C}}$ Sponsored by Transnuclear, Inc. and Transnucleaire (France).
\end{abstract}

from a previous performance test $(\underline{3})$. The fuel assemblies consolidated were Westinghouse $15 \times 15$ PWR from the Surry and Turkey Point Nuclear Power Stations.

Before it was consolidated, the fuel had been stored in the TN-24P and MC-10 storage casks and in the lag storage silo at TAN. Three thermocouples attached to the cask's basket were used to monitor internal temperatures during the loading process. Once the TN-24P storage cask was fully loaded, nine TC lances were inserted through the test lid into guide tubes placed in selected fuel canisters and basket locations. The cask was then moved from the hot shop to the warm shop on a double-wide rail car. Instrumentation leads were connected to appropriate sensors, and the test matrix shown in Table 3-5 was completed. 
The fuel assembly load pattern used during testing was previously shown in Figure 3-18. The load pattern maintained $1 / 8$ symmetry in the cask, to evaluate temperature and dose rate symmetry and to simplify the analytical modeling effort.

The test plan required that gas samples be taken shortly after the cask was filled with a different gas, and immediately before a gas was evacuated from the cask. The gas samples obtained during the test are indicated in Table 3-5. Each time the cask backfill medium was changed, the cask was pumped down, backfilled with the desired medium, pumped down again, and finally backfilled. This ensured purity of all backfill media to $>99 \%$. Nitrogen was used immediately prior to vacuum test runs to obtain a low-pressure (1- to 3-mbar), low-conductivity, vacuum/nitrogen environment.

The test plan formed the basis for developing a set of detailed operating procedures by INEL that outlined the steps required to perform the cask performance test. The procedures are discussed in the next section.

\section{INEL CASK-HANDLING AND OPERATING EXPERIENCE}

This section describes the cask-handling and operating experience gained during cask performance testing with consolidated fuel. The tasks required to conduct cask performance testing included performing storage cask-handling studies, assessing the use of existing facilities and equipment, installing cask ancillary and research equipment at the INEL TAN cask-testing facility, operation preparations, storage cask preparations, operational dry runs, a facility readiness review, fuel transfers and loading, cask performance testing, fuel assembly inspections, and long-term surveillance. INEL personnel performed a dry run to train personnel and check out equipment.

The cask was loaded with consolidated canisters as part of the consolidation process. A typical consolidation cycle included the following basic steps:

1. Two unconsolidated fuel assemblies and one empty canister were taken from storage in the hot shop to the consolidation equipment in the hot cell.

2. Through a series of manually and automatically controlled operations, the top end box of the first unconsolidated assembly was removed and the fuel rods were individually pulled from the assembly and placed in the canister.

3. The fuel rods from the second assembly were similarly placed in the canister.

4. The canister lid was locked in place. 
5. The loaded canister, skeletons (fuel assemblies without fuel rods), and the top loose end boxes were rerioved from the hot cells and taken to the hot shop.

6. The skeletons and end boxes were placed in the TAN water pit for storage.

7. The full canister was loaded into the TN-24P cask.

This sequence was repeated for a total of 24 cycles. After the cask was fully loaded with fuel, it sat idle until the crane had been upgraded to permit lifting it. The cask was then transferred to the warm shop tes $i$ bay where formal testing began.

At the conclusion of the formal testing in the warm shop, the TN-24P cask was moved to the hot shop, where it was prepared for temporary storage and monitoring. The cask was then placed on the long-term surveillance pad and connected to the data collection system.

Each of the tasks required to conduct the TN-24P cask performance testing is described in the following subsections.

\section{Storage and Shipping Cask-Handling Studies}

A detailed cask-handling study was performed to develop the handling logic for the TN-24P storage cask. This study took advantage of previous experience with this cask gained during an earlier performance test involving the TN-24P cask and unconsolidated PWR spent fuel. The major handling difference between this test and the previous test was the increased weight of the consolidated fuel. The study concluded that no significant changes were required to handle the heavier load.

\section{Facilities and Equipment}

Existing TAN equipment and facilities developed for previous cask tests were used. Equipment systems located in the TAN 607 hot shop that were evaluated included the hot shop crane, cask gas/venting system, and facility safety support systems. Equipment and systems evaluated outside the hot shop were the local in-plant rail track, turntable, locomotive, and the warm shop capability for cask testing. These base facility systems and equipment were previously discussed in the section on the INEL cask-testing facility and required virtually no modification.

Two types of project-specific equipment were identified: cask test support and cask-handling/operation equipment. Cask test support equipment was that required to 
gather test data. It consisted of the gas/vacuum/vent system and the data acquisition system. Cask-handling/operation equipment was that required to handle the cask, such as lift yokes, cask lid lifting fixtures, cask surface seal protectors, the cask gas/vacuum/vent valve tree, pressure transducer, and digital readout. Thermocouple lance insertion was closely reviewed. Special semiremote insertion tools were developed to reduce personnel radiation exposure and contamination spread during lance installation and removal.

Both base and project-specific equipment were operationally tested before they were actually used in cask-testing operations. The equipment was tested by an independent, formal system-operation test. When problems were encountered, they were resolved, and the equipment or system was retested.

\section{Operational Preparations}

Operating documentation was developed, personnel were trained, and the TN-24P storage cask was moved from the storage pad to the TAN hot shop for the Dry Rod Consolidation Technology (DRCT) program. A facility readiness review, held prior to the first storage cask test (CASTOR-V/21 cask performance test), approved the facility for cask testing. No formal readiness review was held for the TN-24P cask test.

Documentation Development. Site Work Releases (SWRs) or Hot Cell Work packages controlled all operating tasks performed at the facilities. The SWR work, general work using craft labor, does not require rigorous step-by-step control and review. It usually involves equipment calibration or maintenance. Hot Cell Work packages identify the tasks or subtasks required to accomplish a specific scope of work, and delineate a specific sequence for facility operating tasks. These work packages usually contain one or more detailed operating procedures (DOPS), which are step-by-step instructions for performing a specific task. The SWRs, work packages, and DOPs are controlled documents. As such, they must be revised and approved, should a work step need changing.

The overall project statement of work and the TN-24P test $p 1$ an were used to develop this operating documentation. Information for preparing the procedures came from the cask vendor, safety analysis, equipment drawings, and operating and maintenance manuals. Safety, quality, project, independent safety, and operations personnel rigorously reviewed these work packages and DOPs. 
Hot Cell Work packages were prepared to provide operating instructions for the operating personnel. The first work package provided instructions for cask loading during the DRCT program. The second package instructed personnel in performing the cask test. A third work package provided instructions for removing the TC lances and preparing and moving the cask to the Spent Fuel Storage Cask (SFSC) pad. Detailed Operating Procedures used for handling, operating, and testing the TN-24P dry fuel storage cask are listed in Table 3-6.

A document control office managed the release and change control of the cask operating and safety procedures and documents. The document control office maintained the facility operating project, research data, research photographs, project equipment, and operating cost and schedule files.

Operational Training. The INEL Test Engineer provided operation technicians and supervisory personnel with a refresher personal training session on the TN-24P testing before the beginning of the cask tests.

Operational Dry Run. An operational dry run was performed in the hot shop to train personnel and check out the operating facility, DRCT project-specific equipment, and procedures.

\author{
Table 3-6
}

DETAILED OPERATING PROCEDURES FOR TN-24P PWR CONSOLIDATED

FUEL CASK PERFORMANCE TESTING

DOP NO. Titie

1.13.59 TAN SFSC PROGRAM - Install TC Lances in TN-24P Cask and Leak Check

1.13.15 TAN SFSC PROGRAM - Move TN-24P Storage Cask to Warm Shop/Hot Shop for Consolidated Tests

1.13.62 TAN SFSC PROGRAM - TN-24P External TC Installation, TC Wiring Verification and Dose Rate Measurements

1.13.36 TAN SFSC PROGRAM - TN-24P Cask PWR Consolidated Fuel Vertical Test Matrix Runs No. 1, 2, and 3 (revised $1 / 7 / 88$ )

1.13.37 TAN SFSC PROGRAM - Rotate TN-24P Cask to Horizontal (Revised 1/21/88)

1.13.38 TAN-SFSC PROGRAM - TN-24P Cask Horizontal PWR Consolidated Fuel Test Matrix Runs (Revised 1/26/88) 
The dry run began with the TN-24P in the hot shop (Figure 3-33). Although the actual procedure would ensure that all personnel were evacuated from the hot shop, certain personnel remained in the hot shop for the dry run to observe the operation. However, they did not assist any of the remote operations. During the dry run, different operating technicians repeated the following handling sequences several timès:

- connecting the crane to the fuel grapple and attaching the grapple to the mockup fuel assembly

- $\quad$ placing and removing the mockup fuel assembly into the DRCT strongback carrier (SBC) to simulate fuel assembly loading and canister removal

- transferring the $S B C$ to and from its vertical support stand using a lift bail and crane.

During these operations, the fuel grapple load cell was monitored closely to prevent the possibility of hanging up the fuel assembly, which could cause the grapple

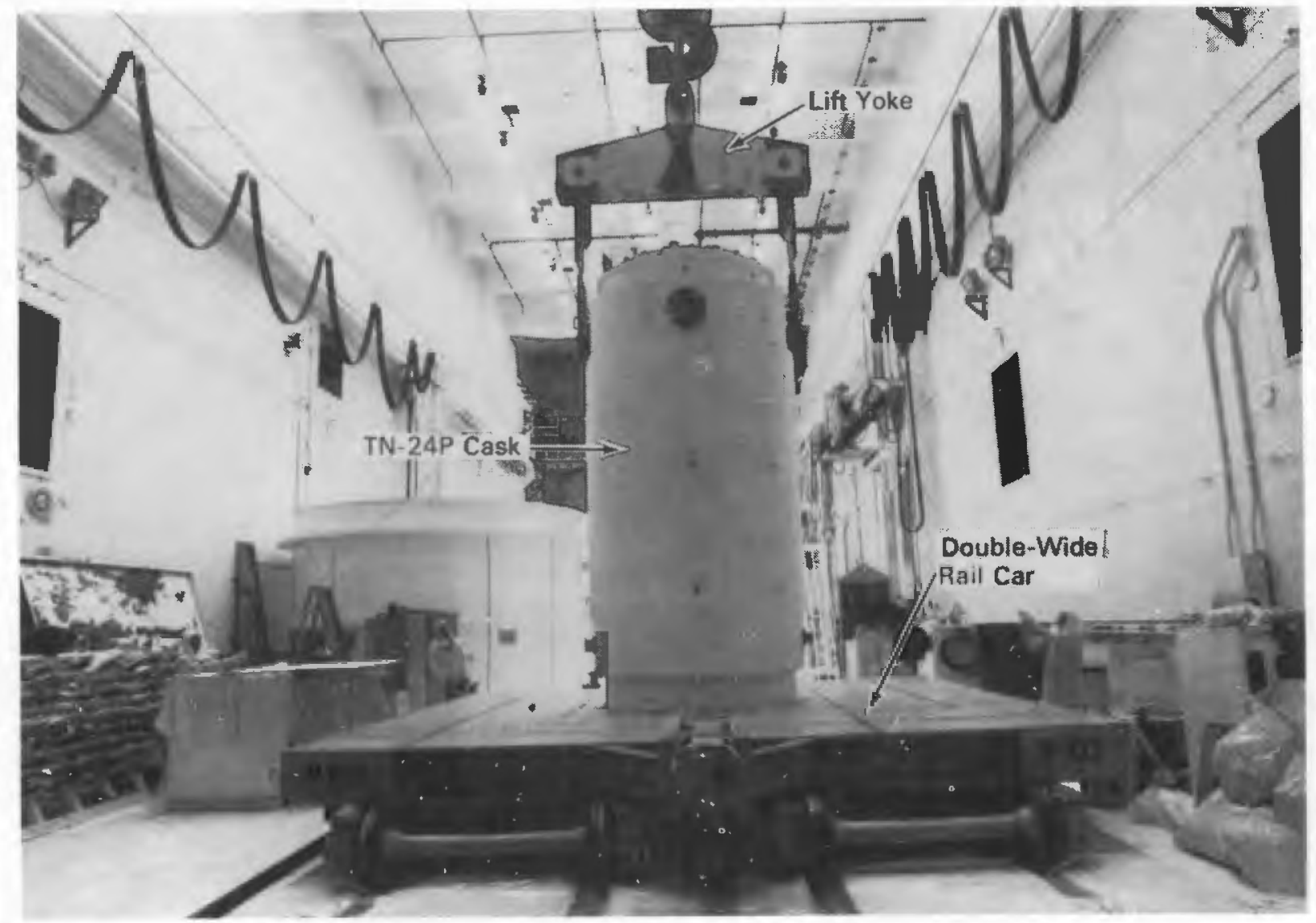

Figure 3-33. TN-24P Cask in Hot Shop 
system to fail. After technician training on the strongback carrier was completed, the mockup fuel assembly and grapple were returned to their storage racks.

\section{Fuel Transfers and Loading}

The TN-24P storage cask was loaded with consolidated fuel from May to October 1987. Loading consolidated fuel into the TN-24P cask was routine, and no problems were encountered. The fuel transfers and loading followed the procedures verified during the dry run. The loading, vacuum pumpdown, and decontamination operations and experience are discussed in this section. Personnel radiation exposure levels estimated to have occurred during fuel transfers, loading, and testing are also presented.

Cask Loading. A gas sample was taken each time before removing the cask 1 id, to ensure that no fission product gases were released.

TN-24P cask surface temperatures reached $65^{\circ} \mathrm{C}$. Therefore, Teflon sheeting with a high melting point replaced the standard polyethylene sheeting. The sheeting served as a barrier to prevent storage cask contamination. The sheeting was attached to the cask with Teflon tape. The seams were loosely overlapped and taped.

To prevent other top surfaces of the work platform near the cask from being contaminated, the following arrangement was used. Teflon sheeting was attached to areas contacting the cask. Polyethylene sheeting was taped to the Teflon at a safe distance from the cask. The contamination barrier also acted as a thermal barrier, preventing some heat transfer from the cask. However, the contamination barrier was used only while the cask was being loaded. It was removed during formal thermal cask testing.

The TN-24P storage cask operations were very satisfactory. Cask-handling and consolidated fuel canister loading operations were performed without difficulty.

Vacuum Pumpdown. A valve tree connected to a cask monitoring port allowed cask vacuum pumpdown and gas backfilling. The valve tree was connected by quickdisconnects and vacuum hose to the gas/vacuum/vent system. A pressure transducer, teed into the valve tree, monitored cask cavity pressure.

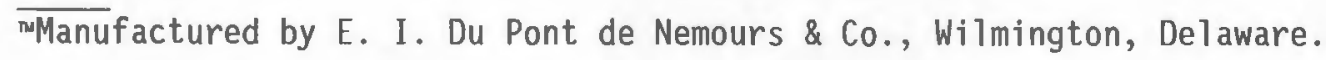


The cask vacuum pumpdown system required approximately 0.5 to $1.0 \mathrm{~h}$ to pump down the cask from 850 mbar atmosphere pressure (12.25 psi) at $1463 \mathrm{~m}$ (4800 ft) elevation to less than 1 mbar $(0.01$ psi). Backfilling the cask with cover gas required approximately $15 \mathrm{~min}$.

Decontamination. Contamination spread was not a major problem during the fuel assembly and canister air transfers between the silo, storage casks, and SBC.

Estimated Personnel Radiation Exposures. During the 9 months personnel were loading and testing the TN-24P cask, operational radiation and temperature monitoring were performed. The monitoring provided current actual data for personnel safety. Temperatures and radiation increased with each fuel loading, and more personnel safety equipment was used. A combination of materials was used to reduce personnel exposures on top of the cask for lid bolt removal, lance installation, and gas samples.

Thermal blankets were placed on the top and down the sides of the cask to reduce the effect of the high-temperature hazards. Blankets for thermal insulation were $0.61 \mathrm{~m}$ $\times 1.2 \mathrm{~m} \times 2.5 \mathrm{~cm}(2 \mathrm{ft} \times .4 \mathrm{ft} \times 1 \mathrm{in.})$ thick. Borated poly sheets, $2.5 \mathrm{~cm}$ thick (1 in.), were used for neutron shielding, and 1.27-cm-thick (1.5-in.) lead wool blankets provided gamma shielding. This loose-laid protective material was repositioned as required for access to different cask penetrations and for $1 \mathrm{id}$ bolt installation. When it was not practical to use shielding, every effort was taken to reduce personnel exposures by reducing time in the radiation field. Personnel radiation exposures during the handling, loading, and testing of the TN-24P cask were:

- fuel handling and loading - 0.3 man-rem

- TC lance installation and removal - 0.4 man-rem

- cask handling - 0.2 man-rem

- $\quad$ testing (instrumentation) - 0.3 man-rem.

Loading and testing the cask required extensive hands-on operation. For example, thermal testing, radiation dose rate monitoring, multiple gas backfilling, and sampling were hands-on operations. These operations were performed to support the cask performance test, but they would not be required for commercial power plant underwater fuel loading. Hence, radiation exposures under actual storage scenarios would be much lower than those encountered during this cask performance testing effort. 


\section{Cask Performance Testing}

Basket temperature data were taken during cask loading. This was done to ensure that fuel would not exceed maximum allowable temperatures during the cask loading and to obtain early cask heat transfer data. The preliminary data ensured that fully loaded cask surface temperatures and fuel temperatures would not exceed allowable values.

A TC lance was installed after loading of the twentieth canister to collect fuel temperature data using the TC lance inserted through a penetration in the test lid and into the guide tube of a selected fuel canister (Figure 3-34). The TC 1ance was connected to the DAS. The DAS collected temperature and pressure data during cask pumpdown and interim storage between fuel loadings. The collected data were transmitted to PNL. Cylindrical spacers, $13 \mathrm{~cm}(1 / 2 \mathrm{in.})$ long, were placed between the TC lance flange and the cask test lid to permit proper installation.

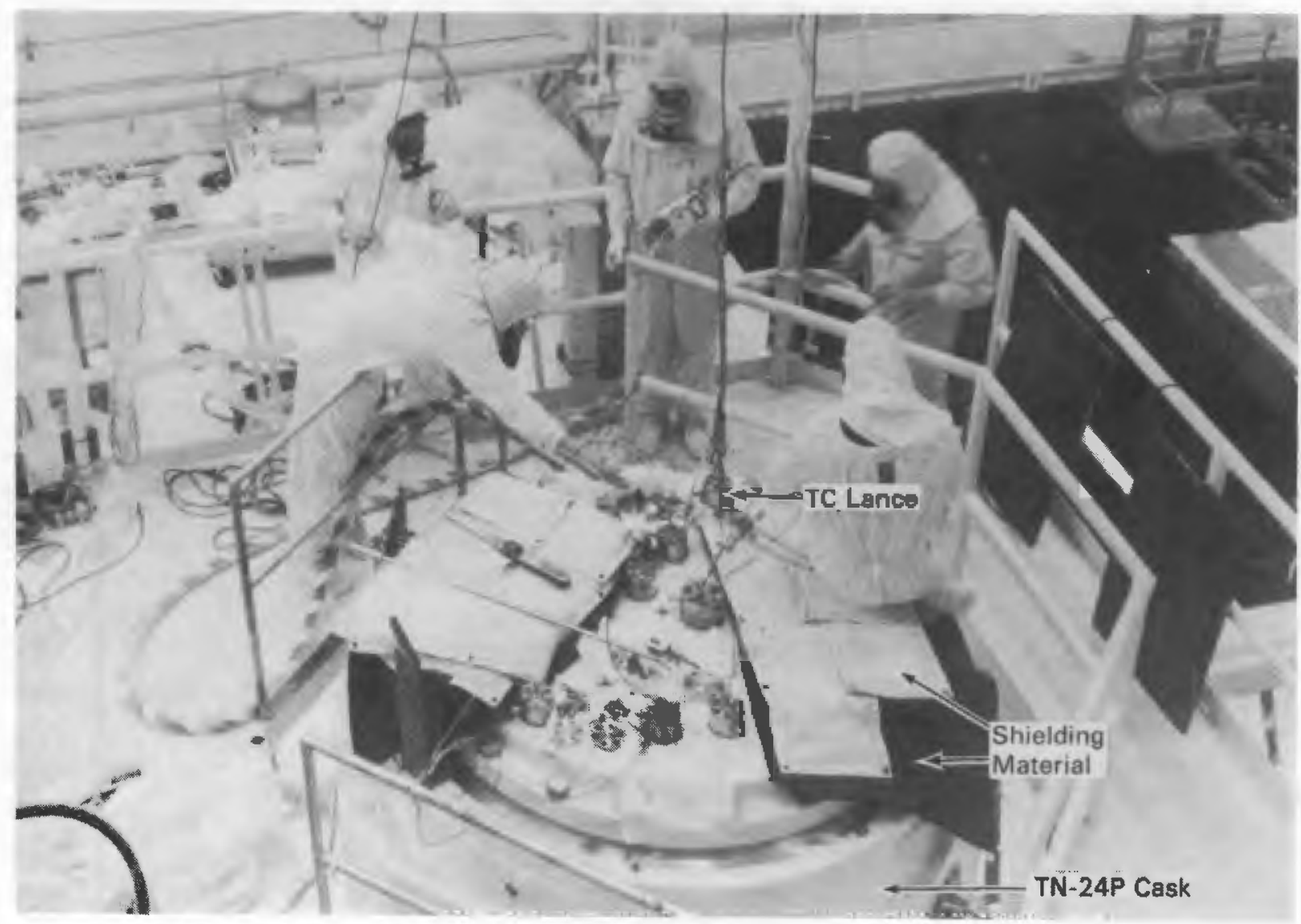

Figure 3-34. Installing thermocouple lances into the fuel assembly guide tubes through the TN-24P test lid. 
When the TN-24P storage cask was fully loaded, it was tested according to the approved test plan. The test 1 id was bolted on. Operations personnel installed nine TC lances through the test lid into seven fuel canister guide tubes and two basket locations. The cask was pumped and backfilled with helium cover gas. The test lid cover and penetrations were leak-checked to ensure proper sealing. The cask was then moved into the warm shop test bay (Figure 3-35), where it was externally instrumented with TCS at predetermined locations (Figures 3-9 and 3-10). A11 TCS and the pressure monitor were connected to the DAS. The cask was then pumped down and backfilled with helium cover gas. A gas sample was collected and sent to the INEL Chemical Processing Plant for analysis to ensure cover gas purity.

The cask was already near the equilibrium temperature because of heat buildup during the cask-loading period. Only a short period was required to reach the peak equilibrium temperature. Monitoring continued for at least $24 \mathrm{~h}$ after steady-state

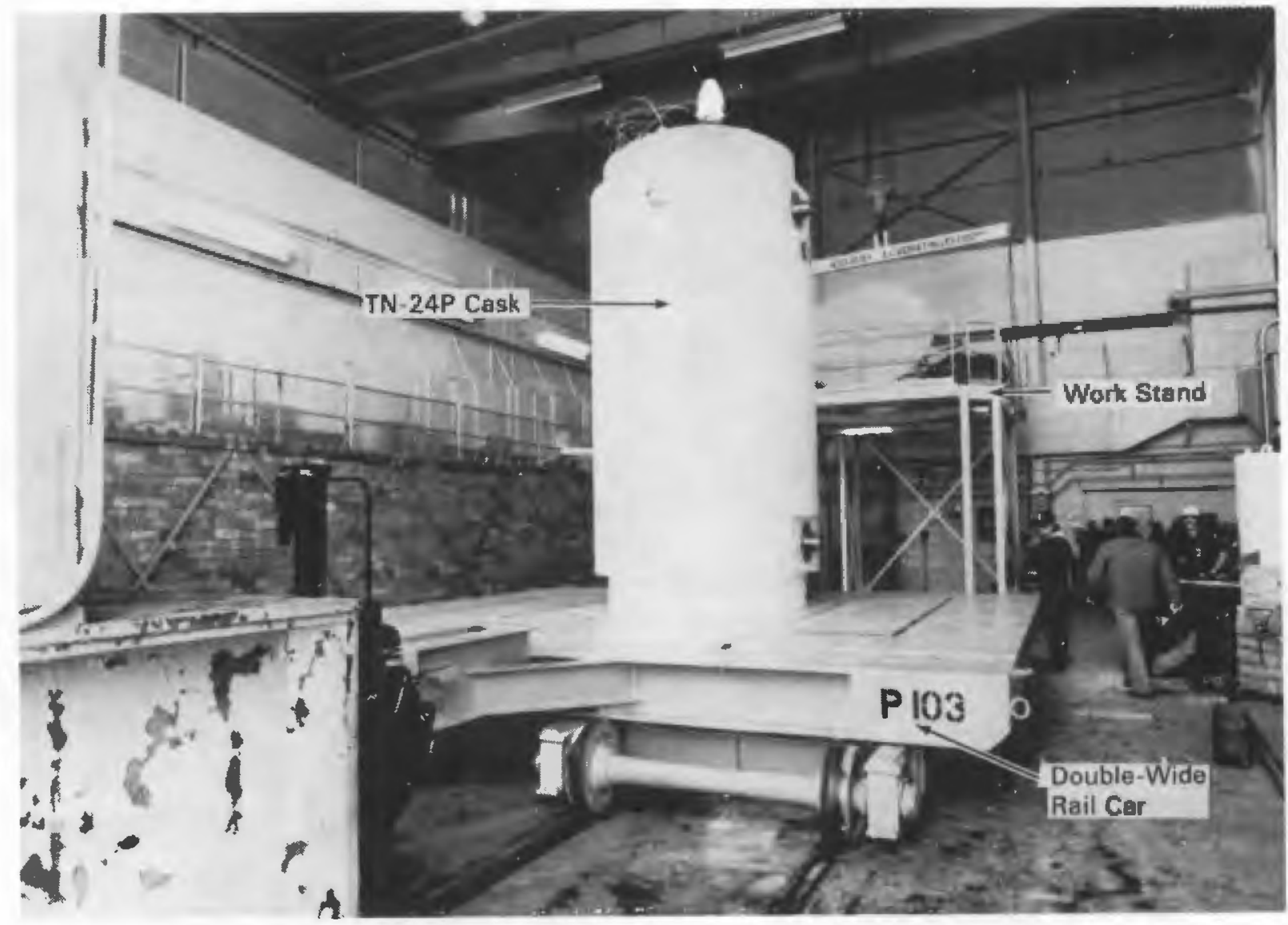

Figure 3-35. TN-24P Cask Being Moved to the Warm Shop Test Bay 
temperaiures had been reached, to verify that the peak temperature had been obtained. Cask cavity gas post-test samples were taken at the completion of the test run.

Once the vertical helium test run data had been verified, the cask cover gas was changed to nitrogen. Gas samples were taken at the beginning and end of the vertical nitrogen test run. Temperature and pressure monitoring continued throughout the vertical nitrogen test run. A vertical vacuum test run was conducted in a similar manner.

Two to three days were required for the cask to reach steady-state temperature after a position or cavity backfill gas change.

When the cask was rotated from the vertical to the horizontal orientation during the performance test, the cask TCS had to be disconnected from the DAS. The cask was moved to the hot shop where the cask was rotated to the horizontal position on the cask transport frame with the hot shop crane. When the cask was back in the warm shop test bay, the TCS were reconnected and the test run monitoring began.

During the horizontal test runs, neutron/gamma radiation dose rate measurements were taken on all cask surfaces. EG\&G Idaho, Inc. health physics technicians and PNL personnel conducted independent surveys using portable instruments.

At completion of the normal horizontal vacuum test run, the cask ends were insulated to simulate the installation of impact limiters on the cask (Figure 3-36). Temperature and pressure data were collected per a contract with the cask manufacturer, Transnuclear, for an additional 5 days. During this time, a Transnucleaire representative took independent measurements of temperatures and dose rates.

At the completion of the cask testing, the TN-24P cask was moved back to the hot shop and prepared for interim storage at the test pad. The cask was returned to the vertical position, the TC lances were removed, and the helium cover gas pressure was adjusted to 1.5 bar. Leak checks and gas sampling were performed to ensure leaktightness and cover gas security. The cask was moved to the long-term surveillance test pad area using the cask transporter in March 1988. 


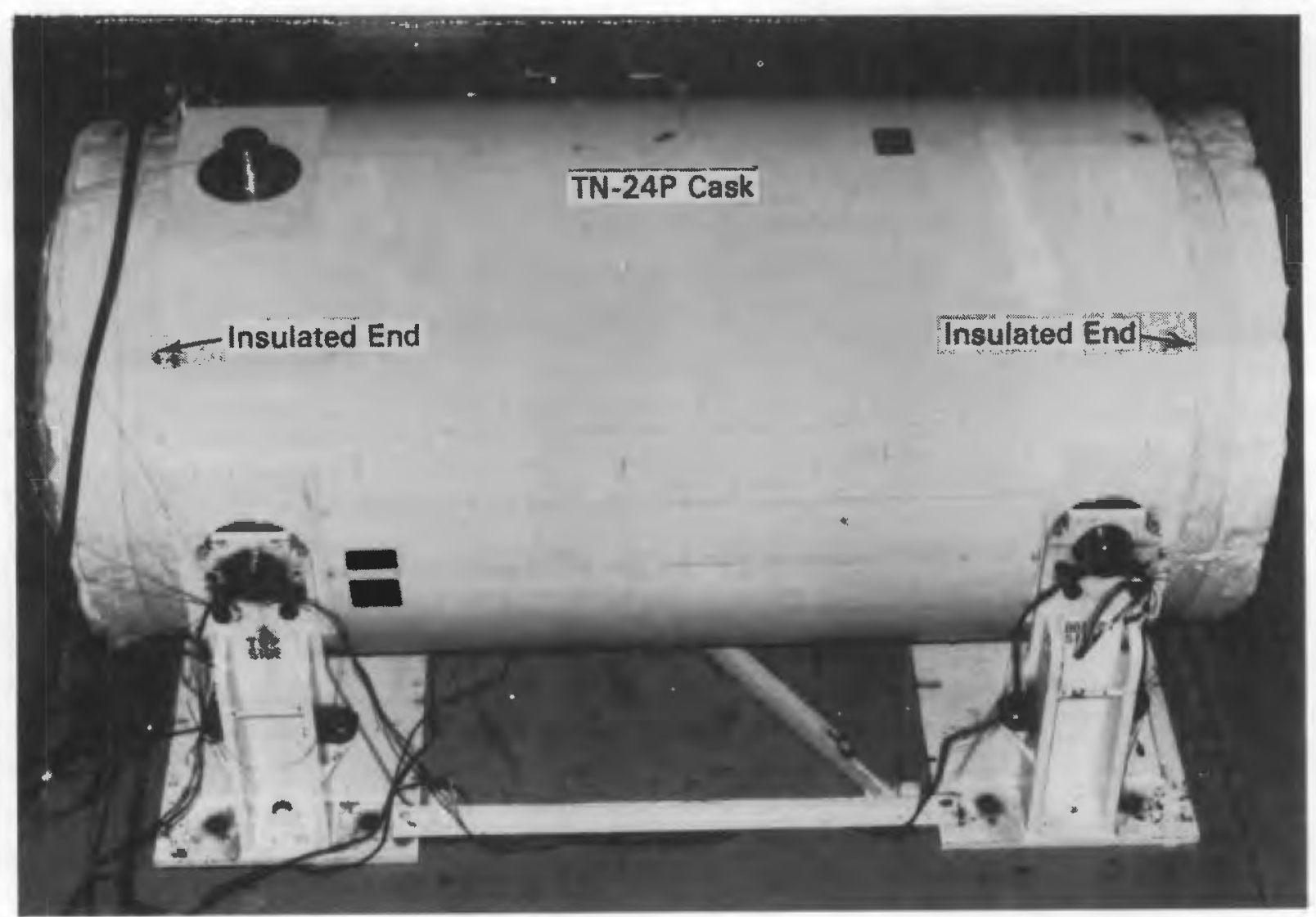

Figure 3-36. TN-24P Cask with Ends Insulated 


\title{
Section 4
}

\author{
CASK HEAT TRANSFER AND SHIELDING, AND FUEL PERFORMANCE
}

Heat transfer and shielding performance data and fuel integrity data obtained for the TN-24P PWR storage cask loaded with consolidated spent nuclear fuel are presented and discussed in this section. Both cask and fuel assembly peak temperatures and associated temperature profiles are presented to assess heat transfer performance. Cask exterior surface peak dose rates and corresponding dose rate profiles are provided to evaluate shielding performance. The thermal and shielding performance of the TN-24P does not represent the performance of a standard TN-24 cask because of structural differences between the two casks as described in Section 3. Spent fuel integrity results, as determined from gas samples taken during the performance test, are also presented.

\section{HEAT TRANSFER}

The cask heat transfer performance test consisted of several runs discussed in detail in Section 3. Test runs were performed inside the TAN warm shop, in both vertical and horizontal orientations, and with vacuum, nitrogen, and helium backfills. The final test was conducted with a vacuum backfill and the ends of the cask insulated to simulate impact limiters. The predicted total decay heat generation of the spent fuel was approximately $23.2 \mathrm{~kW}$ during the 1.5 -month performance test. A vacuum environment was used to determine the maximum temperature that could be encountered in the cask and to assess the radiation heat transfer performance of the cask. Nitrogen runs were performed to determine the effects of convection heat transfer in the TN-24P basket. In addition, studies have been conducted to provide the technical basis for using nitrogen as a long-term storage medium (15). The use of helium as a backfill gas permitted determination of the minimum expected operating temperature of the cask because of the relatively high thermal conductivity (five times higher than nitrogen) of helium. Both vertical and horizontal orientations were incorporated in the test to determine differences in performance. Heat transfer data in the three backfills and both orientations are presented in the following sections, along with discussions of cask performance. 


\section{Heat Transfer Performance Overview}

The cask performance test matrix was developed to determine the effects of cask orientations and backfills. Table 4-1 presents the peak measured guide tube and basket temperatures for all seven test runs. Peak cladding temperatures were estimated by adding the temperature difference between the canister center and the TC lance location from the pretest temperature predictions to the measured temperature. Because the axial location of the peak temperature was close to a measurement location, no corrections based on axial temperature profiles were made to the estimated peak cladding temperatures. The estimated peak cladding temperatures, along with average ambient and surface temperatures, are also shown in Table 4-1. All steadystate temperature data are contained in Appendix $C$.

As can be seen from Table 4-1, fuel cladding temperatures were well below the $375^{\circ} \mathrm{C}$ cask design temperature for all seven runs ( $\underline{7})$. The maximum design heat load for the cask is $24 \mathrm{~kW}$. The high thermal conductivity of helium resulted in the lowest measured peak temperature $\left(205^{\circ} \mathrm{C}\right)$, and the $10 \mathrm{w}$-conductivity vacuum run produced the highest measured temperature $\left(291^{\circ} \mathrm{C}\right)$, as expected.

Table 4-1

TEST MATRIX AND PEAK TEMPERATURES FOR THE TN-24P CASK LOADED WITH CONSOLIDATED FUEL

\begin{tabular}{|c|c|c|c|c|c|c|c|c|}
\hline $\begin{array}{l}\text { Run } \\
\text { No. } \\
\end{array}$ & Orientation & Backfill & $\begin{array}{l}\text { Cask } \\
\text { Heat } \\
\text { Load, } \\
\text { kW } \\
\end{array}$ & $\begin{array}{r}\text { Ambient } \\
\text { Temp, }{ }^{\circ} \mathrm{C} \\
\end{array}$ & $\begin{array}{l}\text { Side } \\
\text { Surface } \\
\text { Temp, }{ }^{\circ} \mathrm{C} \\
\end{array}$ & $\begin{array}{l}\text { Measured } \\
\text { Guide Tube } \\
\text { Temp, }{ }^{\circ} \mathrm{C}\end{array}$ & $\begin{array}{c}\text { Measured } \\
\text { Center } \\
\text { Basket } \\
\text { Temp, }{ }^{\circ} \mathrm{C} \\
\end{array}$ & $\begin{array}{l}\text { Estimated } \\
\text { Peak Clad. } \\
\text { Temp, }{ }^{\circ} \mathrm{C}\end{array}$ \\
\hline 1 & Vertical & Helium & 23.3 & 22 & 71 & 211 & 203 & 211 \\
\hline 2 & Vertical & Nitrogen & 23.3 & 16 & 71 & 267 & 240 & 268 \\
\hline 3 & Vertical & Vacuum & 23.2 & 22 & 70 & 291 & 262 & 293 \\
\hline 4 & Horizontal & Hel ium & 23.2 & 17 & 71 & 205 & 198 & 205 \\
\hline 5 & Horizontal & Nitrogen & 23.2 & 22 & 69 & 251 & 229 & 252 \\
\hline 6 & Horizontal & Vacuum & 23.1 & 23 & 73 & 280 & 252 & 282 \\
\hline $7^{\mathrm{a}}$ & Horizontal & Vacuum & 23.1 & 24 & 85 & 280 & 255 & 282 \\
\hline
\end{tabular}

aThe top and bottom of the cask were insulated to simulate impact limiters during this run. 
A comparison of measured peak temperatures in vertical $\left(211^{\circ} \mathrm{C}\right.$ fuel and $203^{\circ} \mathrm{C}$ basket) and horizontal $\left(205^{\circ} \mathrm{C}\right.$ fuel and $198^{\circ} \mathrm{C}$ basket) runs with helium, and between the vertical $\left(291^{\circ} \mathrm{C}\right.$ fuel and $262^{\circ} \mathrm{C}$ basket) and horizontal $\left(280^{\circ} \mathrm{C}\right.$ fuel and $252^{\circ} \mathrm{C}$ basket) runs with vacuum does not indicate enhanced conduction heat transfer resulting from fuel canisters contacting basket fuel tubes in a horizontal orientation. If enhanced conduction had taken place, the difference between the fuel and basket temperatures should have been less in the horizontal runs than it was in the vertical runs. The data show that the magnitudes are about the same. A comparison of the measured peak temperatures in vertical $\left(267^{\circ} \mathrm{C}\right.$ fuel and $240^{\circ} \mathrm{C}$ basket) and horizontal $\left(251^{\circ} \mathrm{C}\right.$ fuel and $229^{\circ} \mathrm{C}$ basket) nitrogen runs indicates a difference; however, the apparent difference is an artifact of the basket and fuel temperature measurement locations and the shape of the respective axial temperature profiles. For all of the runs except the vertical nitrogen run, the peak TC lance temperature occurs at the same elevation (elevation $2270 \mathrm{~mm}$ in Figure 3-6) as the temperature measurement location in the center of the basket (TC T12F in Figure 3-6). In the vertical nitrogen run, the peak TC lance temperature occurred at an adjacent location (elevation $3070 \mathrm{~mm}$ in Figure 3-6).

There is a small difference in maximum measured temperature due to orientation. The differences are a result of changes in contact resistance between the basket and the wall of the cask and from convection in the open basket locations next to the cask wal1.

In general, the cask heat transfer based on peak temperatures can be concluded to be exceptionally good because peak temperatures in helium, when the cask was dissipating $23 \mathrm{~kW}$, were $160^{\circ} \mathrm{C}$ less than the design temperature $\left(375^{\circ} \mathrm{C}\right)$ for the cask operating with $24 \mathrm{~kW}$. Contributions of the different modes of heat transfer are discussed further in the following sections.

\section{Vacuum Runs}

Three vacuum runs were conducted during the performance test, one in the vertical orientation and two in the horizontal orientation. After the first horizontal vacuum run, the ends of the cask were insulated to simulate the effect of impact limiters. Selected axial temperature profiles for these three runs are presented in this subsection. Additional temperature data are contained in Appendix $C$. For clarity, cubic spline fit curves have been used to connect points in all the axial temperature profiles shown in Section 4. They may not represent actual temperature profiles, but have been added to guide the eye from point to point on each profile. In addition, the upper $T C$ in a fuel lance location (Figure 4-1) may be close enough 


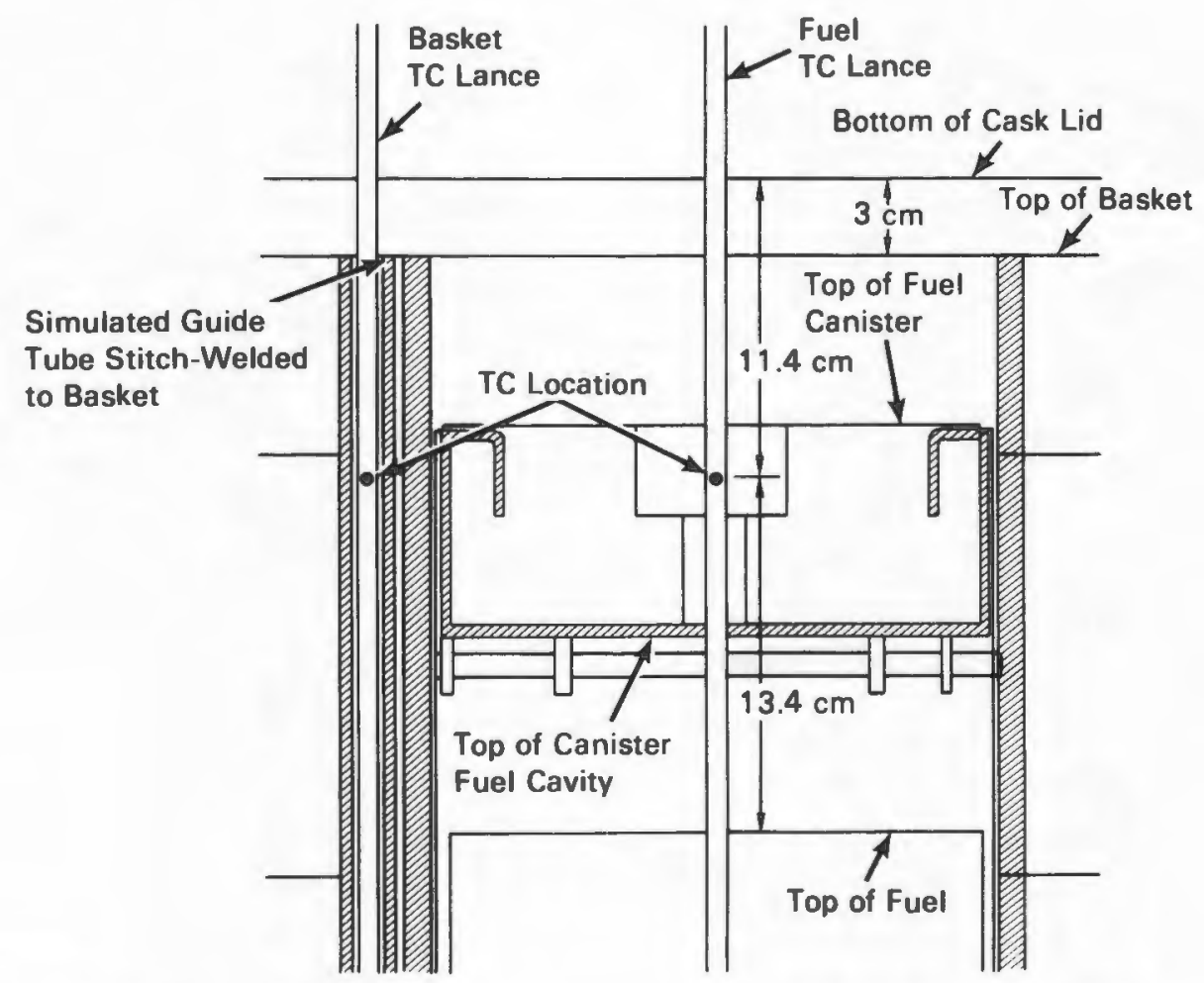

Figure 4-1. Relationship of topmost TC location to cask lid, basket, and fuel canister.

to the 1 id to be influenced by conduction through the TC 1ance to the 1id. Conduction along a TC lance would cause the temperature at the measurement locations to be between that of the gas in the cask and that of the lid. The TC lance in the basket locations is in good enough contact with the basket to give a good representation of the actual basket temperatures.

Selected axial temperature profiles for the vertical vacuum run (Run 3) are shown in Figure 4-2. These profiles show the temperatures for

- four TC lances in fuel assembly guide tubes

- one TC lance in a basket guide tube

- TCs located at the basket center, inner wa11, and outer cask surface.

These locations are shown in the inset to Figure 4-2. The ambient temperature is also shown. The predicted relative axial decay heat profile previously shown in Figure 3-19 may be compared with the temperature profiles to show similarities between temperature and decay heat profiles. 


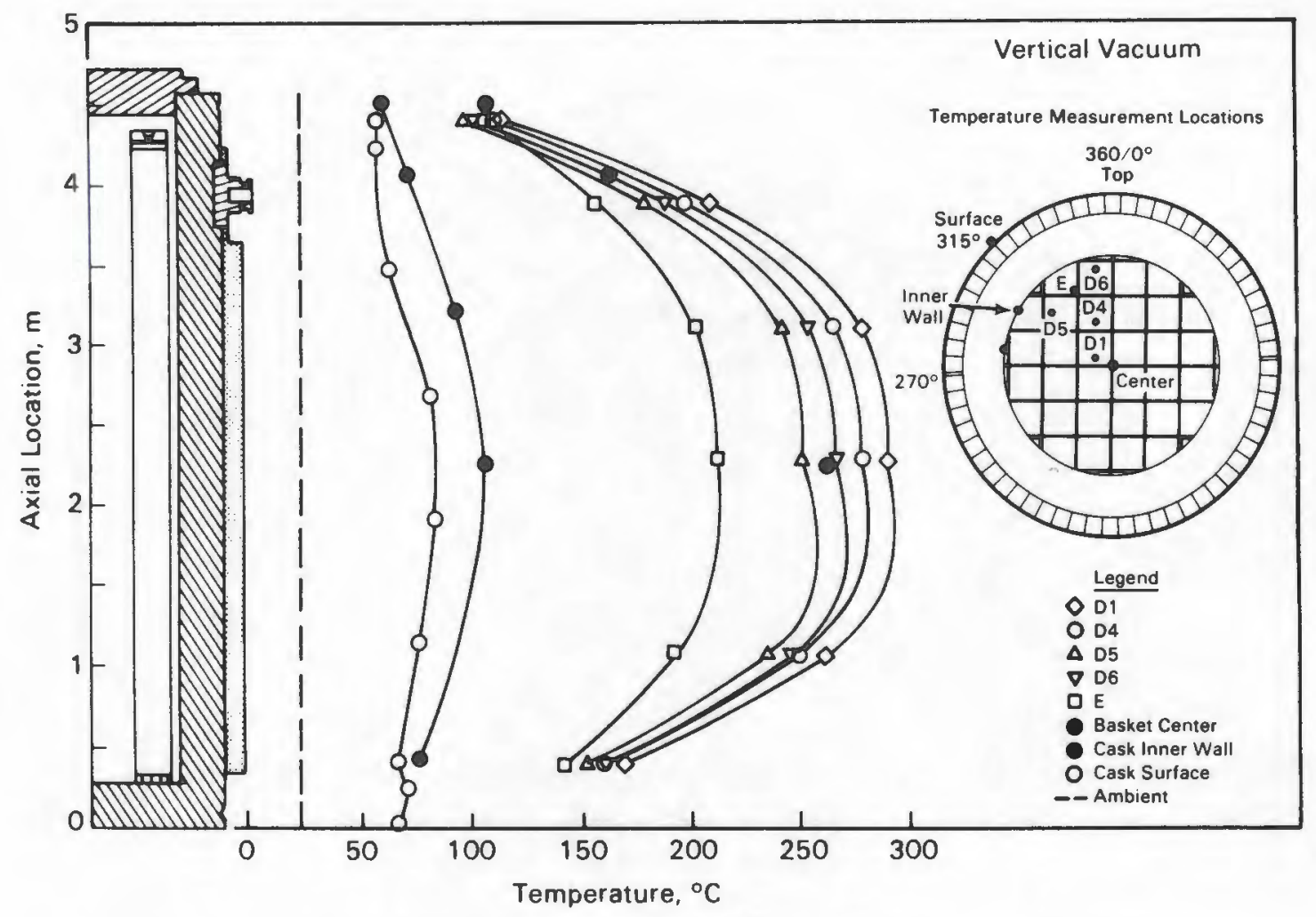

Figure 4-2. Axial Temperature Profiles for the Vertical Vacuum Run

The temperature profiles are symmetrical relative to the active fuel length. The measured peak temperature of $291^{\circ} \mathrm{C}$ occurred at an elevation of $2.3 \mathrm{~m}(7.5 \mathrm{ft})$. Based on a cubic spline fit to the data and the pretest predictions, a peak cladding temperature of $293^{\circ} \mathrm{C}$ occurred at an elevation of about $2 \mathrm{~m}$.

A crossover between the basket and fuel assembly lance temperatures is observed near the top of the cask. This occurs in a location in the cask where no heat is being generated and the aluminum basket acts as a path for heat to be transferred to the cask wall and lid. Conduction in the aluminum basket causes the basket to be hot relative to the lid. Heat transfer from the basket to the lid is by radiation to the 1 id and conduction through the vacuum (low-density nitrogen) at the top of the cask. Convection has been eliminated due to the density of the gas. The upper TC of a TC lance in the basket is in relatively good contact with the basket and should reflect the hotter temperature of the basket at this location, whereas the upper TC in a fuel TC lance measures a temperature between that of the basket and the lid. In the vacuum run the temperature of the upper TC in the fuel lance is influenced by 
radiation from the basket, radiation to the 1 id, conduction through the gas to the basket and lid, and conduction along the lance from the fuel to the lid (Figure $4-1$ ).

Axial temperature profiles for the horizontal vacuum run (Run 6) are shown in Figure 4-3. Except for a small change in magnitude (the peak measured temperature in the horizontal run was $280^{\circ} \mathrm{C}$ compared to $291^{\circ} \mathrm{C}$ for the vertical run), the profiles are similar in shape to those shown in Figure 4-2 for the vertical vacuum run. It can be concluded that convection was negligible in the vacuum runs, as would be expected because of the absence of a gas to convect. If significant convection were present, there should have been a shift in the shape of the temperature profiles between the vertical and horizontal runs. The absence of convection causes the similarity between the decay heat and temperature profiles. Both are symmetrical about the active fuel length.

Axial temperature profiles for the horizontal vacuum run with the ends of the cask insulated (Run 7) are shown in Figure 4-4. Insulating the ends of the cask

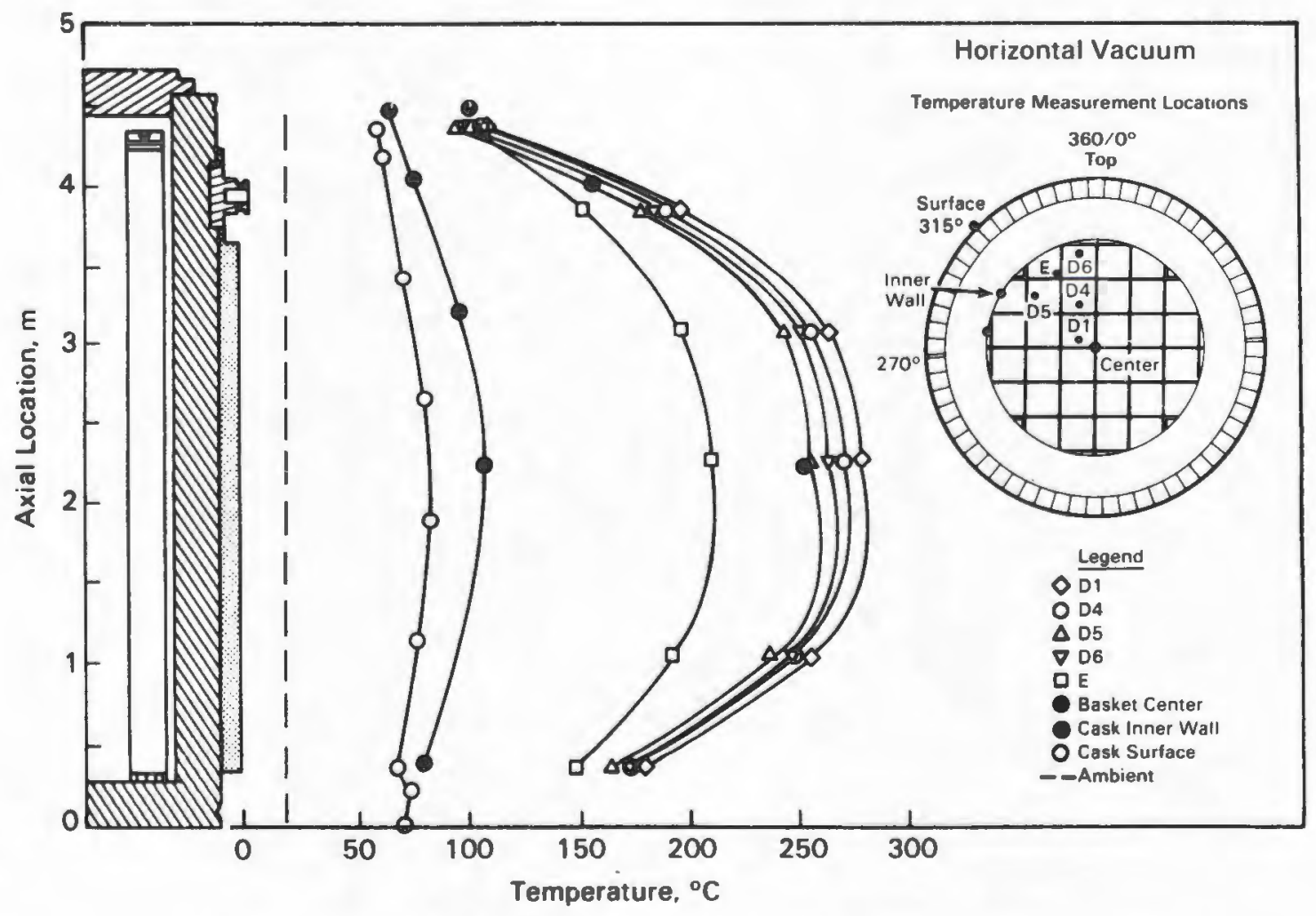

Figure 4-3. Axial Temperature Profiles for the Horizontal Vacuum Run 


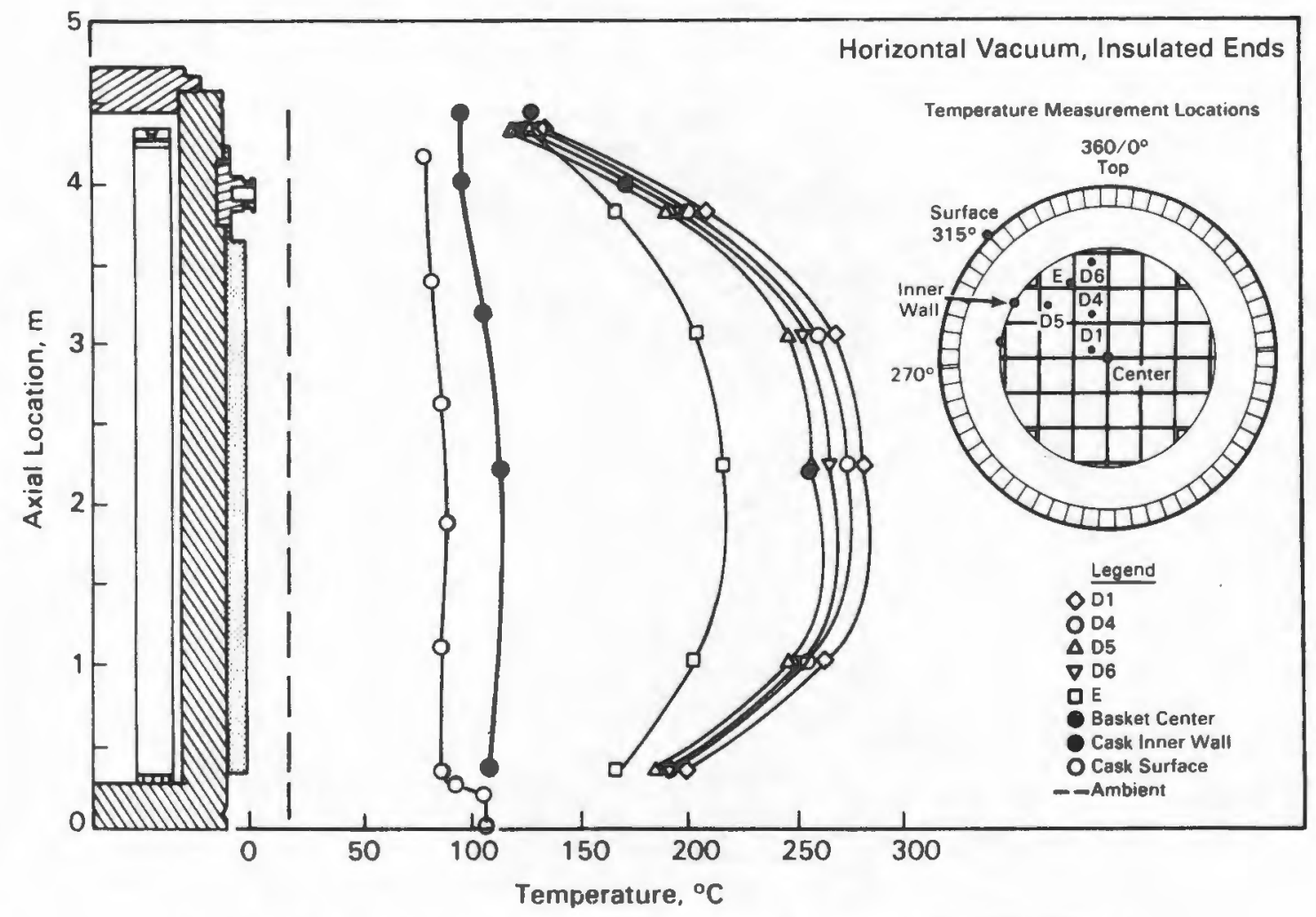

Figure 4-4. Axial temperature profiles for the horizontal vacuum run with cask ends insulated.

redistributed the flow of heat out of the cask but had little impact on peak temperatures in the cask. Other than being a little flatter with higher temperatures at the ends of the cask, the temperature profiles were similar in shape to those measured in the non-insulated vacuum runs.

Temperature symmetry in the cask can be assessed from the axial temperature profiles shown in Figure 4-5 for the vertical and horizontal vacuum runs. The cask basket inset is included on Figure 4-5 to indicate the temperature measurement locations. The three sets of axial profiles are for the lances in symmetrical locations with respect to a horizontal or vertical axis or the center of the cask. Each set of profiles contains two basket temperature lances, $E$ and $F$; two center assembly fuel lances, D1 and Al; and four outer assembly fuel lances, D5 and B5, and D6 and C6.

With the exception of the lower end of lance $E$ and $F$, the temperature differences between symmetrical locations for the vertical vacuum run are less than the expected accuracy of the temperature measurement themselves. Both horizontal runs show good symmetry with respect to the vertical axis, as shown by the temperatures for lances 


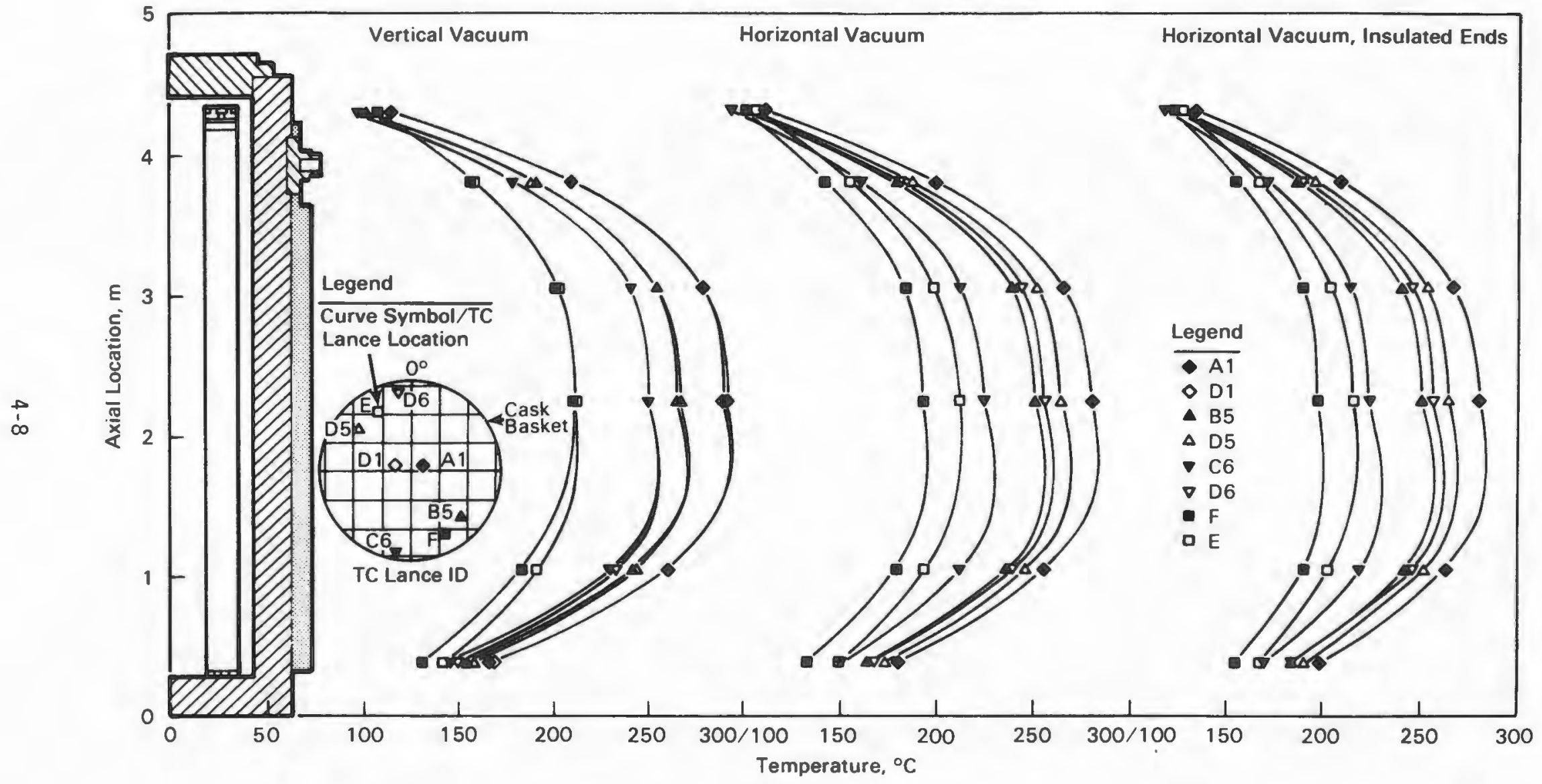

Figure 4-5. Comparison of Axial Temperature Profiles for the Vertical and Horizontal Vacuum Runs 
$A 1$ and $D 1$. The other locations show significant differences in temperatures between the upper and lower cask quadrants. The largest difference is between temperatures in location $\mathrm{D} 6$ and those in location $\mathrm{B} 6$. The reason for the difference is associated with a change in the contact resistance between the cask basket and the cask inner wall. In the vertical orientation, the basket should be fairly symmetrical within the cask and there should be no significant position-dependent differences in contact resistance between the basket and the cask wall. This, coupled with a symmetrical decay heat loading in the cask, leads to symmetrical temperature profiles. In the horizontal orientation, the weight of the basket and fuel (gravity) increases the thermal contact at the bottom side $\left(180^{\circ}\right)$ of the cask and tends to pull the basket away from the top side $\left(0^{\circ}\right)$ of the cask. In addition, instead of the fuel canisters being centered in the basket openings, they rest on basket plates directly under them. Both effects increase heat flow out the bottom side of the cask and decrease heat flow out the top side of the cask. Location D6/C6 experiences the combined effect of thermal contact between fuel and basket and between basket and cask. At location D5/B5 the effect of contact between basket and cask should dominate, because the effect of contact between fuel and basket should be the same for canisters at these locations. The effect of contact between basket and cask is the primary influence for location E/F; the magnitude of the effect is about the same as for location D5/B5, as would be expected.

Insulating the ends of the cask did not change temperature symmetry in the cask, nor did it increase the peak measured temperature in the cask. Insulating the ends of the cask redirects the axial heat flow near the ends of the cask to radial flow to the sides of the cask. As a result, the surface, basket, and fuel temperatures near the ends of the cask ( 1 id and bottom) increase.

Radial temperature profiles for the vacuum backfills are shown in Figure 4-6, which includes sets of profiles for the vertical and horizontal runs. The solid lines connect the temperatures taken in TC lances at common axial distances from the bottom of the cask. Temperature measurements made in the basket locations are not connected with lines. Their elevation is indicated by the type of symbol used. The radius represents the distance the TC was located from the center of the cask, with positive distances representing positions in the upper quadrants. A negative radius represents a position in the lower quadrants of the horizontal cask. The insets show how this was done. 


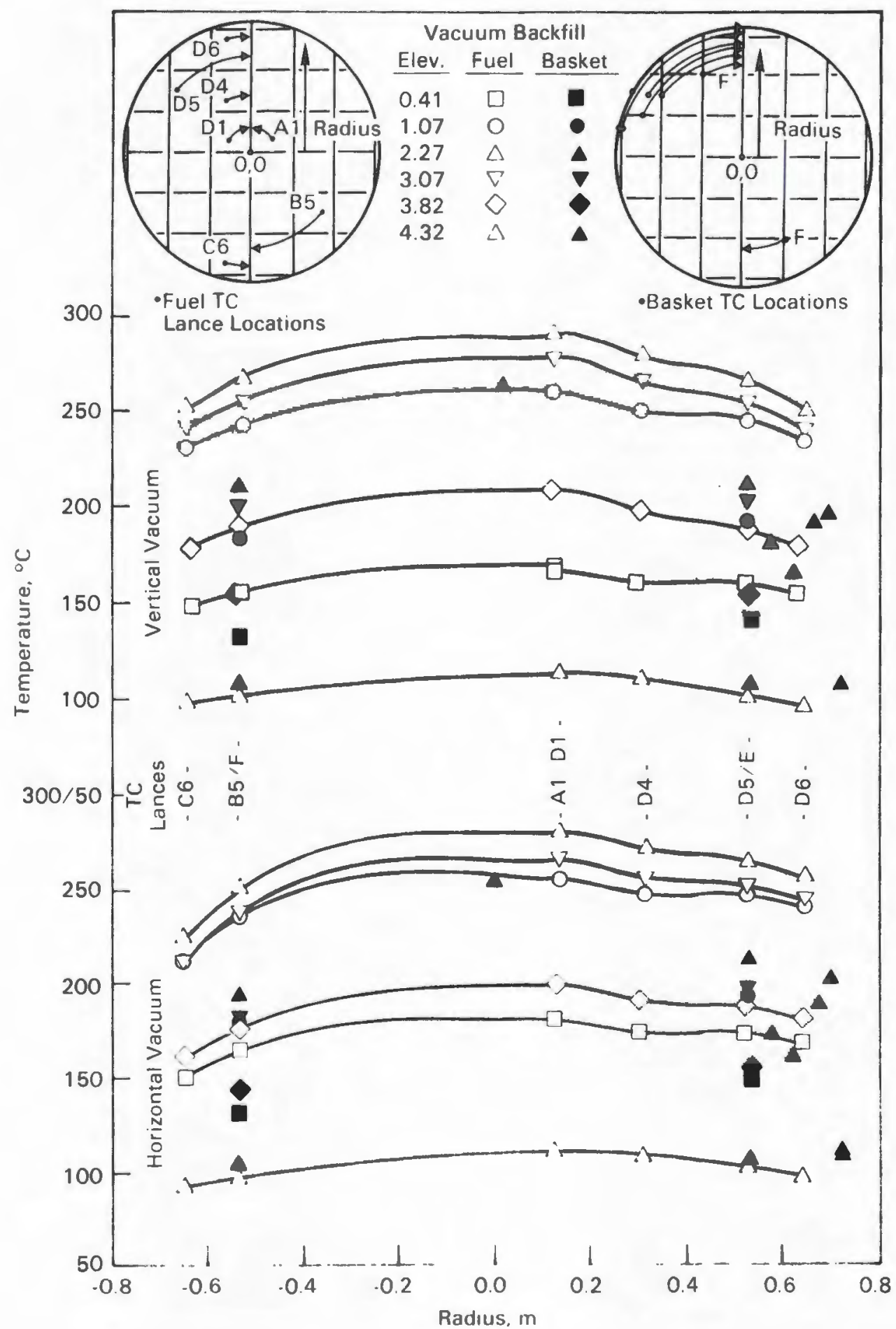

Figure 4-6. Radial Temperature Profiles for the Vertical and Horizontal Vacuum Runs 
The temperature profiles in the horizontal run are skewed slightly, with the hotter temperature in the upper quadrants. However, this effect is more apparent from symmetry plots of Figure 4-5 than it is from comparing the curves in Figure 4-6.

The differences in the shape and magnitude of the radial temperature profiles between the vertical and horizontal vacuum runs reflect the change in thermal contact resistance between the basket and cask inner wall due to cask orientation. In the horizontal run the radial slope of the curves at $0^{\circ}$ is less than in the vertical run, indicating a reduced heat flow at $0^{\circ}$. For the heat flow to decrease, the contact resistance between the basket and the cask wall must have increased. Likewise, at $180^{\circ}$ the slope of the radial temperature curve increases, reflecting a decrease in the contact resistance and an increase in the heat flow through the basket to the cask wall at $180^{\circ}$.

Because the shapes of the radial profiles for the insulated vacuum run parallel those for the noninsulated vacuum run, they are not illustrated. However, they are part of the steady-state temperature data found in Appendix C.

Another item of interest observed in Figure 4-6 is the temperature drop from the basket to the cask inner wall. Based on the information at an elevation of $2.3 \mathrm{~m}$ $(7.5 \mathrm{ft})$, this temperature drop can be 60 to $110^{\circ} \mathrm{C}$ and represents a significant portion of the temperature drop from the center of the cask to the ambient (ambient temperature of about $20^{\circ} \mathrm{C}$ ).

\section{Nitrogen Runs}

Two nitrogen runs were conducted during the performance test, one in the vertical and one in the horizontal orientation. Selected axial temperature profiles for these two runs are presented in Figures 4-7 and 4-8. Additional temperature data are contained in Appendix $C$. The temperature data have been connected by cubic spline curves that may or may not represent actual temperature profiles. These lines have been added for clarity only. Based on data from the vacuum runs and from data that will be presented later for the nitrogen and helium runs, the TC lance temperatures at an elevation of $4.32 \mathrm{~m}$ may be biased low as a result of conduction from the TC lances to the lid.

Axial temperature profiles for the vertical nitrogen run (Run 2) are presented in Figure 4-7 and include temperatures from four TC 1ances in fuel assembly guide tubes, one TC lance in a basket guide tube, center basket thermocouples, inner cask wall thermocouples, and outer surface thermocouples. These measurement locations 
are shown in the inset to Figure $4-7$. The estimated peak fuel temperature $\left(268^{\circ} \mathrm{C}\right)$ in the vertical nitrogen run was in a center assembly at an elevation of about $2.7 \mathrm{~m}$ $(8.9 \mathrm{ft})$.

Axial temperature profiles for the horizontal nitrogen run (Run 5) are presented in Figure 4-8. They include temperatures from the same fuel assemblies, basket, surface, and ambient locations as were shown in Figure 4-7. The estimated peak fuel temperature of $252^{\circ} \mathrm{C}$ occurred at an axial location about $1.9 \mathrm{~m}(6.2 \mathrm{ft})$ from the bottom of the cask. Other than magnitude of the peak temperatures, the axial temperature profiles for the horizontal nitrogen run are of the same shape as the horizontal vacuum runs (Figure 4-3).

Figure 4-9 shows the temperature symmetry in the cask for the vertical and horizontal nitrogen runs. The cask basket inset is included on Figure 4-9 to indicate the temperature measurement locations. The three sets of axial profiles are for the lances in symmetrical locations with respect to a horizontal or vertical axis or the center of the cask. Each set of profiles contains two basket temperature lances, $E$

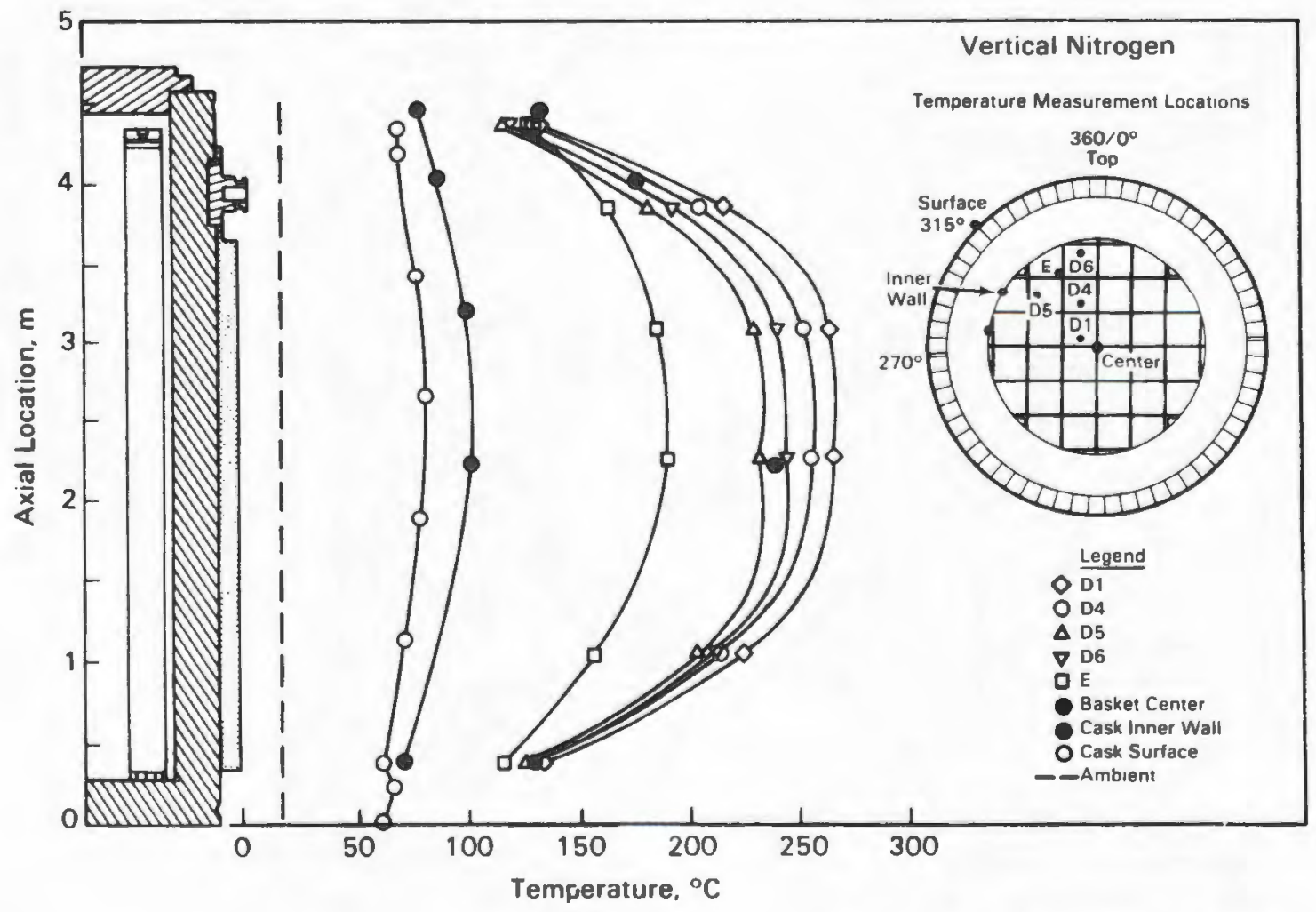

Figure 4-7. Axial Temperature Profiles for the Vertical Nitrogen Run 
and F; two center assembly fuel lances, D1 and Al; and four outer assembly fuel 1 ances, D5 and B5, and D6 and C6. Except for the lower end of lances $E$ and $F$, the temperature differences between symmetrical locations for the vertical nitrogen run are less than the expected accuracy of the temperature measurement themselves.

The horizontal run shows good symmetry with respect to the vertical axis, as shown by the temperatures for lances $A 1$ and D1. The other locations show significant differences in temperatures between the upper and lower quadrants of the cask. The largest difference is between temperatures in location D6 and those in location B6. The difference is associated with a change in the contact resistance between the cask basket and the cask inner wall. In the vertical orientation, the basket should be fairly symmetrical within the cask without significant differences in contact resistance around the cask. This, coupled with symmetrical decay heat loading in the cask, leads to symmetrical temperature profiles. In the horizontal orientation, the weight of the basket and fuel (gravity) increases the contact at the bottom side $\left(180^{\circ}\right)$ of the cask and tends to pull the basket away from the top side $\left(0^{\circ}\right)$ of the cask. In addition, instead of the fuel canisters being centered in the basket

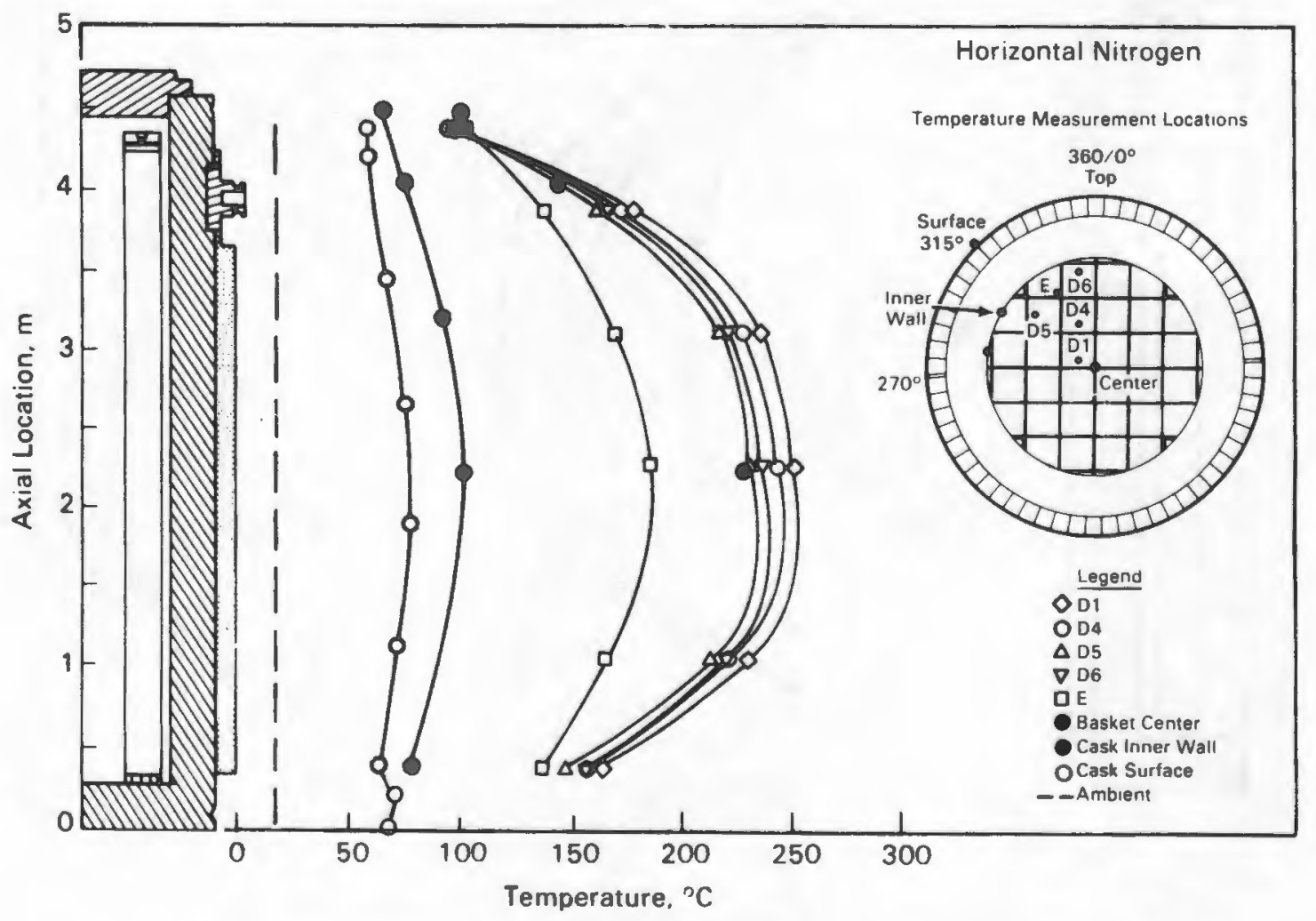

Figure 4-8. Axial Temperature Profiles for the Horizontal Nitrogen Run 
openings, they rest on the basket plate directly under them. Both factors decrease the resistance to heat flow out the bottom side of the cask and increase the resistance to heat flow out the top side of the cask. Location $D 6 / C 6$ experiences the combined effect of fuel against basket and basket against cask. At 1ocation D5/B5 the effect of basket against cask should dominate because the effect of fuel against basket should be the same for both locations. The effect of basket against cask is the primary influence for location E/F; the magnitude of the effect is about the same as for location D5/B5, as would be expected.

The effect of convection is seen as a slight change in shape of the axial profiles in Figure 4-9. If this shape change were due to conduction or radiation, it should have been seen in the vacuum runs. Because the skewing of the temperature profile toward the top of the cask was not seen in the vertical vacuum run, conduction and radiation can be ruled out as a possible cause. The only remaining explanation for the profiles' shape change is convection.

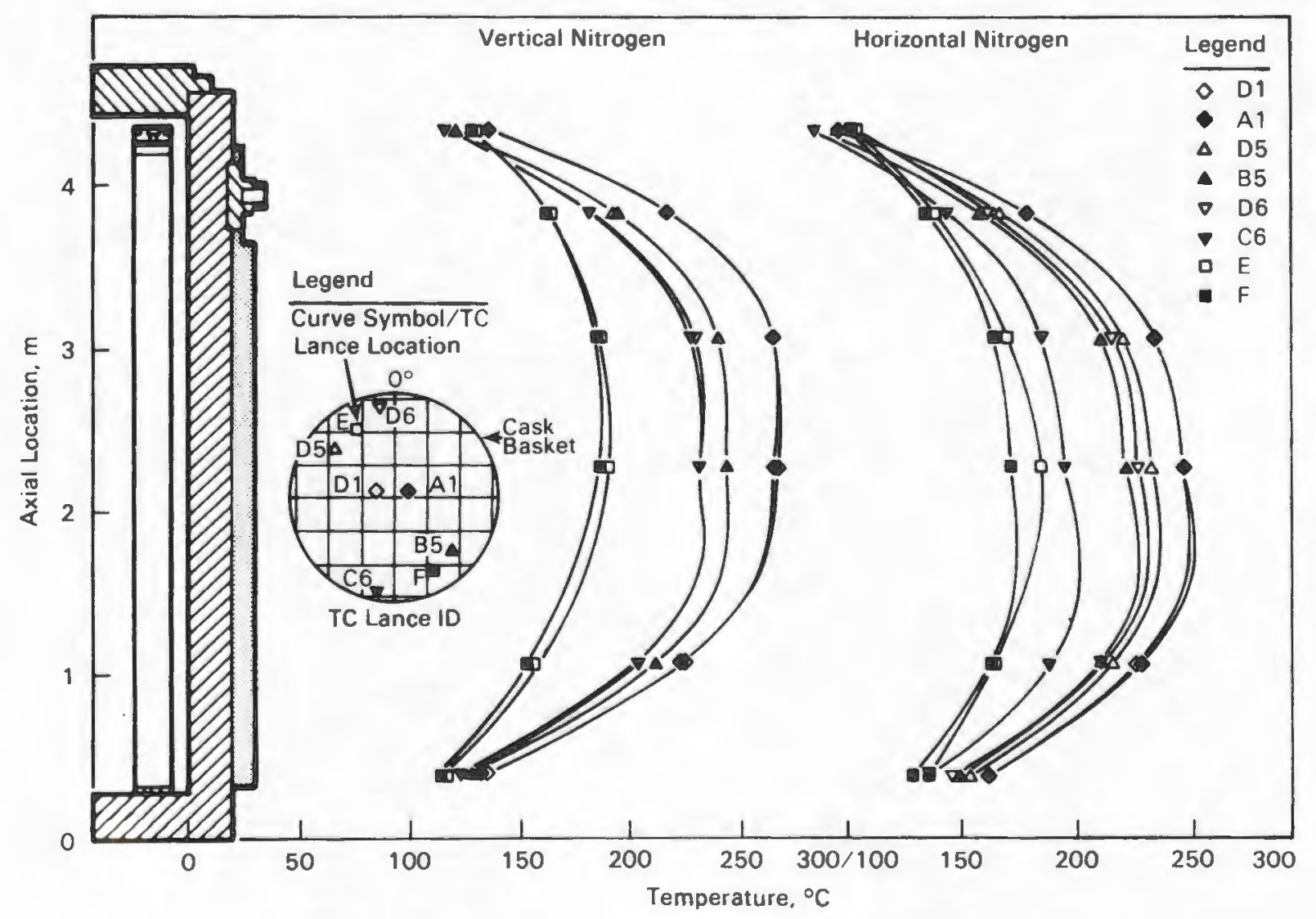

Figure 4-9. Comparison of axial temperature profiles for the vertical and horizontal nitrogen runs 
Two opportunities exist for convection with consolidated fuel in the cask. One is around the canister, and the other is through the canister. Both channels for gas flow are much more restricted than they are for relatively open unconsolidated fuel.

The effect of convection shown by comparing the vertical and horizontal nitrogen runs is much less than that seen in previous cask performance tests $(\underline{2}, \underline{3}, \underline{4}, \underline{16})$ as will be shown later in this section.

When the cask is oriented vertically, convection paths allow gas to flow down the cask wa11, under the basket, and up through fuel locations. These paths will be described. Starting at the 1id, a 30-mm (1.2-in.) gap between the top of the basket and the cask lid allows gas to flow from the canister locations to the outside of the basket. The open basket locations around the outside of the basket provide good channels for gas to flow down the relatively cold cask wall to the bottom of the cask. The basket design provides a $45-\mathrm{mm}(1.8-\mathrm{in}$.$) gap between the bottom of the$ basket and the bottom of the cask where gas can flow from the outside of the cask to the various basket/fuel canister locations. The convection path is completed by flow through or around the canisters. An open flow channel is created by the small gap between the fuel canister and the basket $[2.5 \mathrm{~mm}(0.1 \mathrm{in.})$ if the canister is centered in the basket opening]. A more restrictive flow channel exists through the fuel canister.

For convection to take place in the canister, gas must be able to enter and leave the canister. The top of the canister is relatively open to flow. Several holes have been left in the top plate for the insertion of TC lances. However, the bottom of the canister is quite restrictive to flow. The only openings in the canister bottom are a couple of small triangular gaps in the corners of the bottom plate that have been left for canister drainage and for easier fabrication of the canister's cover. Once gas enters the bottom of the canister, it can flow between the rods, between the rods and the inside canister walls, or through open storage locations. Flow channels through the rods consist of small gaps between touching fuel rods loaded in a triangular array. Flow channels between the inside canister wall and the rods resulted from laying the rods in a triangular array against a flat surface. The remaining channels are the void space caused by open fuel rod storage locations that exist in some canisters. The canisters were designed to hold 410 fuel rods; however, only 408 fuel rods are available from two assemblies.

The radial temperature profiles for both the vertical and horizontal nitrogen runs are shown in Figure 4-10. The shapes of these profiles are very similar to those 


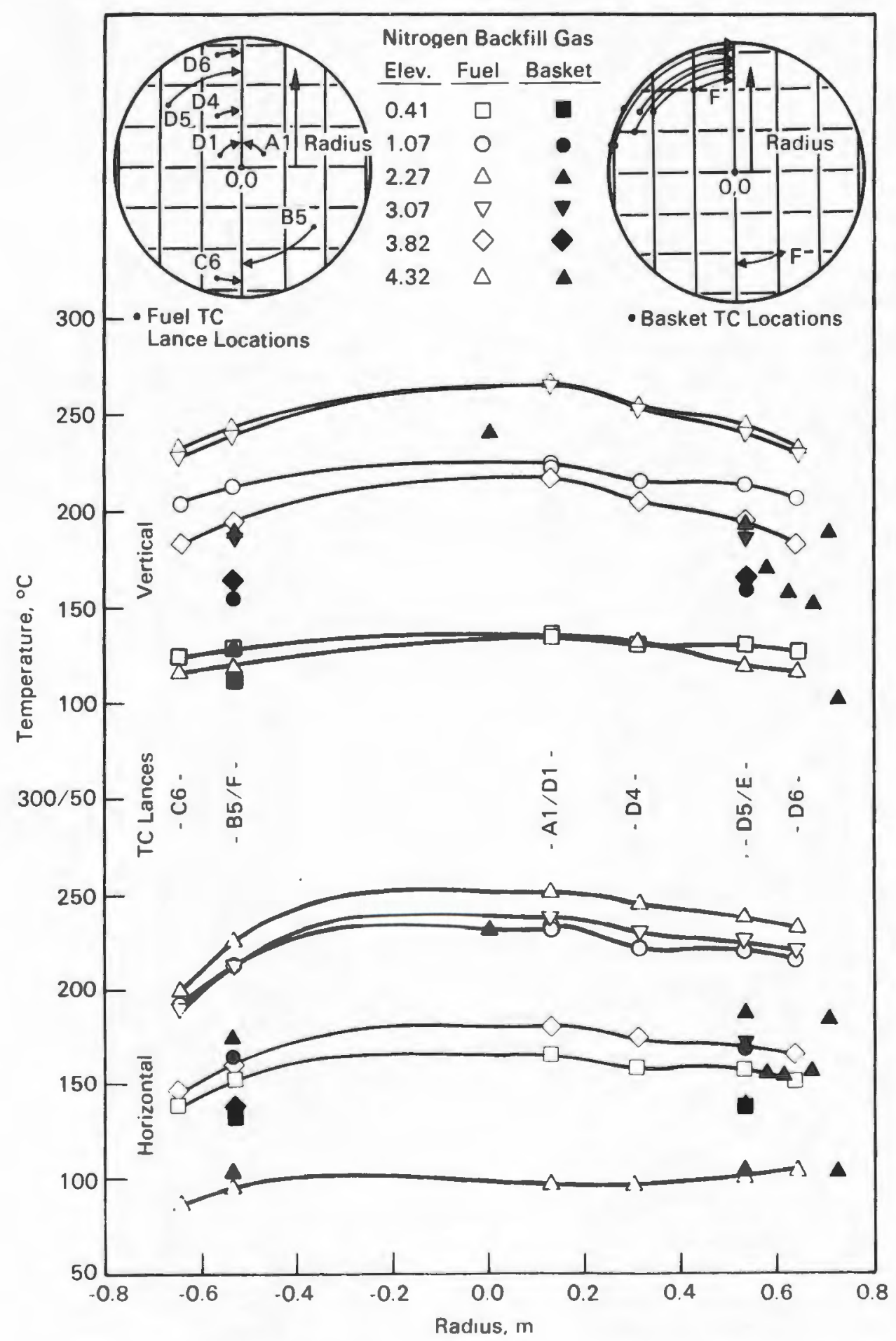

Figure 4-10. Radial temperature profiles for the vertical and horizontal nitrogen runs. 
observed for the vacuum runs. The solid lines in Figure 4-10 connect the data points for the temperatures taken in TC lances at common axial distances from the bottom of the cask. Temperature measurements made in the basket locations are not connected with lines. Their elevation is indicated by the type of symbol used. The radius used represents the distance the TC was located from the center of the cask, with positive distances representing positions in the upper quadrants. A negative radius represents a position in the lower quadrants of the horizontal cask. The insets show how this was done.

The temperature profiles in the horizontal run are skewed slightly, with the hotter temperature in the upper quadrants. However, this effect is more apparent from symmetry plots of Figure 4-9 than it is from comparing the curves in Figure 4-10. The differences in the shape and magnitude of the radial temperature profiles between the vertical and horizontal vacuum runs reflect the change in thermal contact resistance between the basket and cask inner wall due to cask orientation. In the horizontal run the radial slope of the curves at $0^{\circ}$ is less than it is in the vertical run, indicating a reduced heat flow at $0^{\circ}$. For the heat flow to decrease, the contact resistance between the basket and the cask wall must have increased. Likewise, at $180^{\circ}$ the slope of the radial temperature curve increases, reflecting a decrease in the contact resistance and an increase in the heat flow through the basket to the cask wall at $180^{\circ}$.

Another item of interest observed in Figure 4-10 is the temperature drop from the basket to the cask inner wall. Based on the information at an elevation of $2.3 \mathrm{~m}$ $(7.5 \mathrm{ft})$, this temperature drop can be 50 to $90^{\circ} \mathrm{C}$ and represents a significant portion of the temperature drop from the center of the cask to the ambient (ambient temperature of about $20^{\circ} \mathrm{C}$ ).

\section{Helium Runs}

Two helium runs were conducted during the performance test, one in the vertical and one in the horizontal orientation. Selected axial temperature profiles for these two runs are presented in Figures 4-11 and 4-12. Additional temperature data are contained in Appendix C. For clarity, cubic spline curve fits have been used to connect the points for each TC lance or surface temperature profile. Based on data from the vacuum and nitrogen runs and from data that will be presented for the helium runs, the TC lance temperatures at an elevation of $4.32 \mathrm{~m}$ may be biased low as a result of conduction from the TC lances to the lid. 
Axial temperature profiles for the vertical helium run (Run 1) are presented in Figure 4-11 and include temperatures from four TC 1ances in fuel assembly guide tubes, one TC lance in a basket guide tube, center basket TCs, inner cask wall TCs, and outer surface TCs. These measurement locations are shown in the inset to Figure 4-11. The estimated peak fuel temperature $\left(211^{\circ} \mathrm{C}\right)$ in the vertical helium run was in a center assembly at an elevation of about $2 \mathrm{~m}(6.5 \mathrm{ft})$.

Axial temperature profiles for the horizontal helium run (Run 4) are presented in Figure 4-12. They include temperatures from the same fuel assemblies, basket, surface, and ambient locations shown in Figure 4-11. The estimated peak fuel temperature of $205^{\circ} \mathrm{C}$ occurred at an axial location about $2 \mathrm{~m}(6.5 \mathrm{ft})$ from the bottom of the cask. Other than magnitude of the peak temperatures, the axial temperature profiles for the horizontal nitrogen run are of the same shape as those for the horizontal vacuum run (Figure 4-3).

Figure 4-13 shows the temperature symmetry in the cask for the vertical and horizontal helium runs. The cask basket inset is included on Figure 4-13 to indicate the

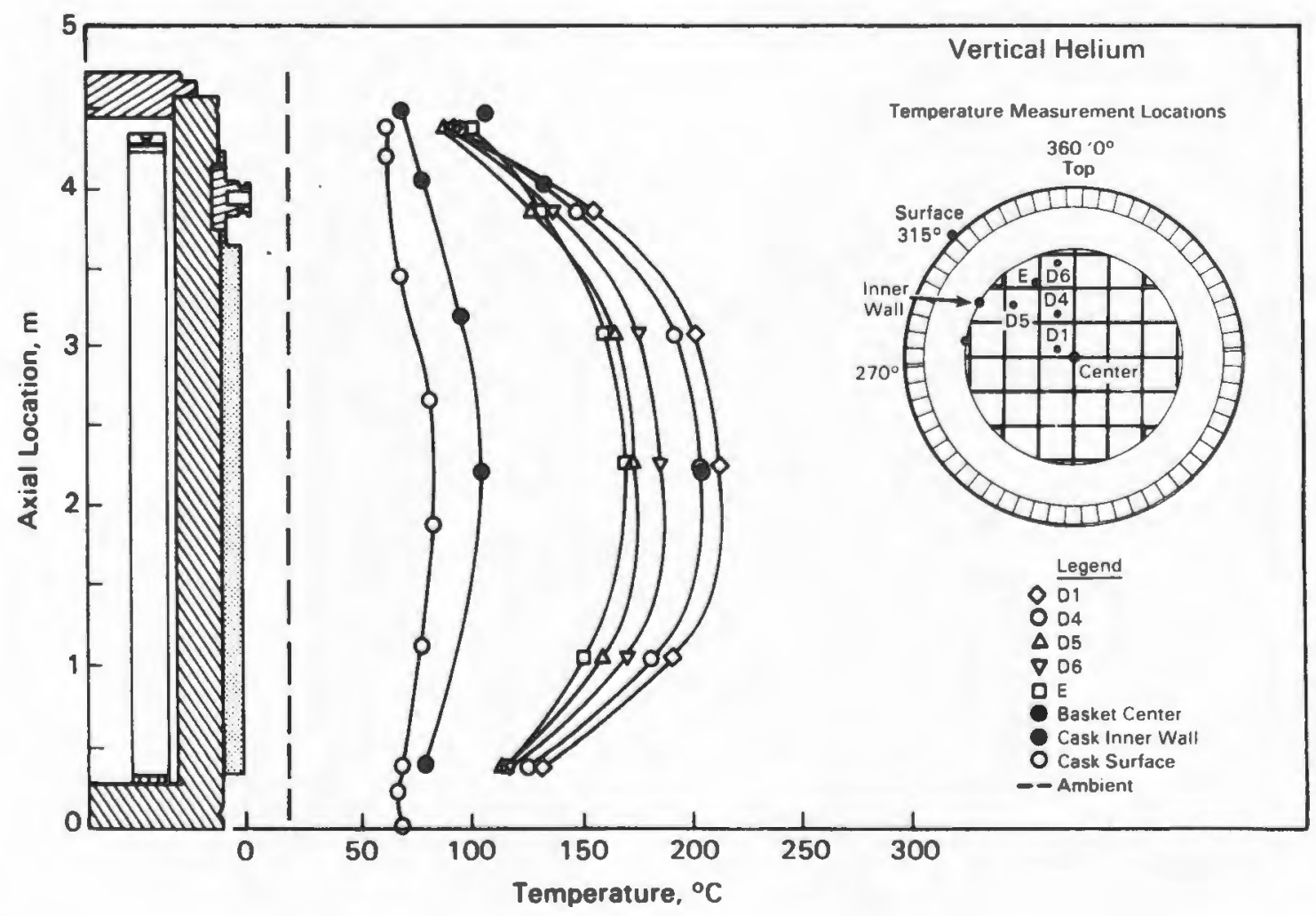

Figure 4-11. Axial Temperature Profiles for the Vertical Helium Run 
temperature measurement locations. The two sets of axial profiles are for the lances in symmetrical locations with respect to a horizontal or vertical axis or the center of the cask. Each set of profiles contains two basket temperature lances, $E$ and F; two center assembly fuel lances, DI and Al; and four outer assembly fue 1 lances, D5 and B5, and D6 and C6. Except for the lower end of 1ances $E$ and $F$, the temperature differences between symmetrical locations for the vertical helium run are less than the expected accuracy of the temperature measurement themselves.

The horizontal run shows good symmetry with respect to the vertical axis, as shown by the temperatures for lances $A 1$ and Dl. The other locations show significant differences in temperatures between the upper quadrant of the cask and the lower quadrant of the cask. The largest difference is between temperatures in location D6 and those in location B6. The difference is associated with a change in the contact resistance between the cask basket and the cask inner wall. In the vertical orientation, the basket should be fairly symmetrical within the cask, without significant differences in contact resistance around the cask. This, coupled with symmetrical decay heat loading in the cask, leads to symmetrical temperature profiles. In the

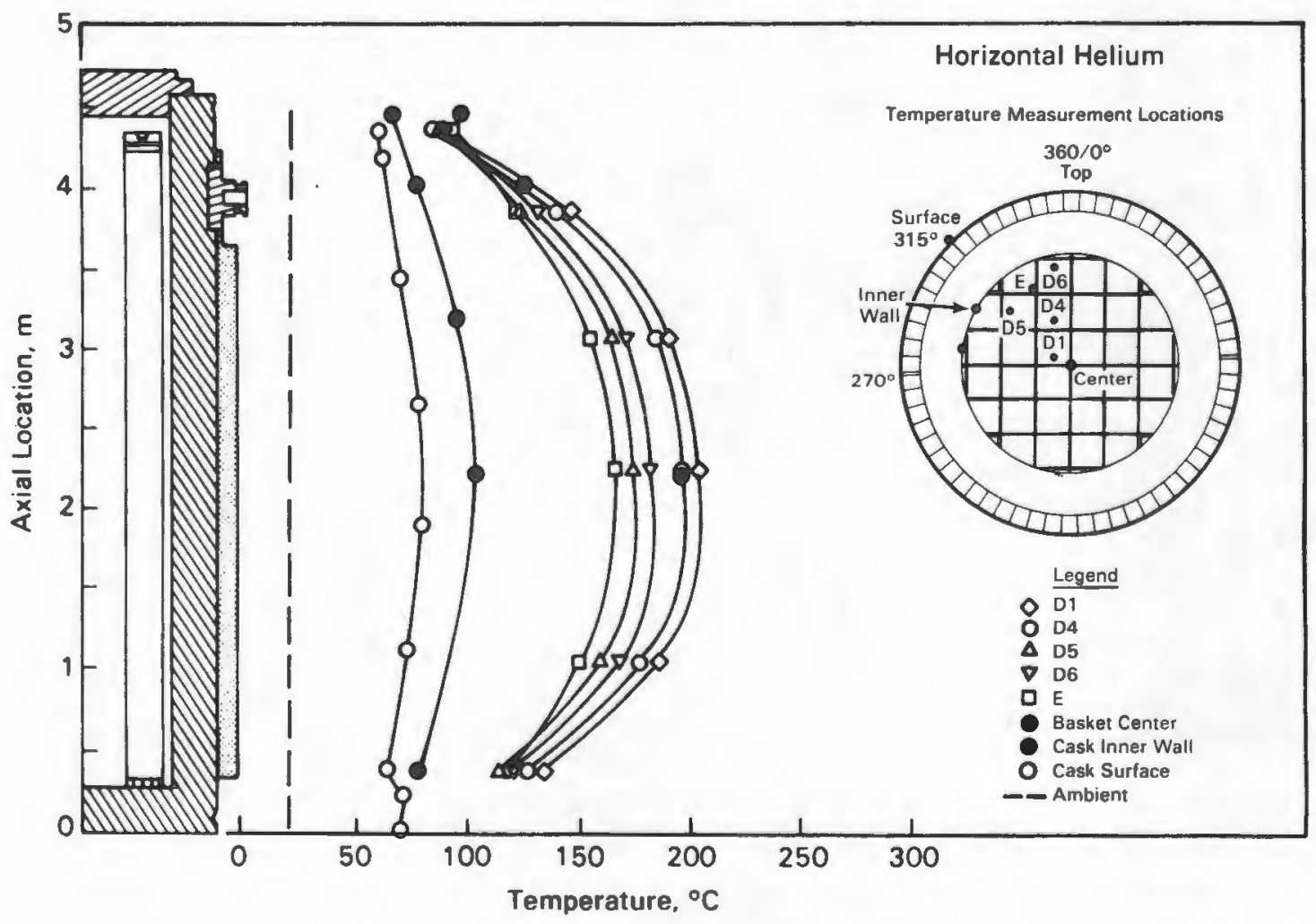

Figure 4-12. Axial Temperature Profiles for the Horizontal Helium Run 
horizontal orientation, the weight of the basket and fuel (gravity) increases the contact at the bottom side $\left(180^{\circ}\right)$ of the cask and tends to pull the basket away from the top side $\left(0^{\circ}\right)$ of the cask. In addition, instead of the fuel canisters being centered in the basket openings, they rest on the basket plate directly under them. Both factors decrease the resistance to heat flow out the bottom side of the cask and increase the resistance to heat flow out the top side of the cask. Location D6/C6 experiences the combined effect of thermal contact between fuel and basket, and basket and cask. At location D5/B5 the effect of contact between the basket and cask wall should dominate, because the effect of thermal contact between the fuel canisters and basket should be the same for both locations. The effect of thermal contact between the basket and cask is the primary influence for location $E / F$; the magnitude of the effect is about the same as for location D5/B5, as would be expected.

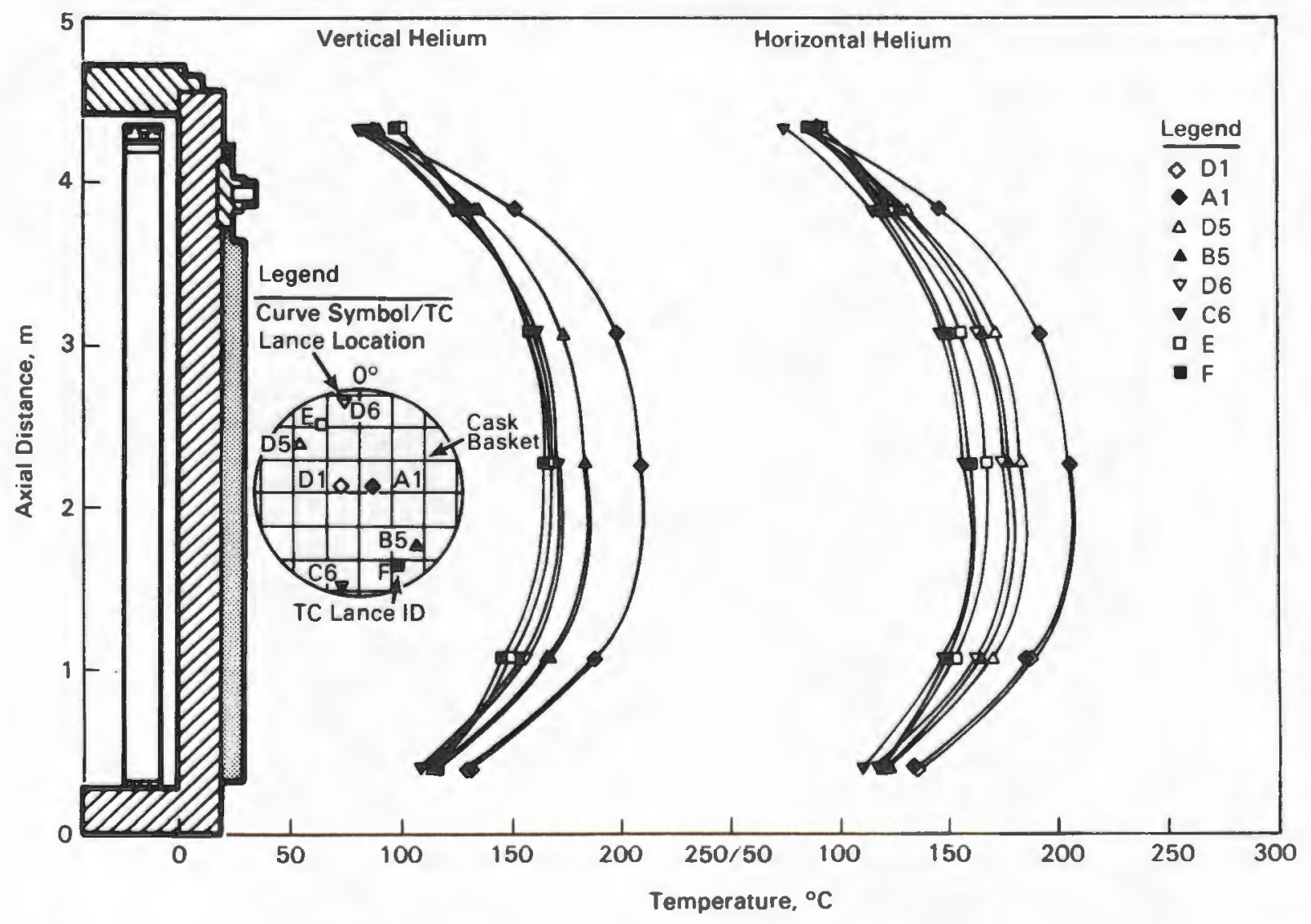

Figure 4-13. Comparison of axial temperature profiles for the vertical and horizontal helium runs. 
The radial profiles for the helium runs are shown in Figure 4-14. Figure 4-14 includes sets of profiles for the vertical and horizontal runs. These profiles are very similar in shape to those observed for the vacuum and nitrogen runs, but they are smaller in magnitude. As was done previously, the solid lines in Figure 4-13

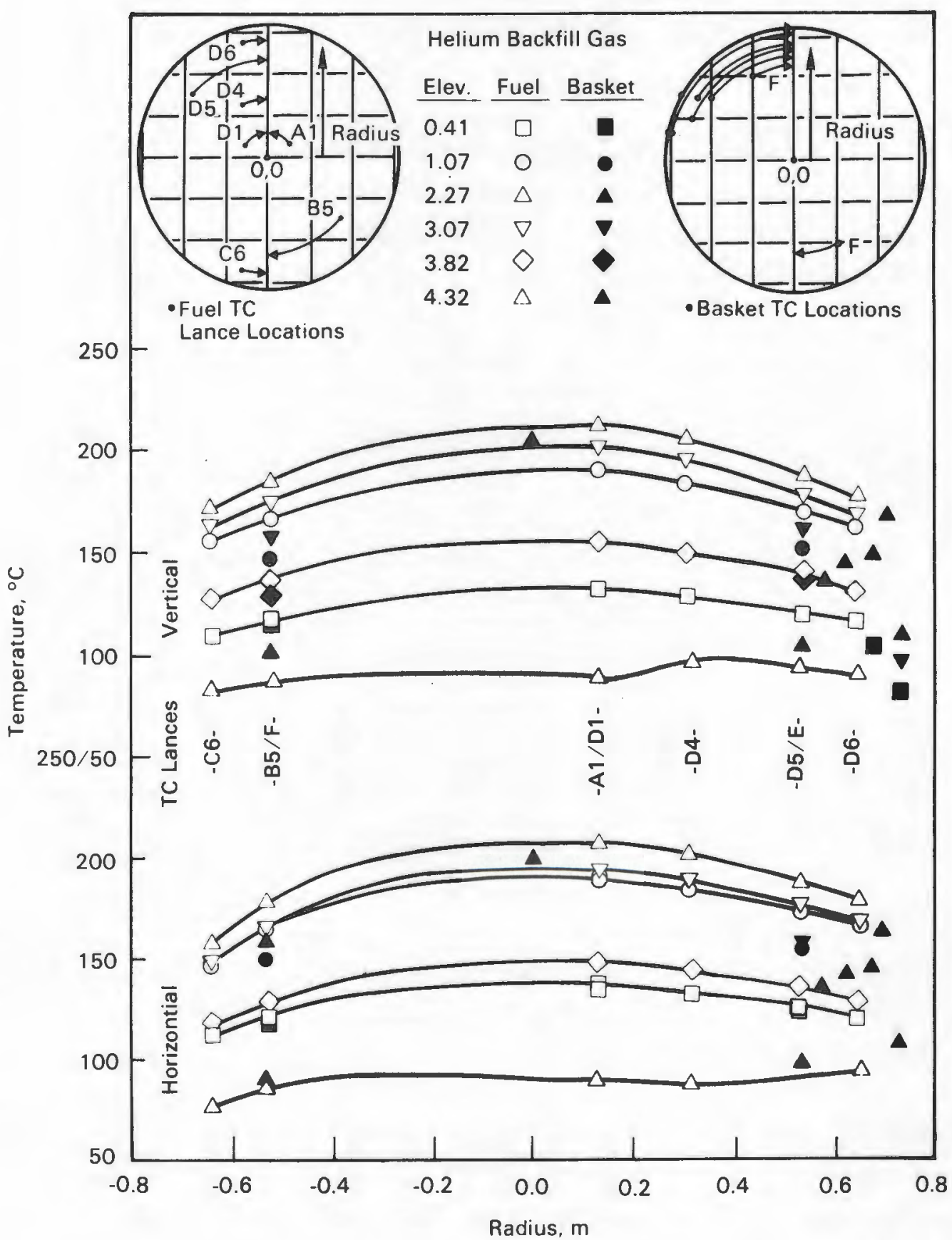

Figure 4-14. Radial temperature profiles for the vertical and horizontal helium runs. 
connect the temperatures taken in TC lances at common axial distances from the bottom of the cask. Temperature measurements made in the basket locations have not been connected with lines. Their elevation is indicated by the type of symbol used. The radius used represents the distance between the TC and the center of the cask.

Positive distances represent positions in the upper quadrants; negative radius represents a position in the lower quadrants of the horizontal cask. The insets show how this was done.

The temperature profiles in the horizontal run are skewed slightly, with the hotter temperature in the upper quadrants. However, this effect is more apparent from symmetry plots of Figure 4-13 than it is from comparing the curves in Figure 4-14. As with the runs described earlier, the differences in the shape and magnitude of the radial temperature profiles between the vertical and horizontal helium runs reflect the change in thermal contact resistance between the basket and cask inner wall due to cask orientation. In the horizontal run the radial slope of the curves at $0^{\circ}$ is less than in the vertical run, indicating a reduced heat flow at $0^{\circ}$. For the heat flow to decrease, the contact resistance between the basket and the cask wall must have increased. Likewise, at $180^{\circ}$ the slope of the radial temperature curve increases, reflecting a decrease in the contact resistance and an increase in the heat flow through the basket to the cask wall at $180^{\circ}$.

Another item of interest observed in Figure 4-14 is the temperature drop from the basket to the cask inner wal1. Based on the information at an elevation of $2.3 \mathrm{~m}$ $(7.5 \mathrm{ft})$, this temperature drop can be 30 to $60^{\circ} \mathrm{C}$ and represents a significant portion of the temperature drop from the center of the cask to the ambient (ambient temperature of about $20^{\circ} \mathrm{C}$ ).

\section{Effects of Backfill Environment}

Effects of backfill environment on guide tube temperatures are discussed in this section. Both axial and radial temperature profiles are compared for the different backfills and cask orientations.

Temperature data demonstrate that helium is the most effective backfill. Peak guide tube temperatures were significantly less $\left(77^{\circ} \mathrm{C}\right.$ for horizontal to $82^{\circ} \mathrm{C}$ for vertical) than for the vacuum runs, and they were less $\left(47^{\circ} \mathrm{C}\right.$ for horizontal to $57^{\circ} \mathrm{C}$ for vertical) than temperatures in nitrogen. Figure 4-15 shows the effect of gas environment and cask orientation on the temperatures measured in a center fue 1 canister. Incidentaliy, these temperatures represent the hottest measured in the 


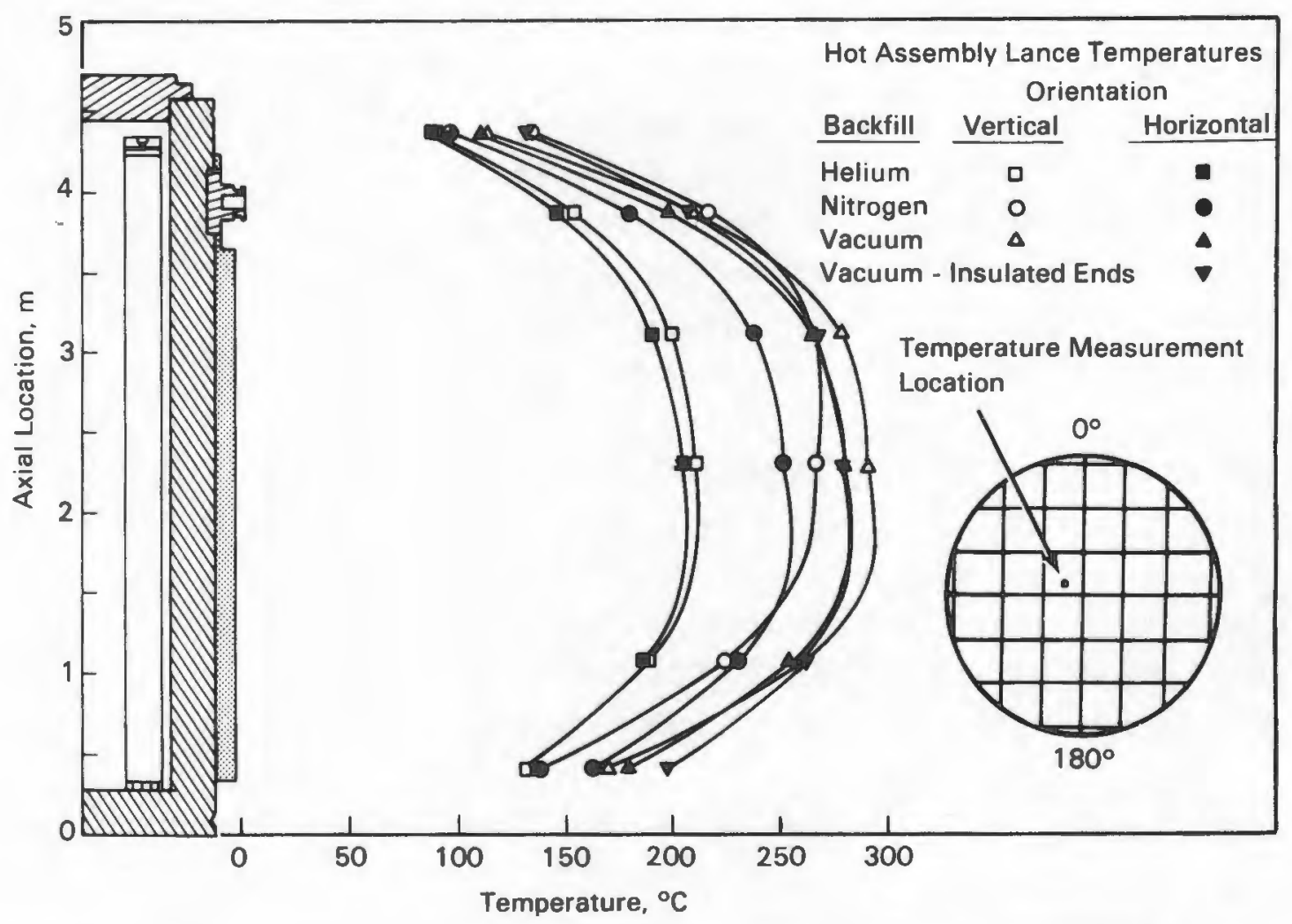

Figure 4-15. Effect of backfill gas environment and cask orientation on axial temperature profiles in the TN-24P cask loaded with consolidated fuel.

cask. The hot lance for all the runs was in the inner fuel canister Al. The vacuum profiles act as a base for determining the effect of convection in the cask. Both uninsulated vacuum runs show similarly shaped profiles, with a small difference in magnitude caused by the difference in conduction paths between the basket and cask due to orientation. The temperature profiles for the other horizontal nitrogen and helium runs are similar in shape but lower in magnitude than those for the uninsulated vacuum runs. The insulated vacuum run is similar in shape to the other vacuum runs and shows that the insulated ends are far enough away from the center of the cask to have little effect on the peak temperature. The similar profile shapes lead to the conclusion that there was no axial convection for the horizontal nitrogen and helium runs. The difference in magnitude is due primarily to the change in contact resistance between the basket and inner cask wall resulting from changing the cask orientation.

Axial convection is apparent in the vertical nitrogen run. The small difference in profiles between the vertical and horizontal helium runs is also associated with 
convection. Convection skews the temperature profiles, moving the location of the peak temperature upward in the cask. The skewing of the temperature profiles is apparent with vertical nitrogen and may be there for the vertical helium. The skewing would be expected to be greater in nitrogen because of the higher temperatures and greater density of nitrogen, which results in greater buoyancy forces and therefore more convection. In the nitrogen case, convection moves the location of the peak axial temperature from an elevation of $1.9 \mathrm{~m}(6.2 \mathrm{ft})$ to $2.7 \mathrm{~m}(8.9 \mathrm{ft})$, whereas in the helium case, the change is too small to measure.

The effect of convection on axial temperature profiles with consolidated fuel in the cask is much less than was seen for the cask loaded with unconsolidated fuel assemblies (unconsolidated). This difference can be seen by comparing the temperature profiles in Figure 4-15 with those in Figure 4-16. Figure 4-16 shows the effect of gas environment and cask orientation on the axial temperature profile for the hot assembly in the TN-24P cask loaded with unconsolidated fuel assemblies ( $\underline{3}$ ).

With unconsolidated fuel assemblies in the cask, convection moved the location of the peak axial temperature from an elevation of $1.9 \mathrm{~m}(6.2 \mathrm{ft})$ for the horizontal cask to $3.6 \mathrm{~m}(11.8 \mathrm{ft})$ for a vertical cask filled with nitrogen and to $2.4 \mathrm{~m}$ $(7.9 \mathrm{ft})$ for a vertical cask filled with helium. The effect of convection is also seen from comparing peak fuel cladding temperatures from the two performance tests (Table 4-2).

The peak cladding temperatures for the vacuum runs are nearly equal even though the heat load in the cask is less for the unconsolidated fuel than for the consolidated fue1. This points out the effectiveness of conduction in the consolidated fuel canister verses conduction in the fuel assembly. Conduction is also the primary mode of heat transfer in the helium and horizontal runs, as indicated by similarity of the temperatures for both the horizontal and vertical runs. Convection is much more effective in the open unconsolidated fuel assemblies than it is in the cask loaded with consolidated fuel, as seen by the higher temperature in the canister than in the fuel assembly for the vertical nitrogen run.

Figure 4-17 shows the radial temperature profiles at the elevation of the peak axial temperature from each of the six runs. Temperatures for all three backfill conditions show good radial symmetry when the cask is in the vertical orientation. In the horizontal orientation, the temperatures are skewed for all three fill conditions; the temperatures in the lower quadrants of the cask are lower because of better contact between the basket and the cask in the lower quadrants caused by the 


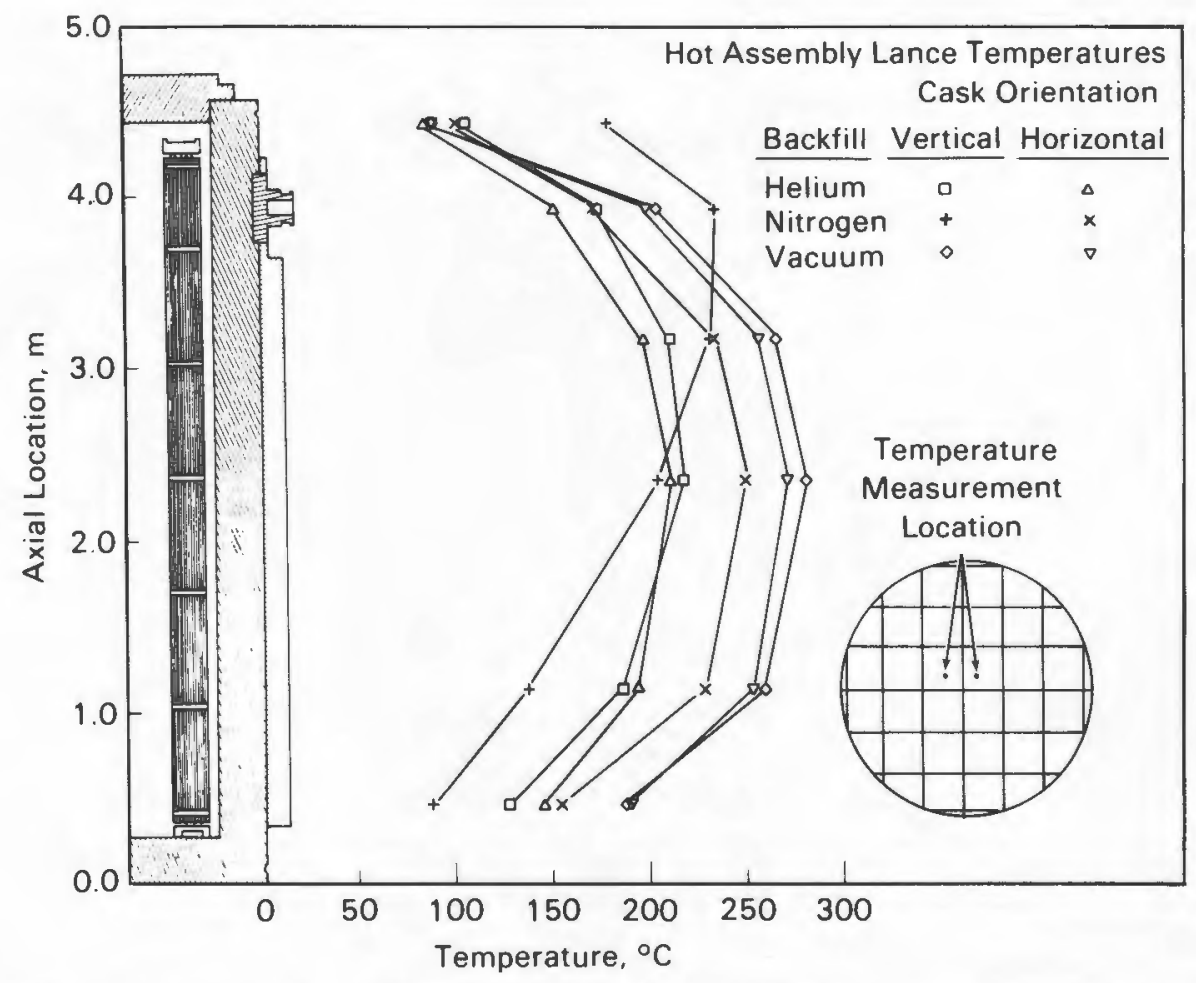

Figure 4-16. Effect of backfill gas environment and cask orientation on axial temperature profiles in the $\mathrm{TN}-24 \mathrm{P}$ cask loaded with unconsolidated fuel.

weight of the fuel pushing the basket against the bottom side of the cask. Figure 4-17 also shows that the relative difference between the fuel and adjacent basket temperature ( 1 ance temperatures at locations $B 5 / F$ and $D 5 / E$ ) is about the same for the vertical and horizontal runs. This may be due to the compensating effect of surrounding fuel assemblies. At the top, fuel assembly D6 comes into better contact with the basket next to lance location $E$ while the canister in D5 pulls away. The net effect of a potentially better heat transfer path from D6 and a poorer heat transfer path from D5 appears to be close to zero, based on the temperature difference between $E$ and D5.

A similar effect is seen between fuel canister locations B5 and B6 and temperature measurement locations $B 5$ and $F$. In any case, the relative fuel-to-basket temperature difference does not change by virtue of cask orientation but does change as a function of gas thermal conductivity (gas backfill). The data are inconclusive as to the effect of cask orientation on contact resistance between the fuel canisters and the basket. 
Table 4-2

COMPARISON OF PEAK FUEL TEMPERATURES IN THE TN-24P CASK LOADED

WITH UNCONSOLIDATED FUEL ASSEMBLIES AND CONSOLIDATED FUEL CANISTERS

\begin{tabular}{|c|c|c|c|c|c|c|c|c|}
\hline \multirow[b]{2}{*}{ Run No. } & \multirow[b]{2}{*}{ Orientation } & \multirow[b]{2}{*}{ Backfill } & \multicolumn{3}{|c|}{ Fuel Assemblies } & \multicolumn{3}{|c|}{ Consolidated Canisters } \\
\hline & & & $\begin{array}{l}\text { Heat } \\
\text { Load, } \\
\text { kW }\end{array}$ & $\begin{array}{l}\text { Ambient } \\
\text { Temp, } \\
\text { 'c } \\
\end{array}$ & $\begin{array}{r}\text { Peak } \\
\text { Clad. } \\
\text { Temp, }{ }^{\circ} \mathrm{C} \\
\end{array}$ & $\begin{array}{l}\text { Heat } \\
\text { Load, } \\
\text { kW }\end{array}$ & $\begin{array}{l}\text { Ambient } \\
\text { Temp, } \\
\text { 'C } \\
\end{array}$ & $\begin{array}{c}\text { Peak } \\
\text { Clad. } \\
\text { Temp, }{ }^{\circ} \mathrm{C}\end{array}$ \\
\hline 1 & Vertical & Helium & 20.6 & 18 & 221 & 23.3 & 21 & 211 \\
\hline 2 & Vertical & Nitrogen & 20.6 & 20 & 241 & 23.3 & 19 & 268 \\
\hline 3 & Vertical & Vacuum & 20.6 & 20 & 290 & 23.2 & 19 & 293 \\
\hline 4 & Horizontal & Helium & 20.5 & 18 & 215 & 23.2 & 20 & 205 \\
\hline 5 & Horizontal & Nitrogen & 20.4 & 21 & 256 & 23.1 & 17 & 252 \\
\hline 6 & Horizontal & Vacuum & 20.3 & 19 & 280 & 23.1 & 20 & 282 \\
\hline 7 & Horizontal & Vacuum ( & nsulat & d ends) & & 23.1 & 21 & 282 \\
\hline
\end{tabular}

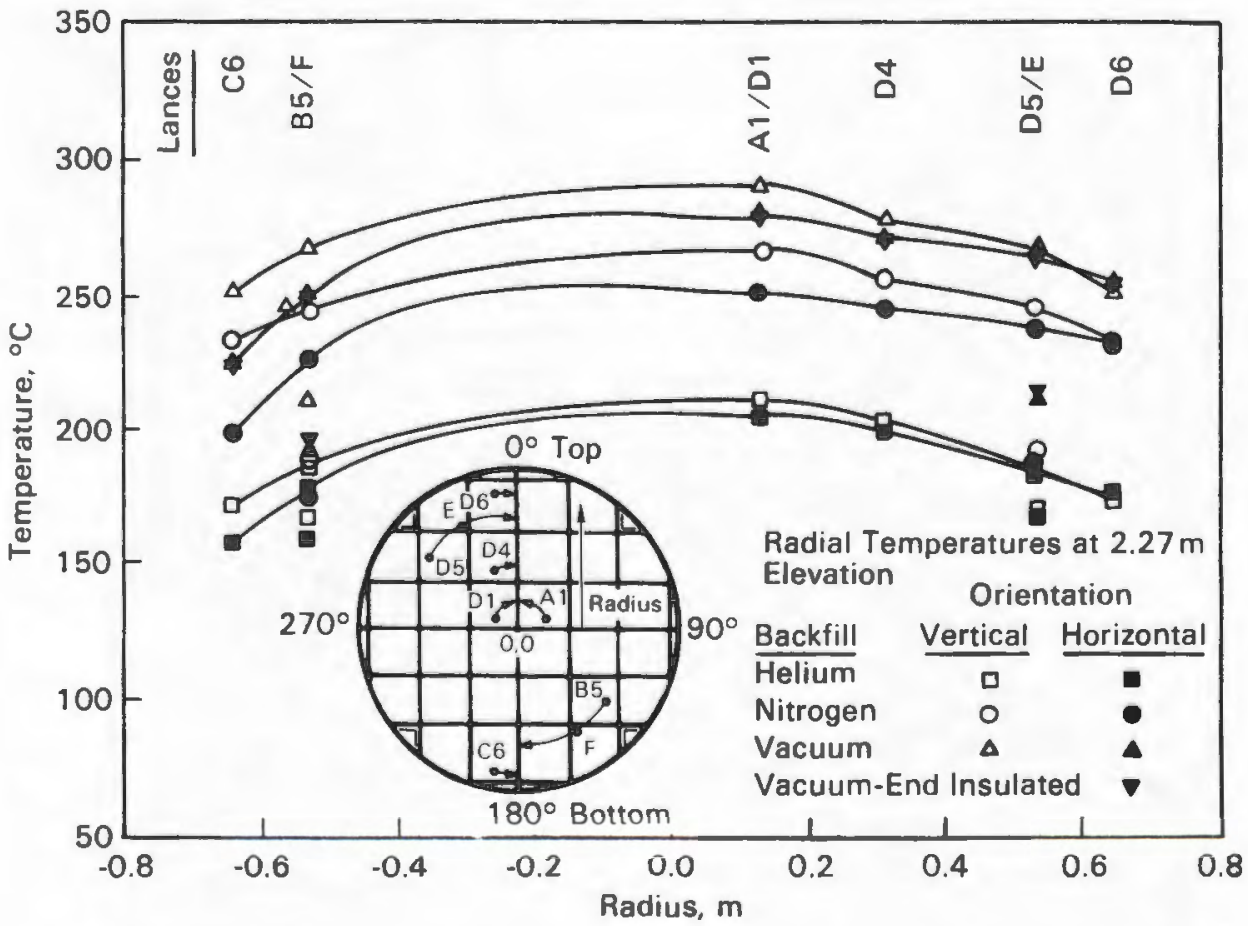

Figure 4-17. Radial temperature profiles measured near peak axial temperature for the TN-24P cask loaded with consolidated fuel. 
Figure 4-17 does not show the anomaly in the radial profiles that was seen for the horizontal nitrogen run with unconsolidated fuel assemblies in the cask. This anomaly is shown in Figure 4-18 (Ref. 3 , Figure 4-19). For unconsolidated fuel the temperature at location D5 was always greater than the temperature at location D6, except for the horizontal nitrogen run. The horizontal nitrogen run also had a bigger increase in temperature difference between $B 5$ and $C 6$ than did any of the other runs. This change in behavior of the temperatures at D5/D6 and B5/C6 for the horizontal nitrogen run with unconsolidated fuel in the cask was attributed to the possible development of a convective cell in the adjoining open basket location in the horizontal cask. Figure 4-17, does not show a change in the relationship of temperatures at $\mathrm{B} 5 / \mathrm{C} 6$ and $\mathrm{D5} / \mathrm{D} 6$ due to change in cask orientation or gas fill.

Because the relationship between $\mathrm{B} 5$ and $\mathrm{C} 6$, and between $\mathrm{D} 5$ and $\mathrm{D} 6$ in Figure 4-17 does not change, either the effect seen for unconsolidated fuel must be due to convection in the fuel assemblies or the larger thermal mass and conduction through

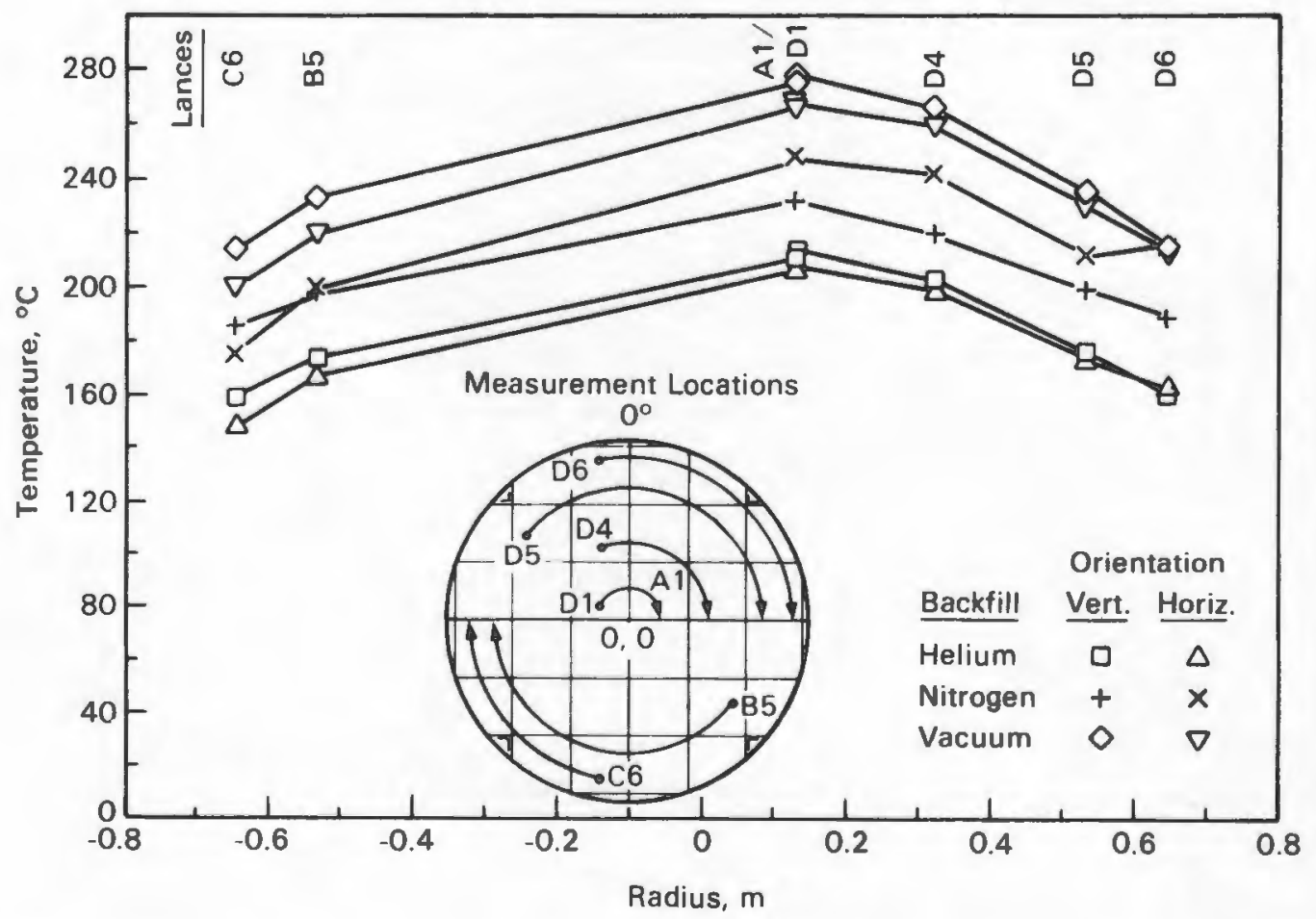

Figure 4-18. Radial temperature profiles measured near peak axial temperatures for TN-24P cask loaded with unconsolidated fuel. 


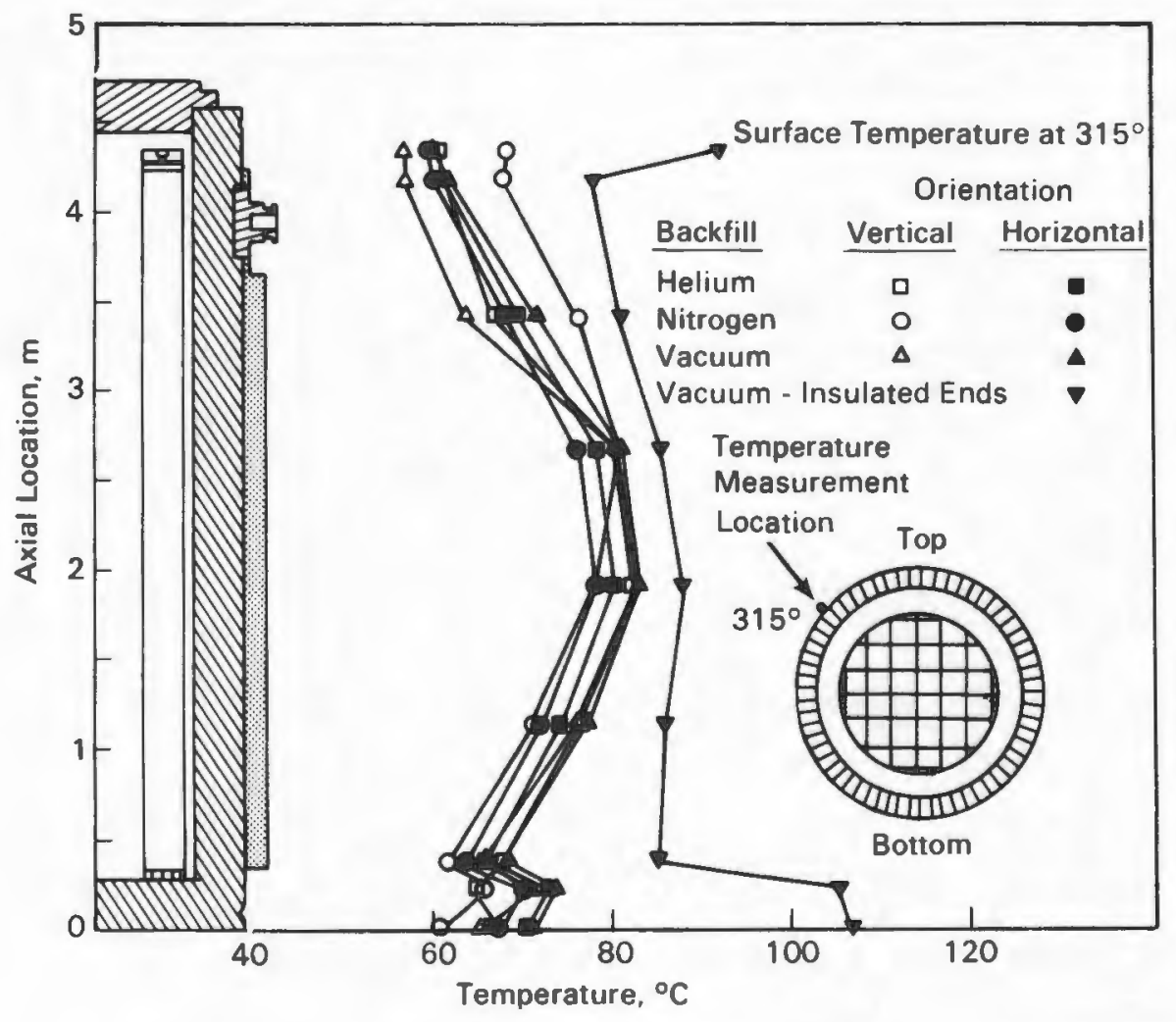

Figure 4-19. Axial Surface Temperature Profiles

the consolidated fuel canister masks the effect. The open fuel assemblies could support a variety of convective cells, whereas the packed nature of the fuel canister and the way the fuel canister rests on the basket prevents convective cells from forming around the fuel canister in the horizontal runs.

Backfill also affects the temperature drop between the basket and the inside wall of the cask. For the vacuum runs this drop was 60 to $110^{\circ} \mathrm{C}$. In the nitrogen runs it was between 50 and $90^{\circ} \mathrm{C}$, and for the helium runs it was between 30 and $60^{\circ} \mathrm{C}$. This temperature drop represents a significant portion of the total temperature drop from the peak temperature in the cask to the ambient temperature.

\section{Surface Temperature Characteristics}

Cask surface temperatures are important from an operation and maintenance standpoint. The ambient temperature, peak measured surface temperature on the 
uninsulated portion of the cask, and the mean surface temperatures are listed in Table 4-3. Axial temperature profiles measured on the cask surface at an angle of $315^{\circ} \mathrm{C}$ are shown in Figure $4-19$; the temperatures around the circumference of the cask are shown in Figure 4-20. The surface temperature data are provided in Appendix C.

Excluding the insulated vacuum run, the highest surface temperature $\left(97^{\circ} \mathrm{C}\right)$ was measured during the horizontal vacuum run on the bottom side (at a location of $180^{\circ}$ ) of the cask at an elevation of $2.65 \mathrm{~m}(8.7 \mathrm{ft})$. However, Figure $4-19$ indicates that the maximum surface temperature (at a location of $315^{\circ}$ ) occurs near an elevation of $2 \mathrm{~m}(6.5 \mathrm{ft})$ and may be a few degrees higher than the temperature measured at $2.65 \mathrm{~m}$ $(8.7 \mathrm{ft})$. Table 4-3 indicates that the maximum side temperature increases for the horizontal runs. The maximum temperature was found at the bottom side of the cask, as seen in Figure 4-20. The increased temperatures for the horizontal runs at $180^{\circ}$ in Figure 4-20 confirm an increase in thermal contact between the basket and the cask wall on the bottom side of the cask during the horizontal runs. Figure 4-20 also shows a fairly uniform temperature around the cask for the vertical run.

Table 4-3

CASK SURFACE TEMPERATURE MEASUREMENTS

\begin{tabular}{|c|c|c|c|c|c|c|c|}
\hline Run No. & Orientation & Backfill & $\begin{array}{l}\text { Ambient } \\
\text { Temp, }{ }^{\circ} \mathrm{C}\end{array}$ & $\begin{array}{l}\text { Maximum } \\
\text { Side } \\
\text { Temp, }{ }^{\circ} \mathrm{C} \\
\end{array}$ & $\begin{array}{l}\text { Average } \\
\text { Side } \\
\text { Temp, }{ }^{\circ} \mathrm{C} \\
\end{array}$ & $\begin{array}{c}\text { Average } \\
\text { Lid } \\
\text { Temp, }{ }^{\circ} \mathrm{C}\end{array}$ & $\begin{array}{l}\text { Average } \\
\text { Bottom } \\
\text { Temp, }{ }^{\circ} \mathrm{C} \\
\end{array}$ \\
\hline 1 & Vertical & Helium & 21 & 82 & 70 & 62 & - \\
\hline 2 & Vertical & Nitrogen & 19 & 81 & 70 & 69 & - \\
\hline 3 & Vertical & Vacuum & 19 & 83 & 69 & 52 & - \\
\hline 4 & Horizontal & Hel ium & 20 & 91 & 70 & 59 & 78 \\
\hline 5 & Horizontal & Nitrogen & 17 & 89 & 69 & 58 & 75 \\
\hline 6 & Horizonta 1 & Vacuum & 20 & 97 & 72 & 57 & 78 \\
\hline 7 & Horizontal & Vacuum ${ }^{\mathrm{a}}$ & 21 & 101 & 85 & 97 & 114 \\
\hline
\end{tabular}

aThe ends of the cask were insulated to simulate impact limiters. 


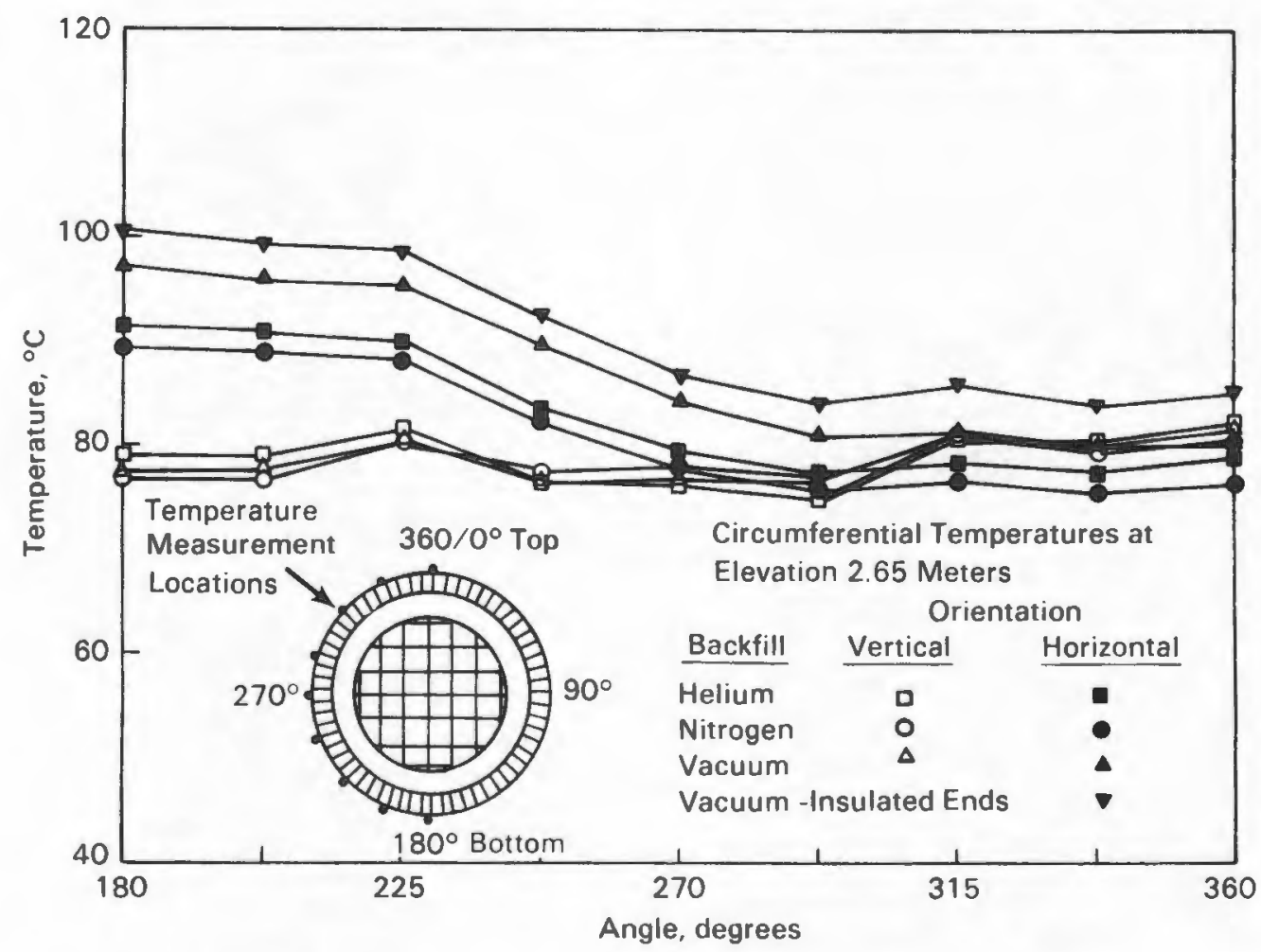

Figure 4-20. Circumferential Surface Temperature Profiles

The average side temperature listed in Table 4-3 represents the average of the temperatures at $315^{\circ}$ along the outside of the uninsulated portion of the cask. The data in both Table 4-3 and Figure 4-20 indicate that the cask surface temperatures at this location vary only slightly with changes in cask orientation or backfill medium.

Except for the vertical nitrogen run, little difference is seen in the lid temperatures for the various backfills and orientations. The modest increase in lid temperature for the vertical nitrogen runs is a result of convection in the cask.

Insulating the ends of the cask had the largest effect on the average cask temperature, resulting in about a $15^{\circ} \mathrm{C}$ increase. As seen in Figure 4-19, insulating the ends has the largest effect near the ends of the cask. The data in Figure 4-19 and Table 4-2 show only a small increase in the overall peak surface and peak fuel temperatures in the cask. The insulation does cause a significant increase of temperature at the ends of the cask, about $40^{\circ} \mathrm{C}$ for both the lid and bottom of the cask. However, the heat flow redistributes near the ends of the cask and causes little increase of temperature near the cask midplane. 


\section{Temperature Transients}

Temperature transients occurred during testing as a result of changes in backfill environment and cask orientation. As much transient temperature data as practical were collected, but, because the TC lances were disconnected during cask rotations, continuous data scanning was not possible.

Figure 4-21 shows the cask temperature history at an elevation of $2.25 \mathrm{~m}(7.4 \mathrm{ft})$ for a center assembly (D1), basket center, outer basket, inner cask wal1, cask surface, and ambient temperature. Vertical lines have been added to the plot to

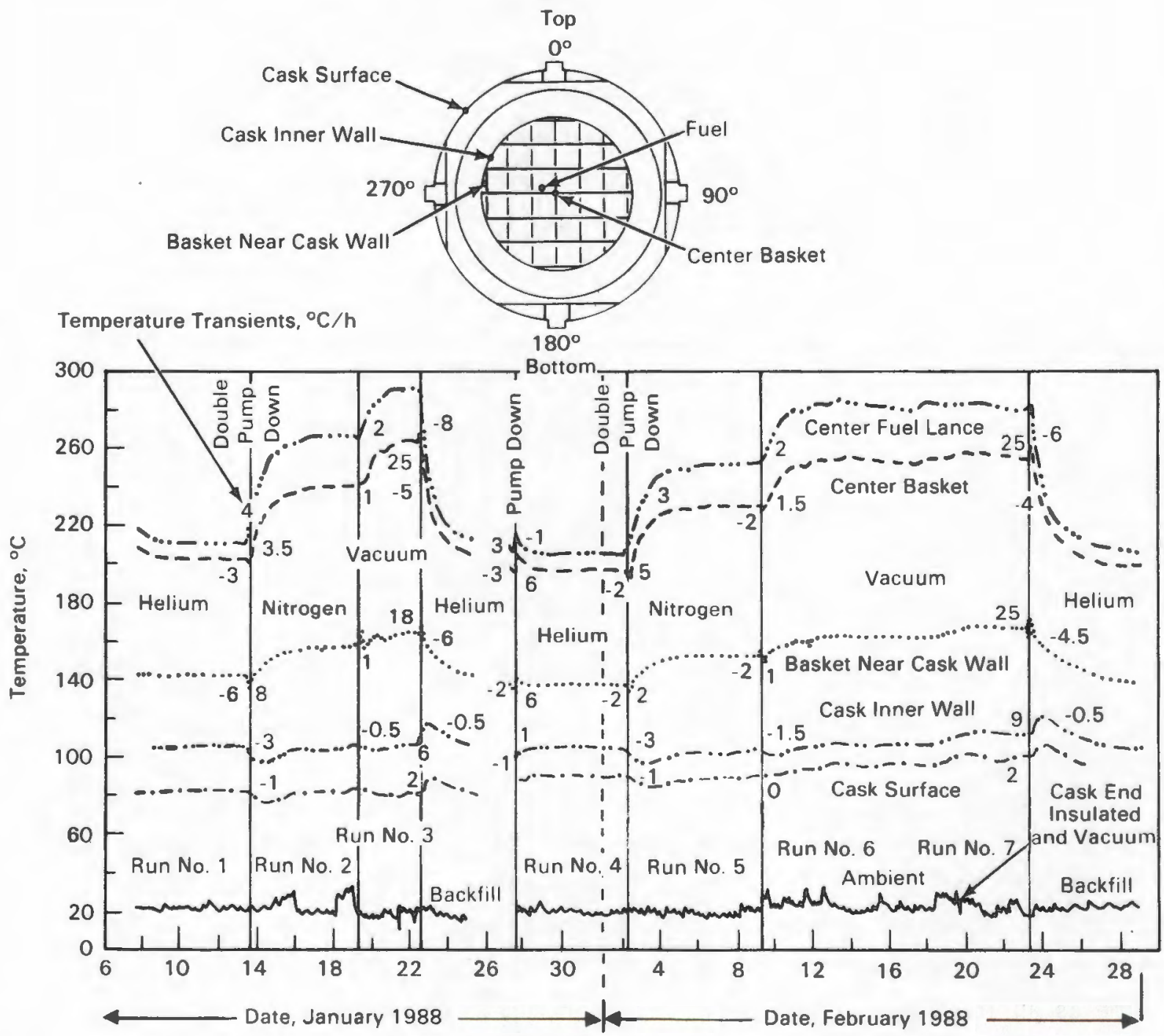

Figure 4-21. Cask, Basket, and Ambient Temperature History During Cask Testing 
differentiate among backfill conditions. Double pumpdowns and backfills were used in any transition from helium to nitrogen to ensure that relatively pure nitrogen was in the cask. Gas samples were taken at the beginning and end of any helium or nitrogen run to ensure the absence of oxygen in the cask and to check on the purity of the backfill during the entire test run.

The data indicate that fuel temperature transients were very mild. The steepest transient fuel temperature rise for a center assembly occurred immediately following the change from helium to nitrogen gas when the cask was in a vertical orientation. The transient was on the order of $4^{\circ} \mathrm{C} / \mathrm{h}$. The steepest measured fuel temperature transient, on the order of $-8^{\circ} \mathrm{C} / \mathrm{h}$, occurred on cooldown after the vertical vacuum run when the cask was backfilled with helium. Maximum transients in the basket occurred at the end of the vacuum run when helium was reintroduced into the cask; these ranged from a short heatup at $25^{\circ} \mathrm{C} / \mathrm{h}$ to a subsequent cooldown of $-6^{\circ} \mathrm{C} / \mathrm{h}$. The cask wall also saw transients from a maximum of $9^{\circ} \mathrm{C}$ on heatup during a helium backfill to a $-3^{\circ} \mathrm{C}$ cooldown for the helium to nitrogen backfill change. Figure 4-21 al so shows the cyclic nature of the ambient temperatures in the warm shop. Typically, the shop temperatures rise during the day and fall at night and on weekends. The average daily temperature preceding the test run is given in the data in Appendix C.

Changing the backfill gas in the cask has several interesting effects that can be seen from the test history. When the backfill is changed from helium to nitrogen, the gas thermal conductivity in the cask is decreased. This increases the thermal resistance between the fuel, basket, and cask wall and has a net effect of increasing the temperatures in the cask. At the beginning of the heatup, part of the decay heat generated in the cask goes to heating the fuel and basket. The remainder flows out of the cask. Until equilibrium, the decay heat generated is divided between that which flows out of the cask and that which heats the fuel and basket. At equilibrium, all the decay heat generated flows out of the cask. The effect of the division of decay between that which flows out of the cask and that which heats the fuel and basket is seen in Figure 4-21. When the backfill is changed from helium to nitrogen or from helium to vacuum, the cask wall temperature decreases, indicating a decrease in heat flow from the cask. Simultaneously, the temperature of the fuel and basket increases. When the cask is backfilled with helium at the end of a vacuum run, a decrease in the temperature of the fuel and basket occurs at the same time as an increase in the cask wall temperature, indicating an increase in the flow of heat from the cask. This increase in heat flow is a result of increased conductivity in the cask that allows the thermal energy stored in the fuel during 
the vacuum and nitrogen runs (energy associated with increased fue 1 temperatures) to flow from the fuel to the basket and cask. The increased energy flow (decay heat plus stored energy) is seen as a temporary increase in the basket and cask temperatures.

Nitrogen and helium backfills have significantly different thermal conductivities and convection characteristics. However, these differences did not result in significant temperature transients in the consolidated spent fuel canisters. In fact, the thermal mass of the fuel, the flat temperature profile across a fuel canister, and the thermal resistance between the basket and fuel canister cause the fuel temperature transients to be significantly less for consolidated fuel than they are for unconsolidated fuel assemblies. Maximum temperature transients for unconsolidated fuel in the TN-24P cask were observed to be $12^{\circ} \mathrm{C} / \mathrm{h}$ to $-30^{\circ} \mathrm{C} / \mathrm{h}(\underline{3}$ ) compared to $4^{\circ} \mathrm{C}$ to $-8^{\circ} \mathrm{C}$ noted for consolidated fuel during this test.

\section{SHIELDING PERFORMANCE}

Portable hand-held instruments were used by PNL and INEL to obtain gamma and neutron dose rate readings at selected measurement locations on the cask surface (see Section 3, Figures 3-11 and 3-12). These locations included 16 points on the lid and bottom, 22 points on the side, and 6 points associated with trunnions. The following sections present data obtained during dose rate measurements and compare the consolidated fuel results with those previously obtained with unconsolidated fuel. A complete listing of the data from this test with consolidated fuel is presented in Appendix D.

\section{Cask Lid and Bottom Dose Rate Measurements}

Figure 4-22 profiles the gamma and neutron dose rates measured on the test 1 id and bottom of the cask at $90^{\circ}$ and $225^{\circ}$ angles. The measurement locations at $90^{\circ}$ have been offset by $115 \mathrm{~mm}$ ( $4.5 \mathrm{in.}$ ) so they are centered over the tops of fuel canisters. The measurement locations with respect to the fuel canisters are shown on the inset to Figure 4-22. The cask 1id measurements were taken without the neutron shield or protective cover in place. The neutron profiles are relatively flat over the central portion of the lid, with a low reading in the center. The reason for the low center neutron reading is not apparent. The gamma profiles are also relatively flat over the central portion of the cask lid, with higher readings near the outer radius. The higher gamma readings near the outside of the lid reflect a step decrease in lid thickness at that location. 


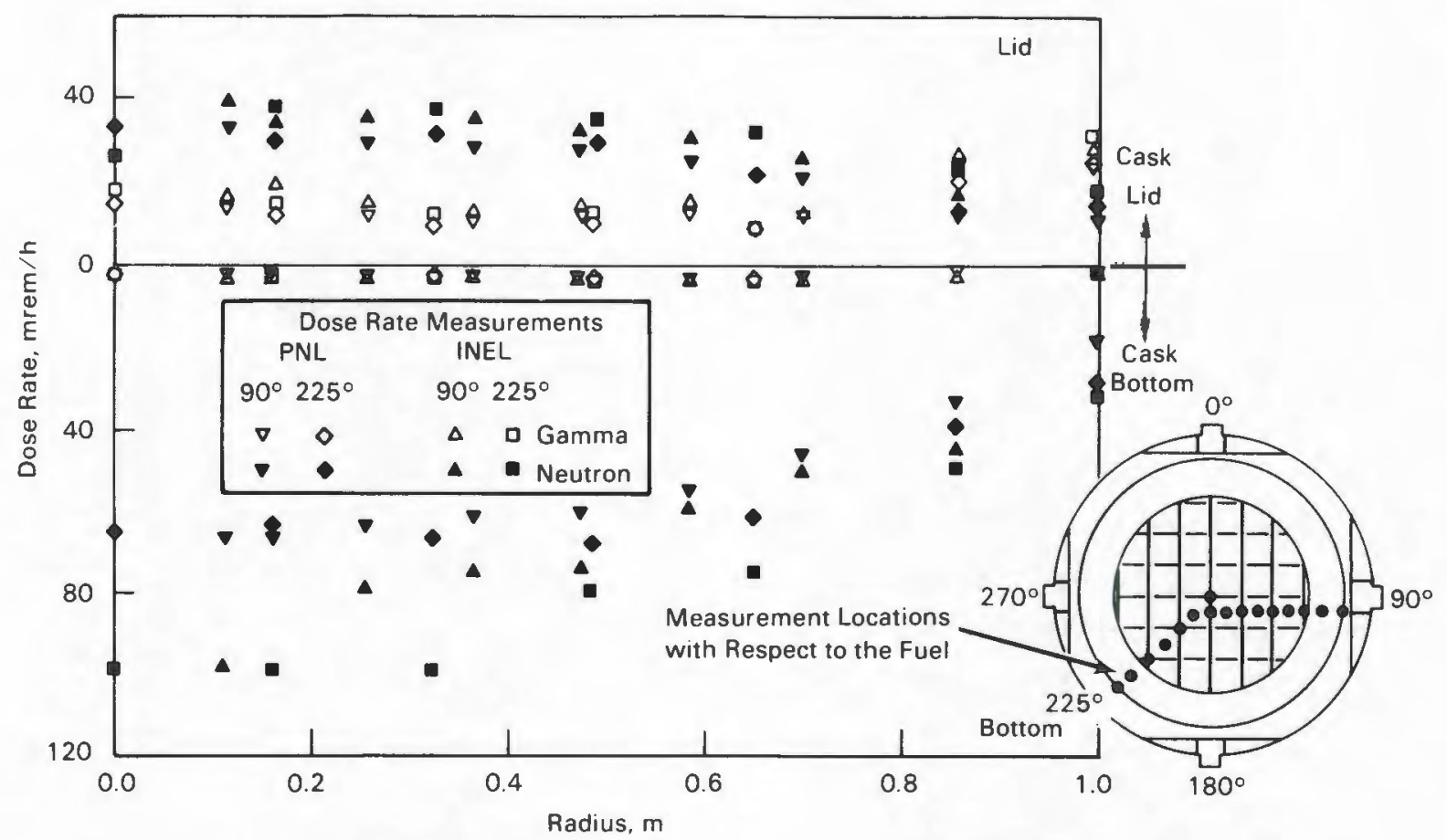

Figure 4-22. Gamma and neutron dose rate profiles measured on cask bottom and test lid with consolidated fuel in the cask.

The dose rate profiles on the bottom of the cask at $90^{\circ}$ and $225^{\circ}$ are also shown in Figure 4-22. The neutron and gamma dose rate profiles are relatively flat over the central portions of the cask. The continuity in the neutron data reflects the readability of the instrument. The PNR-4 used to make the measurements had two scales, one from 0 to $50 \mathrm{mrem} / \mathrm{h}$ and the other from 0 to $5000 \mathrm{mrem} / \mathrm{h}$. Most of the neutron dose information obtained on the bottom of the cask with this instrument used the 0 - to $5000-\mathrm{mrem} / \mathrm{h}$ scale (measurements were in the 1 ower $2 \%$ of this scale) while the SNOOPY used a 0 - to $200-\mathrm{mrem} / \mathrm{h}$ scale.

The radiation dose rate measurements taken at $90^{\circ}$ on the cask 1 id and bottom with consolidated fuel in the cask are compared in Figure 4-23 with those taken previously with unconsolidated fuel assemblies in the cask. In comparing the dose rates, note that the decay heat output from the cask was about the same for both the unconsolidated and the consolidated fuel performance tests $(20.6 \mathrm{~kW}$ for unconsolidated fuel and $23.2 \mathrm{~kW}$ for consolidated fuel). However, the load patterns were different for the unconsolidated fuel and consolidated fuel tests. In the consolidated fuel tests, the hot canisters were loaded in the outer basket locations, and canister decay heat output varied from 700 to $1185 \mathrm{~W}$. In the unconsolidated 
tests, the decay heat output of the fuel assemblies ( $\underline{3}$ ) was more uniform, with decay output varying from 850 to $919 \mathrm{~W}$, and the hotter assemblies were loaded in the center of the basket. With this in mind, two general observations can be made. First, the neutron dose rates are of comparable magnitude for unconsolidated and consolidated fuel in the cask. Second, the gamma dose rates are much lower for consolidated fuel canisters than for unconsolidated fuel assemblies.

The lid centerline gamma dose rate measured with consolidated fuel (13 mrem/ $h$ ) is significantly less than that observed (50 to $60 \mathrm{mrem} / \mathrm{h}$ ) for the previous performance test using unconsolidated fuel. An even bigger drop in the gamma dose rate is seen on the bottom of the cask, where the centerline gamma measurement with unconsolidated fuel ranged from 120 to $170 \mathrm{mrem} / \mathrm{h}$ compared to less than $5 \mathrm{mrem} / \mathrm{h}$ with consolidated fuel. The reduction in gamma dose rates resulted from removal of the ${ }^{60}$ Co-bearing end fittings during the consolidation process. With the end fittings removed, most of the gamma radiation seen on the lid surface is probably associated

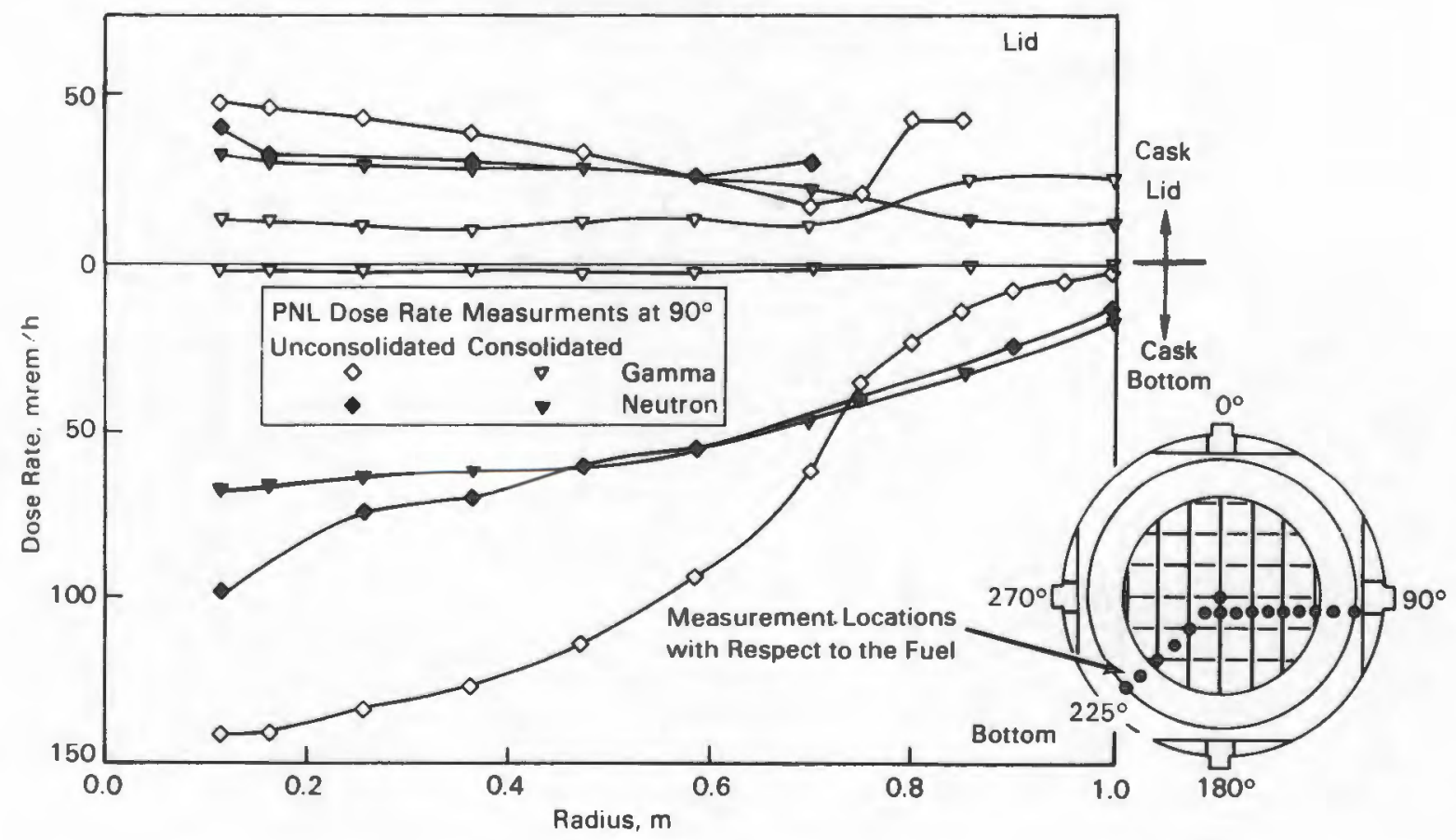

Figure 4-23. Comparison of gamma and neutron dose rate profiles measured on cask bottom and test lid for consolidated or unconsolidated fuel in the TN-24P cask. 
with the activation of the stainless steel springs in the tops of the fuel rods. These spring are placed in the fuel rod plenum region during fabrication, to hold the fuel pellets in place.

The neutron dose rates on the top and bottom of the cask are about the same for consolidated canisters and for unconsolidated fuel. The increase in neutron dose for unconsolidated fuel near the center of the cask is attributed to differences between load patterns for the unconsolidated and the consolidated fuel tests. The hotter assemblies were loaded in the center of the cask for the unconsolidated fuel assembly tests.

\section{Cask Side Dose Rate Measurements}

Dose rates measured on the side of the cask at $60^{\circ}$ and $90^{\circ}$ are shown in Figure 4-24. The neutron dose rate profiles show peaks at the top and bottom, with a flat profile

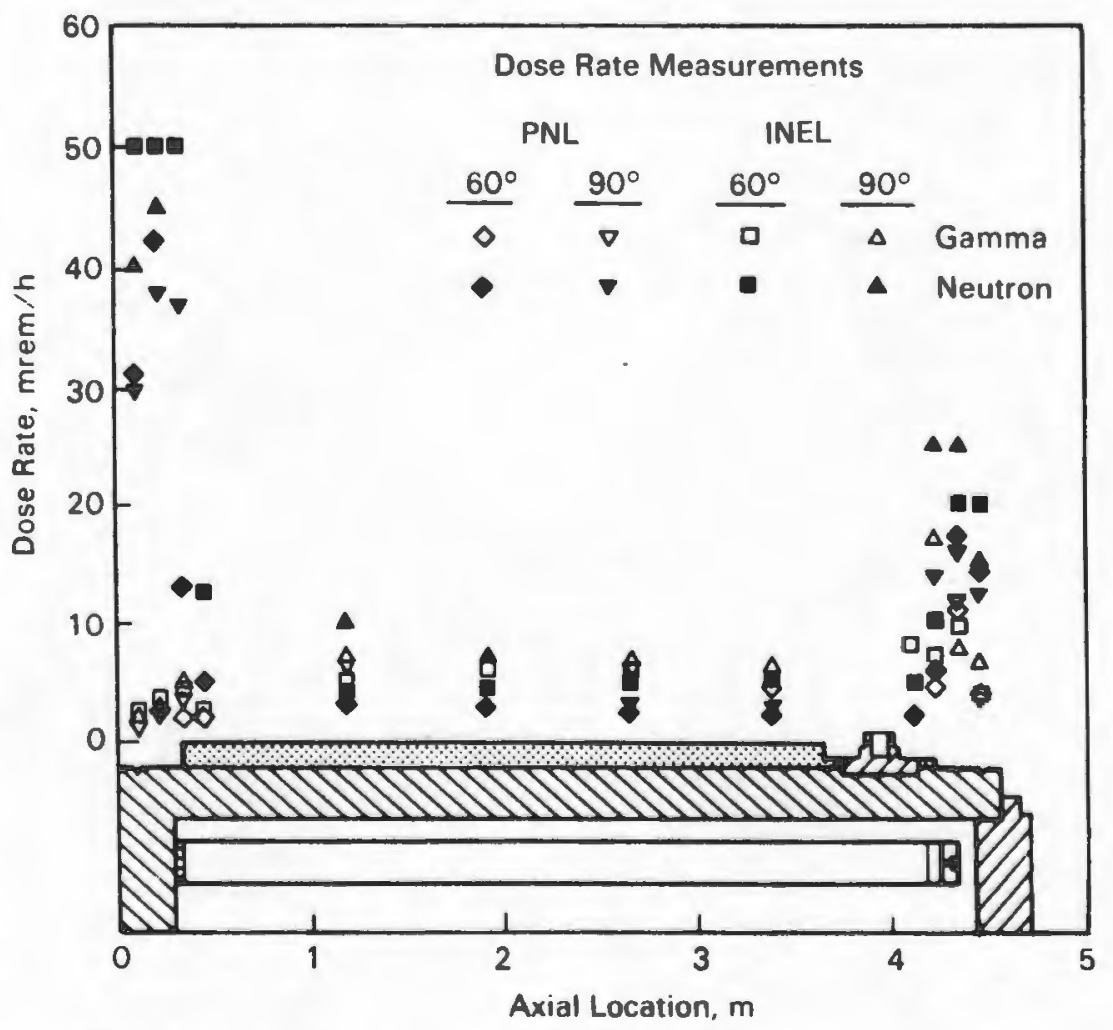

Figure 4-24. Axial gamma and neutron dose rate profiles measured on cask surface with consolidated fuel in the TN-24P cask. 
between. The peaks occur at the ends of the neutron shield, as would be expected. The gamma dose rate profiles show a peak at the top of the cask and a relatively flat profile over the remainder of the cask.

The dose rate profiles on the side of the cask at $90^{\circ}$ when loaded with consolidated fuel are compared in Figure 4-25 with those from the previous test with the cask loaded with unconsolidated fuel assemblies. The neutron dose rate magnitudes with consolidated fuel in the cask are about the same as those observed in the cask performance test with unconsolidated fuel. Both unconsolidated and consolidated fuel produce a neutron profile with peaks at the ends of the neutron shield and relatively flat profiles between the peaks. The axial gamma profiles show significant differences. The magnitudes of the gamma profiles for consolidated fuel are much lower than those observed for unconsolidated fuel. The reduced gamma dose rate results from removal of the upper and lower nozzles and spacer grids from the fuel during the consolidation process. These non-fuel-bearing components, made from Type 304 stainless steel and Incone ${ }^{m}$ 718, are sources of ${ }^{60} \mathrm{Co}$, a gamma emitter. Their removal eliminates the gamma peak at the bottom of the cask, reduces the gamma dose along the side of the cask, and reduces the gamma peak at the top of the cask. The gamma peak at the upper end of the cask is associated with the stainless steel holddown springs in the fuel rods.

\section{Cask Dose Rate Attenuation}

Dose rates were measured at selected locations on the cask surface and at $1 \mathrm{~m}(3.3$ $\mathrm{ft})$ and $2 \mathrm{~m}(6.6 \mathrm{ft})$ adjacent to the cask in air. The attenuation that can be expected from the cask surface to $2 \mathrm{~m}$ away from the cask is illustrated in Figure 4-26.

At the top of the cask, neutron surface dose rates adjacent to the centerline were attenuated from $32 \mathrm{mrem} / \mathrm{h}$ at contact to $7.5 \mathrm{mrem} / \mathrm{h}$ at $1 \mathrm{~m}(3.3 \mathrm{ft})$ from the cask, and $4 \mathrm{mrem} / \mathrm{h}$ at $2 \mathrm{~m}(6.6 \mathrm{ft})$ from the cask surface. The attenuation in neutron dose rate at $r / 2$ (one-half radius out from the center) was about the same as at the center. At the outer radius of the lid, the neutron dose rate at the surface was about $12 \mathrm{mrem} / \mathrm{h}$. The attenuation of this dose rate from $12 \mathrm{mrem} / \mathrm{h}$ at the surface to 3.4 at $2 \mathrm{~m}(6.6 \mathrm{ft})$ is not as great as that observed at the centerline of the $1 \mathrm{id}$. The decrease in attenuation of the dose rate is caused by radial spreading of the. dose rates and the influence of the center dose rate on the outside dose rate (the

"A nickel chromium alloy manufactured by Huntington Alloys, Inc., Huntington, West Virginia. 


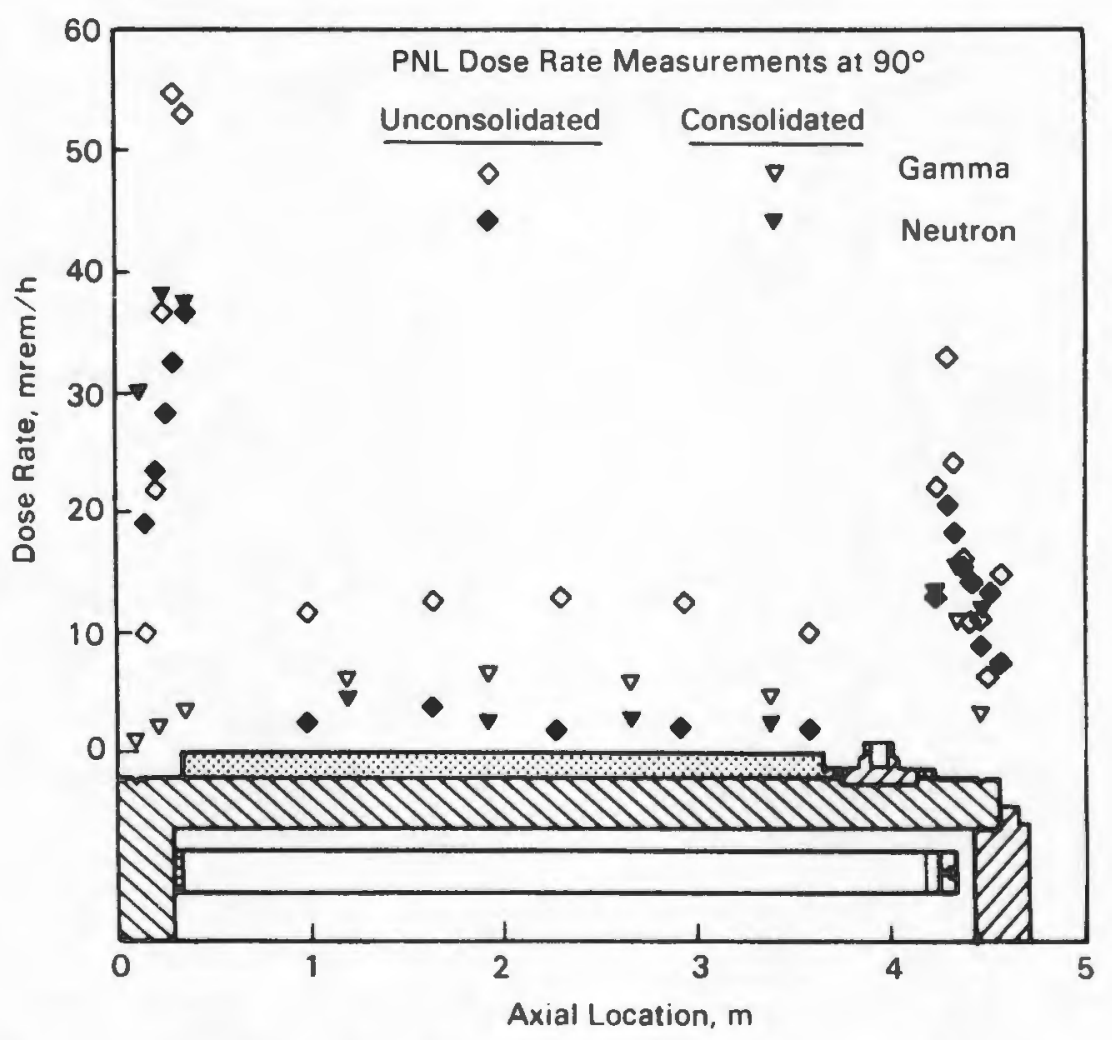

Figure 4-25. Comparison of axial gamma and neutron dose rate profiles measured on cask surface with consolidated or unconsolidated fuel in the TN-24P cask.

peaks and valleys in the dose rates at the surface even out as distance from the cask increases). The gamma doses rates on the top of the lid show the same attenuation trends as were shown by the neutron dose rates; however, the attenuation for gamma is not as great as for neutrons. The bottom and sides of the cask show the same trends with distance. Note that the neutron shield and protective cover were not on the cask during these dose rate measurements because the test $1 \mathrm{id}$ and TC lances were being used. When the neutron shield and protective cover are in place, their presence will significantly reduce the dose rates on the top of the cask.

At the mid point of the side of the cask, the neutron dose rate was attenuated from $3 \mathrm{mrem} / \mathrm{h}$ at the surface to $1.5 \mathrm{mrem} / \mathrm{h}$ at a distance of $2 \mathrm{~m}(6.6 \mathrm{ft})$ away. Likewise, the gamma dose rate was attenuated from $6.3 \mathrm{mrem} / \mathrm{h}$ at the surface to $1.5 \mathrm{mrem} / \mathrm{h}$ at $2 \mathrm{~m}$ (6.6 ft) from the cask.

The cask surface dose rate measurements and comparisons are summarized in Table 4-4. The shielding performance of the cask met the design goal of less than $60 \mathrm{mrem} / \mathrm{h}$ on 


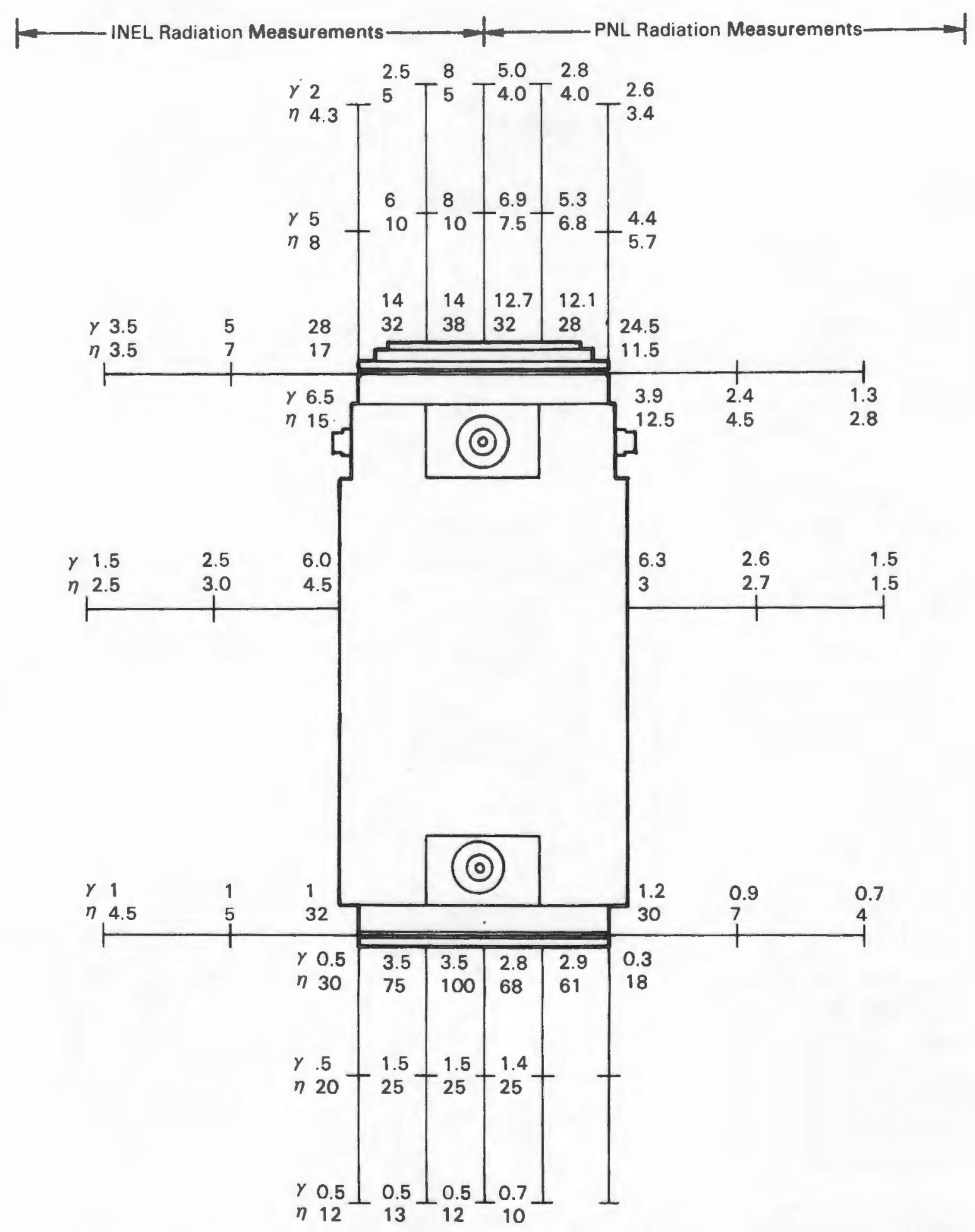

Figure 4-26. Dose Rates (mrem/h) Measured on and Near Cask Surface 
Table 4-4

COMPARISON OF PEAK SURFACE DOSE RATES ON THE TN-24P CASK LOADED WITH UNCONSOLIDATED FUEL ASSEMBLIES OR CONSOLIDATED FUEL CANISTERS

\begin{tabular}{|c|c|c|c|c|c|c|}
\hline \multirow[b]{3}{*}{ Measurement Location } & \multicolumn{3}{|c|}{ Fuel Assemblies } & \multicolumn{3}{|c|}{ Consolidated Canisters } \\
\hline & \multirow{2}{*}{$\begin{array}{l}\text { Heat } \\
\text { Load, } \\
\text { kW }\end{array}$} & \multicolumn{2}{|c|}{ Dose Rate } & \multirow{2}{*}{$\begin{array}{l}\text { Heat } \\
\text { Load, } \\
\text { KW }\end{array}$} & \multicolumn{2}{|c|}{ Dose Rate } \\
\hline & & $\begin{array}{l}\text { Gamma, } \\
\mathrm{mR} / \mathrm{h}\end{array}$ & $\begin{array}{l}\text { Neutron, } \\
\text { mrem } / h\end{array}$ & & $\begin{array}{l}\text { Gamma, } \\
\mathrm{mR} / \mathrm{h}\end{array}$ & $\begin{array}{l}\text { Neutron, } \\
\text { mrem/h }\end{array}$ \\
\hline $\begin{array}{r}\text { Cask lid - center } \\
\text { outside }\end{array}$ & $\begin{array}{l}21 \\
21\end{array}$ & $\begin{array}{r}60 \\
105\end{array}$ & $\begin{array}{l}33 \\
20\end{array}$ & $\begin{array}{l}23 \\
23\end{array}$ & $\begin{array}{l}15 \\
25\end{array}$ & $\begin{array}{l}32 \\
14\end{array}$ \\
\hline $\begin{aligned} & \text { Cask side - } \text { top peak } \\
& \text { center } \\
& \text { bottom peak }\end{aligned}$ & $\begin{array}{l}21 \\
21 \\
21\end{array}$ & $\begin{array}{l}33 \\
13 \\
54\end{array}$ & $\begin{array}{r}22 \\
3 \\
43\end{array}$ & $\begin{array}{l}23 \\
23 \\
23\end{array}$ & $\begin{array}{r}11 \\
7 \\
3\end{array}$ & $\begin{array}{r}17 \\
3 \\
42\end{array}$ \\
\hline Cask bottom - center & 21 & 143 & 64 & 23 & 3 & 68 \\
\hline
\end{tabular}

the cask lid and side. The dose rate on the bottom of the cask exceeded the design goal, but could be reduced easily by the addition of a small amount of neutron shielding. The dose rates on the bottom of the cask are not a problem during vertical storage. Comparison of gamma dose rates for the cask loaded with consolidated fuel to those for the cask loaded with unconsolidated fuel indicates that most of the gamma source is associated with the activation products (main ${ }^{60} \mathrm{Co}$ ) in the non-fuel-bearing components (top and bottom nozzles, spacer grids, and guide tubes).

FUEL INTEGRITY

Before the dry rods were consolidated, leaking fuel rods had been detected in two Turkey Point assemblies and probably one Surry assembly. The magnitude of the leaks suggested single rod leaks of very small size. Visual examination, profilometry, and uniform rod pulling forces during dry rod consolidation did not identify any leaking fuel rods, and exhaust gas monitoring of the consolidation area did not detect the release of any fission gases. Thus, with the exception of three fuel rods, the fuel consolidated and loaded into the TN-24P cask for this performance test was of good integrity.

During cask performance testing, fuel integrity was monitored through periodic gas sampling. General observations made during fuel consolidation and the results of the performance test gas sampling are described in this section. 
Dry Rod Consolidation

The consolidation process resulted in $\approx 9800$ fuel rods being pulled and loaded in canisters. Even with the extra handling, visual observation and exhaust gas monitoring from the consolidation location indicated that no cladding breaches were created during the consolidation process.

The extra handling of the rods during the consolidation process required pulling the rods of the assemblies and placing them in canisters. The rod-pulling process required breakaway forces up to $35.8 \mathrm{~kg}(79.9 \mathrm{lb})$, with an average pulling force after breakaway of $11.5 \mathrm{~kg}(25.4 \mathrm{lb})$. Occasionally, some of the rods were pushed by the rod gripper head during the consolidation process. This was caused by a misalignment of the gripper head with the rod and resulted in temporary bowing of the rod. In other cases, when it was necessary to $1 \mathrm{ift}$ and move individual rods within the consolidation location, the rods bowed significantly under their own weight on both sides of the lifting point(s). During pulling, virtually all rods appeared to have retained good flexibility.

Visual, photographic, and video observations made during the dry rod consolidation help to characterize the consolidated fuel loaded into the TN-24P cask. Observations during the dry rod consolidation resulted in the following description of the fuel:

Fuel rod surface discoloration and a layer of crud buildup were observed. The crud layer was thin, tenacious, and not powdery. A dark mottling surface existed on each fuel rod near spacer grids and was progressively more predominant from the middle to the bottom of the fuel rod. Scratches in the fuel rod surfaces occurred during rod pulling but appear to be very shallow. Fuel rod, fuel assembly, and assembly skeleton bowing was observed; however, the rods were quite flexible and stacked well in the consolidation canister. Random fuel rod growth in each fuel assembly was observed. As-fabricated fuel assembly geometry varied from fuel assembly to fuel assembly (2).

In addition, length variation between rods were observed to be as much as $2 \mathrm{~cm}$ ( $3 / 4$ in). Additional information on the fuel can be found in (9).

\section{Cask Cover Gas Sampling}

The cask cover gas was sampled prior to and at the end of each performance test, to evaluate the integrity of the spent fuel rods. Cover gas samples were taken during the performance test as indicated in Table 4-5. An additional sample was taken prior to removing the TC lances after the cask had been backfilled with helium at 
Table 4-5

COVER GAS SAMPLES TAKEN DURING PERFORMANCE TESTING

\begin{tabular}{|c|c|c|c|c|c|}
\hline $\begin{array}{c}\text { Test } \\
\text { Run No. }\end{array}$ & Cover Gas & Sample No. ${ }^{a}$ & $\begin{array}{c}\text { Cask } \\
\text { Pressure, } \\
\text { mbar } \\
\end{array}$ & $\begin{array}{l}\text { Date Sample } \\
\text { Collected } \\
\end{array}$ & Time \\
\hline 1 & Helium & $A 1-P R^{b}$ & 1579 & $1 / 07 / 88$ & 1500 \\
\hline 1 & Hel ium & $B 1-P R C$ & 1572 & $1 / 07 / 88$ & 1505 \\
\hline 1 & Hel i um & $\mathrm{A} 1-\mathrm{PT} C$ & 1558 & $\cdot 1 / 12 / 88$ & 1000 \\
\hline 1 & Hel i um & $\mathrm{B} 1-\mathrm{PT} \mathrm{T}^{\mathrm{b}}$ & 1555 & $1 / 12 / 88$ & 1005 \\
\hline 2 & Nitrogen & $A 2-P R^{C}$ & 1588 & $1 / 13 / 88$ & 1700 \\
\hline 2 & Nitrogen & $B 2-P R^{b}$ & 1584 & $1 / 13 / 88$ & 1705 \\
\hline 2 & Nitrogen & $\mathrm{A} 2-\mathrm{PT} \mathrm{C}$ & 1511 & $1 / 18 / 88$ & 1000 \\
\hline 2 & Nitrogen & $\mathrm{B} 2-\mathrm{PT}^{\mathrm{b}}$ & 1509 & $1 / 18 / 88$ & 1005 \\
\hline 4 & Helium & $A 4-P R^{C}$ & 1565 & $1 / 27 / 88$ & 1330 \\
\hline 4 & Heli um & $B 4-P R^{b}$ & 1562 & $1 / 27 / 88$ & 1335 \\
\hline 4 & Hel ium & $\mathrm{A} 4-\mathrm{PT} \mathrm{C}$ & 1546 & $2 / 01 / 88$ & 0930 \\
\hline 4 & Hel i um & B4-PT'b & 1536 & $2 / 01 / 88$ & 0935 \\
\hline 5 & Nitrogen & $\mathrm{A} 5-\mathrm{PR}^{\mathrm{C}}$ & 1539 & $2 / 03 / 88$ & 0900 \\
\hline 5 & Nitrogen & $B 5-P R^{b}$ & 1536 & $2 / 03 / 88$ & 0905 \\
\hline 5 & Nitrogen & $\mathrm{A} 5-\mathrm{PTC}$ & 1556 & $2 / 08 / 88$ & 0900 \\
\hline 5 & Nitrogen & B5-PT ${ }^{b}$ & 1554 & $2 / 08 / 88$ & 0905 \\
\hline Post-Test & Helium & A7-PTb & $=$ & $2 / 29 / 88$ & 1540 \\
\hline
\end{tabular}

\footnotetext{
a Number indicates run, first letter differentiates samples for run followed by run number, letters following dash indicate Pre-Run or Post-Test.

$b_{G a s}$ analysis performed at INEL ICPP.

CBackup gas sample--not analyzed.
} 
the conclusion of testing. Each sample was collected in a separate 500-cc stainless steel cylinder equipped with bellows-sealed valves as part of the closure. The cylinders were checked for purity and leaks before they were used for sampling.

The gas samples were sent to INEL's Chemical Processing Plant (CPP) for analysis. The results of the CPP gas analyses are presented in Table 4-6. Mass spectra were analyzed for all common gases with masses less than 100. Only $\mathrm{N}_{2}, \mathrm{O}_{2}, \mathrm{He}$, Ar, and $\mathrm{CO}_{2}$ concentrations above $0.01 \%$ were detected in any of the samples. Analyses of the other species reported are of marginal reliability. Water was reported as a lower limit due to absorption on vessel walls. The accuracy of the mass spectra measurements is noted in Table 4-6.

Table 4-7 presents measured concentrations and detection limits for ${ }^{85} \mathrm{Kr}$ from selected cover gas samples. Two methods were used to determine the radionuclide concentration of ${ }^{85} \mathrm{Kr}$. A screening analysis with a multichannel analyzer was used at the TAN facility; gamma counting with better sensitivity was used at CPP to find ${ }^{85} \mathrm{Kr}$ activity as $10 \mathrm{w}$ as $60 \mathrm{pCi} / \mathrm{Cc}$.

Table 4-6

CASK GAS SAMPLE COMPOSITION

Test Run No.

$\underline{S a m p l e}^{a}$

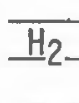

B1-PR

$<0.01$

0.03

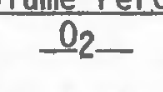

cent

1

$$
\text { Al-PT }
$$

$<0.01$

99.9

0.03

$<0.01$

Ar

$\mathrm{CO}_{2}-\mathrm{Kr} / \mathrm{Xe}$

$$
2
$$

$$
\text { A2-PR }
$$

$<0.01$

$0.08 \quad 99.86$

$<0.01$

$<0.01$

$<0.01<0.01$

2

A2-PT

$<0.01$

0.10

99.82

0.01

$<0.01$

$<0.01<0.01$

$$
4
$$

$$
\text { A4-PR } \quad<0.01
$$

99.95

0.04

$<0.01$

0.04

$<0.01$

$<0.01$

$$
4
$$

$$
\text { A4-PT }
$$

$<0.01$

99.98

0.02

0.01

0.04

$0.04<0.01$

$$
5
$$

A5-PR $\quad<0.01$

$0.10 \quad 99.84$

$<0.01$

$<0.01<0.01$

ND

$5 \quad$ A5-PT $<0.01$

$0.02 \quad 99.95$

0.01

$<0.01$

$<0.01<0.01$

Post-Test A7-PT

$<0.01$

99.97

0.02

0.02

$<0.01$

$<0.01<0.01$

a Number indicates run, first letter differentiates samples for run followed by run number, letters following dash indicate Pre-Run or Post-Iest. 
Table 4-7

${ }^{85} \mathrm{Kr}$ CONCENTRATION OF GAS SAMPLES

\begin{tabular}{|c|c|c|c|c|}
\hline & & Screen & Analysis & CCP Analysis \\
\hline Test Run No. & $\underline{\text { Sample }}^{\mathrm{a}}$ & $\underline{\mathrm{nCi} / \mathrm{Cc}}$ & Ci/cask & $\underline{\mathrm{nCi} / \mathrm{CC}}$ @ STP \\
\hline Pre-Test ${ }^{b}$ & -- & 86.32 & 0.231 & -- \\
\hline 1 & $\mathrm{Al}-\mathrm{PT}$ & 24.53 & 0.066 & $21.3 \pm 1.7$ \\
\hline 2 & $A 2-P T$ & 7.68 & 0.019 & $6.0 \pm 0.5$ \\
\hline 4 & A4-PT & 2.10 & 0.006 & $1.3 \pm 0.14$ \\
\hline 5 & A5-PT & 7.16 & 0.017 & $4.5 \pm 0.4$ \\
\hline Post TestC & A7-PT1 & 7.13 & 0.046 & $14.1 \pm 1.0$ \\
\hline
\end{tabular}

\footnotetext{
aNumber indicates run, first letter differentiates samples for run followed by run number, letters following dash indicate preRun or Post-Test.

${ }^{b}$ Gas sample taken prior to insertion of TC lances (Gas residence time September 28, 1987 to December 18, 1988)

${ }^{C}$ Gas sample taken after conclusion of the performance test prior to TC lance removal.
}

Figure 4-27 shows the ${ }^{85} \mathrm{Kr}$ released for each test run based on the screening measurements, and also shows the expected ${ }^{85} \mathrm{Kr}$ release from a single fuel rod. ${ }^{2}$

The data show a probable single fuel rod gas release during the vertical helium run and helium backfill periods. The other test runs show either slow leakage from rods that had previously developed leaks or the development of slow leaks. The spread in the single-rod ${ }^{85} \mathrm{Kr}$ release reflects the effects of the spread in burnups and timeout-of-reactor for the various fuel assemblies used in consolidation.

The cumulative amount of ${ }^{85} \mathrm{Kr}$ released in the cask is shown in Figure 4-28. Figure 4-28 accounts for most of the time helium or nitrogen backfills were in the cask, from the time the cask was fully loaded with consolidated fuel until the time

aThe expected ${ }^{85} \mathrm{Kr}$ gas release for a single rod is based on 0RIGEN2 predictions of total $85 \mathrm{Kr}$ gas available and experimental measurements indicating that no more than $0.5 \%$ of the available ${ }^{85} \mathrm{Kr}$ gas is released. The rest of the gas is captured in the fuel $(\underline{17}, \underline{18})$. 


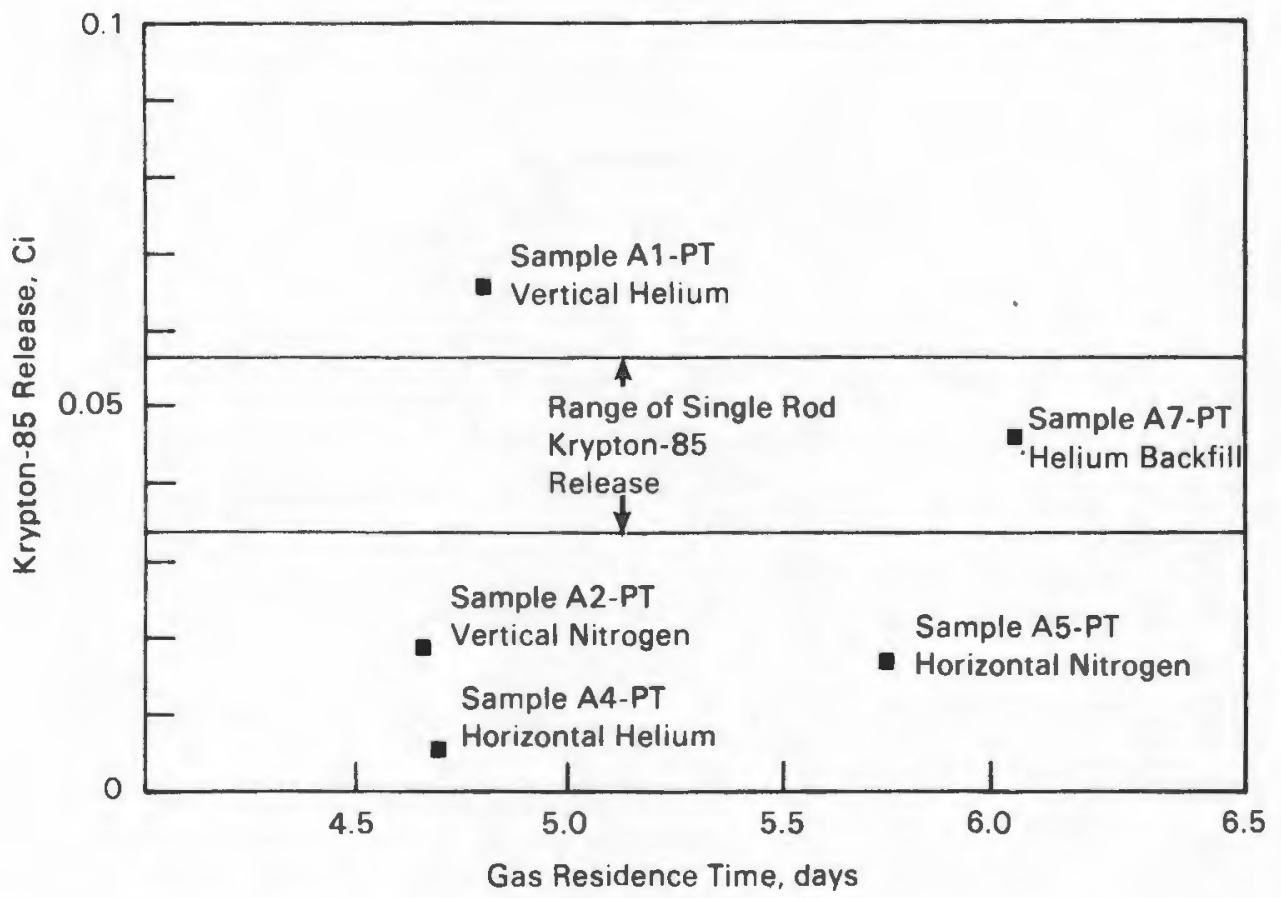

Figure 4-27. ${ }^{85} \mathrm{Kr}$ Release from the Fuel During Test Runs

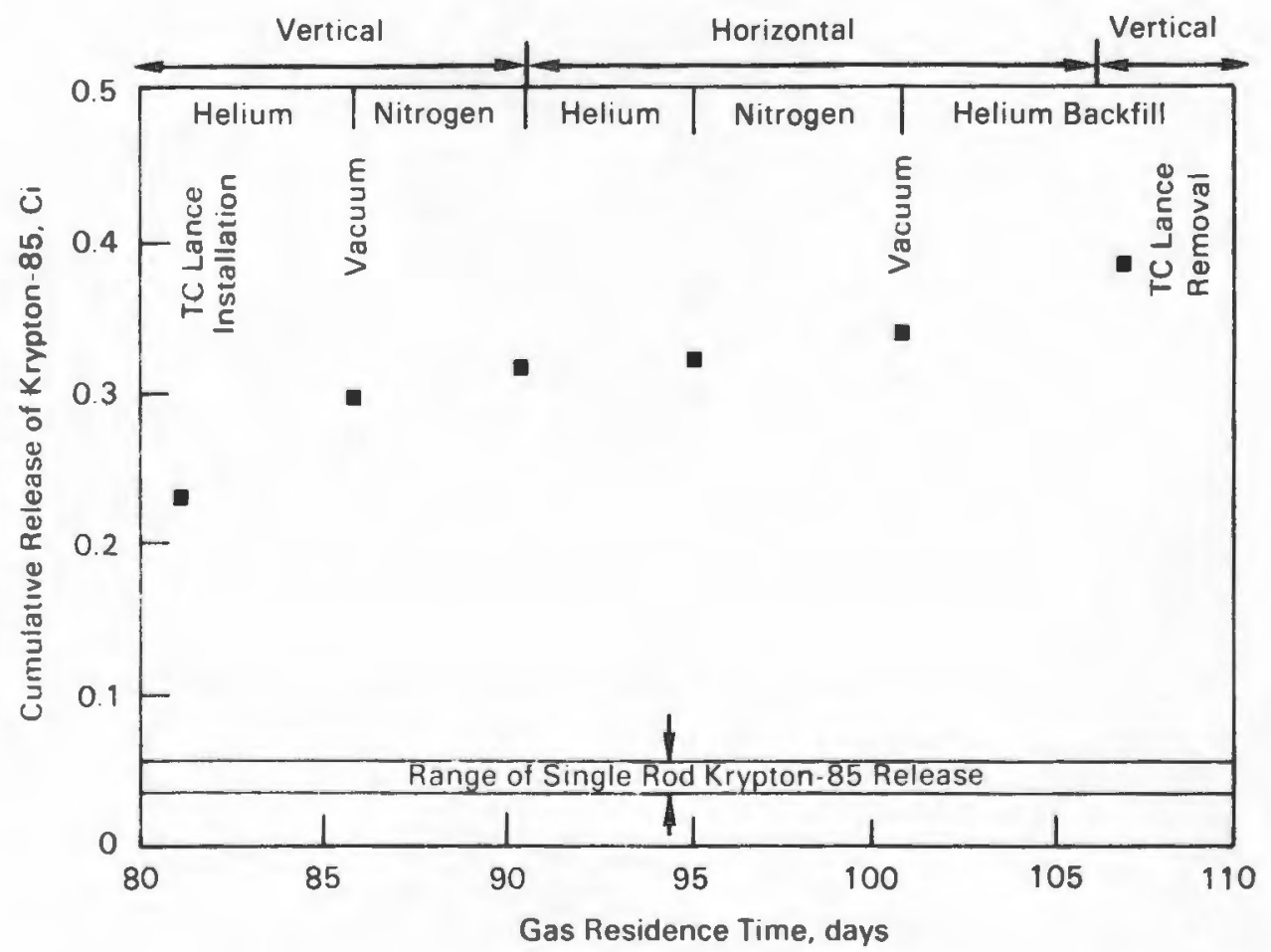

Figure 4-28. Cumulative ${ }^{85} \mathrm{Kr}$ release from fuel from time cask was fully loaded with consolidated fuel to the end of testing. 
the TC lances were removed at the end of testing. The ${ }^{85} \mathrm{Kr}$ release shown in Figure 4-28 does not include any ${ }^{85} \mathrm{Kr}$ that may have been released during the vacuum runs. The data indicate that four or more rods may have developed leaks prior to TC lance insertion before testing, and three or more rods may have developed leaks during testing.

The amount of ${ }^{85} \mathrm{Kr}$ released during this cask performance test is significantly higher than that released in previous cask testing with unconsolidated fuel. Before this test, four cask performance tests of similar duration and scope had been performed; only two indications of ${ }^{85} \mathrm{Kr}$ release were observed. The magnitude of the releases in the previous tests indicated that each was limited to a single rod cladding breach. The previous tests involved about 16,700 spent fuel rods, whereas this test involved about 9800 rods. It is hypothesized that the greater magnitude of ${ }^{85} \mathrm{Kr}$ released in this test is due to additional cladding leaks caused by enlargement of incipient cladding flaws during pulling and flexing of the fuel rods during the consolidation process. The enlarged cladding flaws grew during cask testing until a leak path developed. The leakage did not affect operations. 
Section 5

COBRA-SFS ANALYSIS

The COBRA-SFS (Spent Fuel Storage) computer code was used to predict temperature distributions in the TN-24P spent fuel storage cask loaded with consolidated fuel, to ensure that allowable temperatures would not be exceeded and to further evaluate the code. Results were obtained for cask testing with vacuum, nitrogen, and helium backfills in vertical and horizontal orientations. Descriptions of the COBRA-SFS code, its modeling capabilities, the conservation equations, and geometry models and input are presented, as are comparisons of pretest and post-test code predictions with test data.

\section{COBRA-SFS COMPUTER PROGRAM}

The COBRA-SFS code $(\underline{19}, \underline{20}, \underline{21})$ is a steady-state, lumped-parameter, finite-difference computer code that predicts flow and temperature distributions in spent fuel storage systems and fuel assemblies under mixed and/or natural convection conditions. Derived from the COBRA family of codes $(\underline{22}, \underline{23}, \underline{24}, \underline{25})$, which have been extensively evaluated against in-pile and out-of-pile data, COBRA-SFS retains all the important features of the COBRA codes and extends the range of application to problems with two-dimensional radiation and conduction heat transfer. This capability permits analyses of single- and multiassembly spent fuel storage systems with unconsolidated or consolidated fuel, with a variety of fill media $(\underline{2}, \underline{3}, \underline{4}, \underline{26}$, $\underline{27}, \underline{28}, \underline{29}, \underline{30}, \underline{31}$ ).

COBRA-SFS provides finite-difference solutions to the equations governing mass, momentum, and energy conservation for incompressible flows. Analyses are conducted using a subchannel approach in which the flow areas of assemblies or storage systems are divided axially into discrete control volumes for which the conservation equations of mass, momentum, and energy are written. These equations are then solved using an iterative implicit method. The energy equations for the coolant, rod cladding, fuel, and structural members (slabs) are solved implicitly by iteration, but simultaneously in a plane. Axial conduction in the structural members is considered. A nonparticipating media, gray body radiation heat transfer model also allows two-dimensional radiant heat exchange among all solid members in an enclosure and is iteratively coupled to the rod and wall energy equations. 
The flow field may be either user-prescribed or internally calculated as a function of the gravitational and dynamic pressure losses. Specifications of heat losses from the boundary may vary circumferentially and/or axially, and can include both radiation and convection heat transfer. Axial heat transfer from the subchannel model to plenum regions (regions above and below the fuel assemblies) also can be modeled.

In the following sections, the COBRA-SFS modeling capabilities are outlined, and a brief description of the conservation equations is given.

\section{Modeling Capabilities}

COBRA-SFS allows simulations of a wide range of dry storage systems via input instructions. In addition to the multiassembly cask analysis described in this report, applications have included analyses of single-assembly spent fuel storage systems under multiple orientations and fill media (27), multiassembly systems with unconsolidated spent fuel $(\underline{3}, \underline{29}, \underline{30})$, and analyses of both single- and multiassembly consolidated fuel storage systems $(\underline{3}, \underline{26}, \underline{28}, \underline{31})$. The code contains thermal-hydraulic models for pressure drop, turbulent mixing, diversion crossflow, buoyancy-induced flow recirculation, and conduction and radiation heat transfer. The versatile fuel rod and channel models allow simulation of consolidated fuel assemblies. The code's capabilities and limitations are outlined in Table 5-1.

\section{Conservation Equations}

The COBRA-SFS code solves the conservation equations of mass, momentum, and energy in a fuel assembly or fuel storage system using finite difference equations derived by performing suitable balances on finite control volumes. Empirical relationships are used where needed to close the set of equations. The fluid control volume for continuity, axial momentum, and energy is characterized by a flow cross-sectional area, $A$; an axial length, $\Delta x$; and a gap width, $S$, for the connection between itself and adjacent control volumes. Figure 5-1 shows the relationship of a subchannel control volume to a fuel storage system; a typical subchannel control volume is also displayed. Any series of control volumes connected axially is considered a subchannel. In the following equations, the finite-difference terms are presented with the corresponding word definitions given in brackets immediately below each equation. The list of symbols in the Nomenclature section of this document should be referred to for explanation of the notation. 
Table 5-1

COBRA-SFS CAPABILITIES AND LIMITATIONS

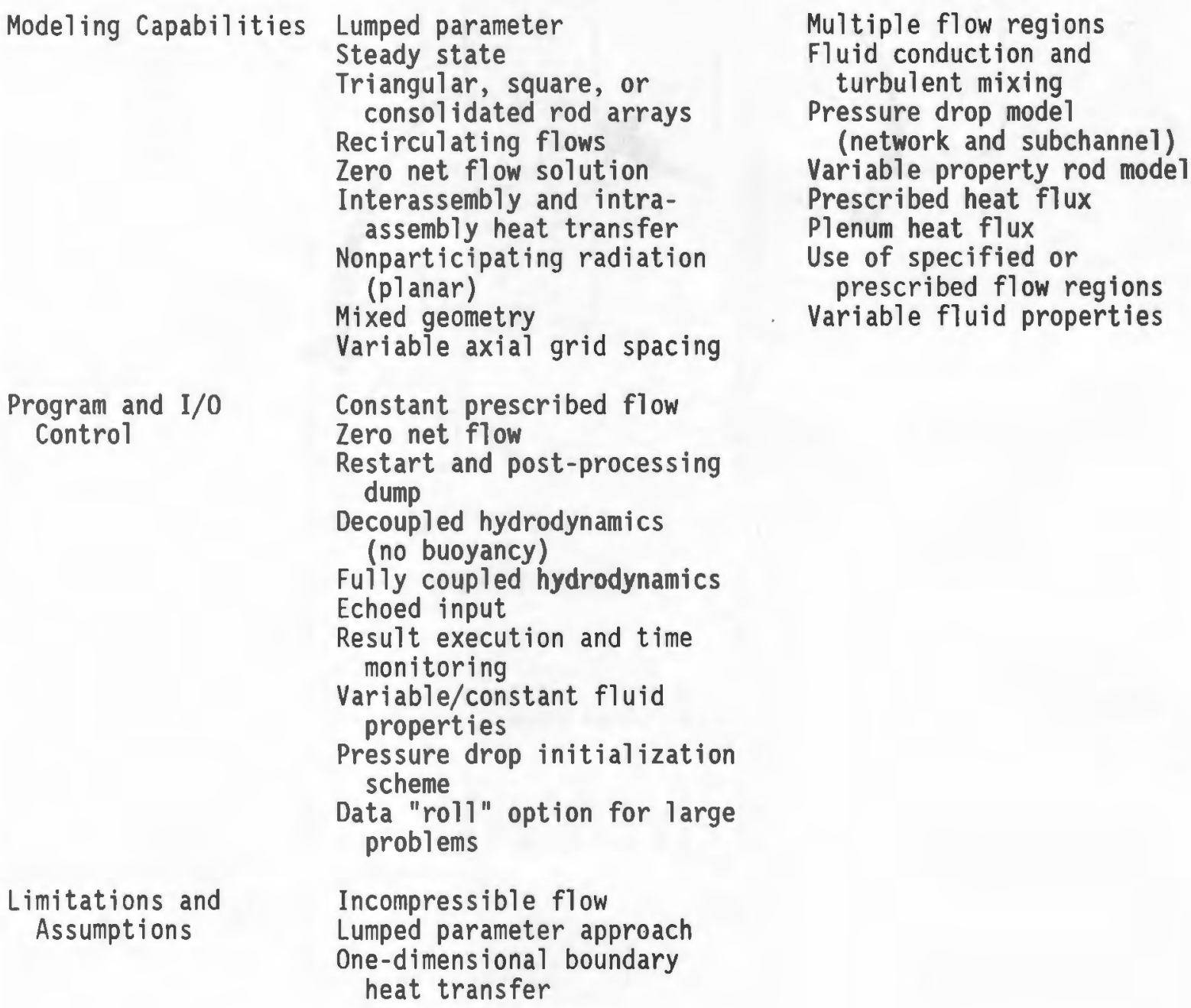

Multiple flow regions

Fluid conduction and turbulent mixing Pressure drop model (network and subchannel) Variable property rod model Prescribed heat flux

Plenum heat flux Use of specified or prescribed flow regions Variable fluid properties Assumptions

$$
\text { insme }
$$

Continuity Equation (for subchannel $i$, axial location $j$ )

$$
\begin{aligned}
& \bar{A} \frac{\rho-\rho^{n}}{j}=\frac{v_{j-1} A_{j-1} \rho_{j-1}^{*}}{\Delta x_{j}}-\frac{v_{j} A_{j} \rho_{j}^{*}}{\Delta x_{j}}-\sum_{k \in \psi_{i}} e_{i k}\left(u_{k} s_{k} \rho_{k}^{*}\right)_{j} \\
& {\left[\begin{array}{l}
\text { mass } \\
\text { storage }
\end{array}\right]=\left[\begin{array}{l}
\text { mass transported } \\
\text { axially }
\end{array}\right]+\left[\begin{array}{l}
\text { mass transported } \\
\text { laterally }
\end{array}\right]}
\end{aligned}
$$

The asterisk denotes that donor cell values are convected by the velocity $v$ or $u$. 


\section{Storage System}

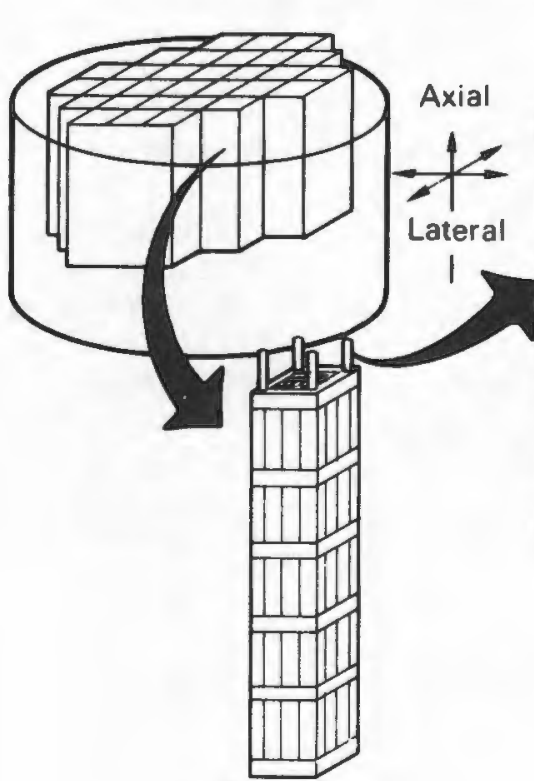

Fuel Assembly
Subchannel

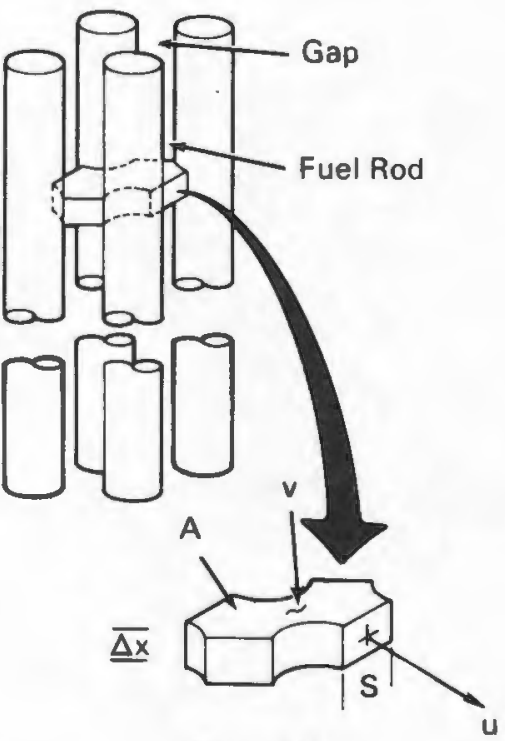

Control Volume

Figure 5-1. Subchannel Definition

Fluid Energy Equation (for channel $i$, axial node $j$ )

$$
\begin{aligned}
& \bar{A} \frac{\rho h-(\rho h)^{n}}{\Delta t} j=\frac{v_{j-1} A_{j-1} \rho_{j-1}^{*} h_{j-1}^{*}}{\Delta x_{j}}-\frac{v_{j} A_{j} \rho_{j}^{*} h_{j}^{*}}{\Delta x_{j}}-\sum_{k \in \psi_{j}} e_{i k}\left(U_{k} A_{k} \rho_{k}^{*} h_{k}^{*}\right)_{j} \\
& {\left[\begin{array}{l}
\text { energy } \\
\text { storage }
\end{array}\right]=\left[\begin{array}{l}
\text { energy transported } \\
\text { axially }
\end{array}\right]+\left[\begin{array}{l}
\text { energy transported } \\
\text { laterally }
\end{array}\right]} \\
& +\sum_{n \in \mu_{j}} \frac{A_{H T R^{H} R}}{\Delta x_{j}} T_{C_{n}}-T+\sum_{m \in v_{i}} \frac{A_{H T W^{H} W}}{\Delta x_{j}} T_{W_{n}}-T \\
& +[\operatorname{rod} \text { heat } f l u x]+[\text { wall heat flux }] \\
& +\sum_{k \in \psi_{i}} r_{i k} s_{k} k_{k} \frac{T_{I I}-T_{J J}}{k Z_{k}}+\sum_{k \in \psi_{i}} e_{i k} W_{T}\left(h_{I I}-H_{J J}\right) \\
& +\left[\begin{array}{l}
\text { Conductive heat } \\
\text { transfer laterally }
\end{array}\right]+[\text { turbulent energy exchange }]
\end{aligned}
$$


A11 other forms of energy transport that are not explicitly represented in Eq. 5-2 (e.g., potential and kinetic energy) have been neglected.

- Axial Momentum Equation (for channel $i$, axial node $j$ )

$\bar{A} \frac{\rho v-(\rho v)^{n}}{\Delta t} j=\frac{A_{j-1} v_{j-1} v_{j-1}^{*} \rho_{j-1}^{*}}{\Delta x_{j}}-\frac{A_{j} v_{j} v_{j}^{*} \rho_{j}^{*}}{\Delta x_{j}}-\sum_{k \in \psi_{j}} e_{i k}\left(U_{k} S_{k} v_{k}^{*} \rho_{k}^{*}\right) j$

$$
\begin{aligned}
& {\left[\begin{array}{l}
\text { axial } \\
\text { momentum } \\
\text { storage }
\end{array}\right]=\left[\begin{array}{l}
\text { axial momentum } \\
\text { transported } \\
\text { axially }
\end{array}\right]+\left[\begin{array}{l}
\text { axial momentum } \\
\text { transported } \\
\text { laterally }
\end{array}\right]} \\
& +\vec{A}_{j} \frac{P_{j-1}-P_{j}}{\Delta x_{j}}+\sum_{k \in \psi_{i}} e_{i k^{W_{T}}\left(v_{I I}-v_{j J}\right)}
\end{aligned}
$$$$
\left[\begin{array}{l}
\text { pressure } \\
\text { gradient }
\end{array}\right]+\left[\begin{array}{l}
\text { turbulent momentum } \\
\text { exchange }
\end{array}\right]
$$$$
\frac{l}{2} \quad \frac{f}{D_{h}}+\frac{C}{\Delta x_{j}} \quad \rho_{j} v_{j}\left|v_{j}\right| A_{j}-A \rho g \cos 0
$$$$
\text { - }\left[\begin{array}{l}
\text { irreversible friction } \\
\text { and form losses }
\end{array}\right] \text { - [gravitational head] }
$$

In the derivative of the axial momentum equation, it is assumed that all irreversible losses can be obtained by use of suitable friction factors and loss coefficients applied to the bulk velocity. Also, it is assumed that pressure changes linearly along the channel volume and that the shear stress terms due to the flow in the adjacent subchannels can be neglected. 
Transverse Momentum Equation (for gap k, axial node $j$ )

$$
\begin{aligned}
& S_{\Delta x_{j}} \frac{\rho u-(\rho u)^{n}}{\Delta t} k=S_{k} v_{j-1} \rho_{j-1}^{*} u_{j-1}^{*}-S_{j} v_{j} \rho_{j}^{*} u_{j}^{*} \\
& {\left[\begin{array}{l}
\text { Tateral } \\
\text { momentum } \\
\text { storage }
\end{array}\right]=\left[\begin{array}{l}
\text { transverse momentum } \\
\text { transported axially }
\end{array}\right]} \\
& +\left(P_{I I}-P_{J J}\right)_{j-1} \frac{S_{k} \Delta x_{j}}{k}-C_{T} u_{k} u_{k} \frac{\rho S \Delta x_{j}}{2 k} \\
& + \text { [pressure gradient] - }\left[\begin{array}{l}
\text { irreversible form and } \\
\text { friction loss }
\end{array}\right]
\end{aligned}
$$

The momentum control volume length, $\ell$, and gap width, $S$, define a transverse momentum control volume as shown in Figure 5-2. Inside this control volume, the transverse velocity is normal to the transverse gap; the flow is assumed to have no transverse component outside the transverse momentum control volume. A further assumption in the transverse momentum equation is that there are no applied body forces in the transverse direction.

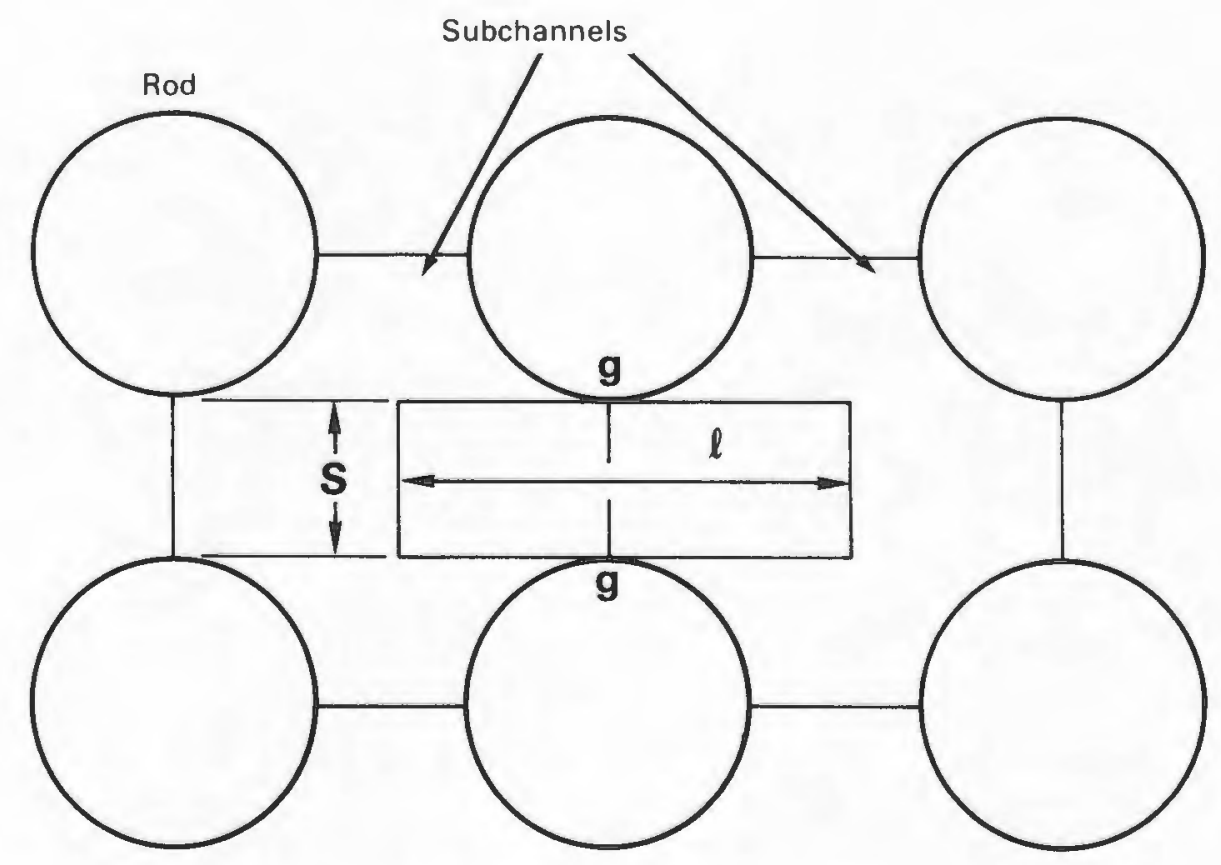

Figure 5-2. Transverse Momentum Control Volume 


\section{Cladding Energy Equation}

$$
\begin{aligned}
& y_{c} \rho_{c} c_{c} \frac{T_{c}-T_{c}^{n}}{\Delta t}=\sum_{n \in \tau_{i}} H_{r} T_{c_{n}}-T-H_{g} \frac{R_{f}}{R_{c}}\left(T_{f s}-T_{c}\right) \\
& {\left[\begin{array}{l}
\text { energy } \\
\text { storage }
\end{array}\right]=\left[\begin{array}{l}
\text { Convective } \\
\text { transfer to } \\
\text { the fluid }
\end{array}\right]+\left[\begin{array}{l}
\text { heat transfer } \\
\text { from fuel }
\end{array}\right]} \\
& +\sigma \sum_{n \in \xi_{j}} F_{i n}\left(T_{c}^{4}-T_{c_{n}}{ }^{4}\right)+\sigma \underset{m \in \lambda_{j}}{\sum} F_{i m}\left(T_{c}^{4}-T_{w_{m}}{ }^{4}\right) \\
& +\left[\begin{array}{l}
\text { radiation heat } \\
\text { transfer from } \\
\text { rods }
\end{array}\right]+\left[\begin{array}{l}
\text { radiation heat } \\
\text { transfer from } \\
\text { walls }
\end{array}\right]
\end{aligned}
$$

By assuming that 1 ) there is no heat transfer axially; 2) the heat is generated uniformly throughout the fuel at a given axial location; and 3) the fuel properties do not vary with the radial variation in temperature, "the cladding temperature is obtained by performing a lumped energy balance on the cladding material at each axial leve1. In Eq. 5-5, it is assumed that the temperature is uniform around the circumference of the cladding. The film coefficient, $H_{R}$, is given by user-specified correlations, and the gap conductance between fuel pellet and cladding, $\mathrm{H}_{\mathbf{g}}$, is assumed constant. $F_{i n}$ and $F_{i m}$ are gray body radiation exchange factors that account for multiple reflections within an enclosure. $F_{i n}$ is a coefficient for rod-to-slab heat transfer. Both are derived by assuming constant surface emissivity. The gray body exchange factors can be user-prescribed or calculated internally by specifying black body view factors and surface emissivity values.

\section{Slab Energy Equation}

$$
\begin{aligned}
& \rho_{w} c_{w} t_{w} \frac{T_{w}-T_{w}^{n}}{\Delta t}=\sum_{n \in W_{i}} U\left(T_{w}-T_{n}\right)+\sigma \sum_{m \in \sigma_{i}} F_{i m}\left(T_{w}^{4}-T_{m}^{4}\right) \\
& {[\text { energy storage }]=\left[\begin{array}{l}
\text { heat transfer } \\
\text { from adjacent } \\
\text { channels }
\end{array}\right]+\left[\begin{array}{l}
\text { radiation heat } \\
\text { transfer from } \\
w a l l s
\end{array}\right]}
\end{aligned}
$$




$$
\begin{aligned}
& +\sigma \sum_{n \in \lambda_{i}} F_{i n}\left(T_{w}^{4}-T_{c_{n}}^{4}\right)+q^{\prime \prime \prime} \\
& +\left[\begin{array}{l}
\text { radiation heat transfer } \\
\text { from rods }
\end{array}+\left[\begin{array}{l}
\text { heat } \\
\text { generation }
\end{array}\right]\right. \\
& +U_{j-1}\left(T_{w}-T_{w_{j-1}}\right)+U_{j+1}\left(T_{w}-T_{w_{j+1}}\right)+\sum_{m \in \alpha_{j}} U\left(T_{w}-T_{w_{m}}\right) \\
& +[\text { axial conduction heat transfer }]+\left[\begin{array}{l}
\text { heat transfer } \\
\text { from adjacent } \\
\text { wal1s }
\end{array}\right]
\end{aligned}
$$

As before, $F_{i m}$ and $F_{i n}$ are the gray body exchange factors from wall node $i$ to wall node $m$ and rod node $n$, respectively. Axial heat transfer from the walls to a plenum region can be included at the first or last axial level.

\section{COBRA-SFS MODELS AND INPUT}

The TN-24P cask was analyzed using a one-half section model to investigate the cask thermal response with unconsolidated spent fuel, in vertical and horizontal orientations. The smaller one-eighth section model developed for the vertical orientation unconsolidated fuel analyses ( $\underline{3}$ ) was insufficient for this analysis, due to the decay heat asymmetries resulting from the fuel loading pattern. The one-half section model, along with boundary specifications and properties used, are described in the following sections.

\section{One-Half Section Cask Model}

The COBRA-SFS one-half section pretest model consisted of 18 uniform axial levels as depicted in Figure 5-3. Each axial level comprised 239 wall nodes, 118 subchannels, and 60 rod nodes (Figure 5-4). Of the 239 wall nodes, 95 were basket nodes, 48 were fuel canister nodes, 48 were cask body nodes, 16 were neutron shield nodes, and 32 were cask shell wall nodes. The 16 outermost shell nodes were zero-thickness nodes that represent the cask surface temperature for the purpose of accurately calculating the contribution of radiation and convection heat transfer to the environment. In the noding of the fuel canisters, the flexibility of the COBRA-SFS rod and channel models was used to selectively lump the 408 PWR spent fuel rods within each canister together and the associated flow areas (channels) together to decrease the size of the computational model. In the pretest analyses the 408 rods were 


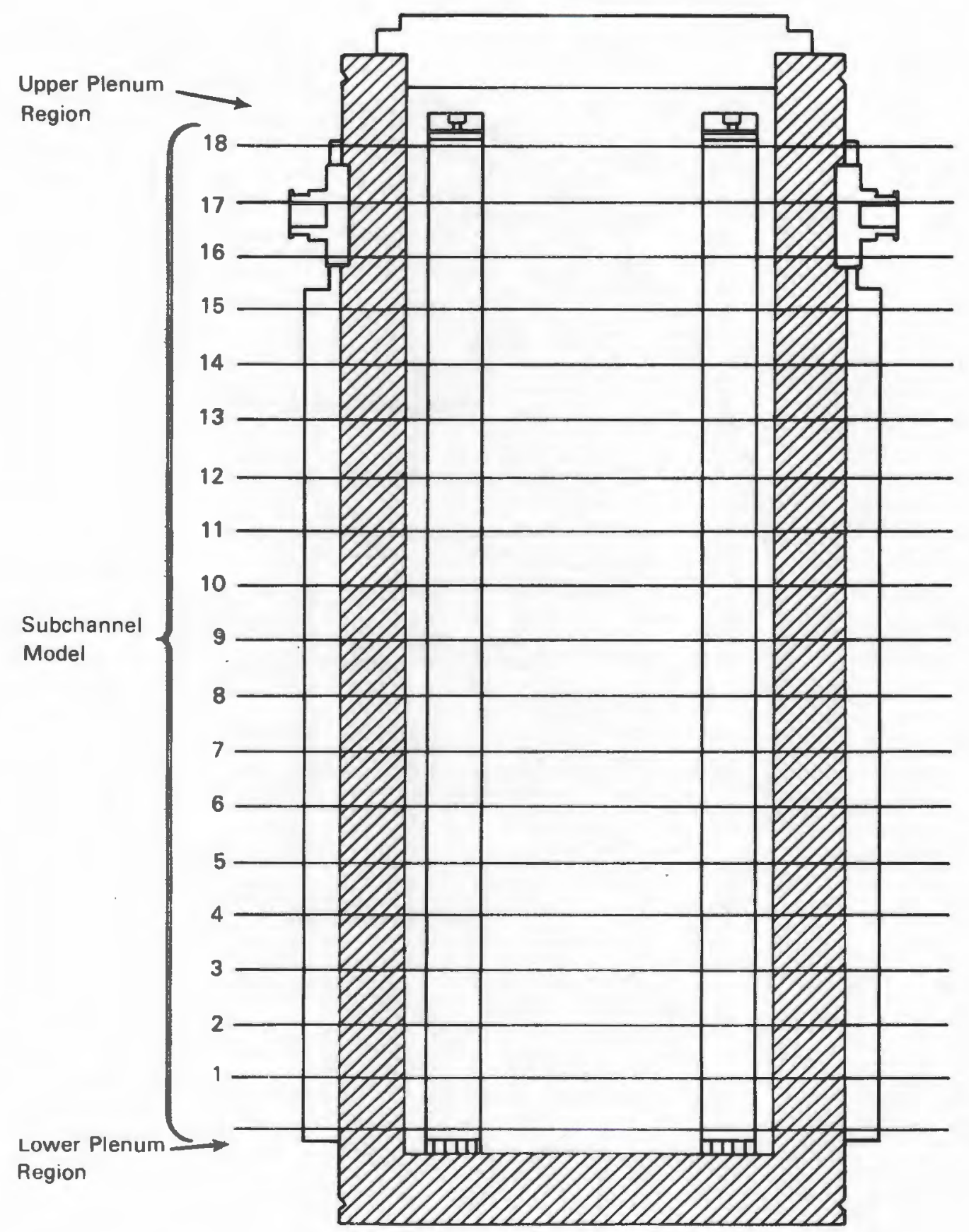

Figure 5-3. Axial Computational Cask Model

represented by 5 lumped rods and the flow area within the canisters was modeled by 9 channels, as displayed in Figure 5-5. Previous work (31) has demonstrated the validity of combining rods with surface temperatures of near the same magnitude to form a single rod surface node. 


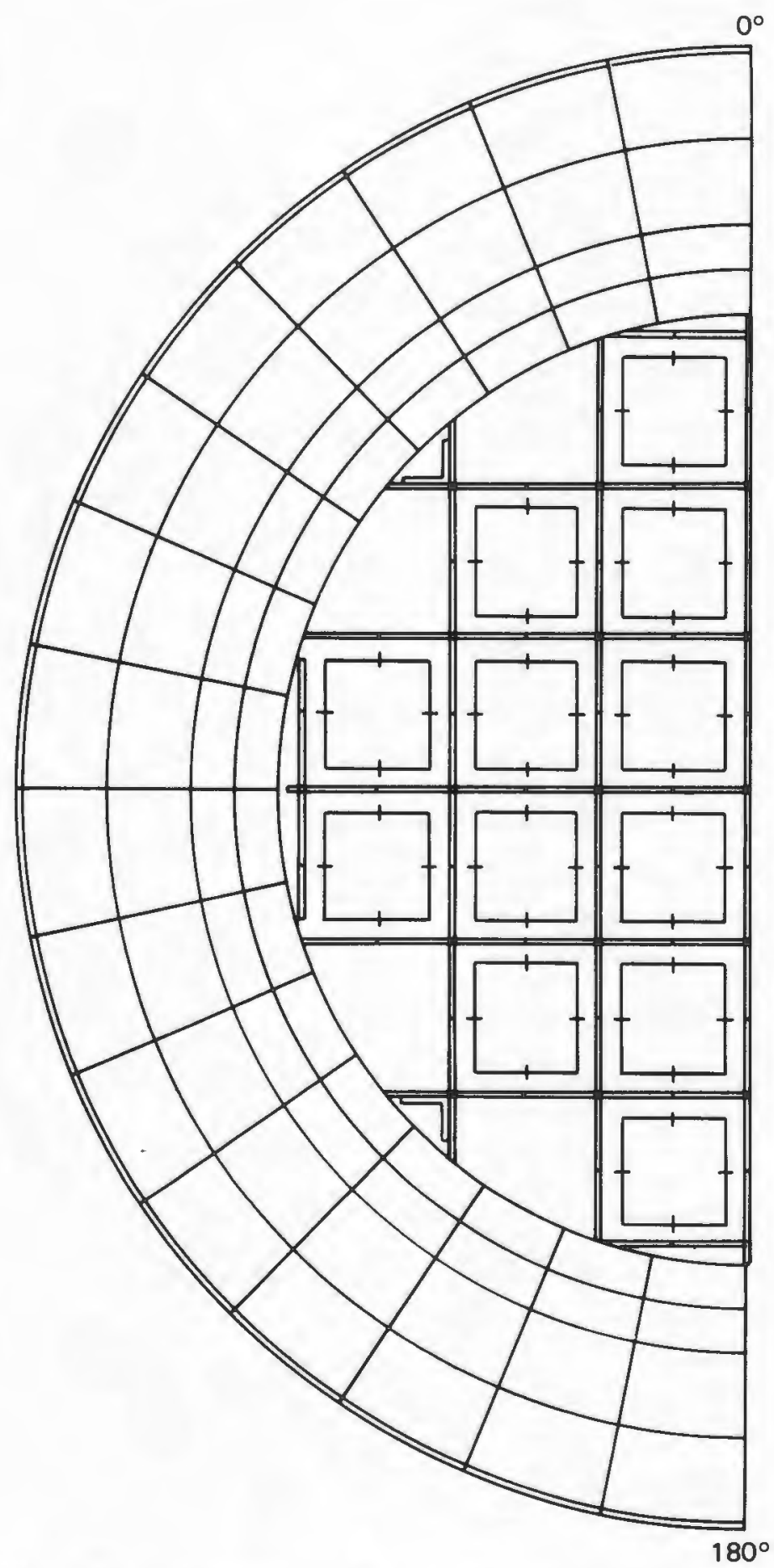

Figure 5-4. One-Half Transverse Section Computational Cask Model

\section{Heat Transfer Models}

The axial decay heat profile displayed in Figure 3-19 was applied to all of the fuel canisters. The assembly decay heat profiles were calculated by the ORIGEN2 


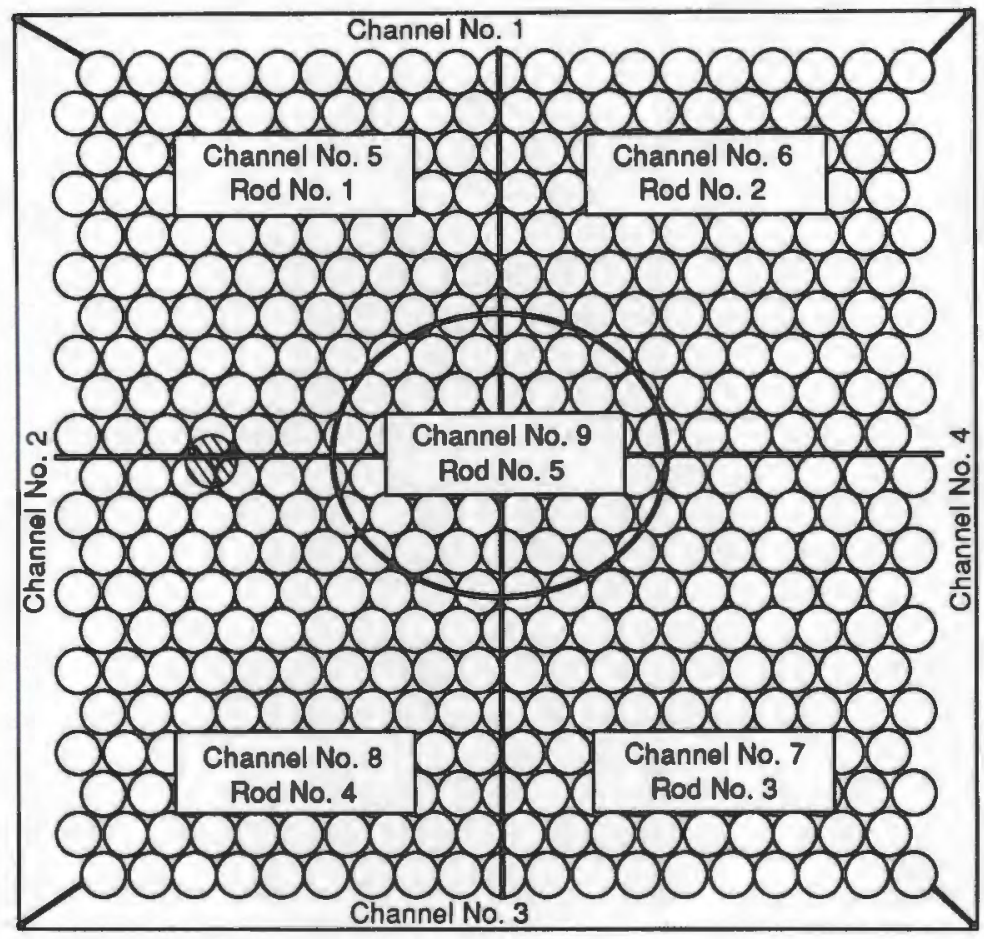

TC Lance Location

Figure 5-5. Pretest Consolidated Fuel Model

computer code (10), based on average gamma scans from similar Turkey Point PWR spent fuel assemblies. The one-half section model incorporated the decay heat rates from quadrants $C$ and $D$ shown in Figure 3-18. The total decay heat rates were extrapolated from ORIGEN2 predictions.

Decay heat from the fuel canisters is removed by conduction, convection, and radiation heat transfer. The following is a discussion of COBRA-SFS modeling of each of these modes.

Fluid-fluid conduction between neighboring subchannels was modeled using a transverse control volume defined by a gap width, a centroid-to-centroid length, and an axial length (Figure 5-2). Axial fluid-fluid conduction was neglected.

Conduction heat transfer in the walls was modeled in the radial, circumferential, and axial directions via an input specification of thermal resistances between neighboring nodes. The thermal resistances can reflect any combination of parallel and/or series resistance paths. An example of such a composite resistance in the 
TN-24P analyses is the polyethylene resin and copper fins, which formed the side neutron shield. In this region a resistance was calculated that represented the two parallel paths through the shield.

One of the dominating resistances in the radial conduction path is from the gap between the aluminum basket and the inner cask wal1. Iteration on the gap resistance was necessary, as the average basket temperature was directly related to the gap resistance. This resistance was calculated through the following procedure: 1) the average basket temperature was predicted, 2) the expansion of the basket was determined, and 3 ) the gap resistance was calculated.

The contribution of convection heat transfer within the cask is dependent on the predicted flow field. For the TN-24P simulations, the flow field was obtained iteratively by adjusting the total pressure drop until 1) the pressure drop across all subchannels was equal and 2) the total net flow rate was zero. Therefore, the basket and the fuel canister flow resistances were important convection parameters. The surface friction for all of the channels was approximated using a friction factor of $f=100 / R e$, which was derived for a square rod array with pitch-todiameter ratios typical of PWRs (32). The heat transfer due to convection between the aluminum basket and the fuel canisters was assumed to be negligible and was therefore not modeled.

Convective heat transfer from the rod and wall surfaces to the fluid was prescribed using a film coefficient having the form $\mathrm{Nu}=3.66(\underline{33})$. This correlation is the analytical solution of the energy equation for a constant temperature and fulty developed temperature and velocity profiles in a circular tube. Previous work (29) that investigated the effect of various values of Nusselt number on COBRA-SFS temperature predictions determined that a value of 3.66 gave the best overall results for the nitrogen and helium fill media.

Radiation heat transfer was treated on an assembly type-by-assembly type basis. In each basket fuel tube containing a consolidated fuel canister holding rods from two PWR fuel assemblies, rod-rod, rod-canister wa11, canister wa11-canister wal1, and canister wall-basket wall radiative heat transfer were modeled by specification of gray body exchange factors. The exchange factors for the fuel rods and walls were calculated using one-quarter pin surface segments and the cross-string correlation method of Hottel (34) to define the radiation view factors. This is a more exact approach than the assumption of uniform radiosity around a rod surface. Radiation exchange in the empty basket enclosures, which consisted of basket walls and the 
inner cask wa11, was determined using wal1-wall view factors input by the user. The COBRA-SFS code used these factors along with appropriate emissivities to calculate the gray body exchange factors.

\section{Boundary Specifications}

The TN-24P COBRA-SFS model comprised three axial regions: 1) the main region containing the fuel canisters, fuel basket, and cask body; 2) the upper plenum region; and 3 ) the lower plenum region. For each axial region, the boundary conditions were specified via heat transfer coefficients representing the heat transfer from the cask surface to ambient air. In this section the boundary conditions used for each model are described.

The outside cask surface was a painted, smooth surface. The heat removal rate from the cask side surfaces by natural convection was calculated using the Nusselt number expression for vertical cylinders in air at 1 atm ( $\underline{35})$.

$$
\mathrm{Nu}=0.13(\mathrm{GrPr})^{1 / 3}
$$

The cask lid heat transfer to ambient was modeled by a natural convection expression for Nusselt number for a horizontal plate in air at 1 atm $(\underline{35})$.

$$
\mathrm{Nu}=0.14(\mathrm{GrPr})^{1 / 3}
$$

In the vertical orientation cases, the cask was placed on a rail car. The rail car was modeled as an external fin, taking into account the increased heat transfer to the ambient.

The radiation heat transfer from the top and side outer surfaces to the surrounding environment was a function of surface emissivity and the ambient conditions. The ambient air was assumed to be a black body at a temperature of $25^{\circ} \mathrm{C}\left(77^{\circ} \mathrm{F}\right)$. The formulation for radiation heat transfer from the cask outer surface to ambient was identical to the expression for parallel plates:

$$
q_{\text {rad }}^{\prime \prime}=\epsilon_{\text {surface }} \sigma\left(T_{\text {surface }}^{4}-T_{\text {ambient }}^{4}\right)
$$

The surface to ambient heat transfer correlations used in the analyses are summarized in Table 5-2. 
Table 5-2

BOUNDARY CONVECTION HEAT TRANSFER CORRELATIONS

\begin{tabular}{llll} 
Type & \multicolumn{1}{c}{ Region } & Natural Convection Component \\
Axial & Upper plenum & $\mathrm{Nu}$ & $=0.14(\mathrm{GrPr}) 1 / 3$ \\
Radial & Upper plenum & $\mathrm{Nu}=0.13(\mathrm{GrPr}) 1 / 3$ \\
Radial & Cask side & $\mathrm{Nu}=0.13(\mathrm{GrPr}) 1 / 3$ \\
Radial & Lower plenum & $\mathrm{Nu}=0.13(\mathrm{GrPr}) 1 / 3$ \\
Axial & Lower plenum & $\mathrm{Nu}=1.0$
\end{tabular}

\section{Material Properties}

The material properties used for the TN-24P model are presented in Table 5-3. A11 surface emissivities and the greater portion of the solid thermal conductivities were provided by Transnuclear, Inc. The thermal properties of the solids were assumed constant, and properties of the fill gas were specified as a function of temperature.

Table 5-3

MATERIAL PROPERTIES

\begin{tabular}{|c|c|c|c|}
\hline \multicolumn{2}{|c|}{$\begin{array}{l}\text { Thermal Conductivities, } \\
\left.\mathrm{W} / \mathrm{m}^{\circ} \mathrm{C} \text { (Btu/ft-h- }{ }^{\circ} \mathrm{F}\right)\end{array}$} & \multicolumn{2}{|c|}{ Surface Emissivities } \\
\hline Steel cask body & $41.5 \quad(24.0)$ & Fuel rods & 0.8 \\
\hline Polyethylene resin & $0.2 \quad(0.1)$ & Fuel basket & 0.8 \\
\hline Aluminum basket & $206.0(119.0)$ & Plated cask surfaces & 0.9 \\
\hline Copper fins & $377.3(218.0)$ & Painted cask surfaces & 0.9 \\
\hline Steel shell & $41.5 \quad(24.0)$ & Copper fin surface & 0.5 \\
\hline Polypropylene & $(0.1)$ & & \\
\hline
\end{tabular}




\section{Modeling Uncertainties}

The COBRA-SFS TN-24P model contained a number of uncertainties in cask design information that limited its ability to accurately predict the thermal performance of the cask. Separate effects analyses have shown that uncertainties in the following parameters account for the greater portion of the total uncertainty:

- The aluminum basket was designed to allow for thermal expansion in the radial direction; no mechanical connections existed between the inside cask wall and the basket. To approximate the thermal resistance attributed to the gap existing between the basket and the inside cask wall, an average basket temperature was predicted, a radial expansion calculated, and a new value for the gap determined. This iterative procedure assumed that the basket was originally centered within the cask (for the vertical orientation) and that the basket expanded uniformly.

- Each fuel canister was assumed to be centered (again, only for vertical orientation), within the basket fuel tube such that the basket-to-fuel canister distance was identical on all four sides of the fuel canister, at all axial locations. It is more likely that the canister is positioned off-center with axially varying distances to the basket walls.

- The heat transfer from the outside cask surface to ambient air through natural convection is difficult to predict accurately. The correlation used is based on a smooth, vertical surface in a static environment.

- The annuli formed by the fuel canisters and the basket were modeled to include conduction and radiation heat transfer only. In actuality, some convection was expected to exist; however, the contribution to the overall heat transfer was assumed to be negligible.

- The connection between the cask bottom and ambient was modeled as a fin. This technique was applied in the previous analysis of the TN-24P cask (푸 with good results.

- The lower plenum was modeled as an empty space in which fill gas was assumed to mix and achieve a constant temperature regardless of radial location within the cask. In reality, the plenum contained the lower unheated portions of the fuel canisters, and the temperature of the fill gas probably varied as a function of radial position.

- The axial decay heat profile used in the COBRA-SFS analyses was not an experimentally measured quantity. Deviations from the true profile result in substantial differences in the predicted temperature as demonstrated by past cask analyses $(\underline{30})$.

- Uncertainty exists in the convective heat transfer coefficient used $(\mathrm{Nu}=3.66)$ in the $\mathrm{TN}-24 \mathrm{P}$ models. 
COBRA-SFS SIMULATIONS COMPARED TO TEST DATA

The COBRA-SFS model was used to predict temperature distributions with in the TN-24P spent fuel storage cask loaded with consolidated spent fuel. The analyses were conducted in two steps. First, a set of predictions was made using the pretest model. It is important to note that each pretest simulation was completed and reported before the corresponding experimental test run was completed. Second, following comparisons of pretest predictions with data, a more detailed model of the consolidated fuel was developed for the post-test simulations. The predictive capability of the COBRA-SFS computer code is assessed for the pretest and post-test simulations in the following sections.

\section{Pretest Predictions Compared to Test Data}

Comparisons are presented in three parts: 1) a summary of peak thermocouple lance temperature predictions is compared to data for all six test runs; 2) pretest axial and radial temperature profiles are compared to data for helium, nitrogen, and vacuum fill gases in the vertical orientation; and 3) pretest axial and radial temperature profiles are compared to data for all three fill gases in the horizontal orientation. All stated percentage temperature deviations are based on the ambientto-peak thermocouple lance temperature difference.

Pretest Peak Temperature Predictions Compared to Test Data. The COBRA-SFS pretest comparisons with experimental data are summarized for the six test runs in bar chart format in Figure 5-6. Peak-to-ambient temperature comparisons for all six test runs are illustrated. All test runs were conducted with the cask located inside the TAN warm shop with an ambient temperature that varied from $18^{\circ} \mathrm{C}\left(65^{\circ} \mathrm{F}\right)$ to $23^{\circ} \mathrm{C}\left(73^{\circ} \mathrm{F}\right)$. In all of the COBRA-SFS simulations, an ambient temperature of $25^{\circ} \mathrm{C}\left(77^{\circ} \mathrm{F}\right)$ was assumed. The peak thermocouple lance temperature for each case was located in the centermost canisters. The axial location of the peak temperature varied as a function of cask orientation and fill gas.

In general, the COBRA-SFS pretest predictions of peak thermocouple lance temperatures underpredicted the experimental data. The largest variation occurred for the horizontal vacuum case, where a $13 \%\left(34^{\circ} \mathrm{C}\right)$ lower peak thermocouple lance temperature was predicted. The mean difference between calculated and measured temperatures of the peak fuel tube for the six test runs was $8 \%\left(21^{\circ} \mathrm{C}\right)$, with a standard deviation of $\pm 4 \%\left( \pm 12^{\circ} \mathrm{C}\right)$. Al1 six simulations underpredicted the peak fuel tube temperature. The test runs with the largest discrepancies between peak temperature predictions and data were the vertical and horizontal vacuum cases. This finding is attributed 


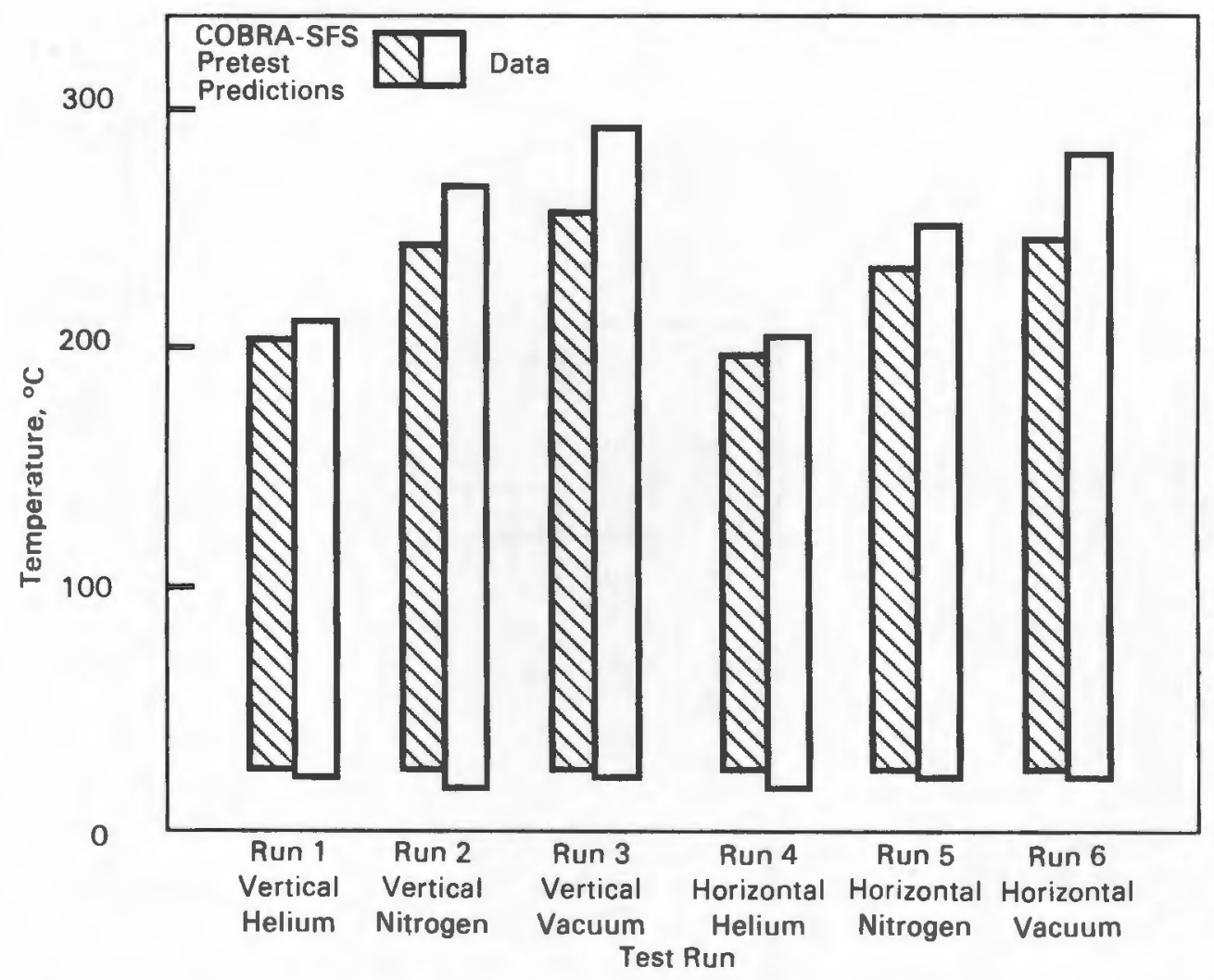

Figure 5-6. Pretest Peak Temperature Predictions Compared to Test Data

to a much too simplified rod lumping model. This will be described in more detail during discussions of the post-test predictions.

Pretest Predictions Compared to Vertical Test Data. The pretest axial temperature profile predictions for the vertical orientation with helium, nitrogen, and vacuum backfills are presented in Figures 5-7, 5-8, and 5-9. Predicted temperature profiles are given along with the discrete data measurements for the following locations: 1) the ambient temperature, 2) the outer cask surface at $0^{\circ}, 3$ ) the basket center, and 4) thermocouple lances in locations D6, D5, D4, D1, and E (see Figures 3-8 and 3-18). A detailed sketch of the locations for presented temperature profiles is shown on each figure.

The helium results given in Figure $5-7$ show a maximum disagreement of $9 \%\left(18^{\circ} \mathrm{C}\right)$ using the pretest model. The predicted peak temperature was $4 \%\left(7.6^{\circ} \mathrm{C}\right)$ lower than the data. The shape of COBRA-SFS predicted axial temperature profiles agreed well with experimental data. Note that the assumed ambient temperature for all six runs 


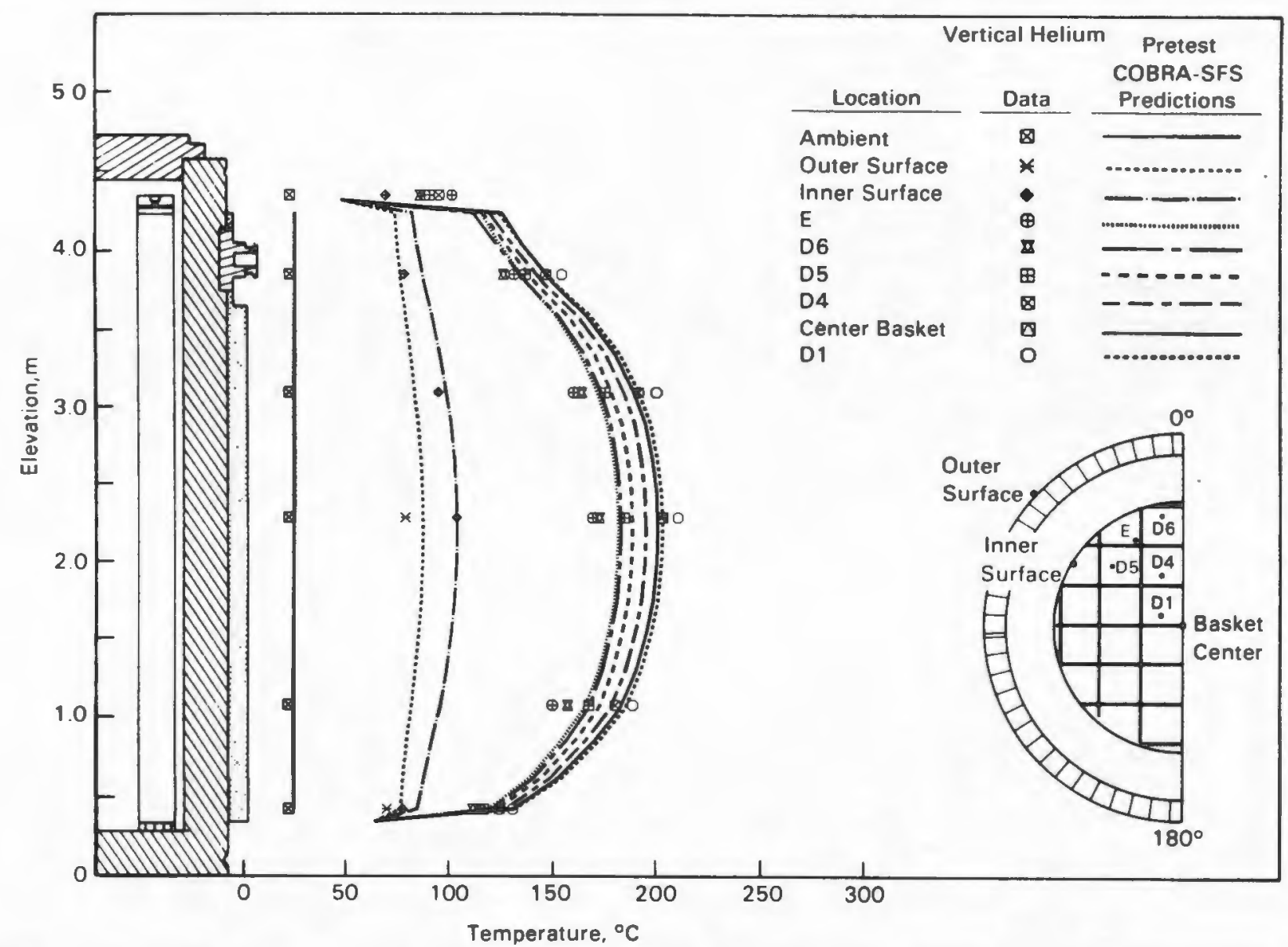

Figure 5-7. Pretest Vertical, Helium Axial Temperature Profile Predictions Compared to Test Data 


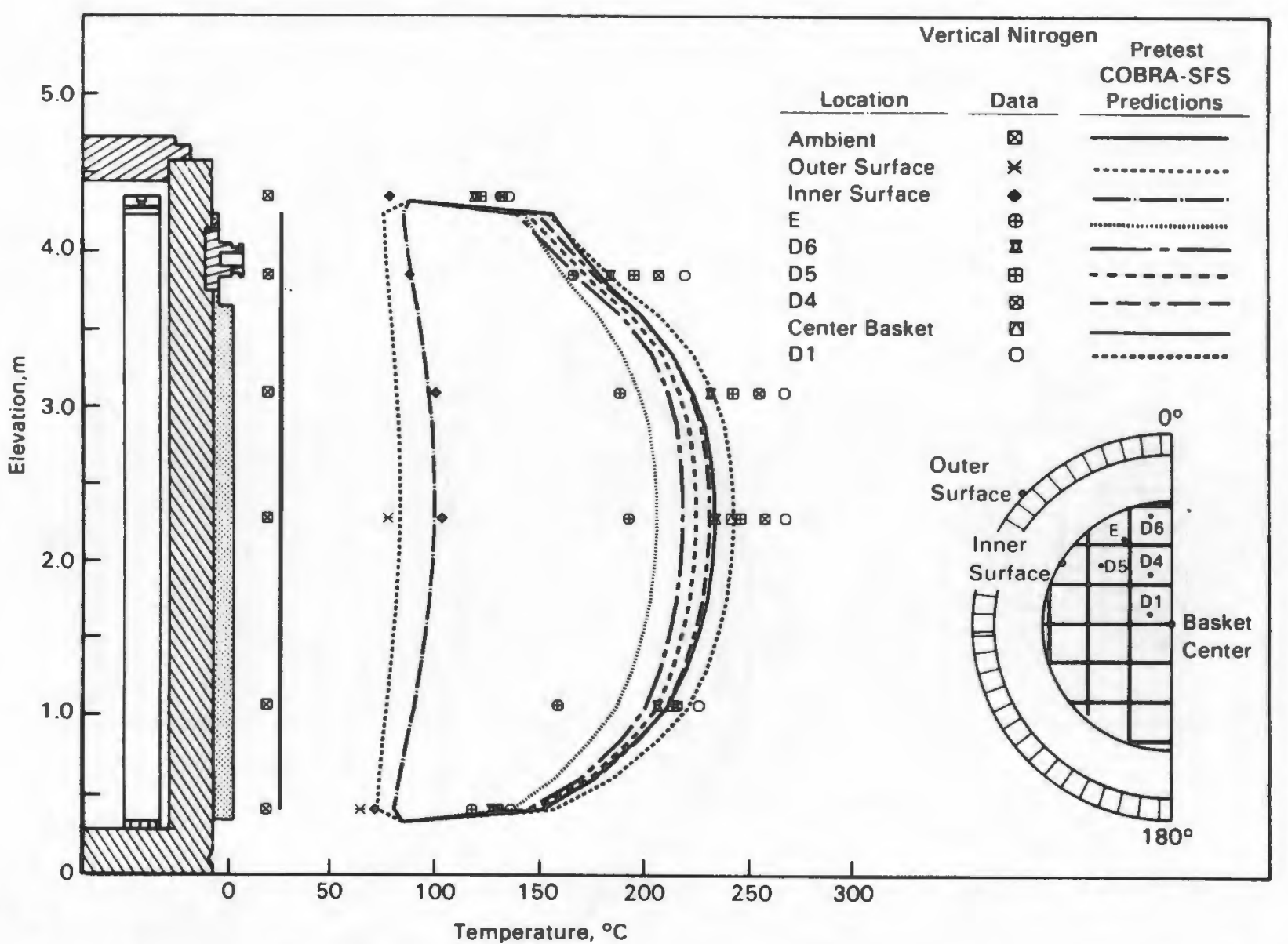

Figure 5-8. Pretest Vertical, Nitrogen Axial Temperature Profile Predictions Compared to Test Data 


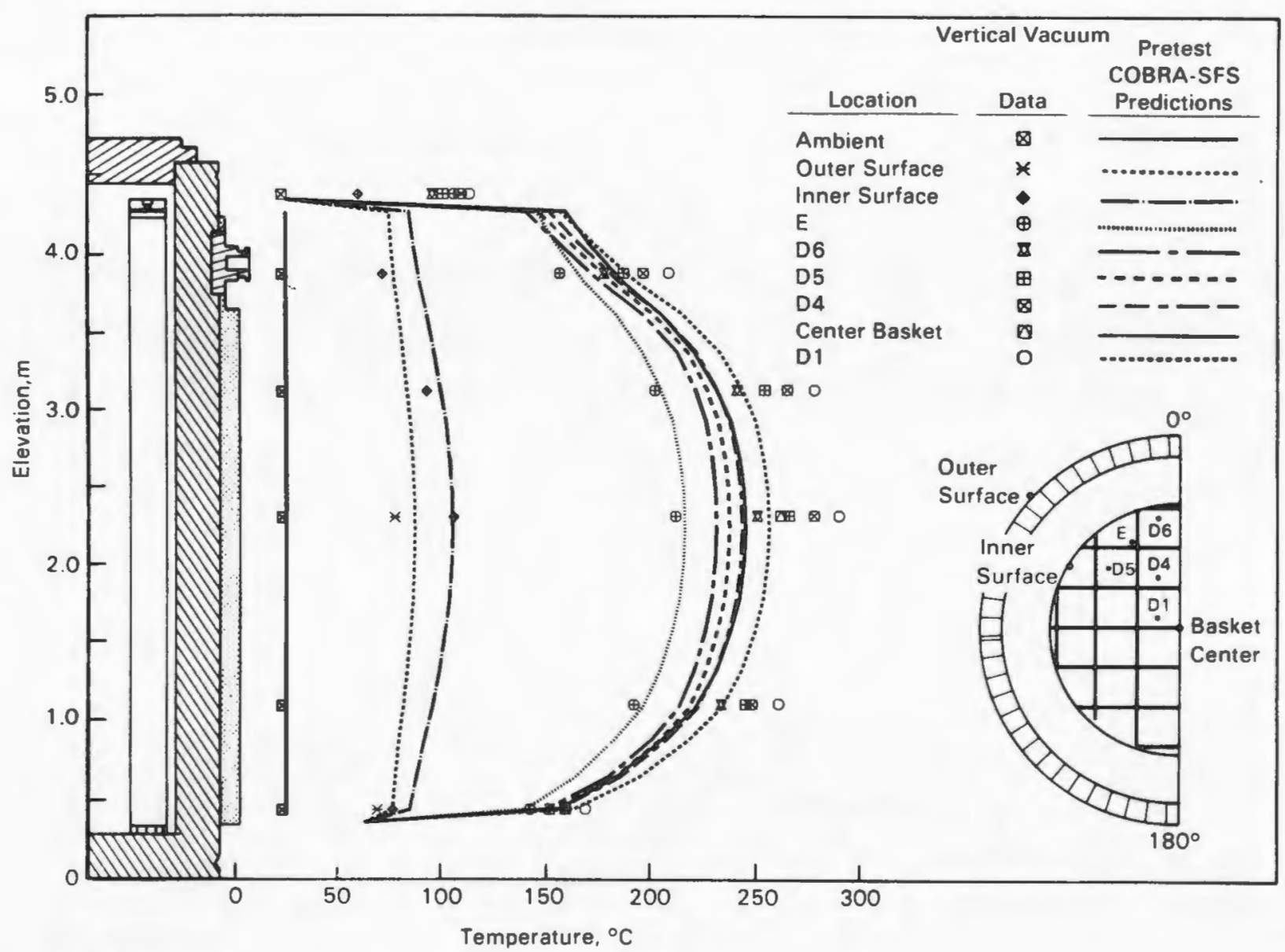

Figure 5-9. Pretest Vertical, Vacuum Axial Temperature Profile Predictions Compared to Test Data 
was slightly lower than the experimental measurements. This could not be addressed in the pretest discussions because the data were not available until after the predictions had been made.

Figure 5-8 shows the results for the vertical nitrogen run. The predictions were based on the assumption that no significant convection would take place in the small annuli between the canisters and the basket. The effect of insufficiently accounting for convection within the TN-24P pretest model is apparent in Figure 5-8. The upward skew of the axial data indicates that convection occurred within the cask for the nitrogen fill gas case. However, convection seems to have little effect on the magnitude of the peak temperature. For this case, the peak temperature difference comparison was fair, and the model underpredicted the experimental data by $10 \%$ $\left(25^{\circ} \mathrm{C}\right)$.

Figure 5-9, the vertical vacuum test run comparison, shows a COBRA-SFS pretest underprediction of $13 \%\left(34^{\circ} \mathrm{C}\right)$. The temperature profiles in this nonconvection run directly reflect the assumed axial power profile. Although the peak temperature was underpredicted, fairly good agreement between the shapes of the axial temperature profiles is noted.

The effect of fill gas on thermal performance is shown in Figure 5-10, which is a composite of the peak temperature profiles for each of the vertical orientation runs. In each case, the model underpredicted the measured temperatures. In addition, the predictions do not show the convection effects seen in the nitrogen measurements. This is because the annular space between the fuel canister and the basket was not modeled.

Diametrical temperature profiles at the location of the peak axial temperatures are presented in Figure 5-11, which shows the distribution of thermal resistance through the cask for the vertical test runs. The location of the measured temperature is shown on the inset to the drawing. The shape of the diametrical temperature profiles reflects the conductivity of the gas in the cask and the basket material. The gas conductivity has significant impact on the temperature drop between the cask wall and the basket, and between the basket and measured fuel temperature. The shape of the temperature profile across the basket is largely a result of the basket material conductivity. The steepest temperature gradient within the cask occurred in the gap between the outer fuel canister and the inside cask wall. The magnitude of this gap shows the effect of gas conductivity. The helium run has the smallest temperature drop, as the gas conductivity for helium is approximately 5 times 


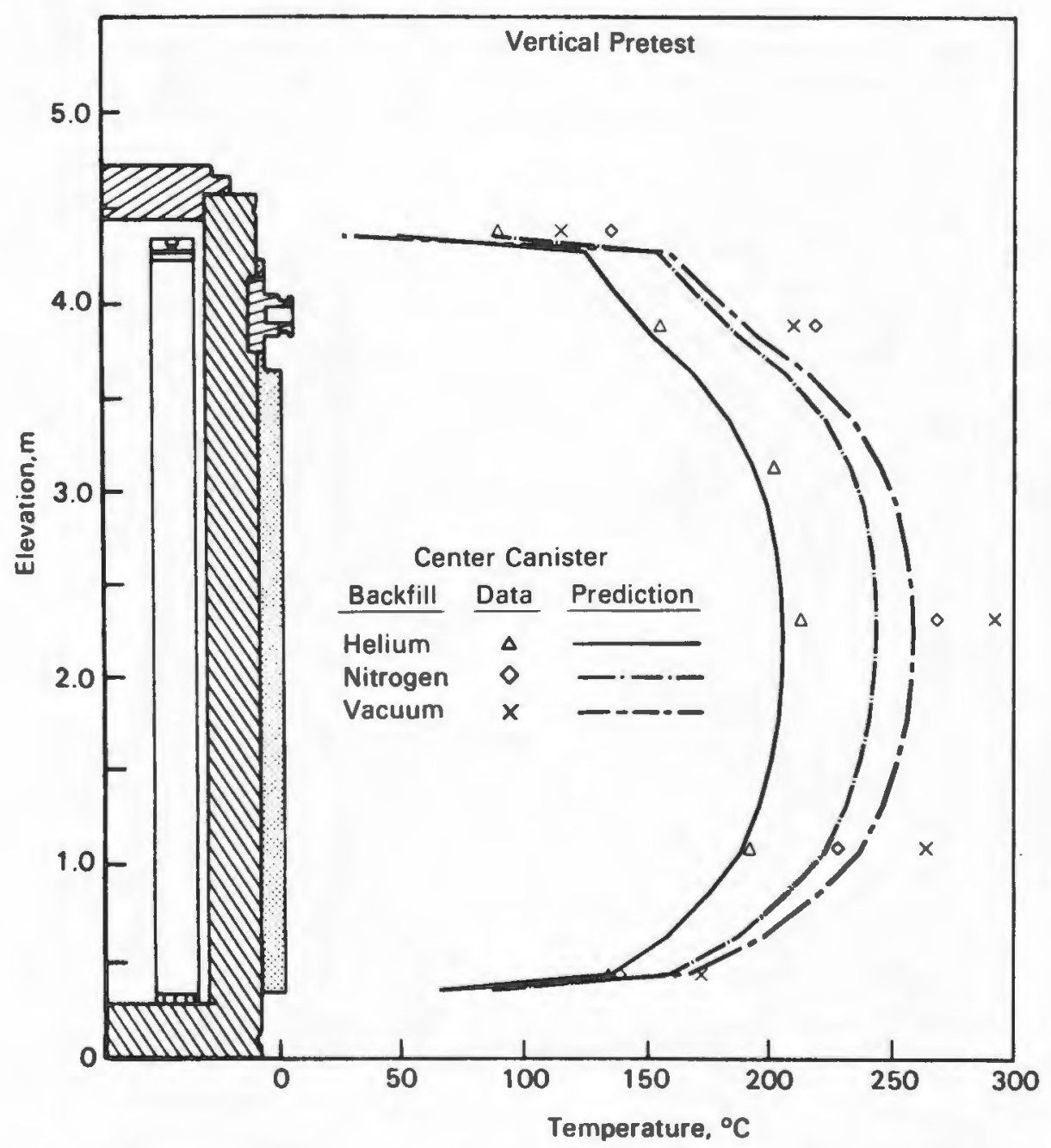

Figure 5-10. Effect of fill gas on pretest vertical axial temperature profile predictions compared to data.

greater than that for nitrogen. The difference in basket and fuel temperature for the various runs is also consistent with the difference in conductivity of the gas. The difference between basket and fuel temperatures for the helium runs is noticeably smaller than for the other two runs.

In the hottest vertical orientation case, the vacuum run, the predicted $106^{\circ} \mathrm{C}$ temperature drop across the gap represented $40 \%$ of the entire temperature drop through the cask. The copper fins embedded in the polyethylene resin neutron shield provided an excellent heat transfer path, with a maximum temperature drop of $29^{\circ} \mathrm{C}$ from the inside wall surface to the shell outer surface for the three vertical test runs. In all three test runs, the COBRA-SFS model underpredicted the measured thermocouple lance temperatures in the radial direction. The greatest disagreements 


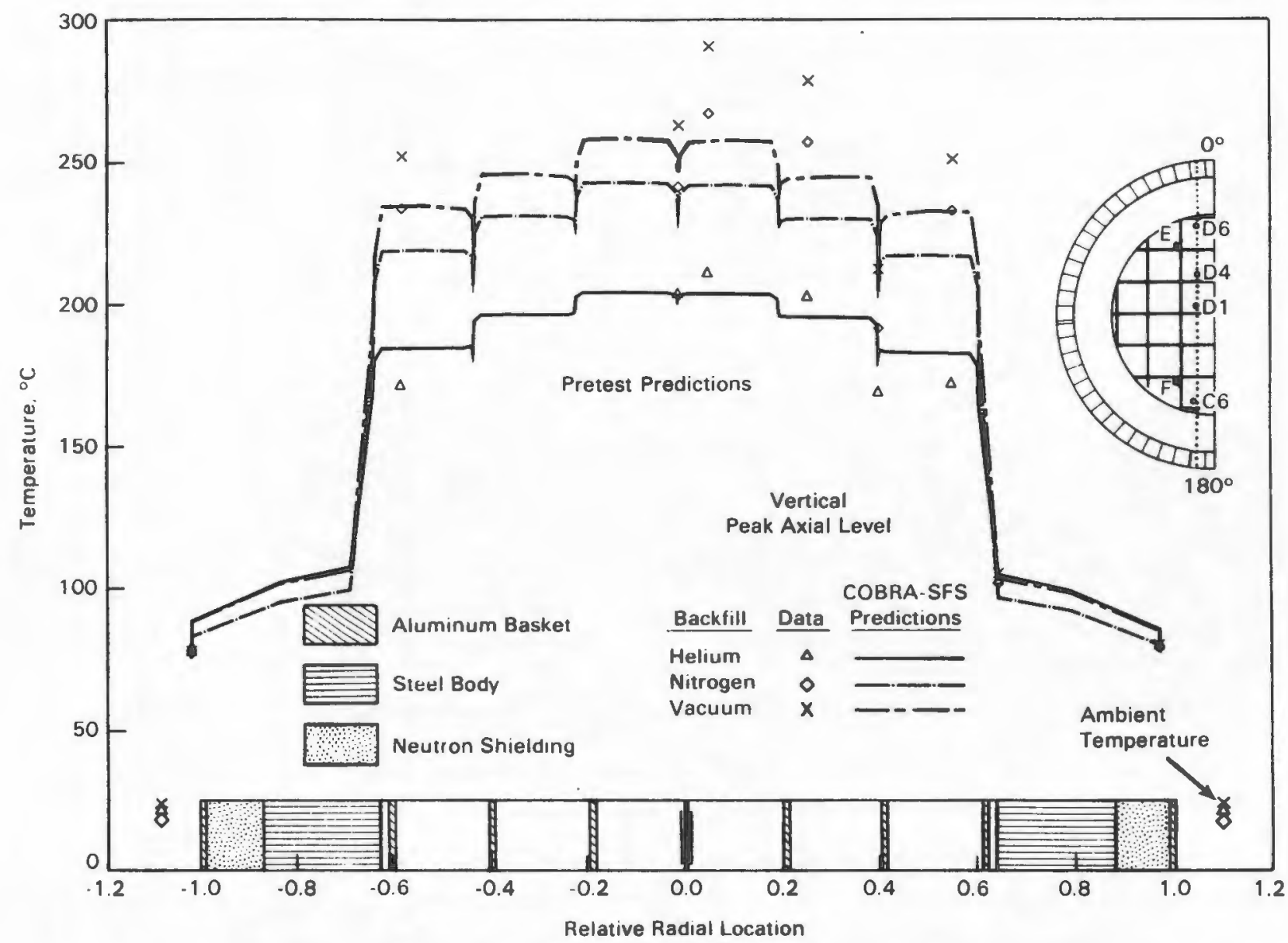

Figure 5-11. Pretest vertical, helium, nitrogen, and vacuum radial temperature profile predictions compared to test data at peak axial locations. 
occurred at the thermocouple lance locations. The large disagreement between measurements at fuel TC lance and predicted temperatures is due to the coarseness of the fuel rod and channel models.

Pretest Horizontal Predictions Compared to Test Data. Convection within the cask was assumed to be negligible in the horizontal orientation and was therefore not included in the COBRA-SFS model. However, two important effects that were accounted for are 1) shifting of the basket into contact with the inside cask wall at the lower side and 2) movement of fuel canisters within each basket fuel tube to the lowest side. The axial temperature profiles shown in Figures 5-12, 5-13, and 5-14 for the horizontal orientation represent the same radial locations as in the vertical model.

The axial profiles for the helium fill gas are presented in Figure 5-12. The peak temperature was underpredicted by $4 \%\left(8^{\circ} \mathrm{C}\right)$. The shape and magnitude of pretest predictions for the horizontal helium run compare well with the measured temperatures. As in the previous unconsolidated fuel analyses of the TN-24P cask ( $\underline{3}$ ), both the measured and calculated temperatures for the horizontal helium case are lower than those of the vertical helium case. This reflects the increased heat transfer due to contact of the aluminum basket with the inside cask wall and shifting of fuel canisters within basket fuel tubes.

The predicted nitrogen horizontal axial profiles displayed in Figure 5-13 show fairly good agreement with data, with the peak measured temperature being underpredicted by $6 \%\left(14^{\circ} \mathrm{C}\right)$. The COBRA-SFS model neglected convection in the horizontal orientation; therefore, it was not possible to model any effects of convection on temperature for the horizontal nitrogen run. The measured and predicted peak temperatures for nitrogen in the horizontal orientation were lower than those in the vertical run. Unlike the unconsolidated fuel analyses of the TN-24P cask ( $\underline{3}$ ), convection in nitrogen for the vertical orientation did not contribute more to overall heat transfer than did the increased heat transfer due to the basket contact with the inside cask wall and canister contact with fuel tube walls in the horizontal orientation.

Predicted axial profiles for the horizontal vacuum case displayed in Figure 5-14 show fair agreement with data. The peak temperature was underpredicted by $13 \%$ $\left(34^{\circ} \mathrm{C}\right)$. The predicted temperature profile shapes are in excellent agreement with the data, as was the case for the vertical runs. The major difference between the vertical and horizontal vacuum test runs was the shifting of the cask internals 


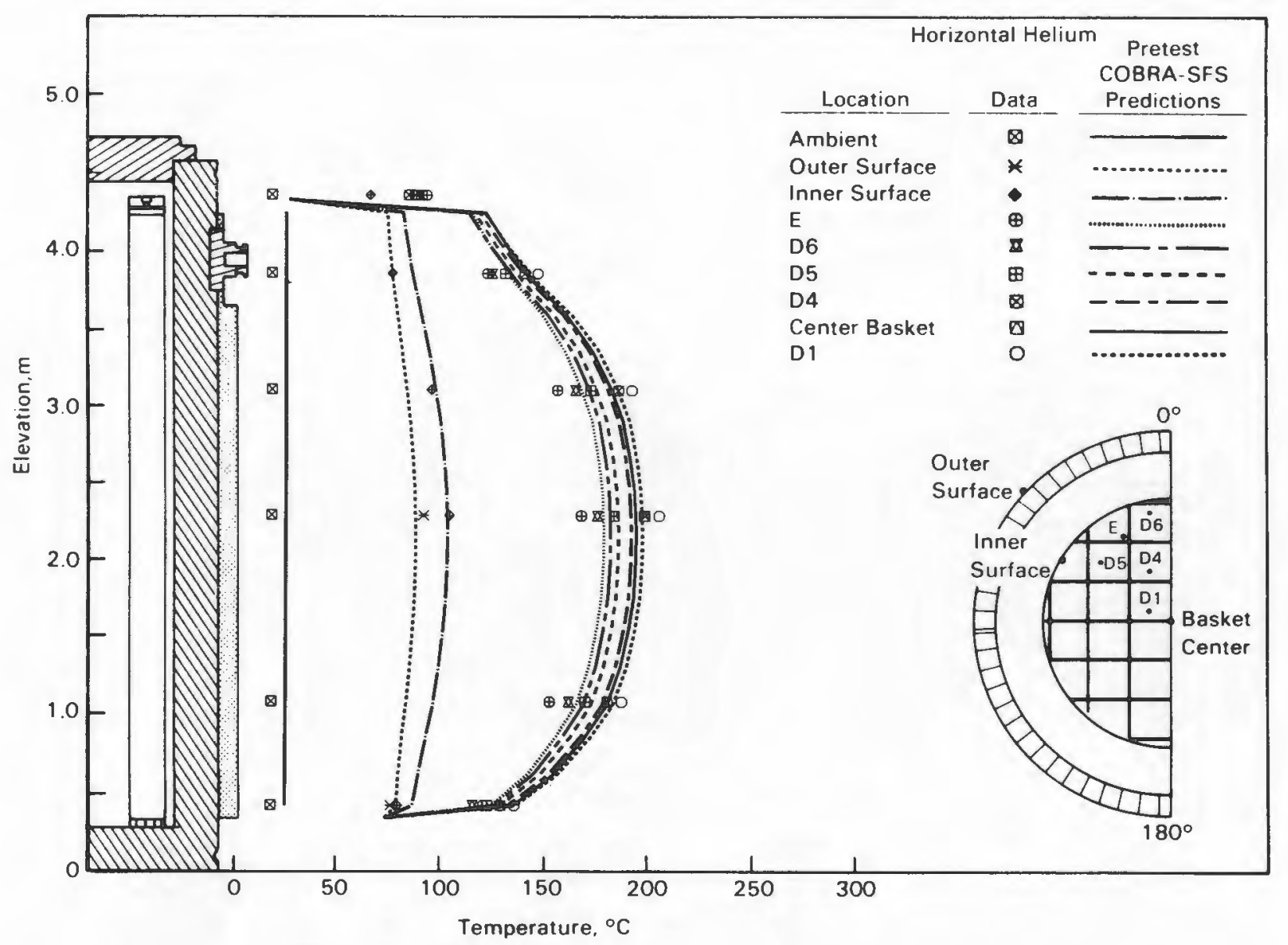

Figure 5-12. Pretest Horizontal, Helium Axial Temperature Profile Predictions Compared to Test Data 


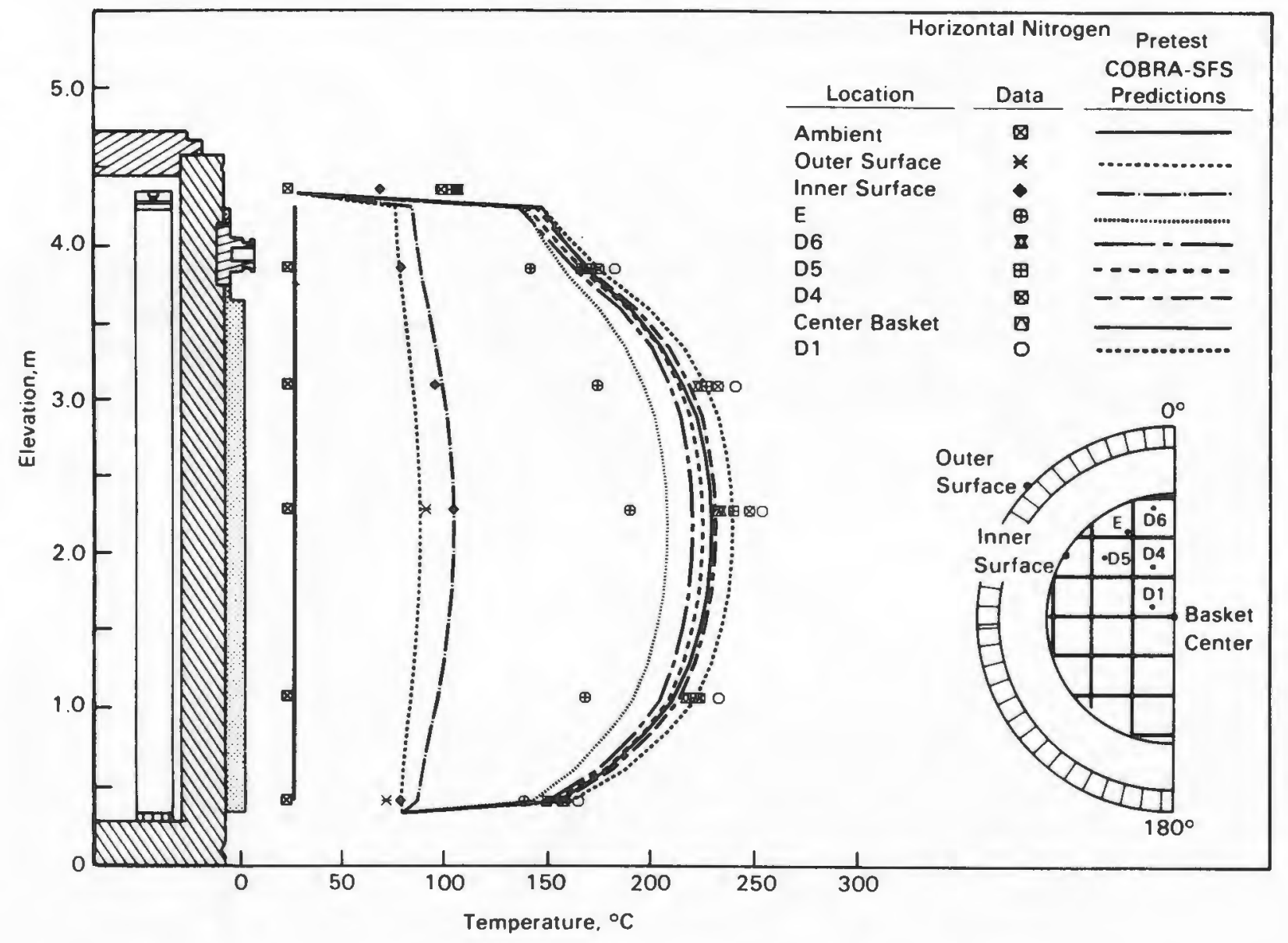

Figure 5-13. Pretest horizontal, nitrogen axial temperature profile predictions compared to test data. 


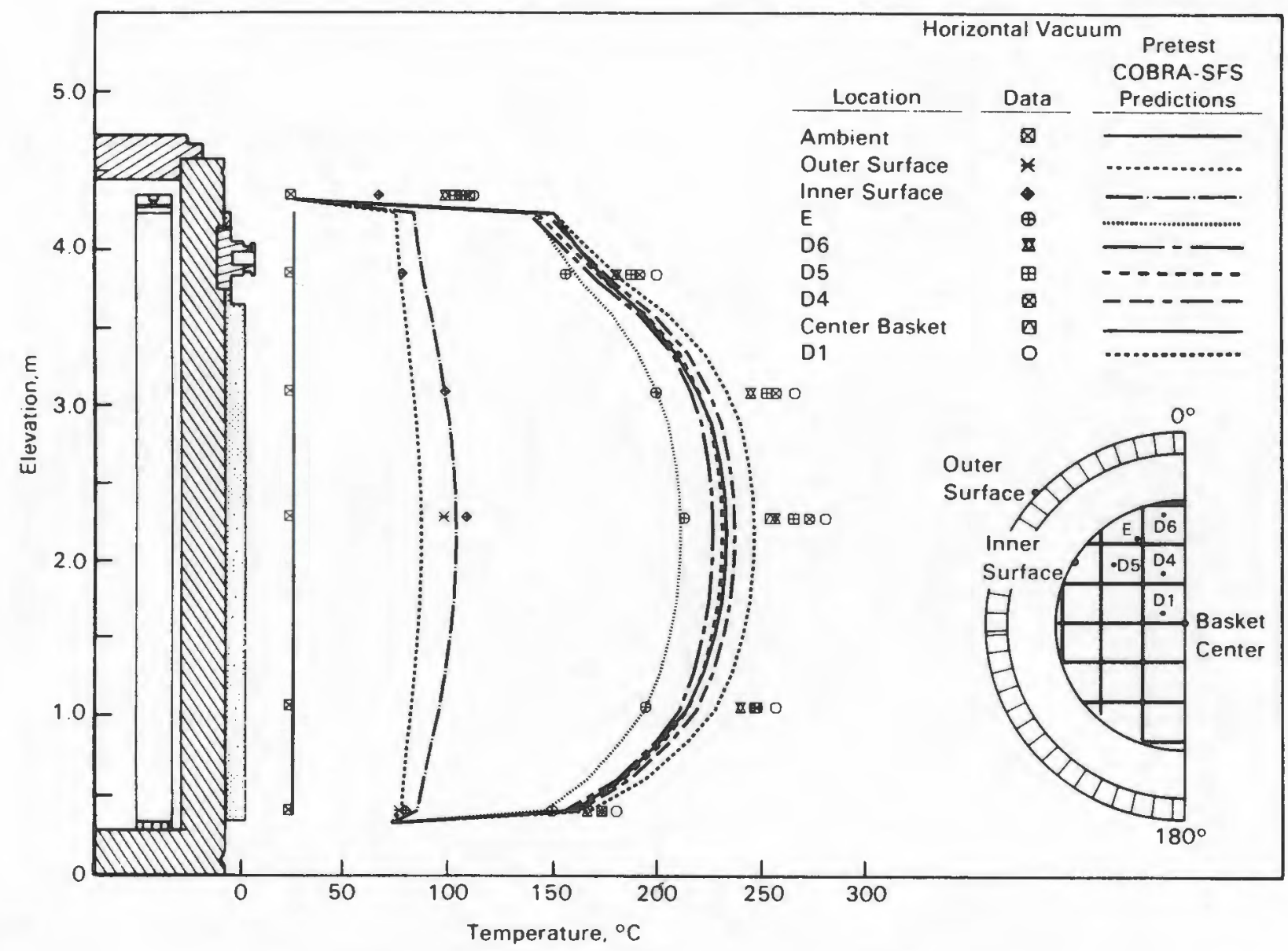

Figure 5-14. Pretest Horizontal, Vacuum Axial Temperature Profile Predictions Compared to Test Data 
(basket and fuel) in the horizontal orientation. Both the predictions and the data show a lower peak temperature for the horizontal run, reflecting the increased heat transfer due to basket contact with the inner cask wall and fuel canister contact with the basket walls.

The effect of fill gas on the horizontal orientation predictions is displayed in Figure 5-15, where the predicted peak temperature profiles for the three fill gases are presented along with the data. The profiles have the same general shape, indicating the absence of convection and the accuracy of the decay heat profile used for the analyses. Only the magnitudes differ, as the result of different backfill gas thermal conductivities.

The diametrical profiles at the peak axial temperature location for each of the three fill gases are shown in Figure 5-16. The main point of interest is the

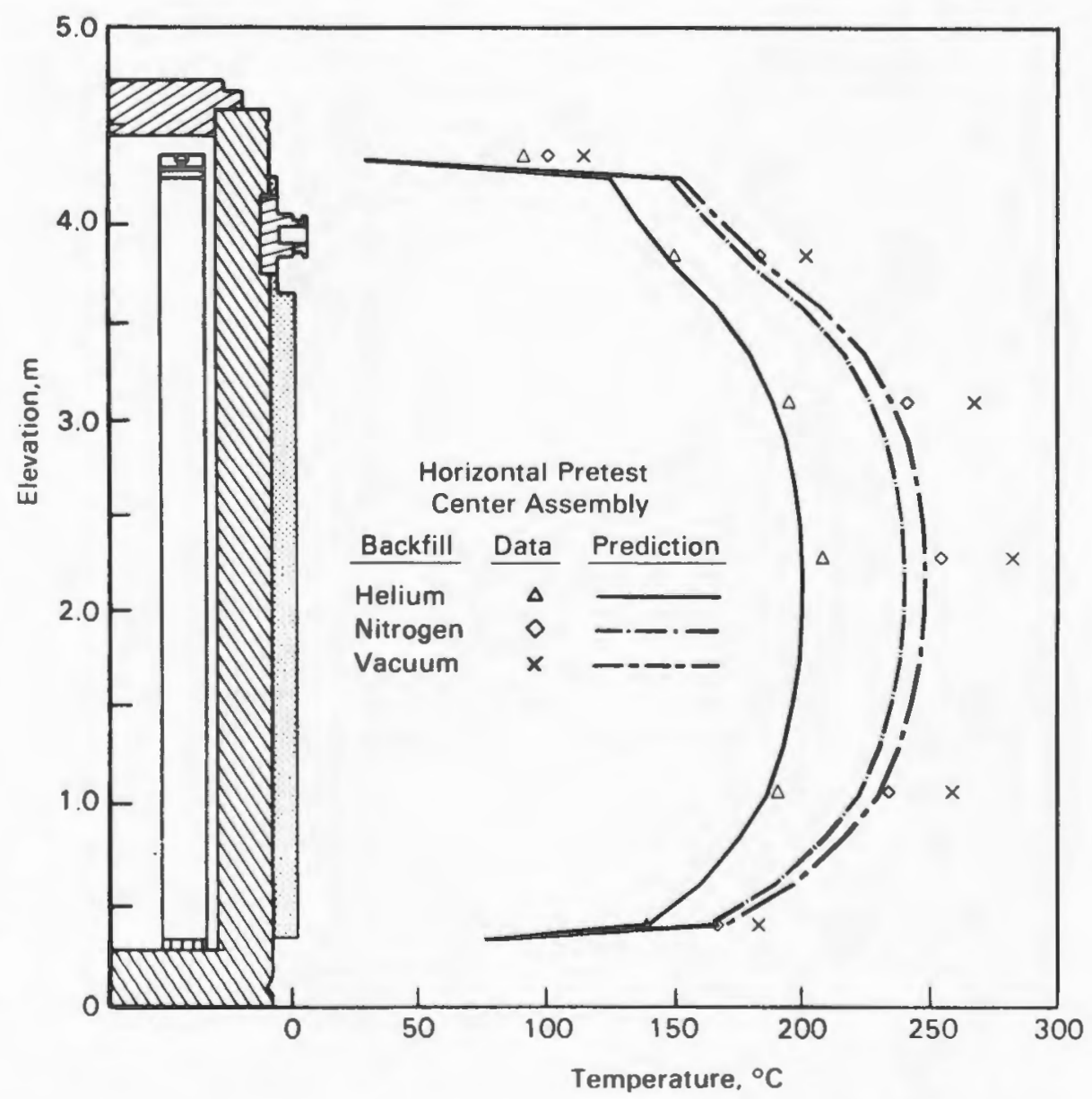

Figure 5-15. Effect of fill gas on pretest horizontal axial temperature profile predictions compared to data. 


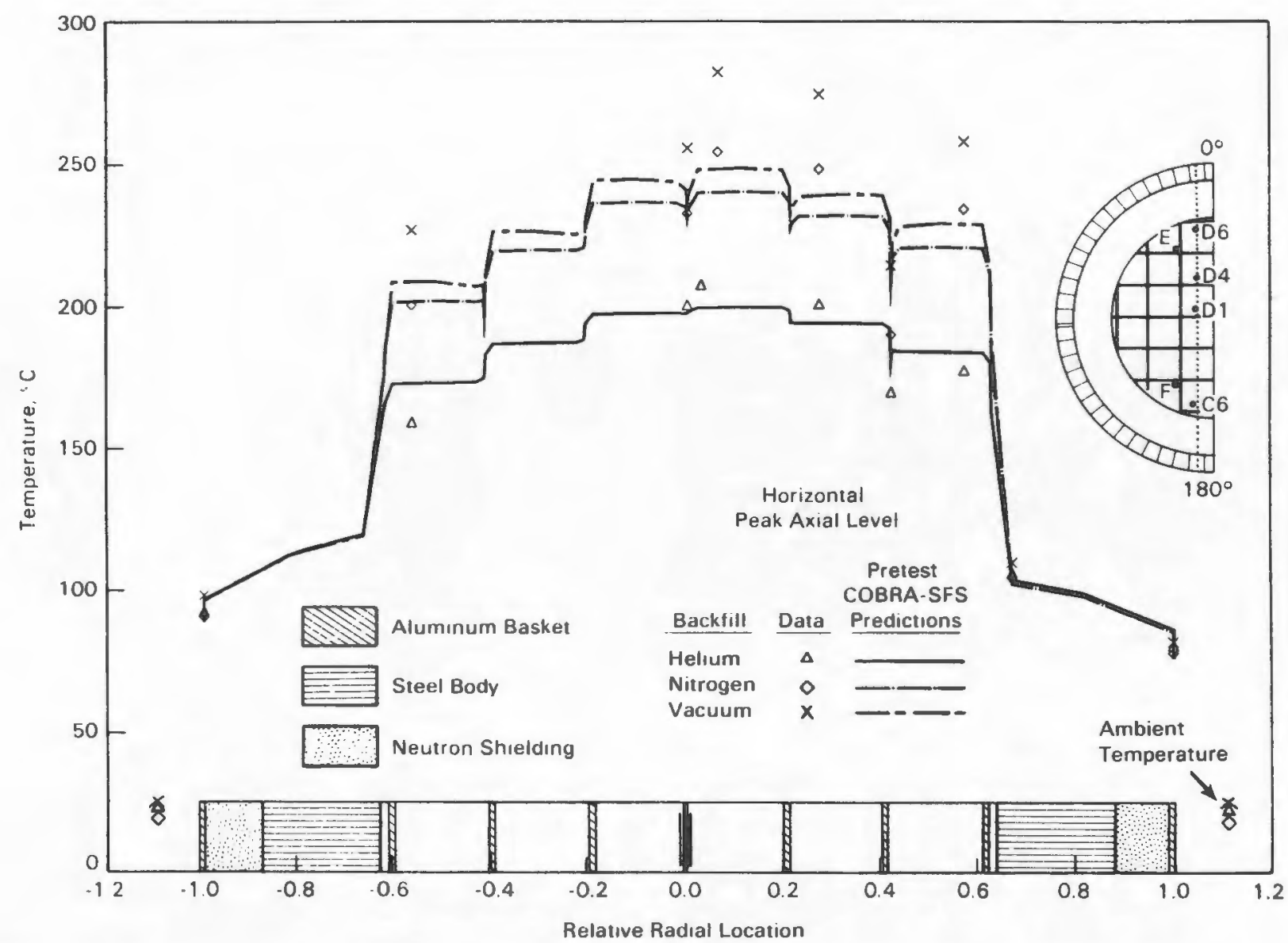

Figure 5-16. Pretest horizontal, helium, nitrogen, and vacuum radial temperature profile predictions compared to test data at peak axial locations. 
observed skew in the radial profiles toward the upper surface $\left(0^{\circ}\right)$ of the cask. The predicted and measured data both show higher canister temperatures in the upper portion of the cask, which resulted from 1) the increased gaps between the basket and the inside cask wall at the upper basket locations $\left(0^{\circ}\right)$ and 2) the decreased gaps between the basket and the inside cask wall near the bottom of the cask $\left(180^{\circ}\right)$. The thermocouple lance temperatures were again predicted within $34^{\circ} \mathrm{C}$.

Conclusions from Pretest Comparisons. Comparisons of pretest predictions with experimental data led to the following conclusions:

- The pretest peak temperature predictions were in good agreement with data. The maximum disagreement was $13 \%\left(34^{\circ} \mathrm{C}\right)$ for the horizontal vacuum run.

- With the exception of the vertical nitrogen run, the shapes of the predicted axial temperature profiles are in good agreement with the measured data. The disagreement in profile shape between predictions and measurements for the vertical nitrogen run was a result of neglecting axial convection in the small gap between the fuel canister and the basket. The data indicate that the gap was sufficiently large to support some convection. The measured data indicate that convection resulted in a small skewing of the axial temperature profile but had little impact on the peak temperature in the cask.

- Predictions of temperatures for each of the six cases were less than the experimental data, with the vacuum cases showing the largest disagreement, followed by the nitrogen cases.

- Thermocouple lance temperatures located in the fuel were consistentiy underpredicted (up to $34^{\circ} \mathrm{C}$ ). The underpredictions of fuel temperatures are primarily a result of the coarseness of the pretest rod and channel models.

\section{Post-Test Predictions Compared to Test Data}

Previous work ( $\underline{3}$ ) provided confirmation of the physical properties used for the TN$24 \mathrm{P}$ cask. The major disagreements existed in the radiation-dominated runs (vacuum and nitrogen back fill cases) and the greatest underpredictions were at the thermocouple lances locations within the fuel canisters, indicating that the coarseness of the rod and channel models was the major contributor to the difference between predictions and measurements. An improved rod lumping pattern was modeled and its effect on the predictions is discussed in the following section.

A discussion of the post-test model alterations precedes the presentation of the individual post-test predictions. The comparisons of post-test predictions with data are presented in the same fashion as those for the pretest: 1) summaries of 
post- and pretest peak thermocouple lance temperatures are compared with data for all six test runs; 2) post-test axial and radial.temperature profiles are compared with data for helium, nitrogen, and vacuum fill gases, for the vertical orientation; and 3) post-test axial and radial temperature profiles are compared with data for the three fill gases in a horizontal position.

Model Changes. Only one post-test change was made to the model. In the pretest model it was assumed that the temperature gradient inside the packed fuel canister would be small. This was consistent with the data and analysis reported for BWR fuel (28). The assumption led to a five-node lumped rod model (a center lumped rod node surrounded by four outer lumped rods as shown in Figure 5-5) for the 408 rods. The five-lumped rod model represented a significant oversimplification of the fuel in the canister and differed substantially from the model used for unconsolidated fuel. The five-lumped rod model (essentially a two-ring model--one center node surrounded by a ring of four nodes) gave low fuel temperatures, which is consistent with the results reported in reference (31) for fuel models with over simplified noding. The model used for an unconsolidated fuel assembly is shown in Figure 5-17. For the post-test study a new, more detailed lumping pattern was developed that would more accurately represent the existing temperature gradients in the consolidated fuel within the TN-24P cask. A concentric "ring" pattern incorporating 13 lumped rod nodes was developed, as shown in Figure 5-18. The detail in this model is more consistent with the model used previously for unconsolidated fuel. All six post-test cases were run using the 13-ring lumping scheme.

No other changes were made to the COBRA-SFS TN-24P mode1. The post-test model is the pretest model with a more detailed consolidated fuel model. As will be seen, the post-test model gave marked improvement in predicted fuel temperatures. The amount of effort required to include some additional improvements could not be justified by their anticipated small improvement in predictions. Other improvements that could have been included were modeling of convection in the small gap between the basket and fuel, refinements to gap conductance between the basket and cask wal1, refinements to the thermal conductivity of the basket, and modeling of actual ambient temperatures.

Post-Test Peak Temperature Predictions Compared to Test Data. Comparisons of the peak- to-ambient pretest and post-test predictions with data for the six test runs are shown in Figure 5-19. For the post-test discussions, the difference in measured and assumed ambient temperature is accounted for by adjusting the predictions by the appropriate magnitude. The post-test model changes improved the predicted peak 


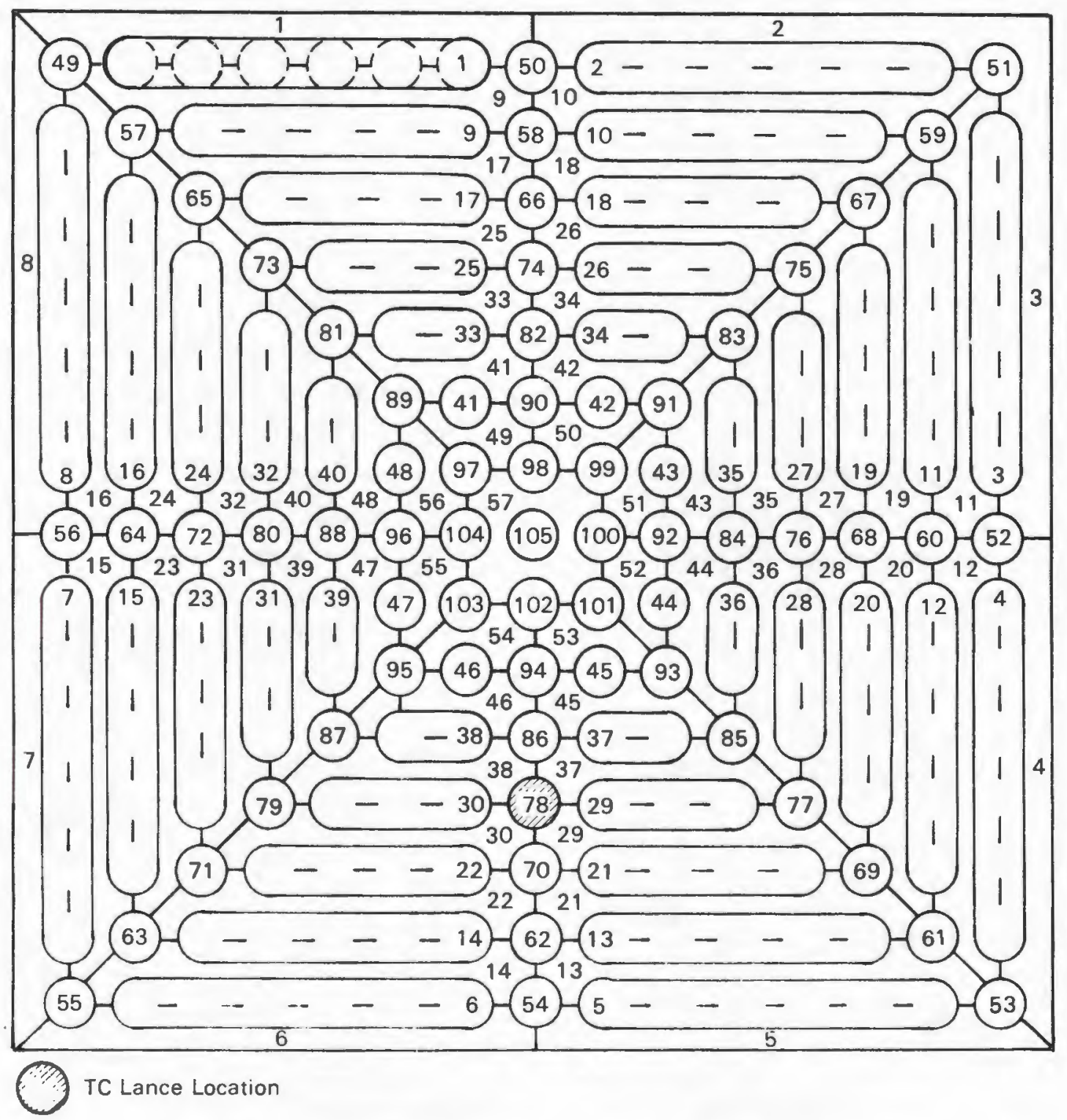

Figure 5-17. Full transverse unconsolidated fuel assembly lumped rod and lumped channel computational model.

thermocouple lance temperatures for a 11 six cases. The greatest discrepancy occurred for the vertical nitrogen case, where a $5 \%\left(13^{\circ} \mathrm{C}\right)$ underprediction exists. The mean temperature difference between the data and the post-test predictions for the six test runs was $3 \%\left(6^{\circ} \mathrm{C}\right)$, with a standard deviation of $\pm 2 \%\left( \pm 5^{\circ} \mathrm{C}\right)$. A summary of the pre- and post-test predictions compared to the experimental data for the six test runs is given in Table 5-4. 
ROD \# 1

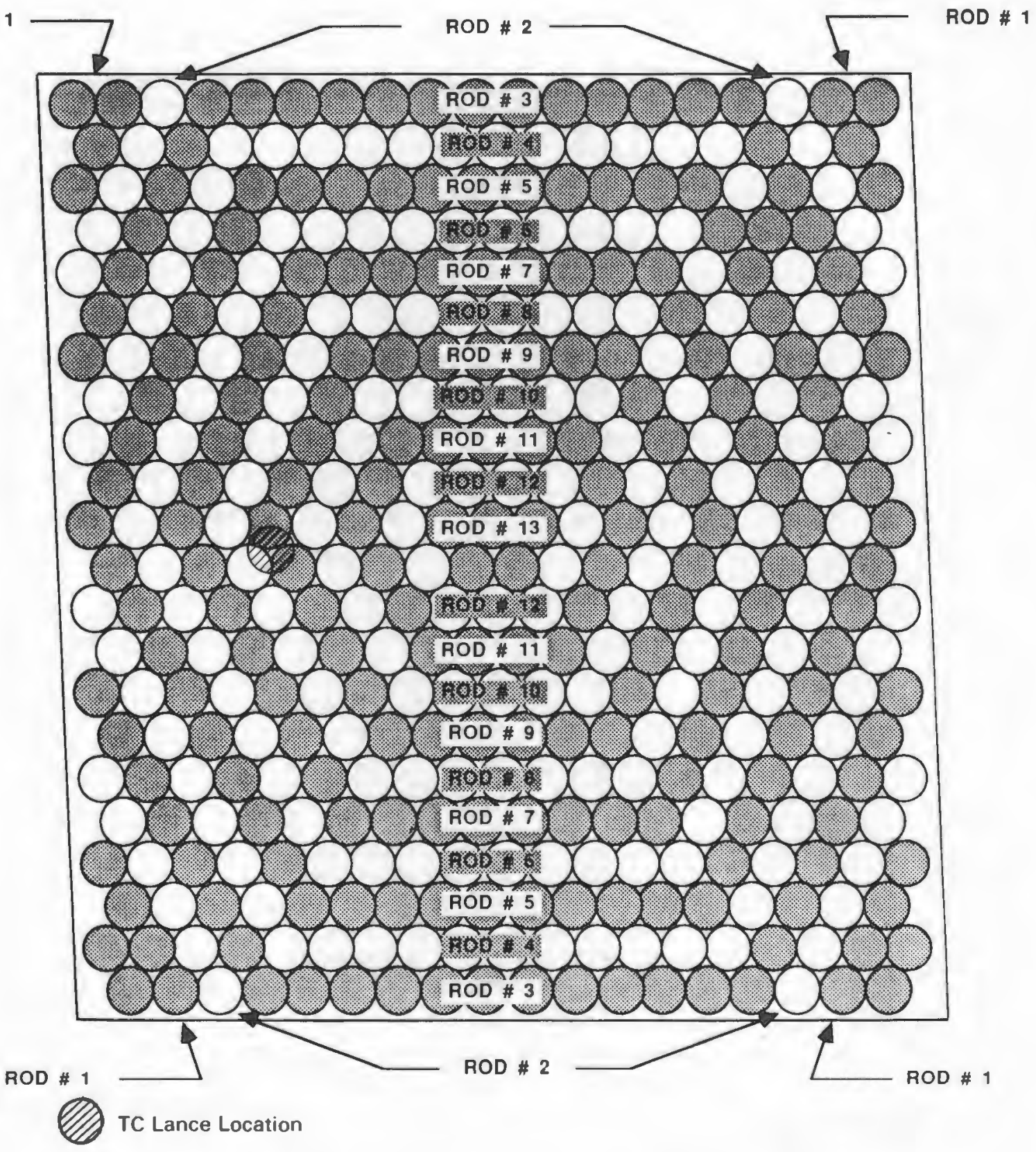

Figure 5-18. Post-Test Consolidated Fuel Model (13 nodes)

Post-Test Vertical Predictions Compared to Test Data. The post-test predictions of axial temperature profiles for the three fill gases in the vertical orientation are shown in Figures 5-20,5-21, and 5-22. Figure 5-20, the helium fill gas case, displays the improvement in the predicted temperature magnitudes. The peak measured temperature was underpredicted in this case by $2 \%\left(4^{\circ} \mathrm{C}\right)$. At other radial locations, predicted temperatures agreed within $14^{\circ} \mathrm{C}$ (worse case is outer basket location E) with measured values. 


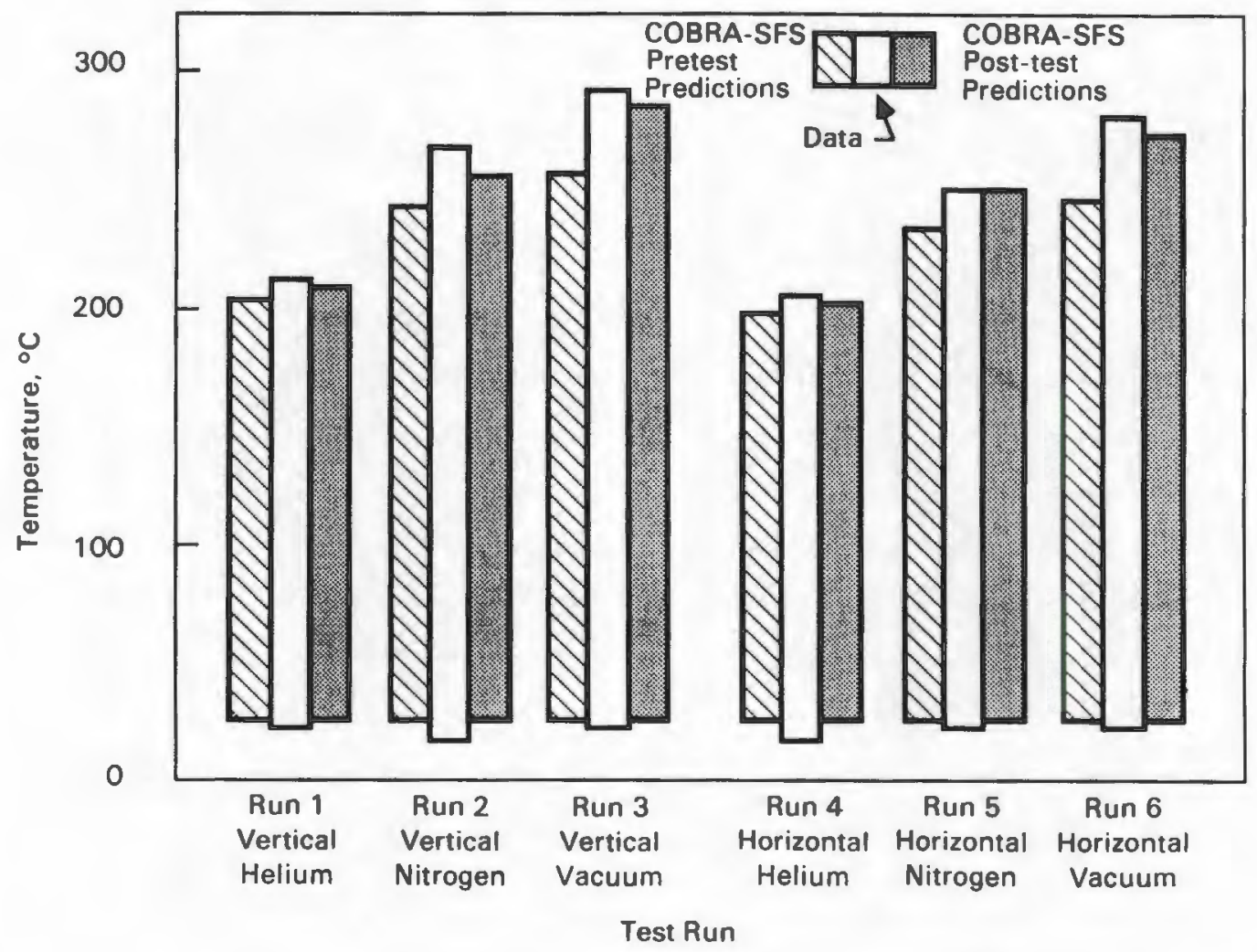

Figure 5-19. Post-test peak temperature predictions compared to pretest predictions and test data

Table 5-4

PEAK TEMPERATURE COMPARISONS

\begin{tabular}{|c|c|c|c|c|c|c|}
\hline \multirow{2}{*}{$\begin{array}{l}\text { Test } \\
\text { Run } \\
\end{array}$} & \multirow[b]{2}{*}{ Backfill } & \multirow[b]{2}{*}{ Orientation } & \multicolumn{2}{|c|}{ Experimental Data } & \multicolumn{2}{|c|}{ COBRA-SFS Predictions ${ }^{\mathrm{a}}$} \\
\hline & & & Ambient, ${ }^{\circ} \mathrm{C}$ & Peak, ${ }^{\circ} \mathrm{C}$ & Pretest, ${ }^{\circ} \mathrm{C}$ & Post-Test, ${ }^{\circ} \mathrm{C}$ \\
\hline 1 & Helium & Vertical & 22 & 211 & 203 & 207 \\
\hline 2 & Nitrogen & Vertical & 16 & 267 & 242 & 254 \\
\hline 3 & Vacuum & Vertical & 22 & 291 & 257 & 283 \\
\hline 4 & Hel ium & Horizontal & 17 & 205 & 197 & 201 \\
\hline 5 & Nitrogen & Horizontal & 22 & 251 & 237 & 251 \\
\hline 6 & Vacuum & Horizontal & 23 & 280 & 246 & 272 \\
\hline
\end{tabular}

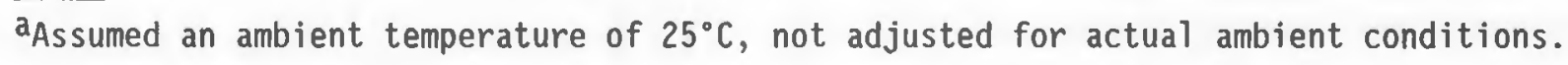




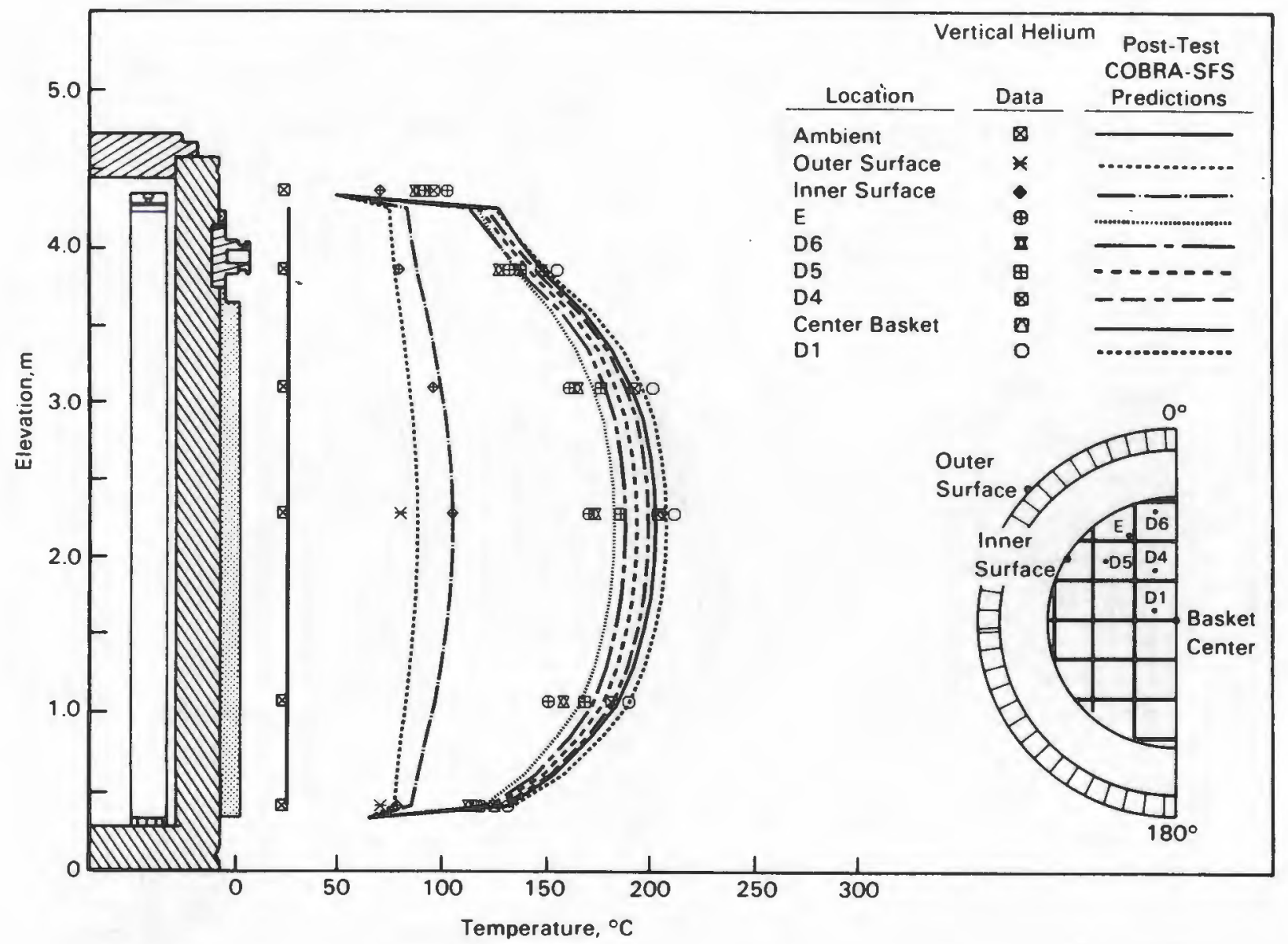

Figure 5-20. Post-Test Vertical, Helium Axial Temperature Profile Predictions Compared to Test Data 


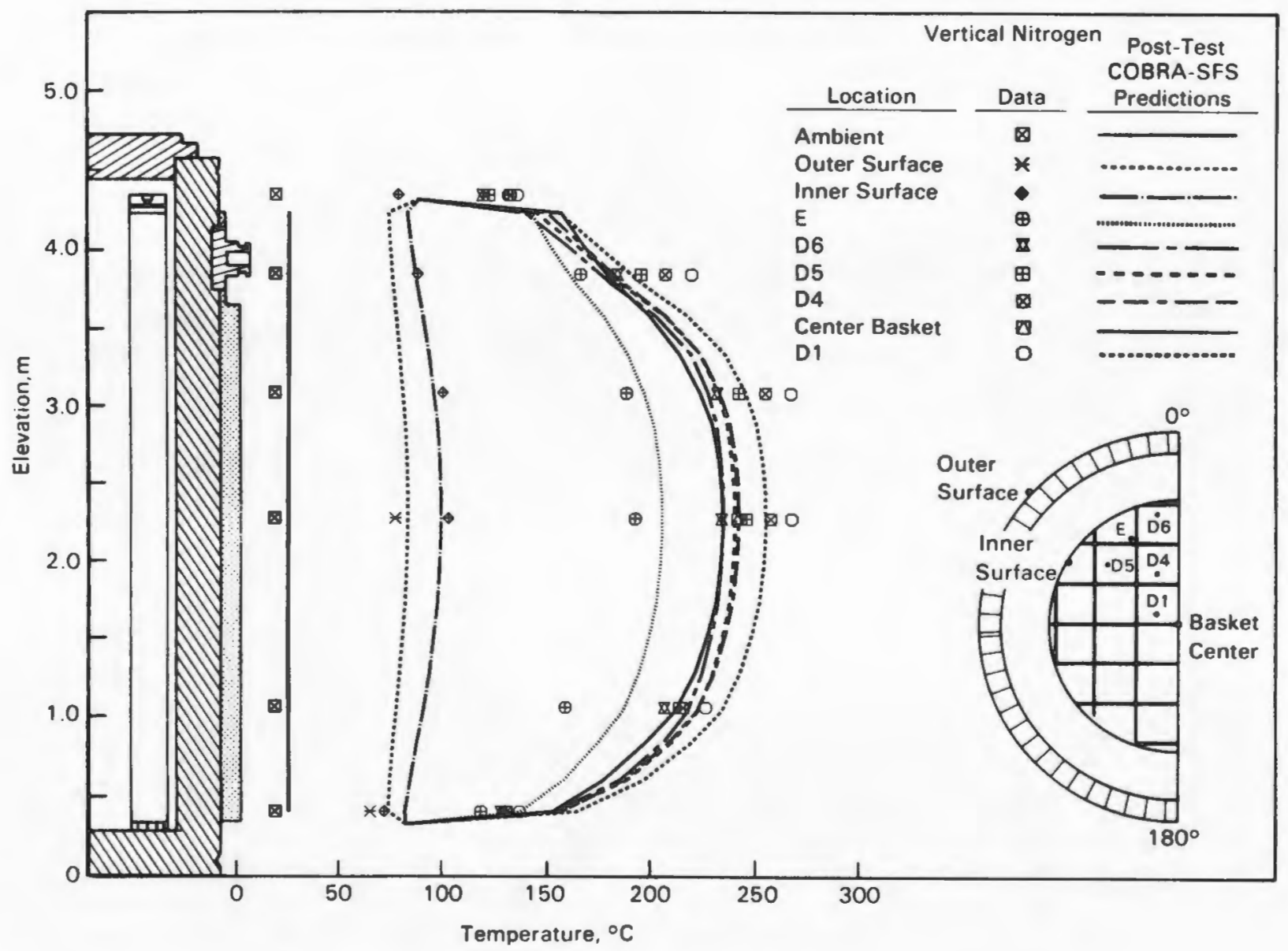

Figure 5-21. Post-test vertical, nitrogen axial temperature profile predictions compared to test data. 


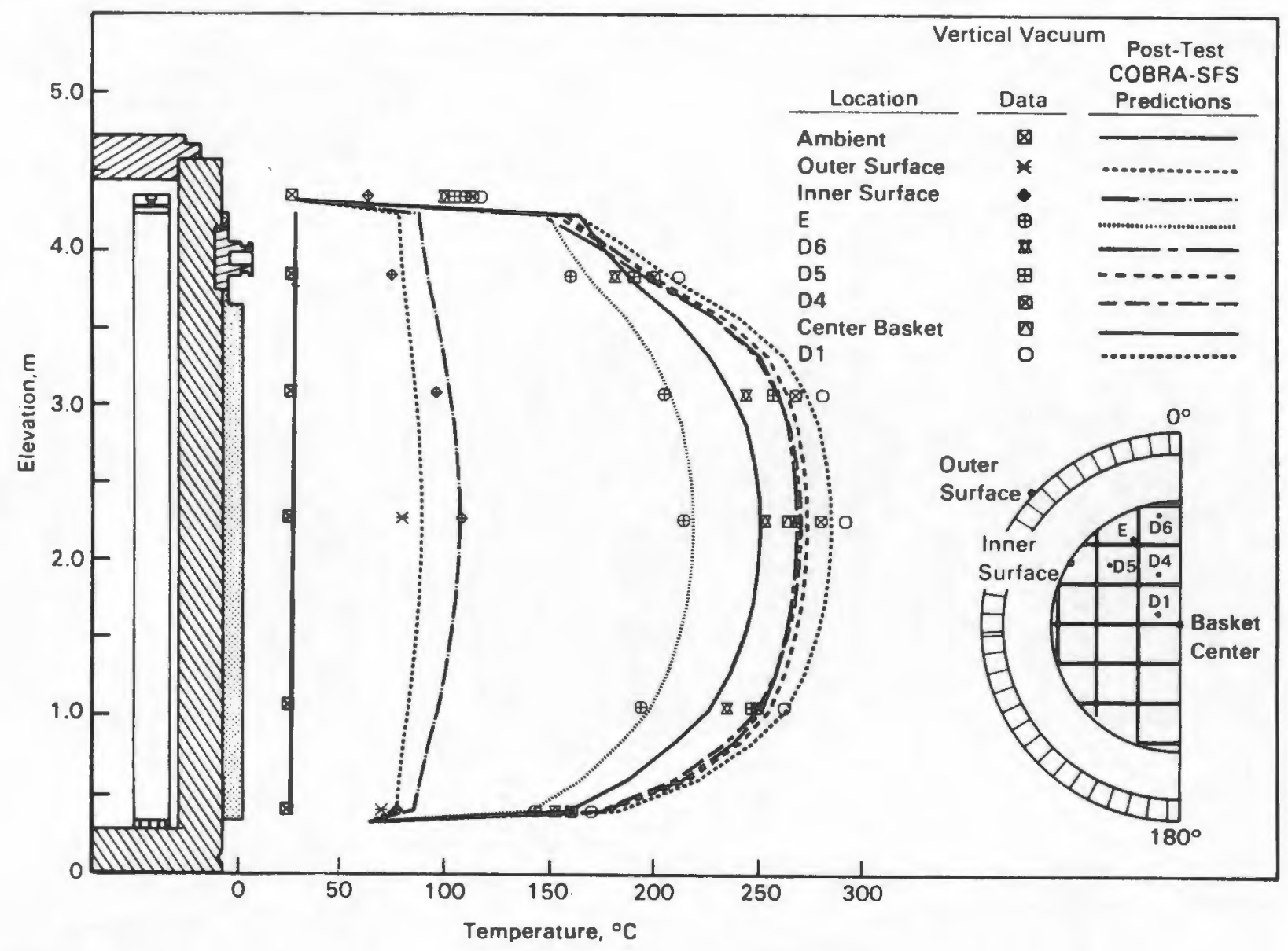

Figure 5-22. Post-Test Vertical, Vacuum Axial Temperature Profile Predictions Compared to Test Data 
A clear improvement in the magnitude of the predicted axial profiles is shown for the nitrogen vertical test run in Figure 5-21. This run proved to be the most difficult to simulate accurately, reflecting the effect of neglecting convective heat transfer. COBRA-SFS underpredicted the peak thermocouple lance temperature in this case by $5 \%\left(13^{\circ} \mathrm{C}\right)$. However, predicted temperatures in the upper portion of the cask were as much as $20^{\circ} \mathrm{C}$ lower, and the outer basket location (E) was overpredicted by $28^{\circ} \mathrm{C}$ in the lower portion of the cask. This is attributed to not modeling convection between the fuel canisters and the basket. The data indicate that convection shifts the peak temperature upward in the cask; however, the axial temperature is relatively flat in the vicinity of the peak temperature, so the peak temperature is probably unaffected by the shift in its location.

The post-test vertical vacuum predictions presented in Figure 5-22 are in excellent agreement $3 \%\left(8^{\circ} \mathrm{C}\right)$ with the experimental data. This result indicates that the conduction and the radiation heat transfer models are accurate, as convection is negligibile. The simulation underpredicted the peak temperature data by only $3 \%$ $\left(8^{\circ} \mathrm{C}\right)$, with good agreement with axial temperature profiles.

Figures 5-20, 5-21, and 5-22 al1 show a tighter grouping of basket and fuel temperatures in the cask than is shown by the data; i.e., the spread in measured temperatures from the center fuel canister (D1) to the outer basket (E) are greater than the predictions. This difference in temperature spread could be caused by using a high value of thermal conductivity for the basket. This was not evaluated as part of the post-test analysis.

Figure 5-23 is a composite of the predicted peak thermocouple lance temperatures for each of the three vertical orientations, along with its respective measured temperature. Temperatures and axial temperature profiles were predicted much more accurately $\left(8^{\circ} \mathrm{C}\right)$ for the helium and vacuum runs than the nitrogen run $\left(13^{\circ} \mathrm{C}\right)$. A prediction accuracy of $30^{\circ} \mathrm{C}$ over the complete length of a canister is believed to be exceptionally good, considering the complexity of the simulation.

The post-test diametrical temperature profiles at peak axial temperature locations for each of the vertical test runs are presented in Figure 5-24. Al1 three runs show good agreement across the diameter of the cask. The vacuum case was in excellent agreement with data $\left(8^{\circ} \mathrm{C}\right)$; the nitrogen profile is underpredicted in the center canisters $\left(20^{\circ} \mathrm{C}\right)$; and the helium case shows good agreement in the center of the cask and $a 20^{\circ} \mathrm{C}$ overprediction in the outer fuel canisters. 


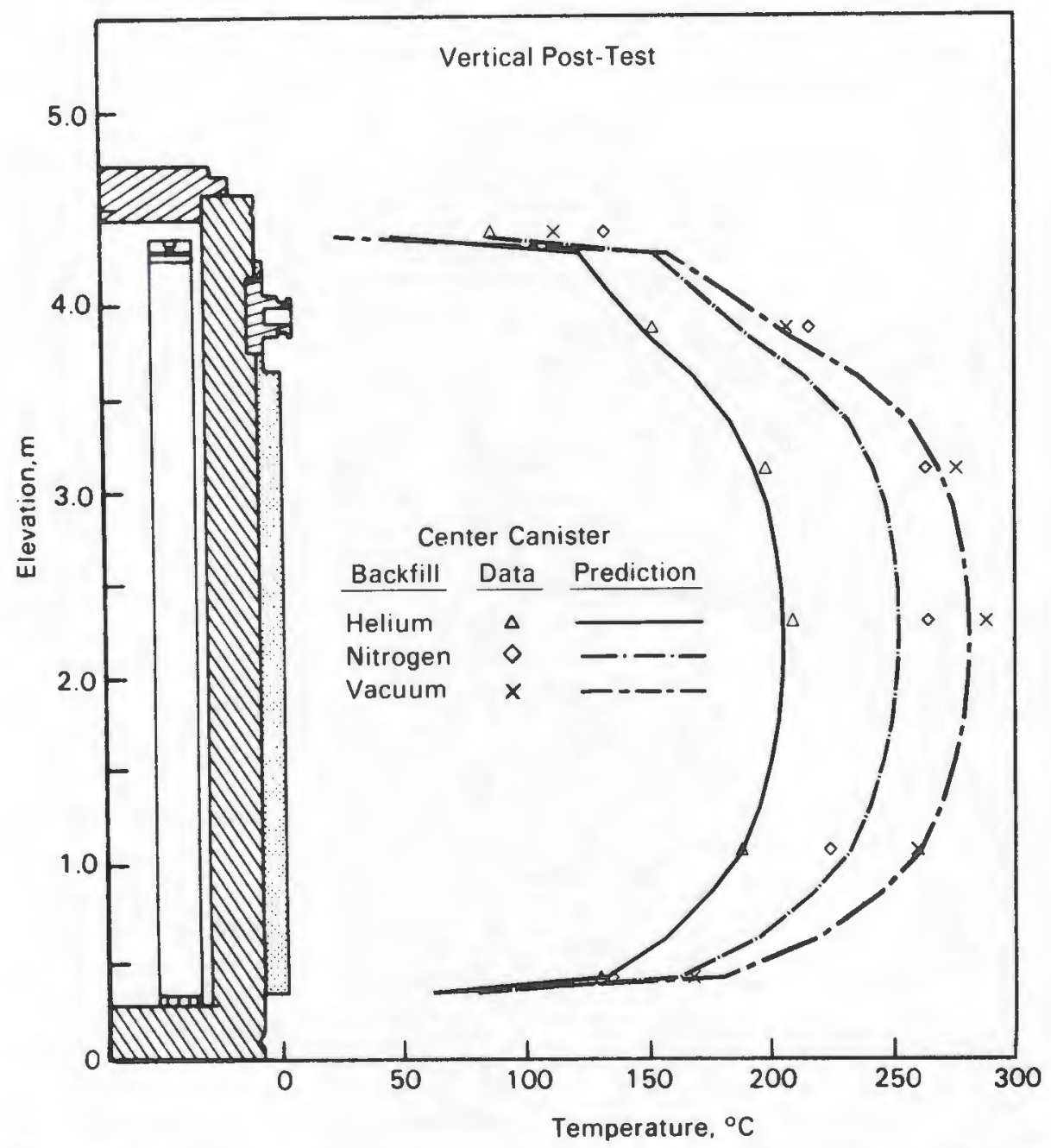

Figure 5-23. Post-test vertical, helium, nitrogen, and vacuum axial temperature profile predictions compared to test data at a center canister location

Post-Test Horizontal Predictions Compared to Test Data. The post-test axial profiles for the horizontal orientation are displayed in Figures 5-25, 5-26, and 5-27. A11 three runs show excellent agreement with measurements. The maximum disagreement for the horizontal nitrogen case is an $18^{\circ} \mathrm{C}$ overprediction in the outer basket (E) location.

The reason for the difference is probably associated with convection in the open basket location containing basket TC lance E. The COBRA-SFS code was not able to model convective cells in the open basket cells in a horizontal orientation.

Convection in these open basket locations would result in additional cooling of the basket and lower temperatures at TC lance location E. 


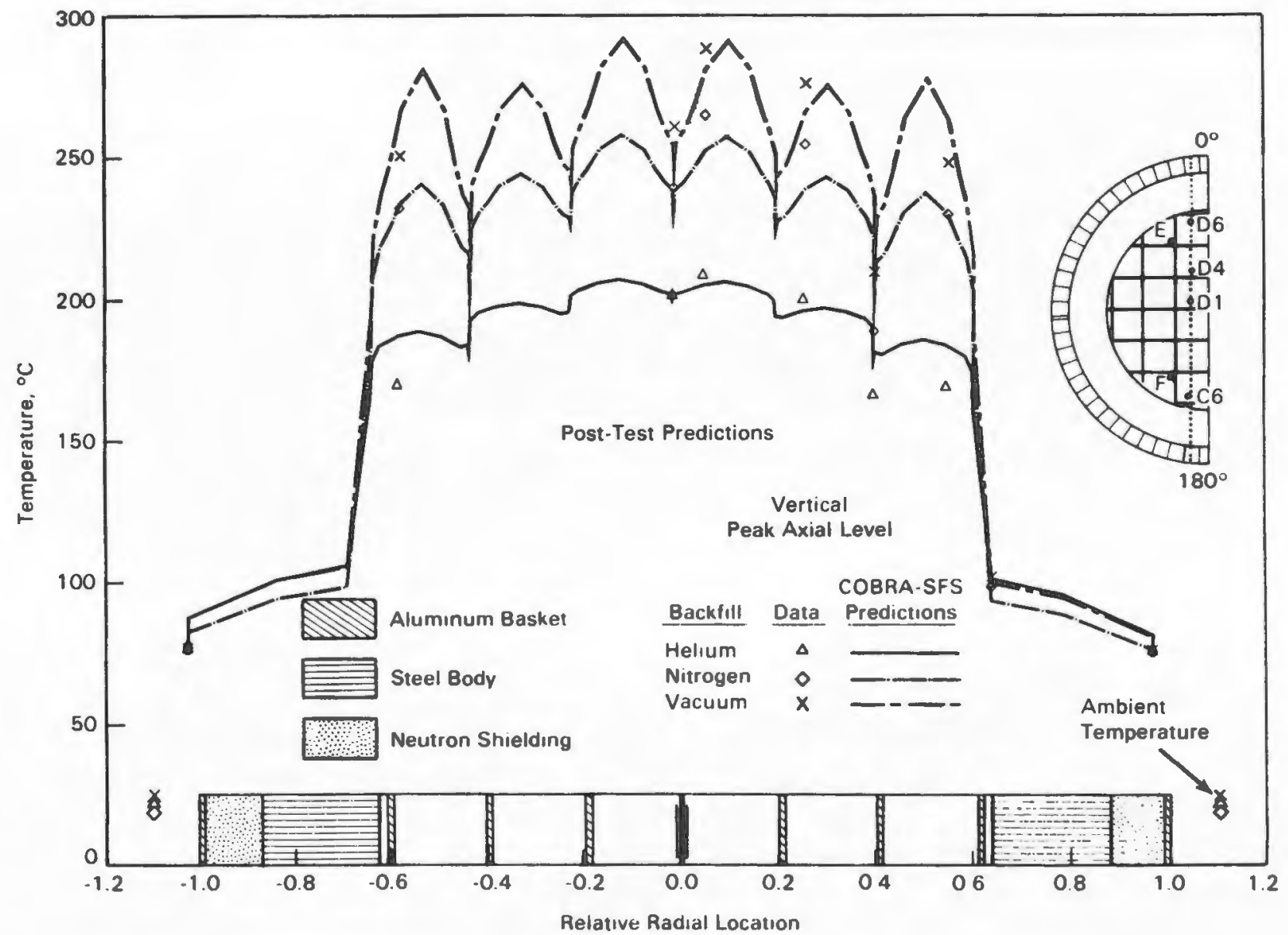

Figure 5-24. Post-test vertical, helium, nitrogen, and vacuum radial temperature profile predictions compared to test data at peak temperature axial locations. 


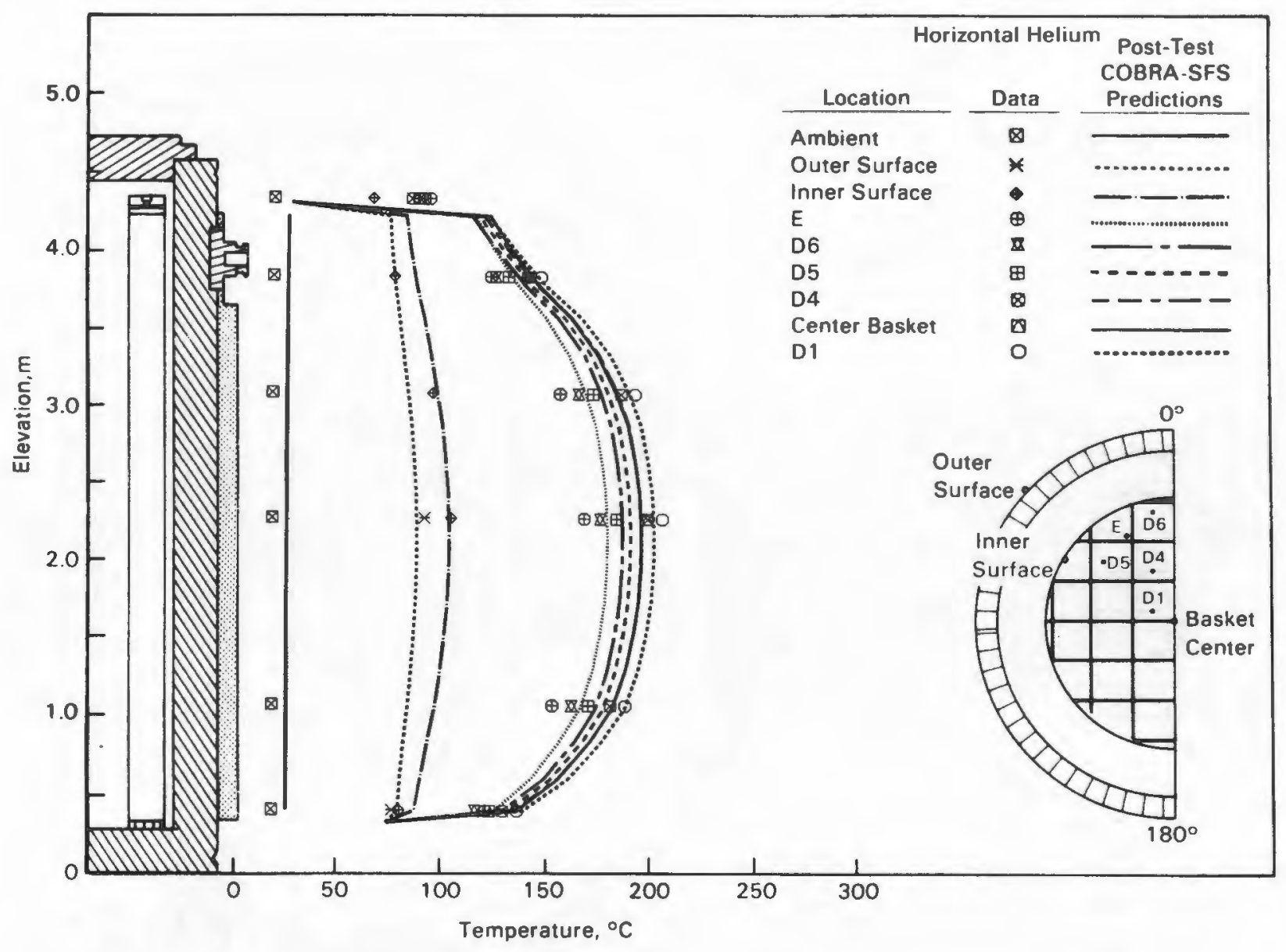

Figure 5-25. Post-test horizontal, helium axial temperature profile predictions compared to test data. 


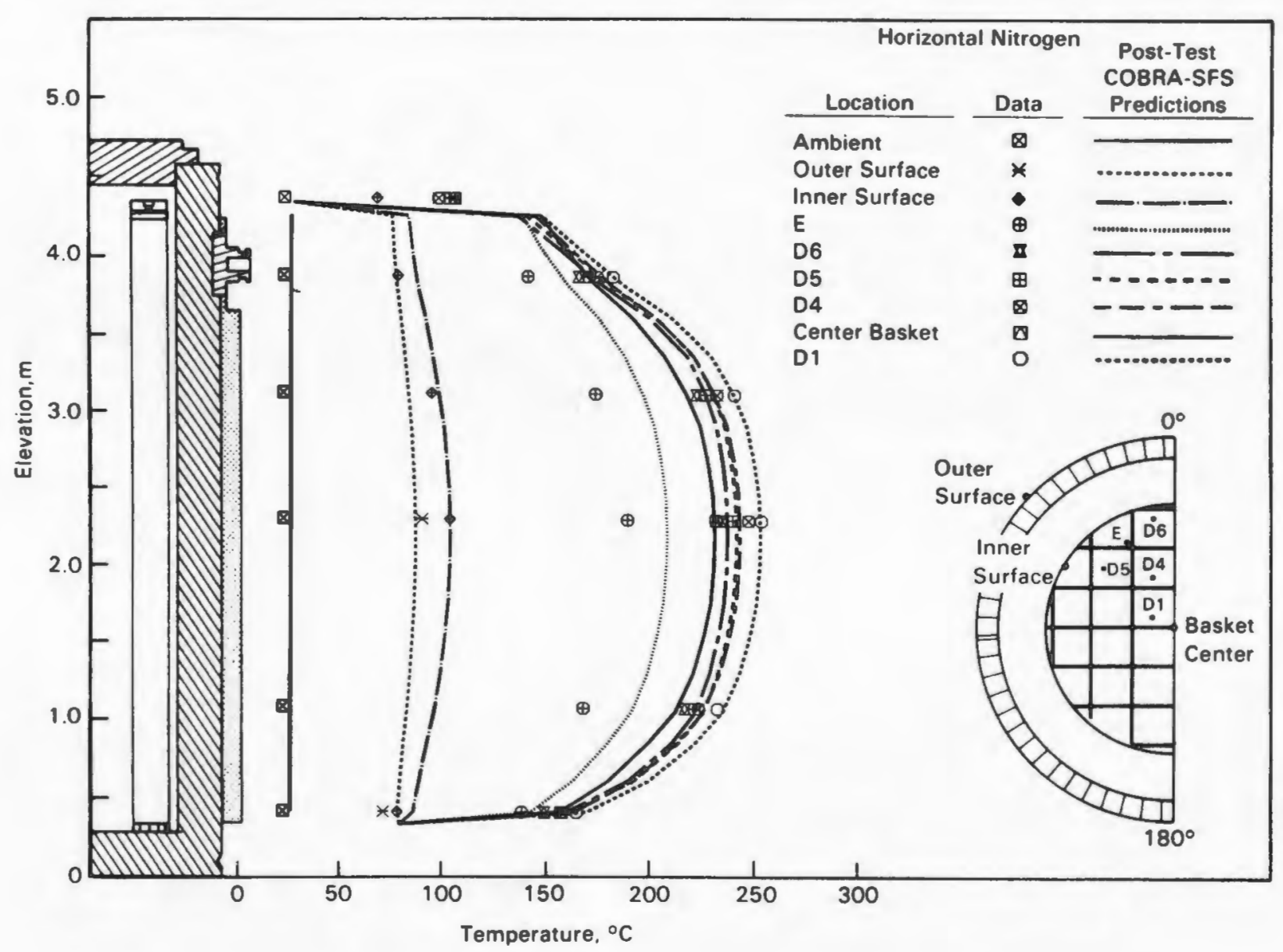

Figure 5-26. Post-test horizontal, nitrogen axial temperature profile predictions compared to test data. 


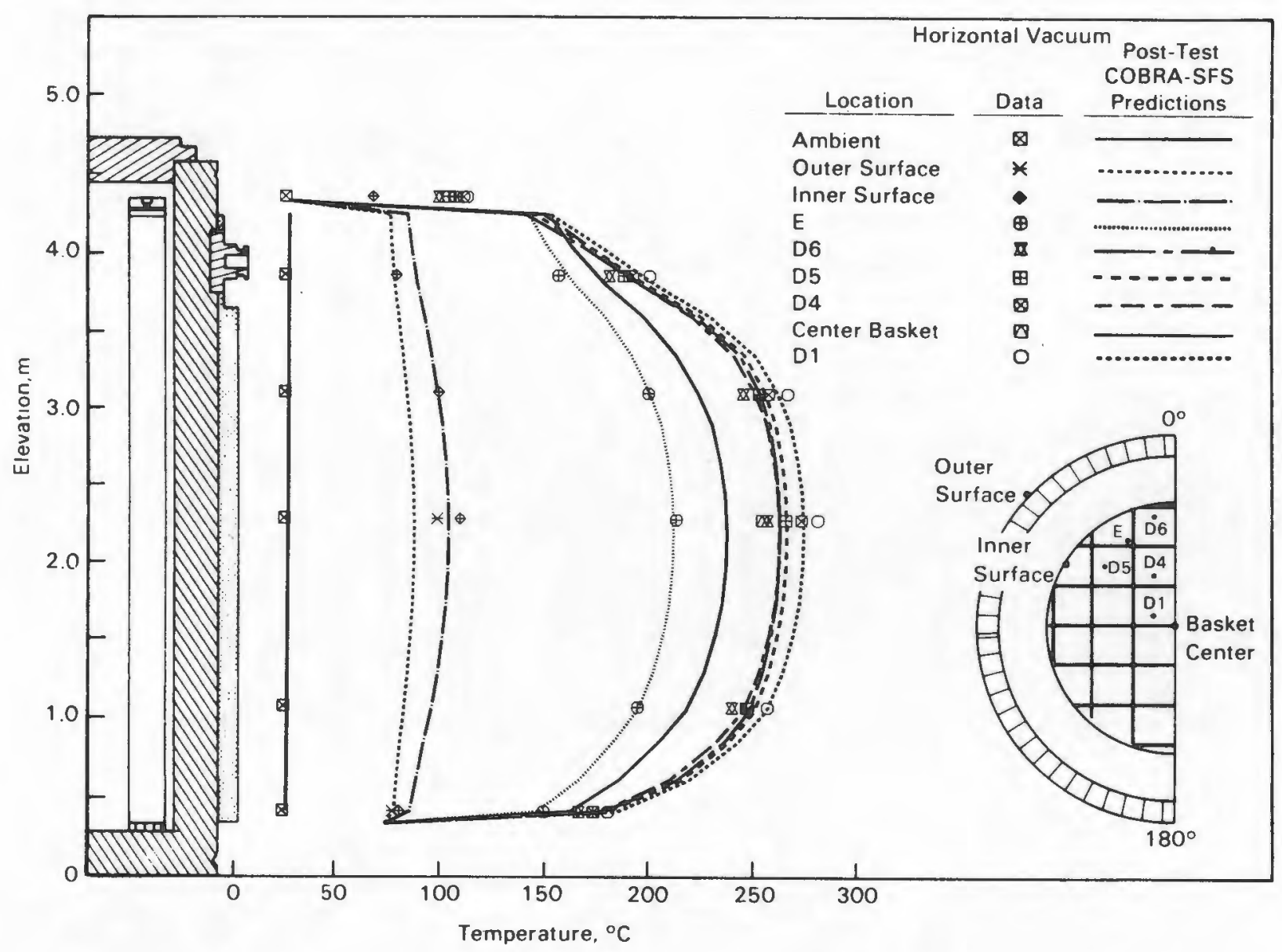

Figure 5-27. Post-test horizontal, vacuum axial temperature profile predictions compared to test data. 
The temperature predictions for the helium fill gas shown in Figure 5-25 are in excellent agreement $\left(11^{\circ} \mathrm{C}\right)$ with data. The peak thermocouple lance temperature was overpredicted by $2 \%\left(4^{\circ} \mathrm{C}\right)$. The only change in the predictions with the post-test model is that the magnitude of the profiles more accurately follows the experimental data.

The predicted horizontal nitrogen axial temperature profiles presented in Figure 5-26 show a substantial improvement. The peak thermocouple lance temperature was matched with the greatest disagreement $\left(18^{\circ} \mathrm{C}\right)$ occurring at the basket location. This disagreement could be caused by convection in the open basket location. Convection was not modeled during the horizontal runs. The temperature profile is in excellent agreement with the data.

Excellent agreement with experimental data is shown in Figure 5-27 for the horizontal vacuum test. Consistent with the other post-test simulations, the greatest improvement was in the magnitude of the temperature profiles. The peak TC lance temperature was underpredicted by $3 \%\left(8^{\circ} \mathrm{C}\right)$. Improvements in this case, as in all six cases, are attributed to the refinement of the lumped rod and channel models. Figure 5-27 also shows good agreement between measurements and predictions at basket location E. Because no convection exists for the vacuum case, the difference between measured and predicted temperature at location $E$ for the horizontal nitrogen run is probably due to convection.

The effect of fill gas on peak temperature for the horizontal post-test runs is shown in Figure 5-28. The peak thermocouple lance temperatures for all three cases have nearly the same profile but differ in magnitude. The helium, nitrogen, and vacuum predictions of peak temperature were all extremely close to the measurements $\left(4^{\circ} \mathrm{C}, 0^{\circ} \mathrm{C}\right.$, and $\left.8^{\circ} \mathrm{C}\right)$.

The post-test diametrical profiles at the peak axial temperature location for the three horizontal runs are shown in Figure 5-29. The greatest discrepancies are noted for the helium outer fuel canisters $\left(22^{\circ} \mathrm{C}\right)$. This could be caused by several effects. Among them could be convection in the open basket cells, using too high a value for thermal conductivity of the basket material, or not having enough refinement to the model in this location. None of these effects was investigated. The post-test predicted temperature distribution through the cask differed by as much as $26^{\circ} \mathrm{C}$ from the pretest predictions, the result of a more detailed fuel model. 


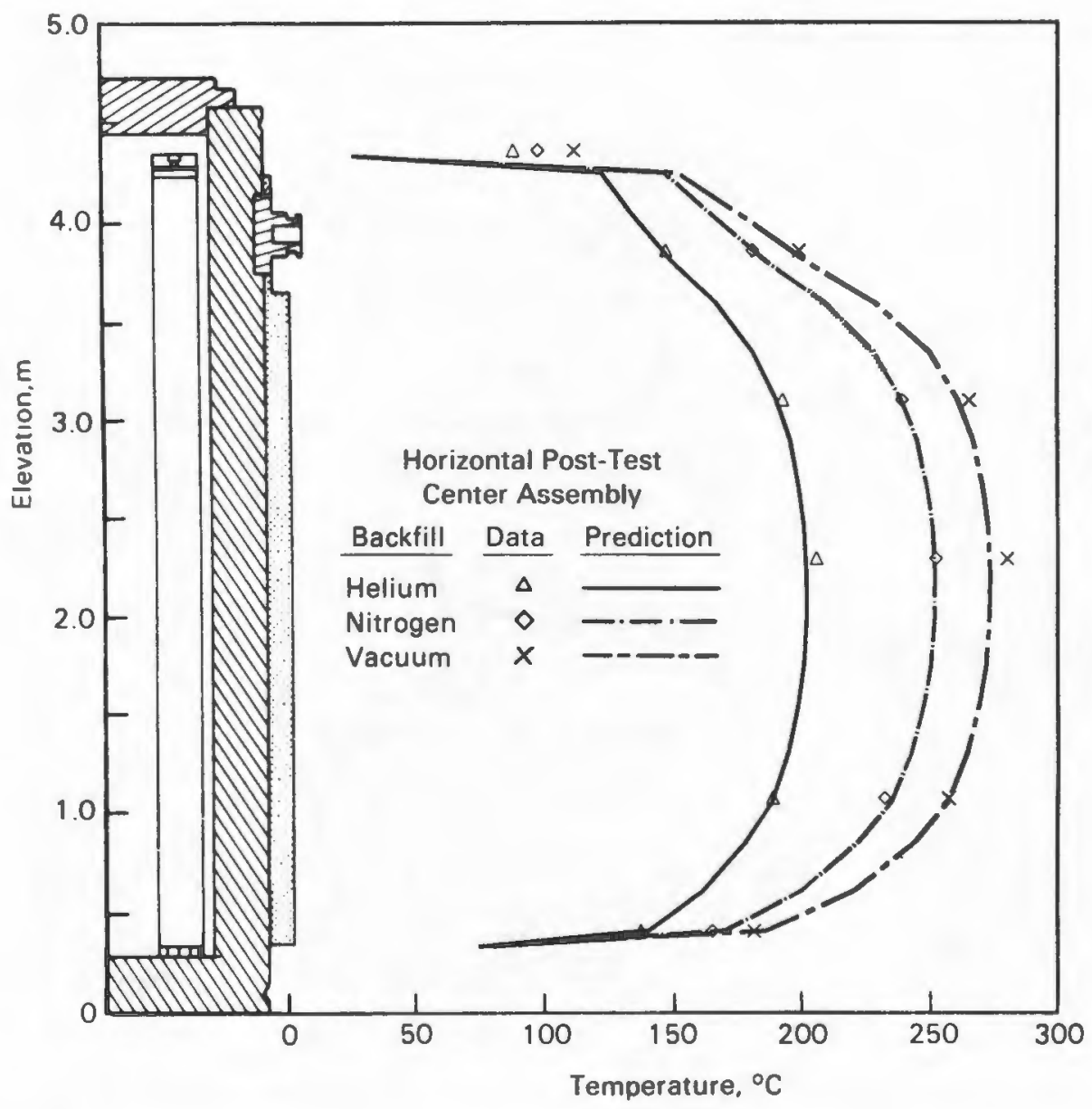

Figure 5-28. Post-test horizontal, helium, nitrogen, and vacuum axial temperature profile predictions compared to test data at a center canister location

Conclusions from Post-Test Comparisons. Comparisons of post-test predictions with experimental data led to the following conclusions:

- The post-test peak temperature predictions were in excellent agreement with data; the maximum disagreement was $8 \%\left(13^{\circ} \mathrm{C}\right)$ for the vertical nitrogen runs.

- The shapes of the predicted axial profiles were also in excellent agreement with measurements for all cases other than the nitrogen test run, which was in reasonably good agreement. Better agreement could have been achieved by modeling of convection between the fuel canisters and the basket. 


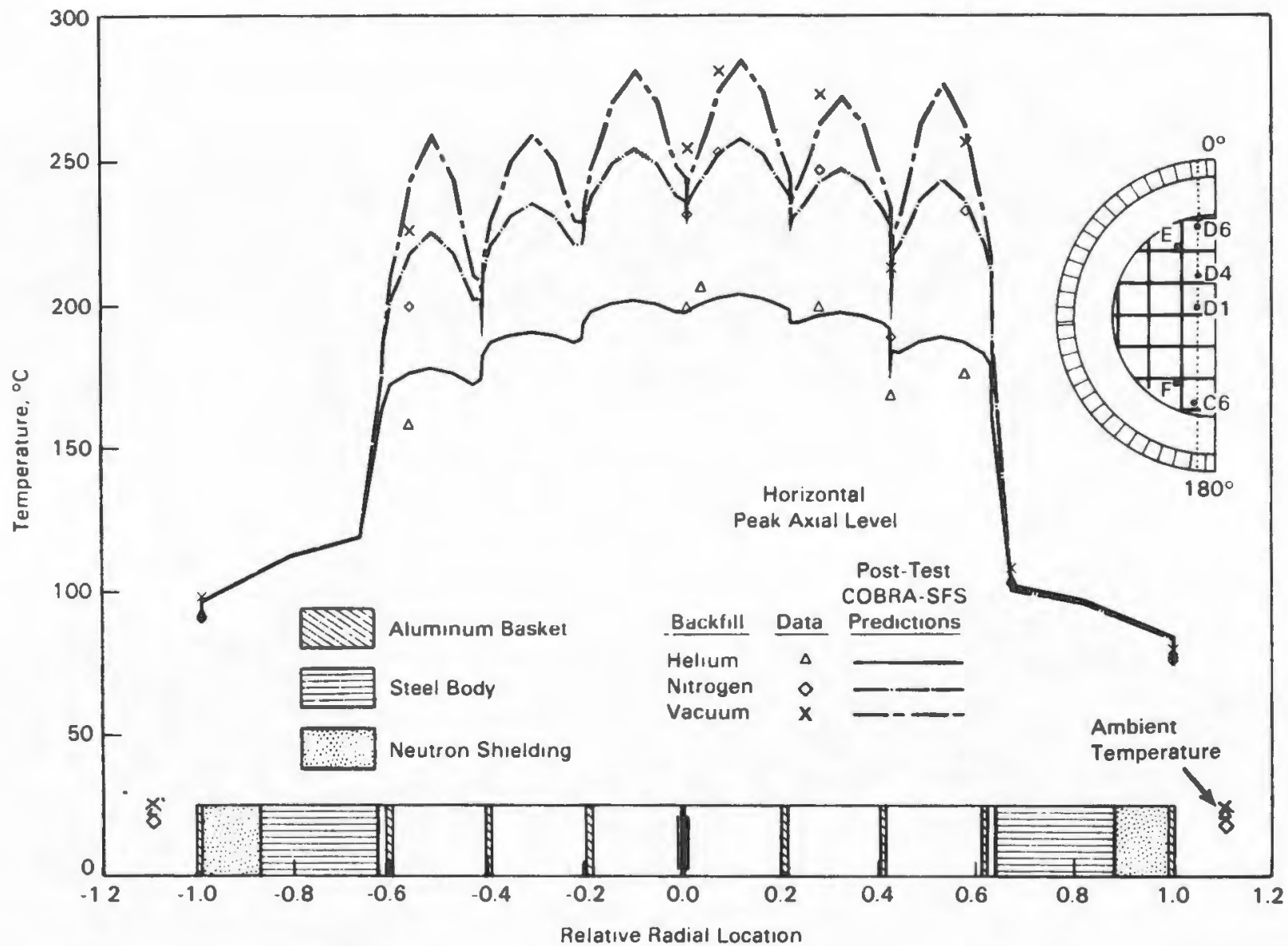

Figure 5-29. Post-test horizontal, vertical, helium, nitrogen, and vacuum radial temperature profile predictions compared to test data at peak temperature axial locations. 


\section{Section 6}

\section{REFERENCES}

1. U.S. Department of Energy. Spent Fuel Storage Requirements - An Update of DOE/RL-86-5. Richland, Washington: Richland Operations Office, 1986. DOE/RL-87-11.

2. D. A. Dziadosz, E. V. Moore, J. M. Creer, R. A. McCann, M. A. McKinnon, J. E. Tanner, E. R. Gilbert, F. L. Goodman, D. H. Schoonen, M. Jensen, and C. Mullen. CASTOR-V/21 PWR Spent Fuel Storage Cask: Testing and Analyses. Palo Alto, California: Electric Power Research Institute, 1986. EPRI NP4887.

3. J. M. Creer, T. E. Michener, M. A. McKinnon, J. E. Tanner, E. R. Gilbert, R. L. Goodman, D. A. Dziadosz, E. V. Moore, H. S. McKay, D. P. Bata7o, D. H. Schoonen, M. Jensen, and C. Mullen. TN-24P PWR Spent Fuel Storage Cask: Testing and Analyses. Palo Alto, California: Electric Power Research Institute, 1987. EPRI NP-5128.

4. M. A. Mckinnon, J. M. Creer, C. L. Wheeler, J. E. Tanner, E. R. Gilbert, R. L. Goodman, D. P. Batalo, D. A. Dziadosz, E. V. Moore, D. H. Schoonen, M. F. Jensen, and J. H. Browder,. The MC-10 PWR Spent Fuel Storage Cask: Testing and Analysis. Palo Alto, California: Electric Power Research Institute, 1987. EPRI NP-5268.

5. A. B. Johnson Jr., J. C. Dobbins, F. R. Zaloudek, E. R. Gilbert, and I. S. Levy. Assessment of the Integrity of Spent Fuel Assemblies Used in Dry Storage Demonstrations at Nevada Test Site. Richland, Washington: Pacific Northwest Laboratory, 1987. PNL-6207

6. I. S. Levy, B. A. Chin, E. P. Simonen, C. E. Beyer, E. R. Gilbert, and A. B. Johnson Jr. Recommended Temperature Limits for Dry Storage of Spent Light Water Reactor Zircaloy-Clad Fuel Rods in Inert Gas. Richland, Washington: Pacific Northwest Laboratory, 1987. PNL-6189

7. IN-24 Dry Storage Cask Topical Report. White Plains, New York: Transnuclear, Inc., 1985. E-7107.

8. TN-24P Cask Operations Manual. White Plains, New York: Transnuclear, Inc., 1985. E-7455, rev. 0 .

9. K. Vinjamuri, E. M. Feldman, C. K. Mullen, B. L. Griebenow, A. E. Arave, and R. C. Hill. Dry Rod Consolidation Technology Project at the Idaho National Engineering Laboratory. Idaho Falls, Idaho: Idaho National Engineering Laboratory, 1988. EGG-WM-8059.

10. A. G. Croff. ORIGEN-2--A Revised and Updated Version of the Oak Ridge Isotope Generation and Depletion Code. Oak Ridge, Tennessee: Oak Ridge National Laboratory, 1980. ORNL-5621. 
11. W. D. Leggett III and L. D. Eisenhart. INCORE Code. Richmond, Virginia: Virginia Power Company, 1967. WCAP-7149.

12. T. K. ROsS. NEWTOTE Code. Richmond, Virginia: Virginia Power Company, 1984. NFD-CCR-6, rev. 8.

13. R. B. Davis. Data Report for the Nondestructive Examination of Turkey Point Spent Fuel Assemblies $\mathrm{BO2}, \mathrm{B03}, \mathrm{B} 17, \mathrm{~B} 41$, and $\mathrm{B} 43$. Richland, Washington: Hanford Engineering Development Laboratory, 1980. HEDL-TME-79-68.

14. Keithley DAS Series 500 Measurement and Control System. Solon, Ohio: Keithley DAC Division and Control, 1984. Document No. 500-904-01B.

15. E. R. Gilbert, C. A. Knox, and G. D. White. "Behavior of Spent LWR Fuel in Nitrogen and in Air." In Proceedings of the Third International Spent Fuel Storage Technology Symposium/Workshop, vol. I, U.S. Department of Energy: Washington, D.C., 1986. CONF-860417, pp. S263-S278.

16. M. A. McKinnon, J. W. Doman, J. E. Tanner, R. J. Guenther, J. M. Creer, and C. E. King. BWR Spent Fuel Storage Cask Performance Test: Volume I - Cask Handling Experience and Decay Heat, Heat Transfer, and Shielding Data. Richland, Washington: Pacific Northwest Laboratory, 1986. PNL-5777, vol. I.

17. 16.J. 0. Barner. Characterization of LWR Spent Fuel MCC - Approved Testing Material - ATM-101. Richland, Washington: Pacific Northwest Laboratory, 1985. PNL-5109 Rev. 1.

18. R. J. Guenther, D. E. B1ahnik, T. K. Campbe11, U. P. Jenquin, J. E. Mende1, L. E. Thomas, and C. K. Thornhi11. Characterization of Spent Fuel Approved Testing Material--ATM-103. Richland, Washington: Pacific Northwest Laboratory, 1988. PNL 5109-103.

19. D. R. Rector, C. L. Wheeler, and N. J. Lombardo. COBRA-SFS: A ThermalHydraulic Analys is Computer Code: Volume I - Mathematical Models and Solution Methods. Richland, Washington: Pacific Northwest Laboratory, 1986. PNL-6049 Vol. I.

20. D. R. Rector, J. M. Cuta, N. J. Lombardo, T. E. Michener, and C. L. Wheeler. COBRA-SFS: A Thermal-Hydraul ic Analysis Code: Volume II - User's Manual. Richland, Washington: Pacific Northwest Laboratory, 1986. PNL-6049 Vol. II.

21. N. J. Lombardo, J. M. Cuta, T. E. Michener, D. R. Rector, and C. L. Wheeler. COBRA-SFS: A Thermal-Hydraulic Analys is Code: Volume III - Validation Assessments. Richland, Washington: Pacific Northwest Laboratory, 1986. PNL-6049 Vol. III.

22. D. S. Rowe. COBRA-IIIC: A Digital Computer Program for Steady-State and Transient Thermal-Hydraulic Analys is of Rod Bundle Nuclear Fuel Elements. Richland, Washington: Pacific Northwest Laboratory, 1973. BNWL-1695.

23. C. W. Stewart, C. L. Wheeler, R. J. Cena, C. A. McMonagle, J. M. Cuta, and D. S. Trent. COBRA-IV: The Model and the Method. Richland, Washington: Pacific Northwest Laboratory, 1977. BNWL-2214. 
24. T. L. George, K. L. Basehore, C. H. Wheeler, W. A. Prather, and R. E. Masterson. COBRA-WC: A Version of COBRA for Single-Phase Multi-Assembly Thermal-Hydraulic Transient Analysis. Richland, Washington: Pacific Northwest Laboratory, 1980. PNL-3259.

25. E. U. Khan, W. A. Prather, T. L. George, and J. M. Bates. A Validation Study of the COBRA-WC Computer Program for LMFBR Thermal-Hydraulic Analysis. Richland, Washington: Pacific Northwest Laboratory, 1981. PNL-4128.

26. J. M. Cuta, D. R. Rector, and J. M. Creer. Thermal-Hydraulic Analysis of Consolidated Spent PWR Fuel Rods. Palo Alto, California: Electric Power Research Institute, 1984. NP-3764.

27. N. J. Lombardo, T. E. Michener, C. L. Wheeler, and D. R. Rector. COBRA-SFS Predictions of Single-Assembly Spent Fuel Heat Transfer Data. Richland, Washington: Pacific Northwest Laboratory, 1986. PNL-5781.

28. J. M. Cuta and J. M. Creer. Comparisons of COBRA-SFS Calculations with Data From Simulated Sections of Unconsolidated and Consolidated BWR Spent Fuel. Palo Alto, California: Electric Power Research Institute, 1986. NP-4593.

29. L. E. Wiles, N. J. Lombardo, C. M. Heeb, U. P. Jenquin, T. E. Michener, C. L. Wheeler, J. M. Creer, and R. A. McCann. BWR Spent Fuel Storage Cask Performance Test: Volume II - Pre- and Post-Test Decay Heat, Heat Transfer, and Shielding Analyses. Richland, Washington: Pacific Northwest Laboratory, 1986. PNL-5777, Vo1. II.

30. D. R. Rector, R. A. McCann, U. P. Jenquin, C. M. Heeb, J. M. Creer, and C. L. Wheeler. CASTOR-1C Spent Fuel Storage Cask Decay Heat, Heat Transfer. and Shielding Analyses. Richland, Washington: Pacific Northwest Laboratory, 1986. PNL-5974.

31. D. R. Rector, J. M. Cuta, and N. J. Lombardo. COBRA-SFS Thermal-Hydraulic Analys is of the CASTOR-1C and REA 2023 BWR Storage Casks Containing Consolidated Spent Fuel. Richland, Washington: Pacific Northwest Laboratory, 1986. PNL-5802.

32. E. M. Sparrow and A. L. Loeffler, Jr. "Longitudinal Laminar Flow Between Cylinders Arranged in Regular Array." AIChE Journal. 5(3):325-330, 1959.

33. W. J. Kays and M. E. Crawford. Convection Heat and Mass Transfer. New York: McGraw-Hi11, Inc., 1980.

34. H. C. Hottel and A. F. Sarofin. Radiative Transfer. New York: McGraw-Hill Book Co., 1967.

35. M. R. Lindeburge. Mechanical Engineering Review Manual, 6th ed. San Carlos, California: The Professional Engineering Program, 1981. 

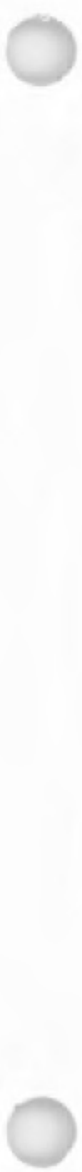
Appendix A

FUEL ASSEMBLY DATA 
Appendix A

FUEL ASSEMBLY DATA

Table A-1

FUEL ASSEMBLY DATA

Initial $\mathrm{UO}_{2} \quad$ Active

Assembly Assembly Burnup, Discharge Enrichment, Content, Fuel Length,

\begin{tabular}{|c|c|c|c|c|c|c|}
\hline $\mathrm{B} 02$ & $T-P$ & 25.67 & 0ct-75 & 2.56 & 457.0 & 144 \\
\hline $\mathrm{B} 03$ & $T-P$ & 25.67 & Oct -75 & 2.56 & 457.0 & 144 \\
\hline B41 & $T-P$ & 25.67 & Oct -75 & 2.56 & 457.0 & 144 \\
\hline B43 & $T-P$ & 25.60 & Oct-75 & 2.56 & 457.0 & 144 \\
\hline D01 & $T-P$ & 28.43 & Nov-77 & 2.56 & 457.0 & 144 \\
\hline D04 & $T-P$ & 28.43 & Nov -77 & 2.56 & 457.0 & 144 \\
\hline D06 & $\mathrm{T}-\mathrm{P}$ & 28.43 & Nov- 77 & 2.56 & 457.0 & 144 \\
\hline D15 & $\mathrm{T}-\mathrm{P}$ & 27.86 & Nov -77 & 2.56 & 457.0 & 144 \\
\hline D35 & $T-P$ & 28.43 & Nov -77 & 2.56 & 457.0 & 144 \\
\hline D40 & $T-P$ & 28.43 & Nov -77 & 2.56 & 457.0 & 144 \\
\hline D46 & $T-P$ & 28.43 & Nov -77 & 2.56 & 457.0 & 144 \\
\hline D47 & $T-P$ & 28.43 & Nov -77 & 2.56 & 457.0 & 144 \\
\hline L04 & MC10 & 24.53 & Sep-77 & 1.86 & 456.4 & 145 \\
\hline L25 & MC10 & 24.18 & Sep-77 & 1.86 & 456.4 & 145 \\
\hline N04 & MC10 & 26.82 & Apr-76 & 2.56 & 449.7 & 145 \\
\hline N05 & $\mathrm{MC} 10$ & 26.82 & Apr-76 & 2.56 & 449.7 & 145 \\
\hline No9 & MC10 & 26.82 & Apr-76 & 2.56 & 449.7 & 145 \\
\hline N11 & MC10 & 27.04 & Apr-76 & 2.56 & 449.7 & 145 \\
\hline N15 & $\mathrm{MC} 10$ & 26.82 & Apr-76 & 2.56 & 449.7 & 145 \\
\hline
\end{tabular}


Table A-1 (contd)

\begin{tabular}{|c|c|c|c|c|c|c|}
\hline $\begin{array}{c}\text { Assembly } \\
\text { ID } \\
\end{array}$ & $\begin{array}{l}\text { Assembly } \\
\text { Source } \\
\end{array}$ & $\begin{array}{l}\text { Burnup, } \\
\text { GWd/MWT }\end{array}$ & $\begin{array}{l}\text { Discharge } \\
\text { Date } \\
\end{array}$ & $\begin{array}{c}\text { Initial } \\
\text { Enrichment, } \\
\%\end{array}$ & $\begin{array}{c}\mathrm{U}_{2}, \\
\text { Content, } \\
\mathrm{kg} \mathrm{U}, \\
\end{array}$ & $\begin{array}{c}\text { Active } \\
\text { Fuel Length, } \\
\text { in. }\end{array}$ \\
\hline N16 & MC10 & 26.82 & Apr- 76 & 2.56 & 449.7 & 145 \\
\hline N17 & MC10 & 27.04 & Apr- 76 & 2.56 & 449.7 & 145 \\
\hline N35 & MC10 & 26.82 & Apr-76 & 2.56 & 449.7 & 145 \\
\hline N36 & MC10 & 26.82 & Apr-76 & 2.56 & 449.7 & 145 \\
\hline N37 & MC10 & 27.04 & Apr-76 & 2.56 & 449.7 & 145 \\
\hline R01 & MC10 & 35.44 & Feb- 79 & 3.10 & 457.8 & 144 \\
\hline R09 & MC10 & 35.33 & Feb- 79 & 3.10 & 457.8 & 144 \\
\hline R15 & MC10 & 35.44 & Feb-79 & 3.10 & 457.8 & 144 \\
\hline R18 & MC10 & 35.44 & Feb- 79 & 3.10 & 457.8 & 144 \\
\hline R34 & MC10 & 35.33 & Feb- 79 & 3.10 & 457.8 & 144 \\
\hline R35 & MC10 & 35.33 & Feb-79 & 3.10 & 457.8 & 144 \\
\hline R41 & MC10 & 35.33 & Feb-79 & 3.10 & 457.8 & 144 \\
\hline W09 & MC10 & 28.29 & Nov-81 & 3.20 & 458.2 & 144 \\
\hline W01 & TN24P & 29.99 & Nov-81 & 3.20 & 458.2 & 144 \\
\hline W02 & TN24P & 29.80 & Nov-81 & 3.20 & 458.2 & 144 \\
\hline W06 & TN24P & 30.52 & Nov-81 & 3.20 & 458.2 & 144 \\
\hline W10 & TN24P & 29.80 & Nov-81 & 3.20 & 458.2 & 144 \\
\hline W13 & TN24P & 30.52 & Nov-81 & 3.20 & 458.2 & 144 \\
\hline W16 & TN24P & 29.80 & Nov-81 & 3.20 & 458.2 & 144 \\
\hline W17 & TN24P & 29.99 & Nov-81 & 3.20 & 458.2 & 144 \\
\hline W19 & TN24P & 29.80 & Nov-81 & 3.20 & 458.2 & 144 \\
\hline W27 & TN24P & 30.52 & Nov-81 & 3.20 & 458.2 & 144 \\
\hline W28 & TN24P & 29.99 & Nov-81 & 3.20 & 458.2 & 144 \\
\hline W34 & TN24P & 30.52 & Nov-81 & 3.20 & 458.2 & 144 \\
\hline W38 & TN24P & 29.99 & Nov-81 & 3.20 & 458.2 & 144 \\
\hline
\end{tabular}


Table A-1 (contd)

\begin{tabular}{|c|c|c|c|c|c|c|}
\hline $\begin{array}{c}\text { Assembly } \\
\text { ID } \\
\end{array}$ & $\begin{array}{l}\text { Assembly } \\
\text { Source } \\
\end{array}$ & $\begin{array}{l}\text { Burnup, } \\
\text { GWd/MWT }\end{array}$ & $\begin{array}{c}\text { Discharge } \\
\text { Date }\end{array}$ & $\begin{array}{c}\text { Initial } \\
\text { Enrichment, } \\
\% \\
\end{array}$ & $\begin{array}{c}\mathrm{U}_{2} \\
\text { Content, } \\
\mathrm{kg} \mathrm{U},\end{array}$ & $\begin{array}{c}\text { Active } \\
\text { Fuel Length, } \\
\text { in. }\end{array}$ \\
\hline W44 & TN24P & 29.99 & Nov-81 & 3.20 & 458.2 & 144 \\
\hline W46 & TN24P & 29.99 & Nov-81 & 3.20 & 458.2 & 144 \\
\hline W49 & TN24P & 29.80 & Nov-81 & 3.20 & 458.2 & 144 \\
\hline W52 & TN24P & 29.99 & Nov-81 & 3.20 & 458.2 & 144 \\
\hline
\end{tabular}


Table A-2

\section{TN-24P STORAGE CASK CONSOLIDATED CANISTER CONTENTS AND LOADING PATTERN}

\begin{tabular}{|c|c|c|c|c|c|c|c|c|c|c|}
\hline \multirow{3}{*}{$\begin{array}{l}\text { Consol idation } \\
\text { Sequence } \\
\end{array}$} & \multicolumn{2}{|c|}{ Canister } & \multicolumn{7}{|c|}{ Fuel Canister Content } & \multirow[b]{3}{*}{ Comments } \\
\hline & \multirow[b]{2}{*}{ Number } & \multirow{2}{*}{$\begin{array}{c}\text { Basket } \\
\text { Location }\end{array}$} & \multicolumn{6}{|c|}{ Fuel Assemblies } & \multirow{2}{*}{$\begin{array}{l}\text { TC Guide } \\
\text { Tube }\end{array}$} & \\
\hline & & & ID & Rods & $\underline{I D}$ & Rods & 10 & Rods & & \\
\hline 1 & 2 & C6 & $W 44$ & 204 & W46 & 203 & & & 1 & \\
\hline 2 & 4 & D3 & W27 & 204 & W34 & 204 & W46 & 1 & & \\
\hline 3 & 5 & C5 & R09 & 204 & R18 & 204 & & & & \\
\hline 4 & 6 & c3 & H19 & 204 & W16 & 204 & & & & \\
\hline 5 & 9 & B6 & w01 & 204 & W38 & 204 & & & & \\
\hline 6 & 7 & A3 & w02 & 204 & w10 & 204 & & & & \\
\hline 7 & 8 & A6 & w52 & 204 & 149 & 204 & & & & \\
\hline 8 & 3 & D6 & w17 & 204 & W28 & 203 & & & 1 & \\
\hline 9 & 10 & 81 & D06 & 200 & D15 & 204 & W28 & 1 & & D06 contained 4 S.S. rods \\
\hline 10 & 11 & c & D35 & 204 & 040 & 204 & & & & \\
\hline 11 & 13 & D1 & D46 & 203 & D47 & 204 & & & 1 & \\
\hline 12 & 12 & A1 & D01 & 200 & D04 & 200 & D46 & 1 & 1 & $\begin{array}{l}\text { D01 and DO4 contained } 4 \text { S.S. } \\
\text { rods each }\end{array}$ \\
\hline 13 & 21 & A2 & N11 & 204 & N05 & 204 & & & & \\
\hline 14 & 20 & 04 & N09 & 204 & N15 & 203 & & & 1 & \\
\hline 15 & 14 & B4 & N36 & 204 & NO4 & 195 & & & & $\begin{array}{l}\text { Rods removed because of canister } \\
\text { closure problem }\end{array}$ \\
\hline 16 & 19 & B2 & 802 & 202 & $\mathrm{~B} 03$ & 199 & $\begin{array}{l}\text { N04 } \\
\text { N15 }\end{array}$ & $\begin{array}{l}8 \\
1\end{array}$ & & $\begin{array}{l}\text { Rods removed from } \mathrm{BO2} \text { and } \mathrm{BO3} \\
\text { for examination }\end{array}$ \\
\hline 17 & 15 & c2 & N17 & 204 & N37 & 204 & $\mathrm{BO3}$ & 2 & & \\
\hline 18 & 16 & A4 & N35 & 204 & N16 & 204 & $\mathrm{~B} 03$ & 2 & & \\
\hline 19 & 25 & $\mathrm{C} 4$ & 104 & 204 & L25 & 204 & 803 & 1 & & \\
\hline 20 & 23 & D5 & R41 & 203 & W09 & 204 & No4 & & 1 & \\
\hline 21 & 24 & A5 & R15 & 204 & R01 & 204 & $\mathrm{BO2}$ & 2 & & \\
\hline 22 & 17 & B5 & R34 & 204 & R35 & 203 & & & 1 & \\
\hline 23 & 22 & D2 & B41 & 204 & B43 & 204 & $\begin{array}{l}\text { R35 } \\
\text { R41 }\end{array}$ & $\begin{array}{l}1 \\
1\end{array}$ & & \\
\hline 24 & 18 & B3 & W06 & 204 & W13 & 204 & & & & \\
\hline
\end{tabular}


Table A-3

DRY ROD CONSOLIDATION - CONSOLIDATED FUEL EXPOSURE TO AIR

Fuel Assembly ID Numbers

\begin{tabular}{|c|c|c|c|c|}
\hline$T N-24 P^{a}$ & $M C-10^{a}$ & $\underline{\operatorname{sil}}^{a}$ & $\begin{array}{l}\text { Consolidation } \\
\text { IAN Hot Cell }\end{array}$ & Total Exposure \\
\hline 583 & -- & - & 199 & 782 \\
\hline 586 & -- & - & 105 & 691 \\
\hline 526 & 28 & -- & 171 & 725 \\
\hline 592 & -- & -- & 80 & 672 \\
\hline 591 & -- & -- & 141 & 732 \\
\hline 587 & -- & -- & 177 & 764 \\
\hline 592 & -- & -- & 171 & 763 \\
\hline 592 & -- & -- & 145 & 737 \\
\hline 392 & -- & -- & 61 & 453 \\
\hline 369 & -- & 13 & 155 & 537 \\
\hline 357 & -- & 24 & 148 & 529 \\
\hline 327 & -- & 35 & 124 & 486 \\
\hline 321 & 41 & -- & 78 & 440 \\
\hline 241 & 117 & -- & 172 & 530 \\
\hline 216 & 142 & -- & 78 & 460 \\
\hline 216 & -- & 47 & 142 & 405 \\
\hline 138 & 168 & -- & 71 & 377 \\
\hline 115 & 244 & -- & 122 & 481 \\
\hline 92 & 244 & - & 151 & 487 \\
\hline 84 & 266 & -- & 78 & 420 \\
\hline 56 & 294 & -- & 106 & 456 \\
\hline 44 & 307 & -- & 163 & 514 \\
\hline 29 & -- & 58 & 104 & 191 \\
\hline 595 & -- & -- & 130 & 725 \\
\hline
\end{tabular}

a Total elapsed time fuel was exposed to air in its respective storage location.

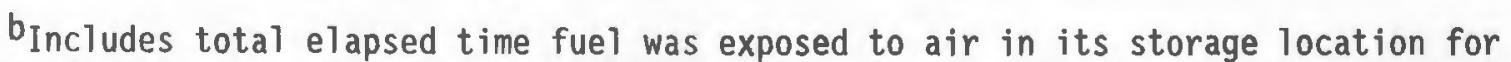
removal for consolidation, consolidation time in the cell, time required to load canister into TN-24P, cask evacuation, and cover gas backfill. Gamma scanning time is also included for fuel assemblies BO1 and DOl. 
"The Turkey Point D-assemblies were all irradiated for 851 EFPD during a residence time of 1073 days. This history was modeled by three full-power periods of 284 days, 284 days, and 283 days separated by two shutdown periods of 111 days each. The B-assemblies were irradiated to 827 EFPD during a residence time of 1382 days. The early part of cycle 1 included an extended period at low power, so that the entire residence time was not modeled. Instead, the power history was assumed to consist of three ful1-power periods of 259 days, 284 days, and 284 days separated by two 111-day shurdown periods to be consistent with the D-assembly irradiations" $(1)$. The reactor operating history for the Surry fuel is found in Tables A-4 through A-8. 
Table A-4

SURRY 2, CYCLE 1 REACTOR OPERATING HISTORY
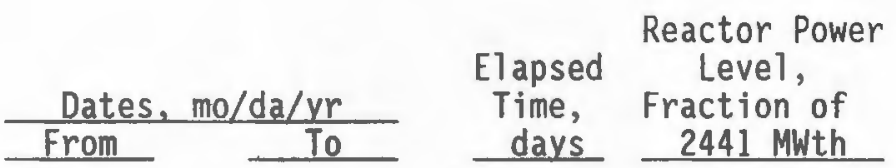

$03 / 07 / 73 \quad 03 / 11 / 73$

$$
0.019
$$

$03 / 11 / 73 \quad 03 / 12 / 73$

0.191

$03 / 12 / 73$

$03 / 20 / 73$

0.281

$03 / 20 / 73$

$03 / 21 / 73$

0.099

$03 / 21 / 73$

$03 / 25 / 73$

0.415

$03 / 25 / 73$

$04 / 01 / 73$

$04 / 01 / 73 \quad 04 / 05 / 73$

$04 / 05 / 73 \quad 04 / 10 / 73$

$04 / 10 / 73 \quad 04 / 11 / 73$

$04 / 11 / 73 \quad 04 / 17 / 73$

$04 / 17 / 73 \quad 04 / 19 / 73$

$04 / 19 / 73 \quad 04 / 21 / 73$

1

8

1

4

0

7

0.009

5

0.478

1

0.142

6

0.809

2

0.354

$04 / 21 / 73$

$04 / 27 / 73$

$04 / 27 / 73$

$05 / 08 / 73$

$05 / 08 / 73$

$05 / 29 / 73$

$05 / 30 / 73$

$05 / 29 / 73$

$06 / 10 / 73$

$05 / 30 / 73$

$06 / 14 / 73$

$07 / 04 / 73$

$06 / 14 / 73$

$07 / 07 / 73$

$07 / 04 / 73$

$07 / 08 / 73$

$07 / 08 / 73$

$08 / 08 / 73$

$08 / 08 / 73$

$08 / 11 / 73$

$08 / 11 / 73$

$10 / 25 / 73$

$10 / 25 / 73$

$10 / 26 / 73$

$10 / 26 / 73$

$11 / 14 / 73$

$11 / 14 / 73$

$11 / 15 / 73$

$11 / 15 / 73$

$11 / 21 / 73$

$11 / 21 / 73$

$11 / 22 / 73$

$11 / 22 / 73$

$11 / 25 / 73$

$11 / 25 / 73$

$11 / 26 / 73$

$12 / 11 / 73$

$11 / 26 / 73$ 
Table A-4 (contd)

\begin{tabular}{|c|c|c|c|}
\hline Dates. & $\angle d a / y r$ & $\begin{array}{l}\text { Elapsed } \\
\text { Time, }\end{array}$ & $\begin{array}{l}\text { Level, } \\
\text { Fraction of }\end{array}$ \\
\hline From & To & & \\
\hline $12 / 11 / 73$ & $12 / 13 / 73$ & 2 & 0.202 \\
\hline $12 / 13 / 73$ & $03 / 04 / 74$ & 81 & 0.854 \\
\hline $03 / 04 / 74$ & $04 / 14 / 74$ & 41 & 0.944 \\
\hline $04 / 14 / 74$ & $06 / 17 / 74$ & 64 & 0 \\
\hline $06 / 17 / 74$ & $06 / 26 / 74$ & 9 & 0.362 \\
\hline $06 / 26 / 74$ & $07 / 08 / 74$ & 12 & 0 \\
\hline $07 / 08 / 74$ & $07 / 10 / 74$ & 2 & 0.291 \\
\hline $07 / 10 / 74$ & $08 / 03 / 74$ & 24 & 0.972 \\
\hline $08 / 03 / 74$ & $08 / 04 / 74$ & 1 & 0.117 \\
\hline $08 / 04 / 74$ & $08 / 06 / 74$ & 2 & 0 \\
\hline $08 / 06 / 74$ & $08 / 07 / 74$ & 1 & 0.218 \\
\hline $08 / 07 / 74$ & $08 / 18 / 74$ & 11 & 0.934 \\
\hline $08 / 18 / 74$ & $08 / 19 / 74$ & 1 & 0.432 \\
\hline $08 / 19 / 74$ & $08 / 22 / 74$ & 3 & 0 \\
\hline $08 / 22 / 74$ & $08 / 23 / 74$ & 1 & 0.195 \\
\hline $08 / 23 / 74$ & $09 / 07 / 74$ & 15 & 0.964 \\
\hline $09 / 07 / 74$ & $01 / 04 / 75$ & 119 & 0 \\
\hline $01 / 04 / 75$ & $01 / 07 / 75$ & 3 & 0.389 \\
\hline $01 / 07 / 75$ & $01 / 10 / 75$ & 3 & 0.785 \\
\hline $01 / 10 / 75$ & $01 / 18 / 75$ & 8 & 0.936 \\
\hline $01 / 18 / 75$ & $01 / 20 / 75$ & 2 & 0.343 \\
\hline $01 / 20 / 75$ & $02 / 02 / 75$ & 13 & 0.978 \\
\hline $02 / 02 / 75$ & $02 / 04 / 75$ & 2 & 0.466 \\
\hline $02 / 04 / 75$ & $03 / 22 / 75$ & 46 & 0.972 \\
\hline $03 / 22 / 75$ & $03 / 24 / 75$ & 2 & 0 \\
\hline $03 / 24 / 75$ & $03 / 25 / 75$ & 1 & 0.63 \\
\hline $03 / 25 / 75$ & $04 / 26 / 75$ & 32 & 0.938 \\
\hline $04 / 26 / 75$ & $04 / 27 / 75$ & 1 & 0.043 \\
\hline
\end{tabular}


Table A-5

SURRY 2, CYCLE 2 REACTOR OPERATING HISTORY

\begin{tabular}{|c|c|c|c|}
\hline \multicolumn{2}{|c|}{ Dates, mo/da/yr } & \multirow{2}{*}{$\begin{array}{l}\text { Time, } \\
\text { days } \\
\end{array}$} & \multirow{2}{*}{$\begin{array}{r}\text { Fraction of } \\
2441 \mathrm{MWth}\end{array}$} \\
\hline From & To & & \\
\hline $06 / 17 / 75$ & $06 / 18 / 75$ & 1 & 0.08 \\
\hline $06 / 18 / 75$ & $06 / 20 / 75$ & 2 & 0.65 \\
\hline $06 / 20 / 75$ & $07 / 06 / 75$ & 16 & 0.992 \\
\hline $07 / 06 / 75$ & $07 / 07 / 75$ & 1 & 0.472 \\
\hline $07 / 07 / 75$ & $07 / 11 / 75$ & 4 & 0 \\
\hline $07 / 11 / 75$ & $07 / 12 / 75$ & 1 & 0.142 \\
\hline $07 / 12 / 75$ & $10 / 09 / 75$ & 89 & 0.949 \\
\hline $10 / 09 / 75$ & $10 / 10 / 75$ & 1 & 0.171 \\
\hline $10 / 10 / 75$ & $10 / 14 / 75$ & 4 & 0 \\
\hline $10 / 14 / 75$ & $10 / 16 / 75$ & 2 & 0.764 \\
\hline $10 / 16 / 75$ & $10 / 19 / 75$ & 3 & 0.987 \\
\hline $10 / 19 / 75$ & $10 / 21 / 75$ & 2 & 0.021 \\
\hline $10 / 21 / 75$ & $10 / 22 / 75$ & 1 & 0.611 \\
\hline $10 / 22 / 75$ & $12 / 30 / 75$ & 69 & 0.971 \\
\hline $12 / 30 / 75$ & $01 / 03 / 76$ & 4 & 0.816 \\
\hline $01 / 03 / 76$ & $01 / 17 / 76$ & 14 & 0.985 \\
\hline $01 / 17 / 76$ & $01 / 25 / 76$ & 8 & 0 \\
\hline $01 / 25 / 76$ & $01 / 26 / 76$ & 1 & 0.418 \\
\hline $01 / 26 / 76$ & $02 / 03 / 76$ & 8 & 0.914 \\
\hline $02 / 03 / 76$ & $02 / 04 / 76$ & 1 & 0.472 \\
\hline $02 / 04 / 76$ & $02 / 11 / 76$ & 7 & 0 \\
\hline $02 / 11 / 76$ & $02 / 12 / 76$ & 1 & 0.052 \\
\hline $02 / 12 / 76$ & $03 / 04 / 76$ & 21 & 0.988 \\
\hline $03 / 04 / 76$ & $03 / 05 / 76$ & 1 & 0.173 \\
\hline $03 / 05 / 76$ & $03 / 09 / 76$ & 4 & 0 \\
\hline $03 / 09 / 76$ & $03 / 11 / 76$ & 2 & 0.413 \\
\hline $03 / 11 / 76$ & $04 / 20 / 76$ & 40 & 0.985 \\
\hline $04 / 20 / 76$ & $04 / 22 / 76$ & 2 & 0.717 \\
\hline $04 / 22 / 76$ & $04 / 23 / 76$ & 1 & 0.009 \\
\hline
\end{tabular}


Table A-6

SURRY 2, CYCLE 3 REACTOR OPERATING HISTORY

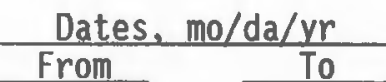

$06 / 10 / 76$

$06 / 11 / 76$

$06 / 13 / 76$

$07 / 30 / 76$

$07 / 31 / 76$

$08 / 03 / 76$

$08 / 04 / 76$

$09 / 15 / 76$

$09 / 16 / 76$

$12 / 19 / 76$

$12 / 20 / 76$

$12 / 22 / 76$

$12 / 23 / 76$

$12 / 26 / 76$

$12 / 27 / 76$

$12 / 30 / 76$

$01 / 01 / 77$

$02 / 10 / 77$

$02 / 11 / 77$

04/11/77

$04 / 12 / 77$

$07 / 11 / 77$

$07 / 12 / 77$

$07 / 24 / 77$

$07 / 25 / 77$

$08 / 13 / 77$

$08 / 14 / 77$

$08 / 15 / 77$

09/09/77
06/11/76

$06 / 13 / 76$

$07 / 30 / 76$

$07 / 31 / 76$

08/03/76

08/04/76

$09 / 15 / 76$

$09 / 16 / 76$

$12 / 19 / 76$

$12 / 20 / 76$

$12 / 22 / 76$

$12 / 23 / 76$

$12 / 26 / 76$

$12 / 27 / 76$

$12 / 30 / 76$

$01 / 01 / 77$

$02 / 10 / 77$

$02 / 11 / 77$

$04 / 11 / 77$

$04 / 12 / 77$

$07 / 11 / 77$

$07 / 12 / 77$

$07 / 24 / 77$

$07 / 25 / 77$

$08 / 13 / 77$

$08 / 14 / 77$

$08 / 15 / 77$

09/09/77

$09 / 10 / 77$

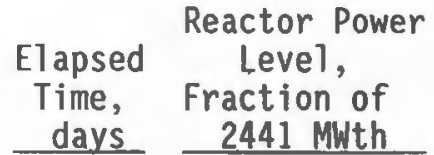

1

0.2

0.755

0.991

0.283

0

0.684

0.986

0.541

0

0.098

0.96

0.658

0

0.201

0.974

0.815

0.978

0.594

0

0.569

0.992

0.813

0

0.315

0.998

0.002

0.646

0.999

0.874 
Table A-7

SURRY 2, CYCLE 4 REACTOR OPERATING HISTORY

\begin{tabular}{|c|c|c|c|}
\hline Dates. & $\angle d a / y r$ & $\begin{array}{l}\text { Elapsed } \\
\text { Time, }\end{array}$ & $\begin{array}{l}\text { Level, } \\
\text { Fraction of }\end{array}$ \\
\hline From & To & & \\
\hline $10 / 09 / 77$ & $10 / 12 / 77$ & 3 & 0.019 \\
\hline $10 / 12 / 77$ & $10 / 13 / 77$ & 1 & 0.539 \\
\hline $10 / 13 / 77$ & $10 / 14 / 77$ & 1 & 0.868 \\
\hline $10 / 14 / 77$ & $11 / 18 / 77$ & 35 & 0.99 \\
\hline $11 / 18 / 77$ & $11 / 19 / 77$ & 1 & 0.109 \\
\hline $11 / 19 / 77$ & $11 / 27 / 77$ & 8 & 0 \\
\hline $11 / 27 / 77$ & $11 / 29 / 77$ & 2 & 0.565 \\
\hline $11 / 29 / 77$ & $03 / 20 / 78$ & 111 & 0.987 \\
\hline $03 / 20 / 78$ & $04 / 08 / 78$ & 19 & 0 \\
\hline $04 / 08 / 78$ & $04 / 09 / 78$ & 1 & 0.185 \\
\hline $04 / 09 / 78$ & $05 / 24 / 78$ & 45 & 1 \\
\hline $05 / 24 / 78$ & $05 / 25 / 78$ & 1 & 0.613 \\
\hline $05 / 25 / 78$ & $05 / 30 / 78$ & 5 & 0 \\
\hline $05 / 30 / 78$ & $05 / 31 / 78$ & 1 & 0.884 \\
\hline $05 / 31 / 78$ & $07 / 07 / 78$ & 37 & 0.989 \\
\hline $07 / 07 / 78$ & $07 / 08 / 78$ & 1 & 0.039 \\
\hline $07 / 08 / 78$ & $08 / 01 / 78$ & 24 & 0 \\
\hline $08 / 01 / 78$ & $08 / 03 / 78$ & 2 & 0.482 \\
\hline $08 / 03 / 78$ & $09 / 30 / 78$ & 58 & 0.997 \\
\hline $09 / 30 / 78$ & $10 / 05 / 78$ & 5 & 0.846 \\
\hline $10 / 05 / 78$ & $10 / 06 / 78$ & 1 & 0.145 \\
\hline $10 / 06 / 78$ & $10 / 15 / 78$ & 9 & 0 \\
\hline $10 / 15 / 78$ & $10 / 16 / 78$ & 1 & 0.633 \\
\hline $10 / 16 / 78$ & $12 / 03 / 78$ & 48 & 0.994 \\
\hline $12 / 03 / 78$ & $12 / 04 / 78$ & 1 & 0.035 \\
\hline $12 / 04 / 78$ & $02 / 03 / 79$ & 61 & 0.992 \\
\hline $02 / 03 / 79$ & $02 / 04 / 79$ & 1 & 0.789 \\
\hline $02 / 04 / 79$ & $02 / 05 / 79$ & 1 & 0.036 \\
\hline
\end{tabular}


Table A-8

SURRY 2, CYCLE 5 REACTOR OPERATING HISTORY
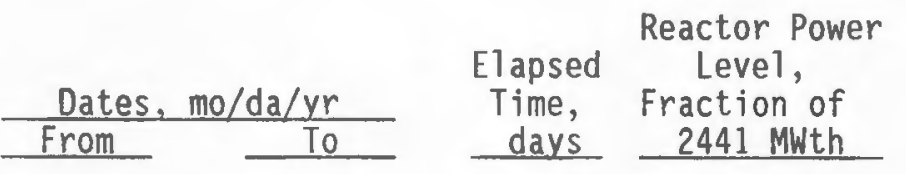

$08 / 17 / 80 \quad 08 / 20 / 80$

3

$08 / 20 / 80 \quad 08 / 23 / 80$

$08 / 23 / 80 \quad 08 / 24 / 80$

$08 / 24 / 80 \quad 08 / 27 / 80$

$08 / 27 / 80 \quad 08 / 29 / 80$

$08 / 29 / 80 \quad 08 / 31 / 80$

$08 / 31 / 80 \quad 09 / 02 / 80$

$09 / 02 / 80 \quad 09 / 04 / 80$

$09 / 04 / 80 \quad 09 / 09 / 80$

$09 / 09 / 80 \quad 11 / 01 / 80$

$11 / 01 / 80 \quad 11 / 03 / 80$

$11 / 03 / 80$

$03 / 21 / 81$

3

0.077

$03 / 21 / 81$

$03 / 23 / 81$

$03 / 23 / 81$

$04 / 06 / 81$

$04 / 06 / 81$

$04 / 07 / 81$

$04 / 07 / 81$

$04 / 18 / 81$

$04 / 18 / 81$

$04 / 19 / 81$

$04 / 19 / 81$

$04 / 28 / 81$

$04 / 28 / 81$

$04 / 29 / 81$

$04 / 29 / 81$

$05 / 05 / 81$

$05 / 05 / 81$

$05 / 07 / 81$

$05 / 07 / 81$

$06 / 29 / 81$

$06 / 29 / 81$

$07 / 01 / 81$

$07 / 01 / 81$

$07 / 17 / 81$

$07 / 17 / 81$

$07 / 19 / 81$

$07 / 19 / 81$

$08 / 13 / 81$

$08 / 13 / 81$

$08 / 14 / 81$

$08 / 14 / 81$

$09 / 03 / 81$

$09 / 03 / 81$

$09 / 10 / 81$

$09 / 10 / 81$

$09 / 11 / 81$

$09 / 11 / 81$

$10 / 11 / 81$

$10 / 11 / 81$

$10 / 13 / 81$

3

1

0.455

0.128

3

0.427

2

0.287

2

0.466

2

0.624

2

0.936

5

0.653

53

0.997

2

0.592

138

0.999

2

0.461

14

0.996

1

0.683

11

0.995

1

0.064

9

0

1

0.758

6

0.998

2

0.573

53

0.998

2

0.795

16

0.998

2

0.556

25

0.998

1

0.779

20

0.995

7

1

0.629

30

0.993

2

0.793 
Table A-8 (contd)

\begin{tabular}{|c|c|c|c|}
\hline \multicolumn{2}{|c|}{ Dates, mo/da/yr } & \multirow{2}{*}{$\begin{array}{c}\text { Elapsed } \\
\text { Time, } \\
\text { days } \\
\end{array}$} & \multirow{2}{*}{$\begin{array}{l}\text { Reactor Power } \\
\text { Leve1, } \\
\text { Fraction of } \\
2441 \text { MWth } \\
\end{array}$} \\
\hline From & To & & \\
\hline $10 / 13 / 81$ & $11 / 07 / 81$ & 25 & 0.996 \\
\hline
\end{tabular}

A- 13 
Table A-9

DRY ROD CONSOLIDATION - UNCONSOLIDATED FUEL EXPOSURE TO AIR

\begin{tabular}{|c|c|c|c|c|}
\hline $\begin{array}{c}\text { Fuel Assembly } \\
\text { ID Number } \\
\end{array}$ & IN-24P & $\begin{array}{l}\text { ion an } \\
n \text { hour } \\
M C-10\end{array}$ & $\begin{array}{l}\text { posure } \\
\text { Silo }\end{array}$ & Total Exposure \\
\hline V03 & 295 & 305 & -- & 600 \\
\hline V10 & 295 & 305 & - & 600 \\
\hline V16 & 295 & 305 & - & 600 \\
\hline V18 & 295 & 305 & - - & 600 \\
\hline V22 & 478 & 102 & - & 580 \\
\hline V26 & 478 & 102 & - & 580 \\
\hline W23 & 478 & 102 & -- & 580 \\
\hline W45 & 478 & 102 & -- & 580 \\
\hline A49 & -- & 346 & -- & 346 \\
\hline L08 & -- & 346 & - & 346 \\
\hline W30 & -- & 346 & -- & 346 \\
\hline W37 & -- & 346 & -- & 346 \\
\hline D09 & - & - & 71 & 71 \\
\hline D16 & -- & -. & 71 & 71 \\
\hline D18 & -- & -- & 71 & 71 \\
\hline D22 & - & -- & 71 & 71 \\
\hline D34 & -- & - & 71 & 71 \\
\hline
\end{tabular}

\footnotetext{
aTotal time fuel was exposed to air in storage location(s) during fuel transfers to the tan hot cell and between $\mathrm{TN}-24 \mathrm{P}$ and $M C-10$ casks.
}

REFERENCE

1. F. Schmittroth. ORIGEN2 Calculations of PWR Spent fuel Decay Heat Compared with Calorimetry Data. Richland, Washington: Hanford Engineering Development Laboratory, January 1984. HEDL-TME 83-32. 
Appendix B

TEMPERATURE AND PRESSURE MEASUREMENT UNCERTAINTIES 
Appendix B

TEMPERATURE AND PRESSURE MEASUREMENT UNCERTAINTIES

Temperature measurement uncertainty is produced by the thermocouples, extension wires, and data acquisition system. Each component in the temperature measurement chain adds to the overall uncertainty. The measurement chain is shown below.

TC $\quad$\begin{tabular}{llll}
\multicolumn{2}{l}{ Extension Wire } \\
\hline
\end{tabular}

Following the derivation of Schenck ( 1$)$, the overall uncertainty is equal to the square root of the sum of the squares of the individual temperature measurement uncertainties. The individual uncertainties are:

Lance Thermocouples

$$
T=0.989 * T_{m}-1.8, \sigma=0.38^{\circ} \mathrm{C}
$$

Vendor Specification for External Thermocouples

$\sigma$ equals the maximum of $\pm 2.2^{\circ} \mathrm{C}$ or $0.75 \%$.

Because the maximum surface temperature was less than $100^{\circ} \mathrm{C}, \sigma= \pm 2.2^{\circ} \mathrm{C}$.

Extension Wire - three segments were used for each thermocouple

$\sigma$ equals the maximum of $\pm 2.2^{\circ} \mathrm{C}$ or $0.75 \%$.

Because the extension wire was near $25^{\circ} \mathrm{C}, \sigma= \pm 2.2^{\circ} \mathrm{C}$.

Data Acquisition System

$\sigma$ was estimated to be less than $1^{\circ} \mathrm{C}$. 
Taking the square root of the sum of the squares of the deviations led to the following estimates of uncertainty for temperature measurements:

- For the lance thermocouples, $\sigma= \pm 4^{\circ} \mathrm{C}$.

- For the surface thermocouples, $\sigma= \pm 4.5^{\circ} \mathrm{C}$.

Pressure measurements were obtained from a Leybold Heraeus model MAC 2000 pressure transducer with a 4- to 20-mil1iampere output. The 4-to 20-mi11iampere signal was fed through a precision resistor to create the signal processed by the data acquisition system. The pressure transducer was calibrated prior to use and had a precision of \pm 0.0112 amperes. The dropping resistor was measured to be a 249.2-ohm resistor with a precision of \pm 0.25 ohms. The equation relating the pressure reading from the data acquisition system to the output of the pressure transducer is of the form

$$
P=0.5017(I * R)-500
$$

where $P=$ pressure

$I=$ milliampere output of pressure transducer

$\mathrm{R}=$ resistance of dropping resistor.

Using the method of Schenck (1), the uncertainty of the pressure measurements is

$$
\begin{aligned}
& \sigma_{p}^{2}=(0.5017 \cdot 249.2)^{2}(0.0112)^{2}+(0.5017 \cdot I)^{2}(0.25)^{2} \\
& \sigma_{p}^{2}=1.9537+0.0157\left(I^{2}\right)
\end{aligned}
$$

which gives an uncertainty of \pm 1.5 mbar for vacuum measurements (near 0 mbar) and \pm 6 mbar for pressure readings in the vicinity of 1500 mbar.

\section{REFERENCE}

1. H. Schenck, Jr. Theories of Engineering Experimentation. New York: McGraw-Hi11, 1961, pp. 40-48. 
Appendix C

HEAT TRANSFER DATA 


\section{Appendix C \\ HEAT TRANSFER DATA}

Table C-1

PRESSURE AND CORRECTED TEMPERATURE MEASUREMENTS FOR THE TN-24P CASK LOADED WITH CONSOLIDATED FUEL

\begin{tabular}{|c|c|c|c|c|c|c|c|c|c|c|c|c|c|}
\hline $\begin{array}{l}\text { RUN No. } \\
1988 \text { DATE } \\
\text { TIME HMS } \\
\end{array}$ & $\begin{array}{c}1 \\
13-J a n \\
100002 \\
\end{array}$ & $\begin{array}{c}2 \\
18-J a n \\
60002 \\
\end{array}$ & $\begin{array}{c}3 \\
22-J a n \\
110002 \\
\end{array}$ & $\begin{array}{r}4 \\
31-J a n \\
80002 \\
\end{array}$ & $\begin{array}{c}5 \\
08-F e b \\
80002 \\
\end{array}$ & $\begin{array}{c}6 \\
15-\mathrm{Feb} \\
180002 \\
\end{array}$ & $\begin{array}{c}7 \\
22-F e b \\
140002 \\
\end{array}$ & Loc. & $\begin{array}{c}\text { Elev. } \\
\text { m } \\
\end{array}$ & $\begin{array}{l}\text { Radius, } \\
\mathrm{cm} \\
\end{array}$ & $\begin{array}{l}\text { Angle, } \\
\text { degrees }\end{array}$ & $\begin{array}{l}x_{1} \\
\text { m } \\
\end{array}$ & $\begin{array}{l}y_{1} \\
m\end{array}$ \\
\hline Pressure & 1553.1 & 1517.2 & 1.5 & 1556.5 & 1557.3 & 4.7 & 3.9 & & & & & & \\
\hline TC1 & 116.2 & 117.5 & 142.6 & 120.9 & 137.4 & 149.1 & 167.1 & $L-1, E$ & & 0.4 & & -0.2447 & 0.4757 \\
\hline TC2 & 150.5 & 158.2 & 192.3 & 152.5 & 166.6 & 193.5 & 201.9 & & & 1.07 & & & \\
\hline TC3 & 169.5 & 191.5 & 212.0 & 167.6 & 187.6 & 211.6 & 214.9 & & & 2.27 & & & \\
\hline TC4 & 160.1 & 187.0 & 202.2 & 156.1 & 172.0 & 198.0 & 202.8 & & & 3.07 & & & \\
\hline TC5 & 131.2 & 164.7 & 157.2 & 122.4 & 139.4 & 154.8 & 166.0 & & & 3.82 & & & \\
\hline TC6 & 101.3 & 130.2 & 106.7 & 93.0 & 104.3 & 105.1 & 126.5 & & & 4.32 & & & \\
\hline$T C 7$ & 131.3 & 136.1 & 169.3 & 135.9 & 163.8 & 179.8 & 198.2 & $L-2, D 1$ & & 0.4 & & -0.1155 & 0.0584 \\
\hline TC8 & 189.2 & 225.2 & 260.7 & 187.3 & 230.7 & 255.5 & 261.6 & & & 1.07 & & & \\
\hline TC9 & 210.6 & 265.9 & 289.3 & 204.9 & 251.2 & 278.9 & 279.1 & & & 2.27 & & & \\
\hline TC10 & 200.1 & 265.2 & 277.8 & 191.9 & 238.2 & 264.3 & 265.9 & & & 3.07 & & & \\
\hline TC11 & 154.2 & 217.8 & 208.8 & 146.6 & 180.2 & 198.3 & 207.3 & & & 3.82 & & & \\
\hline TC12 & 88.1 & 134.4 & 114.0 & 87.3 & 96.9 & 110.9 & 133.6 & & & 4.32 & & & \\
\hline TC13 & 125.0 & 129.9 & 159.9 & 129.2 & 157.1 & 172.8 & 190.8 & $L-3,04$ & & 0.4 & & -0.1155 & 0.2894 \\
\hline TC14 & 180.8 & 214.8 & 248.2 & 180.2 & 221.7 & 246.4 & 252.9 & & & 1.07 & & & \\
\hline TC15 & 202.6 & 256.2 & 277.6 & 198.2 & 245.1 & 271.2 & 271.9 & & & 2.27 & & & \\
\hline TC16 & 191.4 & 253.1 & 264.9 & 185.4 & 229.8 & 255.3 & 257.8 & & & 3.07 & & & \\
\hline TC17 & 146.6 & 205.2 & 196.9 & 140.2 & 172.7 & 190.1 & 198.7 & & & 3.82 & & & \\
\hline TC18 & 94.8 & 131.1 & 110.1 & 84.4 & 96.4 & 109.0 & 130.6 & & & 4.32 & & & \\
\hline TC19 & 117.5 & 129.8 & 159.7 & 122.8 & 156.2 & 172.7 & 189.2 & $L-4,05$ & & 0.4 & & -0.4036 & 0.3465 \\
\hline TC20 & 167.9 & 212.8 & 245.1 & 169.6 & 219.7 & 245.5 & 250.5 & & & 1.07 & & & \\
\hline TC21 & 184.8 & 244.5 & 265.8 & 183.3 & 237.5 & 263.7 & 263.5 & & & 2.27 & & & \\
\hline TC22 & 175.2 & 240.5 & 254.1 & 171.9 & 224.2 & 250.8 & 252.2 & & & 3.07 & & & \\
\hline TC23 & 136.6 & 193.6 & 187.5 & 130.9 & 168.9 & 186.1 & 195.1 & & & 3.82 & & & \\
\hline TC24 & 90.2 & 120.8 & 101.4 & 87.9 & 101.4 & 101.7 & 125.2 & & & 4.32 & & & \\
\hline TC25 & 22.2 & 16.4 & 22.7 & 18.3 & 23.4 & 23.2 & 23.7 & Ambient & & & & & \\
\hline TC26 & 20.8 & 14.0 & 21.4 & 16.0 & 20.3 & 22.4 & 23.9 & Ambient & & & & & \\
\hline
\end{tabular}




\section{Table C-1 (contd)}

\begin{tabular}{|c|c|c|c|c|c|c|c|c|c|c|c|c|c|}
\hline $\begin{array}{l}\text { RUN NO. } \\
1988 \text { DATE } \\
\text { IIME HMS } \\
\end{array}$ & $\begin{array}{c}1 \\
13-J a n \\
100002 \\
\end{array}$ & $\begin{array}{r}2 \\
18-J a n \\
60002 \\
\end{array}$ & $\begin{array}{c}3 \\
22-\sqrt[J a n]{110002} \\
\end{array}$ & $\begin{array}{c}4 \\
31-J a n \\
80002 \\
\end{array}$ & $\begin{array}{c}5 \\
08-F e b \\
80002 \\
\end{array}$ & $\begin{array}{c}6 \\
15-\mathrm{Feb} \\
180002 \\
\end{array}$ & $\begin{array}{c}7 \\
22-F e b \\
140002 \\
\end{array}$ & Loc. & $\begin{array}{c}\text { Elev. } \\
\text { m }\end{array}$ & $\begin{array}{l}\text { Radius, } \\
\mathrm{cm} \\
\end{array}$ & $\begin{array}{l}\text { Angle, } \\
\text { degrees }\end{array}$ & $\begin{array}{l}x, \\
m\end{array}$ & $\begin{array}{l}y, \\
m\end{array}$ \\
\hline TC27 & 22.5 & 18.5 & 23.1 & 18.0 & 21.6 & 23.2 & 23.2 & Ambient & & & & & \\
\hline TC31 & 112.3 & 127.1 & 152.1 & 115.8 & 148.3 & 165.8 & 183.0 & $L-6, D 6$ & 0.4 & & & -0.1155 & 0.6346 \\
\hline TC32 & 157.9 & 205.6 & 233.5 & 161.7 & 215.0 & 238.7 & 244.7 & & 1.07 & & & & \\
\hline TC33 & 172.7 & 232.7 & 250.7 & 175.2 & 231.4 & 254.9 & 255.2 & & 2.27 & & & & \\
\hline TC34 & 164.0 & 230.1 & 241.0 & 164.8 & 220.1 & 243.2 & 244.7 & & 3.07 & & & & \\
\hline TC35 & 126.1 & 182.3 & 178.2 & 124.7 & 163.9 & 179.0 & 188.0 & & 3.82 & & & & \\
\hline TC36 & 85.8 & 117.9 & 96.4 & 89.8 & 104.5 & 97.2 & 120.3 & & 3.32 & & & & \\
\hline TC37 & 109.1 & 124.0 & 146.9 & 110.9 & 137.0 & 150.3 & 169.2 & $L-7$, C6 & 0.4 & & & -0.1155 & -0.6346 \\
\hline TC38 & 155.4 & 203.9 & 230.1 & 146.9 & 191.5 & 212.3 & 218.3 & & 1.07 & & & & \\
\hline TC39 & 171.0 & 232.3 & 250.4 & 157.2 & 198.1 & 224.2 & 223.3 & & 2.27 & & & & \\
\hline TC4O & 162.0 & 227.9 & 240.4 & 147.1 & 187.7 & 211.9 & 213.6 & & 3.07 & & & & \\
\hline TC4 1 & 126.3 & 182.1 & 177.8 & 115.8 & 144.7 & 160.1 & 169.9 & & 3.82 & & & & \\
\hline TC42 & 81.4 & 115.9 & 97.6 & 75.9 & 85.3 & 92.8 & 116.9 & & 4.32 & & & & \\
\hline TC43 & 113.8 & 114.4 & 132.1 & 118.6 & 129.7 & 132.8 & 154.2 & $L-8, F$ & 0.4 & & & 0.2447 & -0.4757 \\
\hline TC44 & 147.2 & 154.4 & 184.0 & 148.6 & 165.1 & 178.9 & 189.6 & & 1.07 & & & & \\
\hline TC45 & 166.3 & 187.1 & 210.5 & 159.7 & 174.2 & 192.9 & 196.7 & & 2.27 & & & & \\
\hline$T C 46$ & 158.9 & 185.8 & 200.6 & 149.7 & 166.5 & 183.4 & 188.9 & & 3.07 & & & & \\
\hline TC47 & 129.2 & 162.9 & 155.7 & 119.5 & 135.3 & 141.7 & 154.2 & & 3.82 & & & & \\
\hline TC48 & 99.4 & 127.8 & 106.7 & 91.1 & 101.5 & 100.3 & 121.9 & & 4.32 & & & & \\
\hline TC49 & 116.2 & 128.3 & 156.0 & 121.5 & 151.6 & 164.7 & 182.6 & $L-9, B 5$ & 0.4 & & & 0.4036 & -0.3465 \\
\hline TC50 & 166.2 & 212.4 & 242.2 & 164.5 & 213.6 & 235.4 & 240.5 & & 1.07 & & & & \\
\hline TC51 & 185.3 & 244.0 & 267.0 & 177.7 & 225.5 & 250.2 & 249.8 & & 2.27 & & & & \\
\hline TC52 & 174.9 & 240.0 & 255.0 & 165.9 & 213.8 & 238.1 & 239.0 & & 3.07 & & & & \\
\hline TC53 & 137.1 & 194.7 & 190.0 & 128.4 & 161.1 & 176.6 & 185.9 & & 3.82 & & & & \\
\hline TC54 & 86.0 & 119.8 & 101.5 & 85.4 & 94.9 & 97.2 & 120.6 & & 4.32 & & & & \\
\hline TC55 & 129.4 & 133.2 & 166.6 & 134.2 & 162.7 & 178.7 & 197.4 & $L-10, A 1$ & 0.4 & & & 0.1155 & 0.0584 \\
\hline TC56 & 188.1 & 223.2 & 259.3 & 185.4 & 232.6 & 254.4 & 261.6 & & 1.07 & & & & \\
\hline TC57 & 210.6 & 267.3 & 291.0 & 205.1 & 251.4 & 280.0 & 280.0 & & 2.27 & & & & \\
\hline TC58 & 199.2 & 265.6 & 278.3 & 191.8 & 237.6 & 264.7 & 265.8 & & 3.07 & & & & \\
\hline TC59 & 153.0 & 217.1 & 208.8 & 146.4 & 180.7 & 199.2 & 207.8 & & 3.82 & & & & \\
\hline$T C 60$ & 85.6 & 135.6 & 112.7 & 86.6 & 95.9 & 110.0 & 132.7 & & 4.32 & & & & \\
\hline \multirow[t]{2}{*}{ TC61 } & 67.5 & 61.4 & 65.7 & 71.0 & 67.7 & 70.9 & 106.9 & SIDE & 0.01 & & 0 & & \\
\hline & & & & & & & & SURFACE & & & & & \\
\hline TC62 & 82.3 & 80.4 & 81.5 & 78.9 & 76.3 & 80.2 & 85.3 & & 2.65 & & 0 & & \\
\hline TC63 & 70.2 & 64.0 & 69.0 & 76.0 & 70.3 & 76.3 & 114.6 & & 0.01 & & 180 & & \\
\hline
\end{tabular}


Table C-1 (contd)

\begin{tabular}{|c|c|c|c|c|c|c|c|c|c|c|c|c|c|}
\hline RUN No. & 1 & 2 & 3 & 4 & 5 & 6 & 7 & & & & & & \\
\hline 1988 DATE & 13-Jan & 18-Jan & 22-Jan & 31-Jan & $08-F e b$ & $15-$ Feb & 22-Feb & & Elev. & Radius, & Angle, & $x$, & $y_{\text {, }}$ \\
\hline IIME HMS & 100002 & 60002 & 110002 & 80002 & 80002 & 180002 & 140002 & Loc. & m & $\mathrm{cm}$ & degrees & $m$ & m \\
\hline TC64 & 79.1 & 76.6 & $\pi .5$ & 91.5 & 89.4 & 97.0 & 100.7 & & 2.65 & & 180 & & \\
\hline TC65 & 78.9 & 76.6 & 77.5 & 90.9 & 89.0 & 95.6 & 99.3 & & 2.65 & & 202.5 & & \\
\hline TC66 & 81.3 & 80.2 & 79.9 & 90.0 & 88.1 & 95.3 & 98.6 & & 2.65 & & 225 & & \\
\hline TC67 & 76.6 & 77.3 & 76.5 & 83.6 & 82.2 & 89.5 & 92.4 & & 2.65 & & 247.5 & & \\
\hline TC68 & 76.1 & 78.0 & 76.5 & 79.5 & 77.8 & 84.2 & 86.8 & & 2.65 & & 270 & & \\
\hline TC69 & 74.8 & 7.0 & 76.3 & $\pi 7.3$ & 75.5 & 80.8 & 84.0 & & 2.65 & & 292.5 & & \\
\hline TC70 & 67.2 & 60.7 & 65.4 & 70.6 & 67.4 & 71.2 & 106.6 & & 0.01 & & 315 & & \\
\hline TC71 & 65.0 & 66.1 & 70.9 & 73.2 & 70.2 & 73.5 & 105.3 & & 0.25 & & 315 & & \\
\hline TC72 & 67.9 & 61.9 & 66.0 & 66.2 & 63.9 & 68.0 & 85.1 & & 0.4 & & 315 & & \\
\hline TC73 & 76.6 & 71.4 & 76.2 & 74.3 & 72.2 & 77.2 & 86.0 & & 1.15 & & 315 & & \\
\hline TC74 & 82.5 & 78.7 & 83.0 & 80.4 & 78.3 & 83.4 & 88.3 & & 1.9 & & 315 & & \\
\hline TC75 & 80.6 & 81.0 & 81.4 & 78.5 & 76.7 & 81.2 & 85.8 & & 2.65 & & 315 & & \\
\hline TC76 & 67.3 & 76.4 & 63.9 & 69.8 & 68.5 & 71.9 & 81.0 & & 3.4 & & 315 & & \\
\hline TC77 & 61.3 & 68.3 & 57.1 & 61.3 & 60.4 & 62.4 & 78.1 & & 4.15 & & 315 & & \\
\hline TC78 & 61.2 & 68.4 & 57.2 & 59.9 & 59.6 & 60.1 & 92.1 & & 4.31 & & 315 & & \\
\hline TC79 & 80.3 & 79.1 & 80.0 & 77.5 & $\pi .4$ & 79.4 & 83.9 & & 2.65 & & 337.5 & & \\
\hline TC80 & 62.4 & 70.7 & 52.9 & 60.7 & 59.7 & 58.2 & 98.6 & CASK & 0 & & 0 & & \\
\hline & & & & & & & & TOP & & & & & \\
\hline TC81 & 62.1 & 69.8 & 52.3 & 59.5 & 58.5 & 56.8 & 97.2 & & 0.35 & & 0 & & \\
\hline TC82 & 60.7 & 67.8 & 52.7 & 58.6 & 57.3 & 56.3 & 95.2 & & 0.7 & & 0 & & \\
\hline$T \cos 3$ & 61.9 & 69.8 & 52.1 & 59.5 & 58.6 & 57.2 & 97.1 & & 0.35 & & 315 & & \\
\hline $\mathrm{TC8} 4$ & 60.3 & 67.9 & 52.2 & 58.5 & 57.8 & 57.0 & 95.9 & & 0.7 & & 315 & & \\
\hline TC85 & 0.0 & 0.0 & 0.0 & 80.6 & 76.6 & 79.7 & 117.9 & $\begin{array}{l}\text { CASK } \\
\text { воTTOM }\end{array}$ & 0 & & 0 & & \\
\hline TC86 & 0.0 & 0.0 & 0.0 & 77.4 & 73.6 & 76.7 & 112.5 & & 0.5 & & 0 & & \\
\hline TC87 & 0.0 & 0.0 & 0.0 & 77.4 & 73.6 & 76.9 & 112.8 & & 0.5 & & 315 & & \\
\hline TC97 & 78.0 & 70.9 & 76.4 & 79.6 & $\pi .2$ & 79.6 & 107.2 & $\begin{array}{l}\text { BASKET } \\
\text { T01 }\end{array}$ & 0.405 & 0.727 & & -0.639 & 0.347 \\
\hline TC9̣8 & 104.2 & 102.5 & 106.1 & 104.2 & 102.5 & 108.0 & 112.9 & T020 & 2.23 & 0.727 & & -0.639 & 0.347 \\
\hline TC99 & 104.8 & 102.7 & 106.0 & 103.8 & 101.6 & 105.6 & 110.8 & T022 & 2.23 & 0.727 & & -0.718 & 0.116 \\
\hline TC100 & 94.7 & 99.3 & 93.4 & 95.3 & 93.6 & 97.6 & 105.2 & T03 & 3.18 & 0.727 & & -0.639 & 0.347 \\
\hline IC101 & 78.1 & 86.6 & 71.7 & 76.4 & 76.7 & 77.0 & 95.1 & T04 & 3.99 & 0.727 & & -0.639 & 0.347 \\
\hline TC102 & 68.9 & $\pi .3$ & 60.0 & 65.9 & 66.4 & 65.7 & 94.1 & T05 & 4.42 & 0.727 & & -0.639 & 0.347 \\
\hline TC103 & 100.3 & 96.5 & 130.3 & 103.6 & 123.5 & 137.5 & 155.5 & T1B & 0.405 & 0.694 & & -0.578 & 0.347 \\
\hline TC104 & 133.2 & 169.7 & 180.5 & 132.9 & 153.6 & 170.8 & 175.4 & Т1२В & 2.23 & 0.578 & & -0.462 & 0.347 \\
\hline TC105 & 144.0 & 152.1 & 190.8 & 140.3 & 156.4 & 188.6 & 192.0 & T128B & 2.23 & 0.674 & & -0.578 & 0.347 \\
\hline
\end{tabular}




\section{Table C-1 (contd)}

\begin{tabular}{|c|c|c|c|c|c|c|c|c|c|c|c|c|c|}
\hline RUN No. & 1 & 2 & 3 & 4 & 5 & 6 & 7 & & & & & & \\
\hline 1988 DATE & 13-Jan & 18-Jan & 22-Jan & $31-$ Jan & $.08-F e b$ & $15-$ feb & 22-Feb & & Elev. & Radius, & Angle, & $x$, & $y_{1}$ \\
\hline TIME HMS & 100002 & 60002 & 110002 & 80002 & 80002 & 180002 & 140002 & Loc. & m & $\mathrm{cm}$ & degrees & m & m \\
\hline TC106 & 140.9 & 155.7 & 164.6 & 137.5 & 150.5 & 161.0 & 165.8 & T12E & 2.23 & 0.622 & & -0.578 & 0.231 \\
\hline TC107 & 203.3 & 240.3 & 261.7 & 197.8 & 229.7 & 252.5 & 255.0 & T12F & 2.20 & 0 & & 0 & 0 \\
\hline TC108 & 163.3 & 189.4 & 199.3 & 158.1 & 182.8 & 202.0 & 204.4 & T12G & 2.23 & 0.703 & & -0.693 & -0.116 \\
\hline TC109 & 132.6 & 178.5 & 163.4 & 126.0 & 145.5 & 157.7 & 170.9 & T23F & 3.99 & 0 & & 0 & 0 \\
\hline TC110 & 106.4 & 134.3 & 107.9 & 97.8 & 102.7 & 103.3 & 127.7 & T26K & 4.42 & 0 & & 0 & 0 \\
\hline
\end{tabular}


Appendix D

DOSE RATE DATA 


$$
\text { Appendix D }
$$

DOSE RATE DATA

Table D-1

RADIATION SURVEY INSTRUMENT MEASUREMENTS RESULTS FOR TN-24P

PERFORMANCE TEST WITH CONSOLIDATED FUEL

Side Locations - PNL Measurements

\begin{tabular}{|c|c|c|c|c|c|c|c|}
\hline $\begin{array}{l}\text { Elev. } \\
(\mathrm{m})\end{array}$ & $\begin{array}{l}\text { Distance } \\
\text { from Cask } \\
\text { (m) }\end{array}$ & $\frac{\text { Gamma D }}{\text { Measured }}$ & $\begin{array}{l}-60 \text { Degrees - } \\
\text { ose Rate } \\
\text { Corrected }^{\text {Correcte }}\end{array}$ & $\begin{array}{l}\text { Neutron } \\
\text { Dose Rate }\end{array}$ & $\frac{\text { Gamma Do }}{\text { Measured }}$ & $\begin{array}{l}\text {-90 Degrees } \\
\text { ose Rate } \\
\text { Corrected }\end{array}$ & $\begin{array}{c}\text { Neutron } \\
\text { Dose Rate }\end{array}$ \\
\hline 0.100 & 0.0 & 1.2 & 1.4 & 31.0 & 1.0 & 1.2 & 30.0 \\
\hline 0.215 & 0.0 & 2.4 & 2.8 & 42.0 & 2.0 & 2.3 & 38.0 \\
\hline 0.330 & 0.0 & 1.8 & 2.1 & 13.0 & 3.2 & 3.7 & 37.0 \\
\hline 0.445 & 0.0 & 2.0 & 2.3 & 5.0 & & & \\
\hline 1.180 & 0.0 & 4.3 & 5.0 & 3.3 & 5.5 & 6.3 & 4.5 \\
\hline 1.915 & 0.0 & 4.5 & 5.2 & 3.0 & 6.0 & 6.9 & 3.0 \\
\hline 2.650 & 0.0 & 4.4 & 5.1 & 2.7 & 5.5 & 6.3 & 3.0 \\
\hline 3.385 & 0.0 & 3.8 & 4.4 & 2.4 & 4.5 & 5.2 & 3.0 \\
\hline 4.120 & 0.0 & 4.6 & 5.3 & 2.4 & & & \\
\hline 4.235 & 0.0 & 4.0 & 4.6 & 6.0 & 12.0 & 13.8 & 14.0 \\
\hline 4.350 & 0.0 & 9.5 & 10.9 & 17.0 & 10.0 & 11.5 & 16.0 \\
\hline 4.465 & 0.0 & 3.7 & 4.3 & 14.5 & 3.4 & 3.9 & 12.5 \\
\hline
\end{tabular}

$\begin{array}{lllll}0.100 & 1.0 & 0.8 & 0.9 & 7.0 \\ 2.650 & 1.0 & 2.3 & 2.6 & 2.7 \\ 4.465 & 1.0 & 2.1 & 2.4 & 4.5 \\ 0.100 & 2.0 & & & \\ 2.650 & 2.0 & 0.6 & 0.7 & 4.0 \\ 4.465 & 2.0 & 1.3 & 1.5 & 1.5 \\ & & 1.1 & 1.3 & 2.8\end{array}$

${ }^{2}$ Gamma Dose Rate $=m R / h$

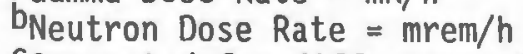

${ }^{c}$ Corrected for differences in atmospheric pressure between calibration and measurement location. 
Table D-1 (contd)

Side Location - INEL Measurements

\begin{tabular}{|c|c|c|c|c|c|}
\hline \multirow[b]{2}{*}{$\begin{array}{l}\text { Elevation } \\
(\mathrm{m})\end{array}$} & \multirow{2}{*}{$\begin{array}{l}\text { Distance } \\
\text { from Cask } \\
\text { (m) }\end{array}$} & \multicolumn{2}{|c|}{-...-60 Degrees-_........ } & \multicolumn{2}{|c|}{ Gamma Degrees-.-.-. } \\
\hline & & $\begin{array}{c}\begin{array}{c}\text { Gamma } \\
\text { Dose Rate }\end{array} \\
\end{array}$ & $\begin{array}{l}\text { Neutron } \\
\text { Dose Rate }\end{array}$ & $\begin{array}{c}\text { Gamma } \\
\text { Dose Rate }\end{array}$ & $\begin{array}{l}\text { Neutron } \\
\text { Dose Rate }\end{array}$ \\
\hline 0.100 & 0.0 & 2.5 & 50.0 & 2.0 & 40.0 \\
\hline 0.215 & 0.0 & 3.5 & 50.0 & 2.5 & 45.0 \\
\hline 0.330 & 0.0 & 4.5 & 50.0 & 5.0 & 50.0 \\
\hline 0.445 & 0.0 & 2.5 & 12.5 & & \\
\hline 1.180 & 0.0 & 5.0 & 4.5 & 7.0 & 10.0 \\
\hline 1.915 & 0.0 & 6.0 & 4.5 & 7.0 & 7.0 \\
\hline 2.650 & 0.0 & 6.0 & 5.0 & 6.5 & 4.5 \\
\hline 3.385 & 0.0 & 5.0 & 5.0 & 6.0 & 5.0 \\
\hline 4.120 & 0.0 & 8.0 & 5.0 & & \\
\hline 4.235 & 0.0 & 7.0 & 10.0 & 17.0 & 25.0 \\
\hline 4.350 & 0.0 & 9.5 & 20.0 & 7.5 & 25.0 \\
\hline 4.465 & 0.0 & 4.0 & 20.0 & 6.5 & 15.0 \\
\hline 0.100 & 1.0 & & & 2.5 & 14.0 \\
\hline 2.650 & 1.0 & & & 3.0 & 3.5 \\
\hline 4.465 & 1.0 & & & 5.0 & 7.0 \\
\hline 0.100 & 2.0 & & & 4.0 & 7.0 \\
\hline 2.650 & 2.0 & & & 3.0 & 4.5 \\
\hline 4.465 & 2.0 & & & 3.5 & 3.5 \\
\hline
\end{tabular}

वGamma Dose Rate $=m R / h$

$b_{\text {Neutron Dose Rate }}=\mathrm{mrem} / \mathrm{h}$ 
Table D-1 (contd)

Top Location at 90 Degrees

\begin{tabular}{|c|c|c|c|c|c|c|}
\hline \multirow{3}{*}{$\begin{array}{l}\text { Radius } \\
\text { (m) }\end{array}$} & \multirow{3}{*}{$\begin{array}{l}\text { Distance } \\
\text { from Cask } \\
\text { (m) }\end{array}$} & \multicolumn{2}{|c|}{. } & \multicolumn{3}{|c|}{ - } \\
\hline & & Gamma & Neutron & Gamma & ose Rate & Neutron \\
\hline & & Dose Rate ${ }^{\mathrm{a}}$ & Dose Rate ${ }^{b}$ & Measured & Corrected $^{\mathrm{C}}$ & Dose Rate $^{\mathrm{D}}$ \\
\hline 0.000 & 0.0 & 14.0 & 38.0 & 11.0 & 12.7 & 32.0 \\
\hline 0.115 & 0.0 & 18.0 & 33.0 & 10.5 & 12.1 & 30.0 \\
\hline 0.230 & 0.0 & 13.0 & 35.0 & 9.5 & 10.9 & 29.0 \\
\hline 0.345 & 0.0 & 12.0 & 35.0 & 8.5 & 9.8 & 28.0 \\
\hline 0.460 & 0.0 & 14.0 & 32.0 & 10.5 & 12.1 & 28.0 \\
\hline 0.575 & 0.0 & 14.0 & 30.0 & 11.5 & 13.2 & 25.0 \\
\hline 0.690 & 0.0 & 11.0 & 25.0 & 9.5 & 10.9 & 22.0 \\
\hline 0.850 & 0.0 & 26.0 & 17.0 & 21.0 & 24.2 & 12.0 \\
\hline 0.990 & 0.0 & 28.0 & 17.0 & 21.5 & 24.8 & 11.5 \\
\hline 0.000 & 1.0 & 8.0 & 10.0 & 6.0 & 6.9 & 7.5 \\
\hline 0.460 & 1.0 & 6.0 & 10.0 & 4.6 & 5.3 & 6.8 \\
\hline 0.990 & 1.0 & 5.0 & 8.0 & 3.8 & 4.4 & 5.7 \\
\hline 0.000 & 2.0 & 8.0 & 5.0 & 4.3 & 5.0 & 4.0 \\
\hline 0.460 & 2.0 & 2.5 & 5.0 & 2.4 & 2.8 & 4.0 \\
\hline 0.990 & 2.0 & 2.0 & 4.3 & 2.3 & 2.6 & 3.4 \\
\hline
\end{tabular}

Top Locations at 225 Degrees

\begin{tabular}{|c|c|c|c|c|c|c|}
\hline $\begin{array}{l}\text { Radius } \\
\text { (m) }\end{array}$ & $\begin{array}{l}\text { Distance } \\
\text { from Cask } \\
\text { (m) }\end{array}$ & $\begin{array}{c}\text { Gamma } \\
\text { Dose Rate }\end{array}$ & $\begin{array}{c}\text { Neutron } \\
\text { Dose Rate }\end{array}$ & Measured & $\frac{\text { ose Rate }}{\text { Corrected }}$ & $\begin{array}{l}\text { Neutron } \\
\text { Dose Rate }\end{array}$ \\
\hline 0.000 & 0.0 & 16.0 & 25.0 & 12.5 & 14.4 & 32.0 \\
\hline 0.163 & 0.0 & 13.0 & 37.0 & 10.5 & 12.1 & 30.0 \\
\hline 0.325 & 0.0 & 11.0 & 37.0 & 9.0 & 10.4 & 32.0 \\
\hline 0.488 & 0.0 & 11.0 & 35.0 & 9.0 & 10.4 & 30.0 \\
\hline 0.651 & 0.0 & 8.0 & 32.0 & 7.0 & 8.1 & 21.0 \\
\hline 0.857 & 0.0 & 24.0 & 23.0 & 17.5 & 20.2 & 13.0 \\
\hline 0.995 & 0.0 & 31.0 & 18.0 & 22.0 & 25.3 & 14.0 \\
\hline
\end{tabular}

\footnotetext{
TGamma Dose Rate $=\mathrm{mR} / \mathrm{h}$

beutron Dose Rate $=\mathrm{mrem} / \mathrm{h}$

${ }^{\mathrm{C}}$ Corrected for differences in atmospheric pressure between calibration and measurement location.
} 
Table D-1 (contd)

Bottom Locations at 90 Degrees

\begin{tabular}{|c|c|c|c|c|c|c|}
\hline $\begin{array}{l}\text { Radius } \\
\text { (m) }\end{array}$ & $\begin{array}{l}\text { Distance } \\
\text { from Cask } \\
(\mathrm{m}) \\
\end{array}$ & $\begin{array}{c}\text { Gamma } \\
\text { Dose Rate }\end{array}$ & $\begin{array}{l}\text { Neutron } \\
\text { Dose Rate }\end{array}$ & Mamma D & $\frac{\text { ose Rate }}{\text { Corrected }}$ & $\begin{array}{l}\text { Neutron } \\
\text { Dose Rate }\end{array}$ \\
\hline 0.000 & 0.0 & 3.5 & 100.0 & 2.3 & 2.6 & 68.0 \\
\hline 0.115 & 0.0 & 3.5 & 100.0 & 2.3 & 2.6 & 67.0 \\
\hline 0.230 & 0.0 & 3.0 & 80.0 & 2.5 & 2.9 & 64.0 \\
\hline 0.345 & 0.0 & 3.0 & 75.0 & 2.1 & 2.4 & 62.0 \\
\hline 0.460 & 0.0 & 3.5 & 75.0 & 2.5 & 2.9 & 61.0 \\
\hline 0.575 & 0.0 & 3.5 & 60.0 & 2.6 & 3.0 & 56.0 \\
\hline 0.690 & 0.0 & 3.0 & 50.0 & 1.9 & 2.2 & 47.0 \\
\hline 0.850 & 0.0 & 1.0 & 45.0 & 0.7 & 0.8 & 33.0 \\
\hline 0.990 & 0.0 & 0.5 & 30.0 & 0.3 & 0.3 & 18.0 \\
\hline 0.000 & 1.0 & 1.5 & 25.0 & & & \\
\hline 0.460 & 1.0 & 1.5 & 25.0 & & & \\
\hline 0.990 & 1.0 & 0.5 & 20.0 & & & \\
\hline 0.000 & 2.0 & 0.5 & 12.0 & & & \\
\hline 0.460 & 2.0 & 0.5 & 12.0 & & & \\
\hline 0.990 & 2.0 & 0.5 & 12.0 & & & \\
\hline
\end{tabular}

\footnotetext{
a Gamma Dose Rate $=\mathrm{mR} / \mathrm{h}$

b Neutron Dose Rate $=\mathrm{mrem} / \mathrm{h}$

${ }^{\mathrm{C}}$ Corrected for differences in atmospheric pressure between calibration and measurement location.
} 
Table 0-1 (contd)

Bottom Locations at 225 Degrees

\begin{tabular}{|c|c|c|c|c|c|c|}
\hline \multirow[b]{2}{*}{$\begin{array}{l}\text { Radius } \\
\text { (m) }\end{array}$} & \multirow{2}{*}{$\begin{array}{l}\text { Distance } \\
\text { from Cask } \\
\text { (m) }\end{array}$} & \multicolumn{2}{|c|}{ - $\ldots$ - INEL - $\ldots$} & \multicolumn{2}{|c|}{ - } & \multirow{2}{*}{$\begin{array}{l}\text { Neutron } \\
\text { Dose Rate }\end{array}$} \\
\hline & & $\begin{array}{c}\text { Gamma } \\
\text { Dose Rate }\end{array}$ & $\begin{array}{l}\text { Neutron } \\
\text { Dose Rateb }\end{array}$ & $\frac{\text { Gamma }}{\text { Measured }}$ & $\frac{\text { ose Rate }}{\text { Corrected }}$ & \\
\hline 0.000 & 0.0 & 3.0 & 100.0 & 2.5 & 2.9 & 67.0 \\
\hline 0.163 & 0.0 & 3.5 & 100.0 & 2.2 & 2.5 & 65.0 \\
\hline 0.325 & 0.0 & 3.5 & 100.0 & 2.2 & 2.5 & 67.0 \\
\hline 0.488 & 0.0 & 3.5 & 80.0 & 2.3 & 2.6 & 68.0 \\
\hline 0.651 & 0.0 & 4.0 & 75.0 & 2.6 & 3.0 & 62.0 \\
\hline 0.857 & 0.0 & 2.0 & 50.0 & 1.0 & 1.2 & 40.0 \\
\hline 0.995 & 0.0 & 1.0 & 30.0 & 0.4 & 0.5 & 28.0 \\
\hline 0.000 & 1.0 & & & 1.2 & 1.4 & 25.0 \\
\hline 0.000 & 2.0 & & & 0.6 & 0.7 & 10.0 \\
\hline
\end{tabular}

व'Gamma Dose Rate $=m R / h$

Beutron Dose Rate $=\mathrm{mrem} / \mathrm{h}$

c Corrected for differences in atmospheric pressure between calibration and measurement location. 


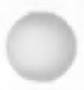

0

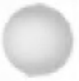

